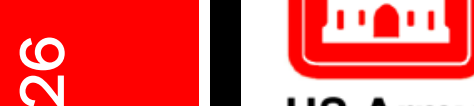

\section{US Army Corps}

of Engineers ${ }_{\circledast}$

Engineer Research and

Development Center

\section{ERDC}

INNOVATIVE SOLUTIONS

for a safer, better world

Environmental Security Technology Certification Program (ESTCP)

\title{
Systems Approach to Improved Facility Energy Performance
}

James P. Miller

February 2019
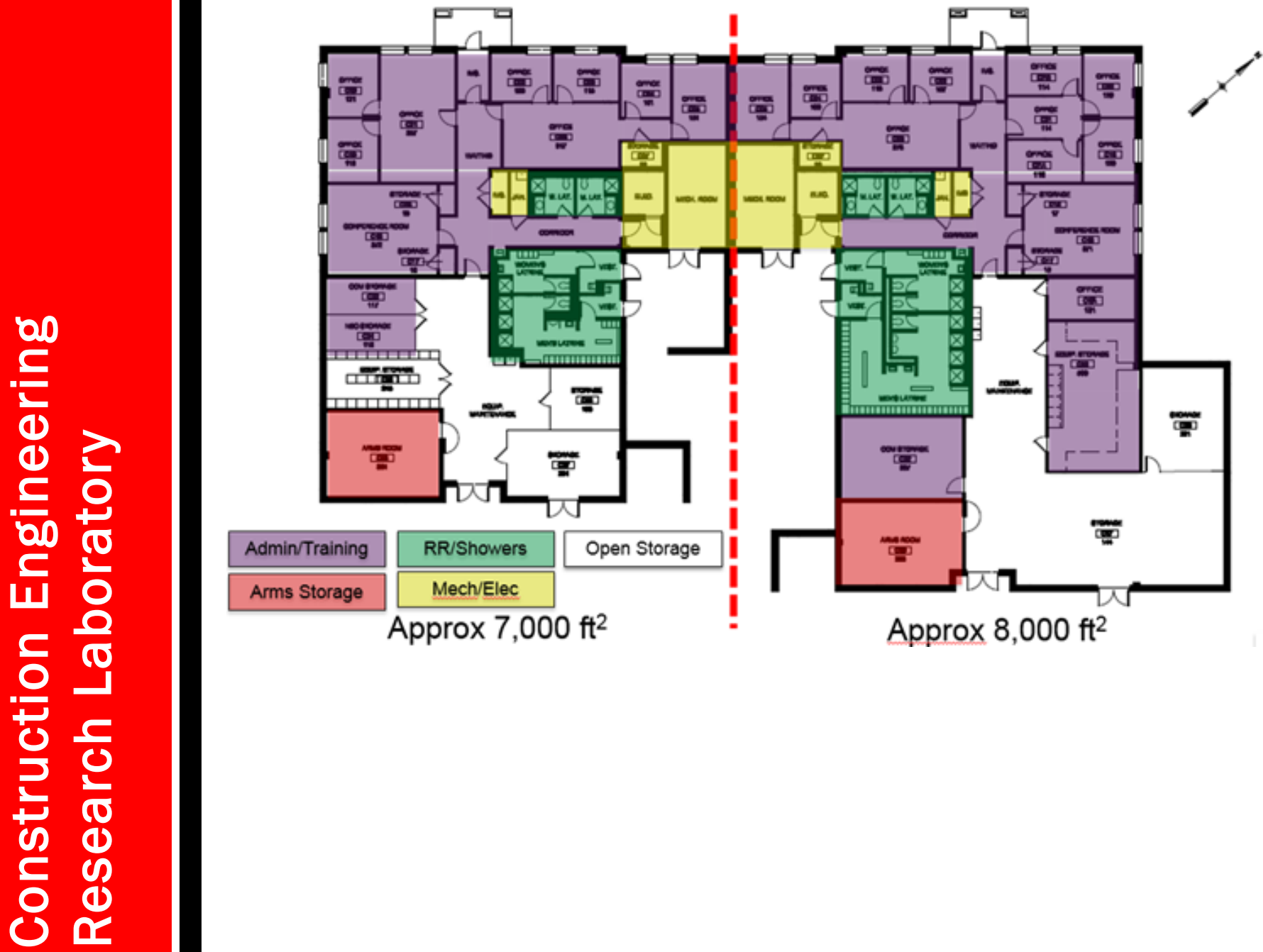

Approved for public release; distribution is unlimited. 
The U.S. Army Engineer Research and Development Center (ERDC) solves the nation's toughest engineering and environmental challenges. ERDC develops innovative solutions in civil and military engineering, geospatial sciences, water resources, and environmental sciences for the Army, the Department of Defense, civilian agencies, and our nation's public good. Find out more at www.erdc.usace.army.mil.

To search for other technical reports published by ERDC, visit the ERDC online library at http://acwc.sdp.sirsi.net/client/default. 


\section{Systems Approach to Improved Facility Energy Performance}

James P. Miller

U.S. Army Engineer Research and Development Center (ERDC)

Construction Engineering Research Laboratory (CERL)

2902 Newmark Dr.

Champaign, IL 61824

Final Report

Approved for public release; distribution is unlimited.

Prepared for Strategic Environmental Research and Development Program/Environmental Security Technology Certification Program (SERDP/ESTCP), Energy and Water Project EW201155, via MIPRs No. W74RDV23461416, W74RDV20749510, W74RDV20749509, W74RDV53553148, and W74RDV70303974. 


\section{Abstract}

The Department of Defense (DoD) is interested in improving its facilities to enhance energy performance and improve mold and mildew mitigation. This research effort used a pair of administrative facilities (Bldgs $1540 A \& B$ ) at Fort Detrick, MD to investigate the use of radiant heating and cooling systems to cost effectively improve such facilities using technologies that are easily maintainable by existing staff. This project found that: (1) it is feasible to significantly improve the air tightness of an existing building envelope without implementing major changes or disruptions to the interior or exterior surfaces of the building envelope; (2) radiant heating and cooling systems can adequately maintain comfort conditions in administrative buildings in locations with significant heating and cooling loads; (3) radiant cooling systems, when combined with a Dedicated Outdoor Air Supply (DOAS) system to properly dehumidify outdoor air and maintain proper space humidity conditions, can prevent condensation forming on the surface of the radiant cooling panels; (4) radiant heating and cooling systems are capable of improved energy efficiency when compared with conventional all-air Heating, Ventilating, and Air-Conditioning (HVAC) systems; (5) radiant systems are cost competitive with conventional all-air HVAC systems, and (6) radiant systems are easily maintainable and require no special skills for HVAC technicians.

DISCLAIMER: The contents of this report are not to be used for advertising, publication, or promotional purposes. Citation of trade names does not constitute an official endorsement or approval of the use of such commercial products. All product names and trademarks cited are the property of their respective owners. The findings of this report are not to be construed as an official Department of the Army position unless so designated by other authorized documents. 


\section{Executive Summary}

The Department of Defense (DoD) is continually interested in improving their facilities in a variety of aspects, including enhancing energy performance and improving mold and mildew mitigation. This motivated a DoD funded research effort on a pair of single-story, brick clad administrative facilities (Bldgs 1540A\&B) at Fort Detrick, MD. Bldg 1540A was the focus of facility improvements, and Bldg $1540 \mathrm{~B}$ served as the control for comparison. These side-by-side buildings were approximately 20 years old, of separate but nearly mirrored construction, and had the separating space between them enclosed to enable a continuous roof. However, the two buildings retained their separate conditioned envelopes. The selected building related concerns targeted in this research effort, and their corresponding performance objectives, are:

- Concern: Mold and mildew problems resulting from uncontrolled relative humidity (RH).

- Objective: Reduce mold and mildew potential by achieving an average RH below $60 \%$.

- Concern: Occupant comfort.

- Objective: Satisfy American Society of Heating, Refrigerating, and Air-Conditioning Engineers (ASHRAE) Standard 55, Thermal Environmental Conditions for Human Occupancy.

- Concern: Reducing energy consumption.

- Objectives: Achieve a building air leakage rate less than $0.15 \mathrm{cfm} / \mathrm{ft}^{2}$ at $75 \mathrm{~Pa}$.; Achieve a 20\% reduction in heating, cooling, and ventilation system energy.

- Concern: Economic improvement.

- Objective: Cost-effective investment with a simple payback less than 5 years; Easily maintainable by existing staff.

Each building contained its own heating, ventilating, and air-conditioning (HVAC) and boiler systems. However, Bldg 1540A was retrofitted with three complementary and innovative technologies that collectively addressed the aforementioned concerns. These technologies were:

- Improved building envelope air tightness to minimize unconditioned outdoor air infiltration.

- A dedicated outdoor air system (DOAS) to properly condition makeup air.

- A ceiling-mounted radiant heating and cooling system. 
These technologies were considered successful despite the fact that they did not entirely meet some of their aggressive objectives. The analysis and results from Bldg 1540A were as follows: Blower door testing was used to assess building envelope air leakage, and enabled sealing efforts that decreased infiltration from 0.82 to $0.39 \mathrm{cfm} / \mathrm{ft}^{2}$ at $75 \mathrm{~Pa}$. While infiltration was greater than the $0.15 \mathrm{cfm} / \mathrm{ft}^{2}$ at $75 \mathrm{~Pa}$. objective, it was a $52 \%$ reduction in building air leakage. The DOAS system dehumidified the outdoor air used to both ventilate the space and to supply makeup air for air that was mechanically exhausted. The temperature of the conditioned space was managed by the radiant heat transfer of water flowing through the ceiling panels - absorbing heat and cooling the space during cold water flow, and emitting heat and warming the space during hot water flow.

The combined DOAS and ceiling-mounted radiant panel systems demonstrated their long-term ability to satisfy ASHRAE Standard 55 (2010). The 95th percentile of Bldg 1540A space temperatures and $\mathrm{RH}$ values during occupied hours (6:00 a.m. to 6:00 p.m.) were between 62 and $78^{\circ} \mathrm{F}$, and 28 and $58 \% \mathrm{RH}$, respectively. These $\mathrm{RH}$ values also satisfied the aim of reducing mold and mildew potential. Energy reduction goals were also achieved. Overall, Bldg 1540A consumed 46\% less energy compared with the prior fiscal year, and 20\% less energy than Bldg $1540 \mathrm{OB}$ during this fiscal year. Economically, an absence of maintenance concerns demonstrated the system's Operations and Maintenance (O\&M) success; however, the system's 26.7 year simple payback exceeded the 5 year objective. Table ES-1-1 lists the quantitative and qualitative performance objectives of this work.

Renovation activities in Bldg 1540A began in Nov 2014 and were completed in Apr 2015. Mechanical system deficiencies in Bldg 1540B were repaired and both sides of the building were commissioned/recommissioned to operate according to their respective design intent. Bldg 1540A was reoccupied in Jun 2015 and a 12-month period of measuring and recording energy performance of both sides of the building commenced in September 2015. 
Table ES-1. Performance objectives.

\begin{tabular}{|c|c|c|}
\hline Performance Objective & Success Criteria & Results \\
\hline \multicolumn{3}{|c|}{ Quantitative Performance Objectives } \\
\hline \multirow{3}{*}{$\begin{array}{l}\text { Reduced building envelope air } \\
\text { leakage }\end{array}$} & \multirow{3}{*}{$<0.15 \mathrm{cfm} / \mathrm{ft}^{2}$ of air leakage at $75 \mathrm{~Pa}$} & $0.39 \mathrm{cfm} / \mathrm{ft}^{2}$ of air leakage at $75 \mathrm{~Pa}$ \\
\hline & & $\begin{array}{l}\text { Estimated } 0.27 \mathrm{cfm} / \mathrm{ft}^{2} \text { of air leakage at } 75 \mathrm{~Pa} \text { with } \\
\text { improved fenestration }\end{array}$ \\
\hline & & Objective not met. \\
\hline Reduced energy consumption & $\begin{array}{l}20 \% \text { reduction in heating, cooling and } \\
\text { ventilation system energy }\end{array}$ & $\begin{array}{l}46 \% \text { reduction in overall energy usage (electric }+ \text { gas) } \\
\text { Objective met }\end{array}$ \\
\hline Cost effectiveness & $\begin{array}{l}\text { Simple Payback: }<5 \text { yrs. } \\
\text { Savings-to-Investment Ratio (SIR): > } 1.2\end{array}$ & $\begin{array}{l}\text { Simple Payback of } 26.7 \mathrm{yrs} . \\
\text { SIR of } 1.0 \\
\text { Objective not met. }\end{array}$ \\
\hline \multicolumn{3}{|c|}{ Qualitative Performance Objectives } \\
\hline Improved comfort & $\begin{array}{l}\text { Temperatures and RH within comfort } \\
\text { criteria defined by ASHRAE Standard 55- } \\
\text { 2010, Section 5.2.1.1 “Graphic Zone } \\
\text { Comfort Method" }\end{array}$ & $\begin{array}{l}\text { The building satisfied ASHRAE Standard } 55-2010 \text { by } \\
\text { maintaining an average of } 70^{\circ} \mathrm{F} \text { and } 43 \% \mathrm{RH} \\
\text { between } 6 \text { a.m. and } 6 \text { p.m. } \\
\text { Objective met. }\end{array}$ \\
\hline $\begin{array}{l}\text { Reduced relative mold/mildew } \\
\text { potential }\end{array}$ & $\begin{array}{l}\text { Measurement of interior surfaces at or } \\
\text { below } 80 \% \text { surface } \mathrm{RH}\end{array}$ & $\begin{array}{l}\text { The building's } 43 \% \text { RH average was well below } \\
\text { ASHRAE's } 60 \% \text { RH recommendation for the } \\
\text { prevention of mold growth. } \\
\text { Objective met }\end{array}$ \\
\hline $\begin{array}{l}\text { Easily operable and } \\
\text { maintainable }\end{array}$ & $\begin{array}{l}\text { Maintainable by existing staff, no special } \\
\text { skills required, less O\&M burden }\end{array}$ & Objective met \\
\hline
\end{tabular}

This project resulted in a number of significant findings:

1. It is feasible to significantly improve the air tightness of an existing building envelope without implementing major changes or disruptions to the interior or exterior surfaces of the building envelope.

2. Radiant heating and cooling systems can adequately maintain comfort conditions in administrative buildings in locations with significant heating and cooling loads.

3. Radiant cooling systems, when combined with a DOAS system to properly dehumidify outdoor air and maintain proper space humidity conditions, can operate without condensation forming on the surface of the radiant cooling panels.

4. Radiant heating and cooling systems are capable of improved energy efficiency when compared with conventional all-air HVAC systems.

5. Radiant systems are easily maintainable and require no special skills for HVAC technicians.

6. The radiant system installed in this project did not prove to be cost competitive with respect to a conventional all-air HVAC system. Considering first cost, energy savings, and reduced maintenance costs, the demonstrated system was calculated to have a long simple payback of 26.7 years. Nevertheless, it may be possible that using different approaches and technologies could cause a radiant system to compete favorable with traditional all-air HVAC systems. 


\section{Contents}
Abstract ii

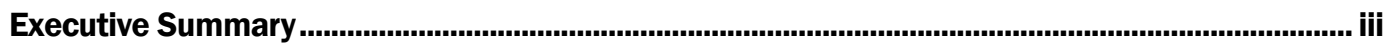
Tables and Figures................................................................................................................. vifi

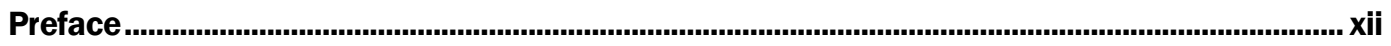



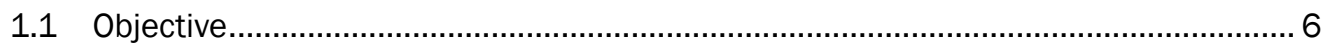

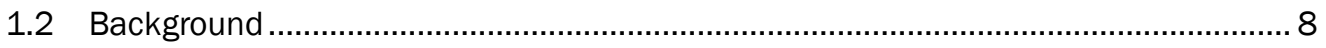

1.3 Regulatory drivers .................................................................................... 11

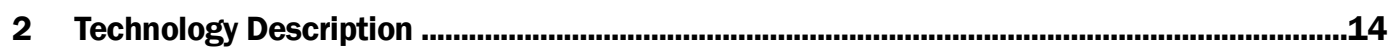

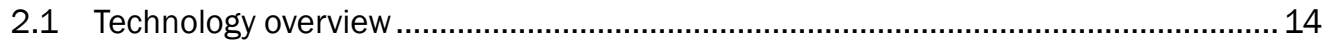

2.2 Description .......................................................................................................... 14

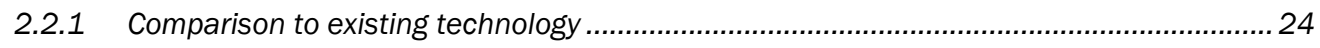

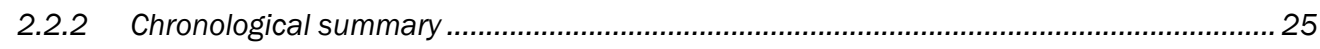

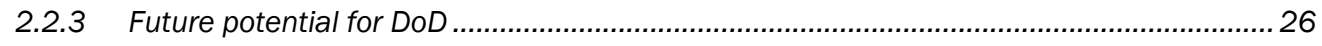

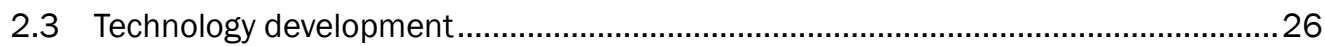

2.4 Advantages and limitations of the technology .................................................. 27

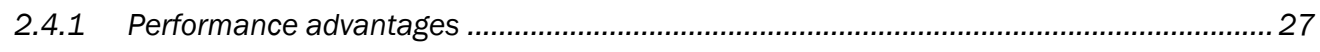

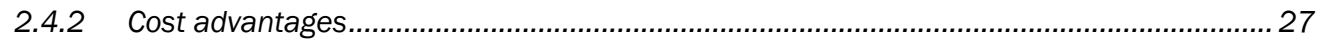

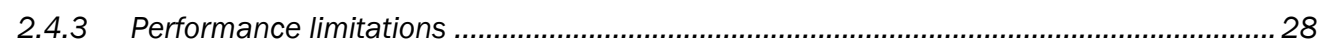

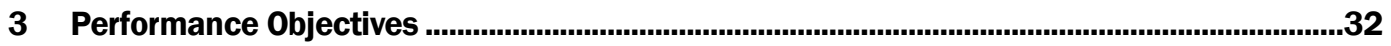

3.1 Quantitative objective: Reduced building envelope air leakage ................................33

3.2 Quantitative objective: Reduced energy consumption .............................................40

3.3 Quantitative objective: Cost effectiveness ............................................................. 41

3.4 Qualitative objective: Improved comfort..........................................................42

3.5 Qualitative objective: reduced relative mold/mildew potential..............................43

3.6 Qualitative objective: Easily operable and maintainable....................................... 43

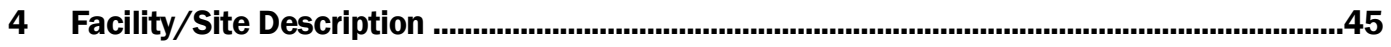

4.1 Facility/site selection criteria ........................................................................ 45

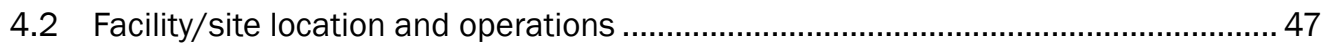

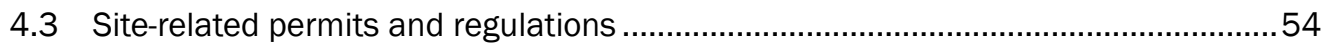

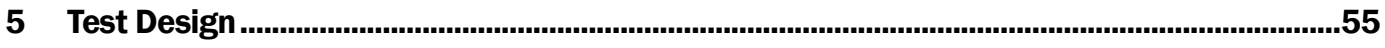

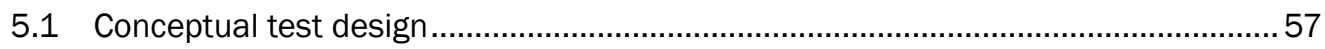

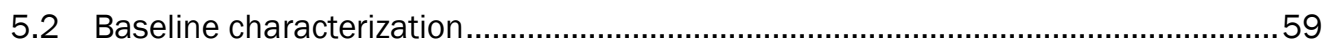

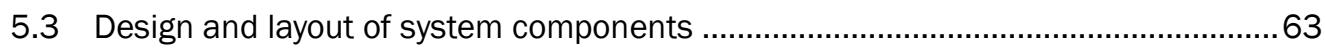

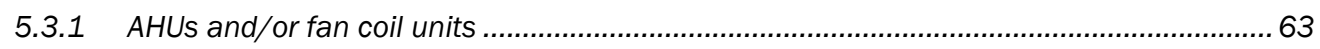

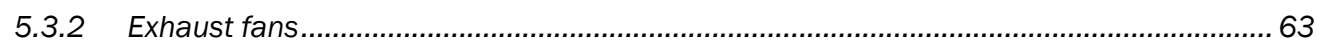

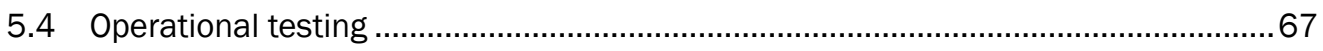

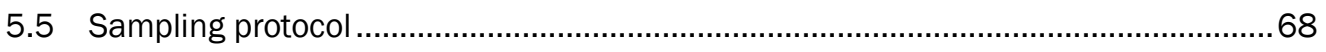




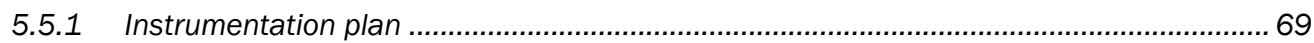

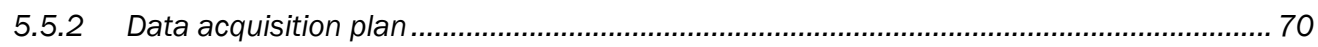

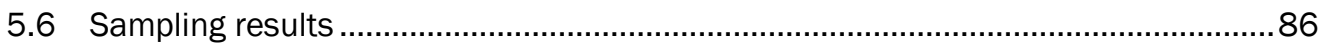

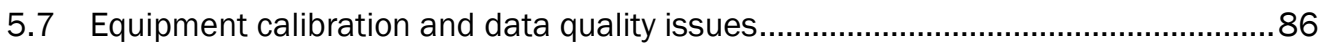

6 Performance Assessment .........................................................................................................88

6.1 Baseline performance ................................................................................ 88

6.2 Reduced building envelope air leakage ............................................................92

6.3 Reduced energy consumption .........................................................................93

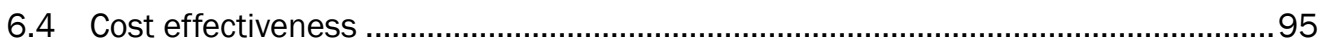

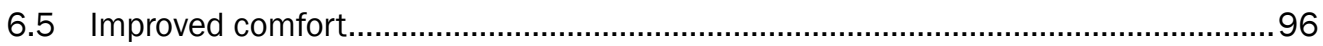

6.6 Reduced relative mold/mildew potential ............................................................99

6.7 Easily operable and maintainable ................................................................100

6.8 Performance review ....................................................................................... 101

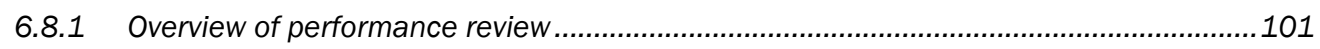

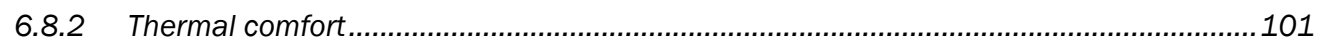

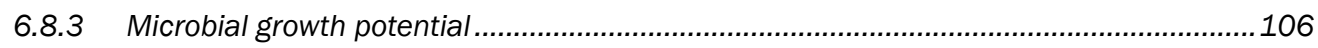

6.8.4 Comparison with baseline energy Performance............................................................107

6.8.5 Energy performance comparison of Bldgs 1540A\&B for monitoring periods Sep 2014 to Aug 2015 and Sep 2015 to Aug 2016 .......................................................112

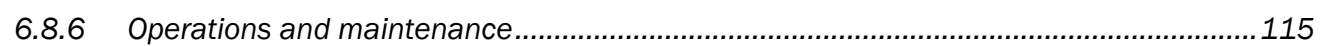

6.8.7 Distinct building issues and differences...................................................................115

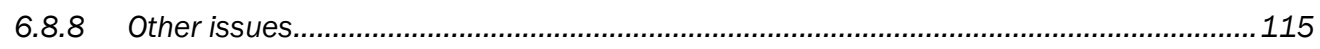

7 Cost Assessment..................................................................................................................... 117

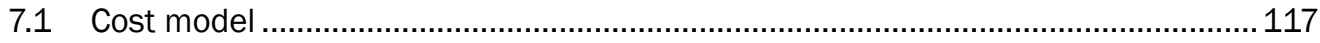

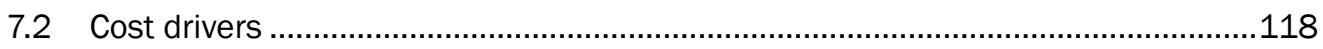

7.3 Cost analysis and comparison ...............................................................118

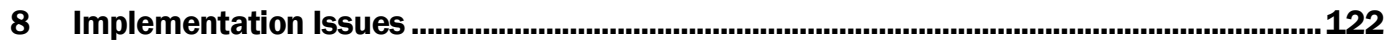

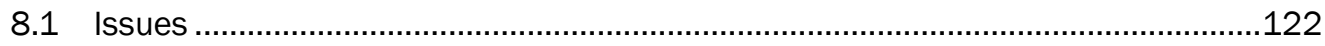

8.2 Lessons Learned ............................................................................................ 123

8.3 Other possible Lessons Learned to consider ....................................................127

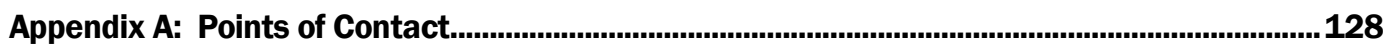

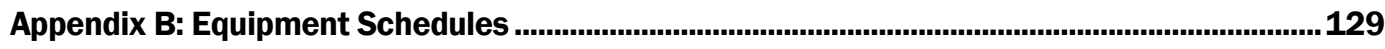

Appendix C: BIdg 1540B Deficiencies List...............................................................................143

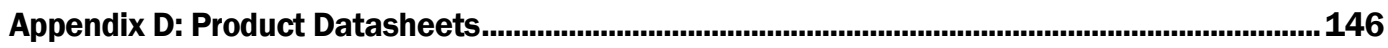

Appendix E: Criteria Change Request for UFC 3-410-01.....................................................150

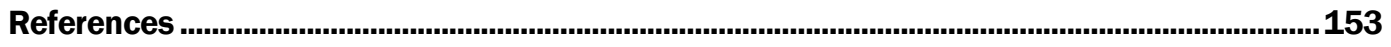

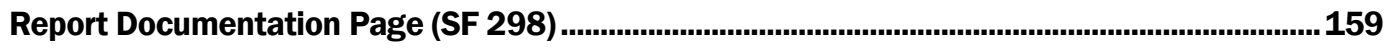




\section{Tables and Figures}

\section{Tables}

ES-1 Performance objectives ............................................................................................

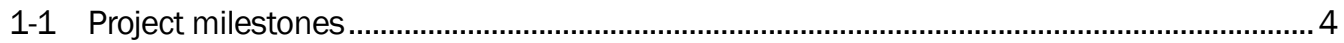

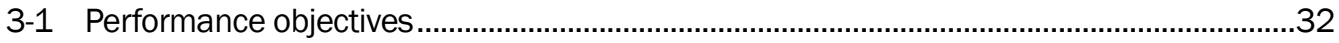

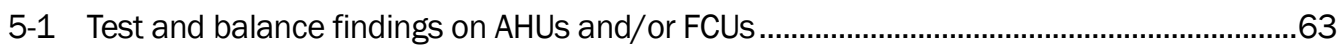

5-2 Test and balance findings on exhaust fans ..............................................................63

5-3 Data sampling, recording, and storage protocol ..............................................................68

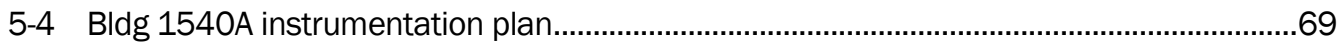

5-5 Bldg 1540B instrumentation plan ......................................................................

5-6 Acronym list for the EnTouch Energy Management System diagram...................................74

5-7 Data sampling, recording and storage protocol ..............................................................

6-1 FY2013 utilities data for BIdg 1540 from Fort Detrick's DPW ...........................................8

6-2 Energy related baseline parameters for Bldgs 1540A\&B...............................................90

6-3 First 12-month energy performance monitoring period for Bldgs 1540A\&B (Sep 2014 thru Aug 2015) ..................................................................................................

6-4 Second 12-month energy performance monitoring period for Bldgs 1540A\&B (post retrofit, occupied, Sep 2015 thru Aug 2016)..............................................................91

6-5 Overview of performance objectives............................................................................. 102

6-6 Monthly outdoor temperatures and interior thermal comfort ranges.............................. 106

6-7 Monthly electric and gas usage data for BIdg 1540A during the periods of Sep 2014 through Aug 2015 and Sep 2015 through Aug 2016. Also shown are

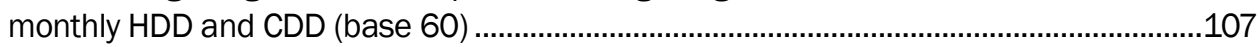

6-8 Bldg 1540B monthly electric and gas usage data for the periods of Sep 2014

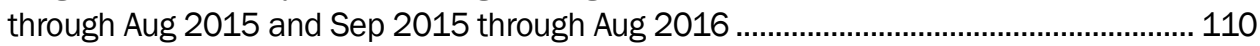

6-10 Summary table of energy performance .......................................................................... 114

7-1 Cost model for the demonstrated system......................................................................117

7-2 Financial overview of the efforts made to improve the condition of Bldgs

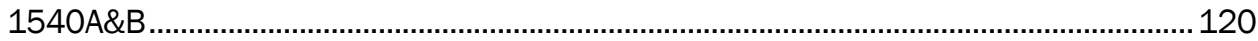

7-3 Annual finances associated with envelope leaks in Bldg 1540A .................................... 120

7-4 A comparison of materials and labor first costs between radiant panel and

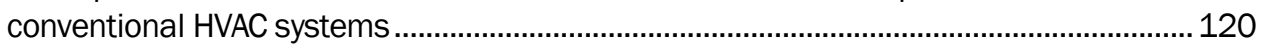

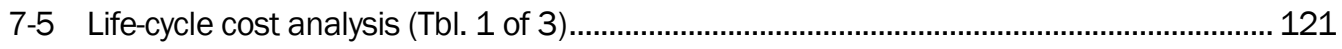

7-6 Life-cycle cost analysis (Tbl. 2 of 3)............................................................................. 121

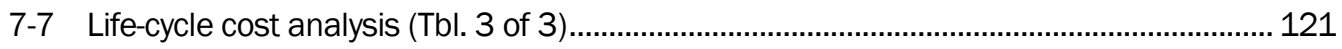

B-1 Bldg 1540A mechanical equipment schedule............................................................. 129

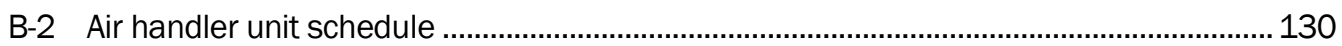

B-3 Air-cooled scroll chiller schedule ................................................................................. 131

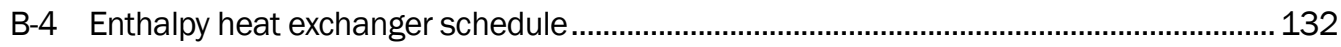

B-5 Preheat coil schedule ............................................................................................. 132

B-6 Fan schedule

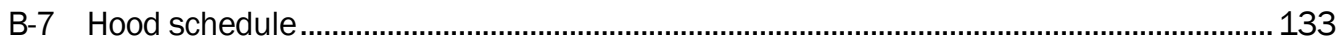


B-8 Minimum code required outside air ventilation rates .................................................. 133

B-9 Pump schedule .................................................................................................... 133

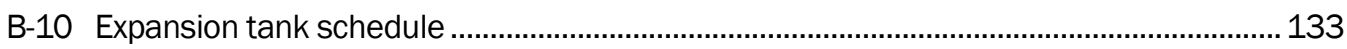

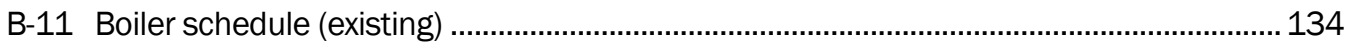

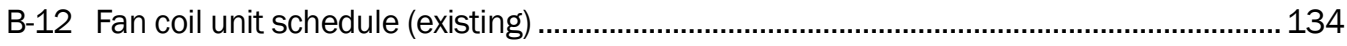

B-13 Cabinet unit heater schedule (existing) .................................................................. 134

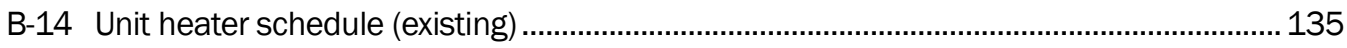

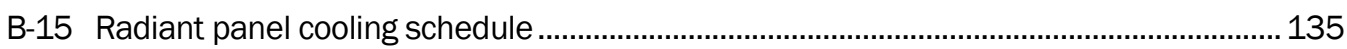

B-16 Radiant panel heating schedule .................................................................................. 140

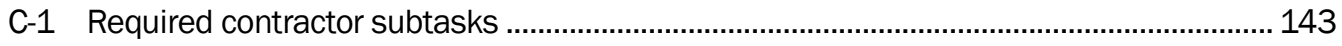

\section{Figures}

2-1 Radiant heating/cooling panel for ceiling mount application ............................................15

2-2 Upper surface view of a two-circuit radiant heating/cooling panel for suspended-

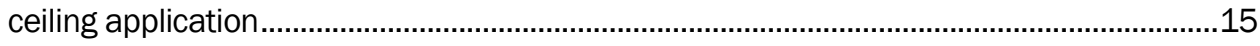

2-3 Finished surface view of a suspended-ceiling radiant panel .............................................15

2-4 Partial plan view (northeast half) of Bldg 1540A showing radiant panels ..........................17

2-5 Partial plan view (southwest half) of Bldg 1540A showing radiant panels. The 11 smaller panels shown in Room C018B (highlighted) added to address a cooling

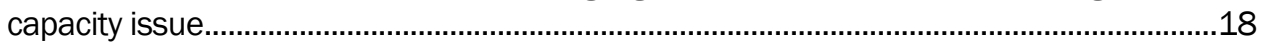

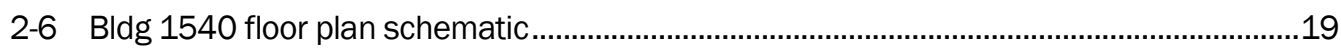

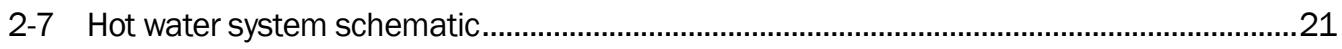

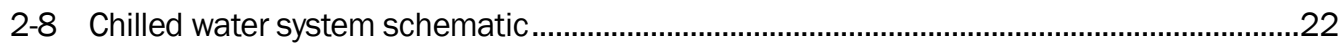

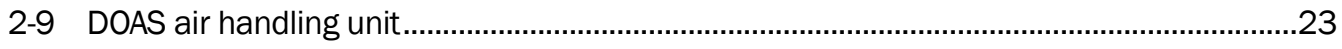

2-10 Temperature display for IA Training Rm C018B for 24-hr period ending at 4:55

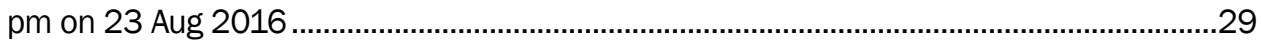

2-11 Temperature display from Energy Monitoring System for IA Training Rm C018B for the 7-day period 16-23 Aug 2016 ...............................................................................30

3-1 Leakage sources at pipe penetrations and at framing systems........................................36

3-2 Leaks sealed at pipe hangers in "heated-only" portion of Bldg 1540A ……......................36

3-3 Sealing of conduit penetrations in cavity space above the suspended ceiling of BIdg 1540A (left) and at the mounting location of a $4 \times 4$ conduit box (right) ......................37

3-4 Sealing of leaks around an exhaust fan in the mechanical room .......................................37

3-5 Sealing of a major opening above the hard ceiling above the men's latrine .......................37

3-6 Single hung window (4x4-ft) in Bldg 1540A (typical of 10) ...............................................39

4-1 NE corner of BIdg 1540 (left) and SW corner of Bldg 1540 (right) ...................................46

4-2 Floor plan of Bldg 1540A and Bldg 1540B .................................................................46

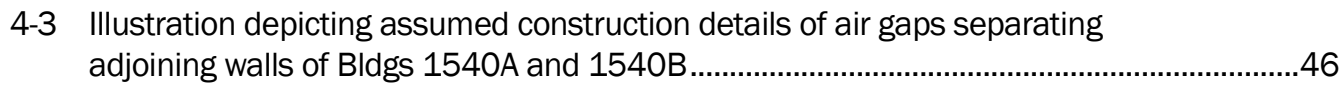

4-4 Screen capture of the online EnTouch energy management system platform for

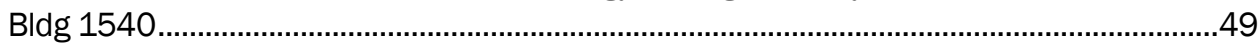

4-5 Map of Fort Detrick showing location of Bldg 1540 ….................................................50

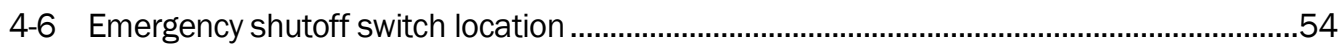

5-1 Air barrier testing apparatus ........................................................................................61 
5-2 Typical EnTouch EMS zone thermostat and temperature/humidity logger........................62

5-3 Typical temperature and RH dataloggers........................................................................62

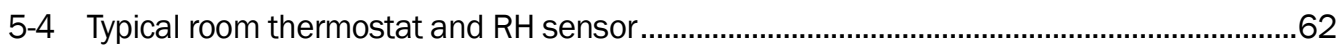

5-5 Existing utility gas meter for Bldg 1540A ................................................................62

5-6 Existing utility gas meter for BIdg 1540B ..................................................................62

5-7 Partial plan view (southwest half) of Bldg 1540A showing radiant panels. Rm C018B (highlighted) shows 11 additional smaller panels installed to address a cooling capacity issue

5-8 Partial plan view (northeast half) of Bldg 1540A showing radiant panels .........................65

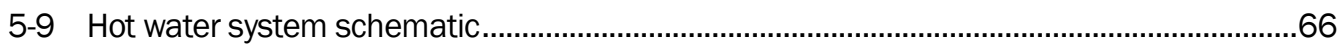

5-10 Chilled water system schematic .......................................................................................66

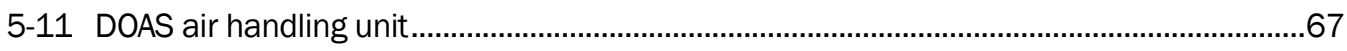

5-12 Diagram highlighting the EnTouch Energy Management System and its components for Bldgs 1540A\&B (as updated 13 Jan 2016) ….........................................72

5-13 EMS panel with monitoring devices installed....................................................................76

5-14 Boiler BTU meter connected to programming software ...................................................... 76

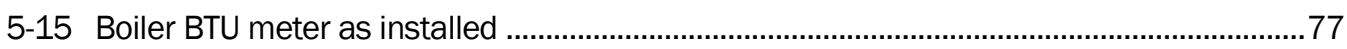

5-16 Building envelope DP sensor and wall temperature/RH sensors installed above

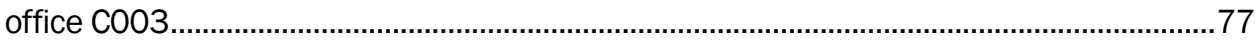

5-17 Building envelope DP Sensor (high side inside room, low side outside building) and wall temperature/RH sensor installed above office $\mathrm{COO3}$..........................................78

5-18 EMS master monitoring device with Global System for Mobile Communications

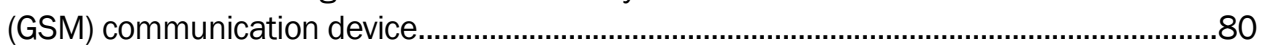

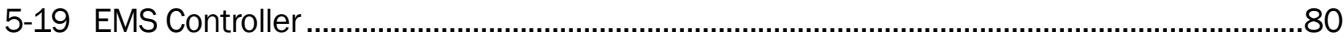

5-20 EMS installation within the BIdg 1540B mechanical room, showing EMS controller and outside air $(\mathrm{OA})$ temperature sensor ……...................................................

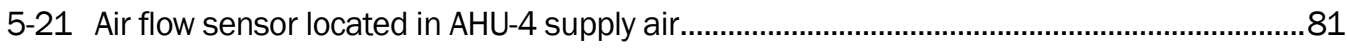

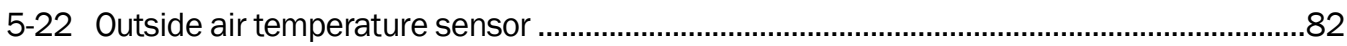

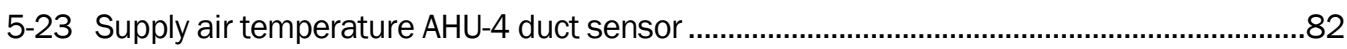

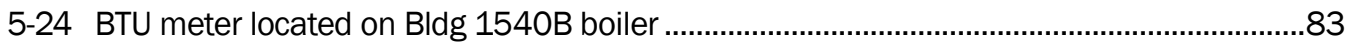

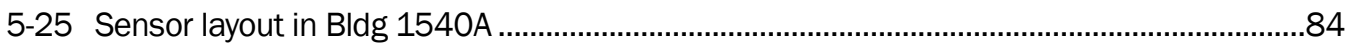

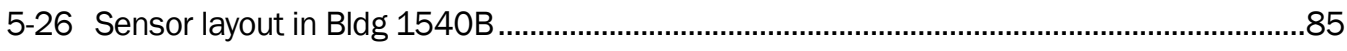

6-1 Satellite view of Bldgs 1540A\&B (maps.google.com) …...................................................92

6-2 A graphical zone method chart derived from ASHRAE Standard 55 ............................... 103

6-3 Thermal comfort values for Bldg 1540 during occupied hours (6 a.m. to 6 p.m.)........... 104

6-4 Interior temperatures recorded within BIdg 1540A.......................................................... 105

6-5 The optimum humidity range for human comfort and health (30 to $60 \%$ ), as published in the 2012 ASHRAE Handbook on HVAC Systems and Equipment................107

6-6 Bldg 1540A total energy usage (electric + gas) for the period Sep 2015 to Aug

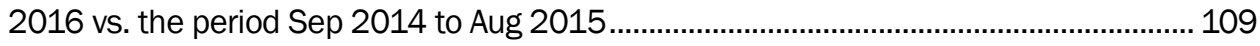

6-7 Bldg 1540A realized a 20\% decrease in electrical usage for the period Sep 2015 to Aug 2016 vs. the period Sep 2014 to Aug 2015.................................................... 109

6-8 Bldg 1540A realized a 56\% decrease in gas usage for the period Sep 2015 to

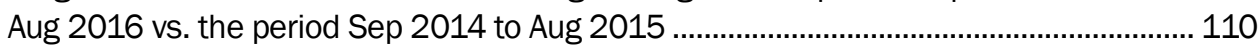

6-9 Bldg 1540B total energy usage (electric + gas) for the period Sep 2015 to Aug 2016 vs. the period Sep 2014 to Aug 2015 
6-10 Bldg 1540B realized a 14\% increase in electrical usage for the period Sep 2015 to Aug 2016 vs. the period Sep 2014 to Aug 2015 ..

6-11 BIdg 1540B realized a 37\% decrease in gas usage for the period Sep 2015 to Aug 2016 vs. the period Sep 2014 to Aug 2015

6-9 Post-retrofit monitoring period (Sep 2015 to Aug 2016) electricity and gas utility usage for Bldgs 1540A\&B.

6-12 Fiscal year 2015/2016 overall energy usage comparison for Bldgs 1540A\&B (electricity + gas). Overall, Bldg 1540A used 20\% less energy than Bldg 1540B

6-13 Fiscal year 2015/2016 electricity usage comparison for Bldgs 1540A\&B. Bldg 1540A consumed 30\% more electrical energy than BIdg 1540B

6-14 Fiscal year 2015/2016 gas utility usage comparison for Bldgs 1540A\&B. Bldg 1540 A consumed $43 \%$ less gas energy than Bldg 1540B 114

D-1 EnTouch Remote Sensor Module (RSM-100) datasheet.................................................. 146

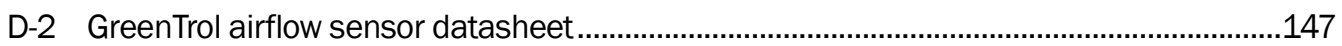

D-3 Badger BTU meter datasheet ................................................................................. 148

D-4 Honeywell humidity/temperature sensor datasheet..................................................... 149 


\section{Preface}

Funding for this demonstration was provided by the Environmental Security Technology Certification Program (ESTCP) under Military Interdepartmental Purchase Requests (MIPRs) No. W74RDV23461416, W74RDV20749510, W74RDV20749509, W74RDV53553148, and W74RDV70303974 under FY14 Energy and Water Project EW-201150. The ESTCP technical monitor was Scott Clark.

The work was managed by the Energy Branch (CFE) of the Facilities Division (CF) of ERDC-CERL. At the time of publication, Mr. Andrew Nelson was Chief, CEERD-CF-E; L. Michelle Hansen was Acting Chief, CEERDCF; and Kurt Kinnevan, CEERD-CV-T was the Technical Director. The Deputy Director of ERDC-CERL was Dr. Kirankumar V. Topudurti and the Director was Dr. Ilker R. Adiguzel.

Thanks are owed to ESTCP, particularly Dr. James Galvin, for his unwavering support of this project. Mr. Brian Dean and Mr. Scott Clark, of HydroGeoLogic, Inc.(HGL), are acknowledged for their technical advice throughout the critical planning and renovation stages of this project. Mr. Timothy Tetreault and Ms. Sarah Medepalli provided continued support as the project transitioned to the data collection and reporting phase. Mr. Larry Potter, Fort Detrick's Director of Public Works, for his support of this project throughout it many stages. Mr. Larry Wright, Directorate of Public Works (DPW) Operations and Maintenance (O\&M) Supervisor and Mr. Mark Zangara, Fort Detrick's Energy Manager both provided invaluable support. Fort Detrick's 21 ${ }^{\text {st }}$ Signal Brigade and $514^{\text {th }}$ Signal Battalion are recognized for their support, patience, and cooperation, especially during the months when they were displaced from their building while the demonstration system was being installed and tested. Mr. Paul Smeck, O\&M Supervisor of the 21st Signal Brigade, provided invaluable service coordinating activities between the Contractors and the building occupants. Thanks are proffered to the U.S. Army Corps of Engineers (USACE) Baltimore District, including Mr. Glenn Murphey, Ms. Katie Brown, and Mr. Patrick Welker for their excellent support in overseeing day-to-day construction activities, system commissioning, and coordination of Contractor access to the installation.

COL Bryan S. Green was Commander of ERDC, and Dr. David W. Pittman was the Director. 


\section{Introduction}

This project was originally conceived as a result of the Army's efforts to address chronic and persistent mold and mildew problems in Army facilities. Mold and mildew infestations of Army facilities pose indoor air quality concerns and risk the health, wellness and quality of life of soldiers. Remediating mold and mildew in facilities costs the Army millions of dollars annually.

In recent years, mold and mildew became a public relations concern for the Army and the other services as well. Major news stories documented the poor state of Army barracks facilities. For example, USA TODAY (2008) reported that "At Fort Campbell, soldiers struggle in the hot Kentucky summers to keep mold from taking over their showers." As a result of a 2008 worldwide review of conditions in barracks facilities, the Army committed to spend $\$ 248$ million to address mold, plumbing, and temperature-control problems at eight major installations in the Continental United States (CONUS) and Hawaii (USA Today 2008).

Concerns about mold and mildew in Army facilities are not a recent occurrence. For many years, the Army has attempted to address these problems through routine maintenance, minor remediation efforts, and major renovation of Army facilities. In many cases, building interiors were completely demolished and replaced and new HVAC systems installed. Unfortunately, in spite of the millions of dollars invested, the Army's efforts to get a handle on this issue persistently failed to achieve long-term fixes. Both newly constructed and recently renovated facilities in hot and humid locations commonly experienced mold and mildew problems within a few years of completion.

Project Background and Potential Contribution to DoD. This project was initiated to demonstrate integration of three innovative technologies that would address DoD's need to simultaneously address mold and mildew problems, maintain indoor air quality, provide occupant comfort, and reduce energy consumption in military facilities. Building envelope improvements reduce infiltration of moist outdoor air in and through wall structures where it can contribute to ideal conditions for development of mold 
and mildew, cause damage to building structural elements and architectural finishes, and negatively affect health and comfort within facilities. Reduced infiltration of unconditioned outdoor air also lowers a building's overall heating and cooling loads, eliminates drafts, and improves occupant comfort.

A tightened building envelope increases the importance of assuring adequate ventilation. Many military facilities employ variable air volume (VAV) systems, which are notorious for their inability to deliver adequate ventilation air at part load conditions. This problem is addressed by integration of a dedicated outdoor air system (DOAS), which provides the required volume of conditioned ventilation air under all load conditions. In addition, a DOAS system is better able to dehumidify air entering a building because it modulates its dehumidification capacity based on the actual moisture content of the ventilation air stream.

Combining an improved, tightened building envelope with a DOAS system enables excellent control of humidity conditions inside a building. With humidity conditions under control, a radiant heating and cooling system becomes a feasible choice for managing the sensible comfort conditions inside of the building. Radiant systems heat and cool spaces by circulating hot (or chilled) water through radiant ceiling panels so that heat transfer between objects and occupants in the space and the radiant heating/cooling process occurs primarily via radiant heat transfer (rather than by convective heat transfer). The radiant panel system is expected to perform better than a conventional HVAC system. According to the Dec 2013 ASHRAE Journal article "Cooling Load Calculations For Radiant Systems" (Bauman, Feng, and Schiavon 2013), an experimental study revealed "The radiant system has a higher cooling rate than the air system, meaning that it is faster to remove heat gains while maintaining equivalent comfort conditions. For the tested cases, $75 \%$ to $82 \%$ of the total heat gain was removed by the radiant system ... while for the air system, $61 \%$ to $63 \%$ was removed." With good control of humidity conditions in the building, there should be little risk of moisture condensing on the cold surfaces of radiant panels when operating in the cooling mode. 
Project Intent: The intent of this project was to demonstrate the feasibility and benefits resulting from the integration of building envelope improvements with a DOAS system and a radiant heating/cooling system. The significance of this effort included:

- Tightened Building Envelope: Significant tightening of the Bldg 1540A envelope was an important accomplishment because it demonstrated the potential for DoD to greatly improve the building envelopes of many thousands of existing military facilities. In many cases, the Contractor used minimally invasive sealant methods such as sealing with closed-cell spray polyurethane foam (ccSPF) and/or caulking with backer material where necessary. In several locations, large unfinished openings in the building's air barrier were sealed with gypsum board and drywall compound.

- Proper Building Ventilation and Humidity Control: We successfully demonstrated that a DOAS system can maintain building humidity conditions at levels that will not cause condensation on radiant cooling surfaces and maintain building conditions that are relatively less favorable to the formation of mold and mildew than buildings without a DOAS system.

- Radiant Heating/Cooling System: By successfully installing and demonstrating a radiant heating/cooling system we showed that it is possible to condition a building in a humid climate without experiencing condensation on cool radiant surfaces. We also demonstrated that radiant heating/cooling systems are able to efficiently and cost effectively heat and cool admin/training facilities and satisfy occupant comfort requirements while being easily operable and maintainable.

Project Timeline. ESTCP approved this project for funding in Fiscal Year 2011 (FY11). An extended project delay occurred resulting from a decision by the original demonstration site to withdraw from the project. Our original proposal to ESTCP was to perform this demonstration on a VOLAR Barracks facility at Fort Polk, LA. As Fort Polk was in the midst of an ongoing program to renovate 31 of these existing barracks facilities, we proposed to revise the plans and specifications for one of these facilities and have the renovation Contractor execute the revised plans and specifications on that facility. Following Fort Polk's withdrawal from the demonstration, we conducted a DoD-wide search to find a suitable replacement demonstration site. Fort Detrick's Bldg 1540 was identified as the new 
demonstration site. Because Bldg 1540 was quite different from the VOLAR Barracks at Fort Polk, our entire approach to the project had to be revised. A revised proposal was submitted to ESTCP in the second quarter of FY12. Subsequently, ERDC Contract No. W9132T-14-C-0001 was awarded to the PERTAN Group on 30 Oct 2013. This project was scheduled to be executed over a 30-month period. Table 1-1 lists major project milestones and descriptions of these milestones.

Table 1-1. Project milestones.

\begin{tabular}{|c|c|c|}
\hline Milestone & Start & Finish \\
\hline Contract Award & 30 Oct 2013 & 30 Oct 2013 \\
\hline Onsite Kickoff Meeting & 20 Nov 2013 & 20 Nov 2013 \\
\hline $\begin{array}{l}\text { “Before” Air Tightness Testing of Demonstration Building } \\
\text { Envelope (1540A) }\end{array}$ & 7 May 2014 & 8 May 2014 \\
\hline Prepare Concept Retrofit Design & 12 May 2014 & 20 Jun 2014 \\
\hline Finalize Retrofit Design & 21 Jun 2014 & 6 Aug 2014 \\
\hline Retrofit System Installation (1540A) & 17 Nov 2014 & 24 Apr 2015 \\
\hline System Commissioning of Demonstration Bldg (1540A) & 7 May 2015 & 8 May 2015 \\
\hline $\begin{array}{l}\text { "After" Air Tightness Testing of Demonstration Building } \\
\text { Envelope }(1540 A) *\end{array}$ & 10 Aug 2015 & 14 Aug 2015 \\
\hline $\begin{array}{l}\text { Identification, repair of Mechanical System Deficiencies in } \\
\text { Baseline Bldg 1540B }\end{array}$ & 6 Mar 2014 & 7 Aug 2015 \\
\hline Recommissioning of Baseline Bldg $1540 \mathrm{~B}$ & 10 Aug 2015 & 14 Aug 2015 \\
\hline Energy Monitoring & 1 Sep 2015 & 30 Sep 2016 \\
\hline Data Analysis and Draft Final Report & 1 Sep 2015 & 30 Sep 2016 \\
\hline Final Report and Cost and Performance (C\&P) Report & 1 Jan 2017 & 31 Mar 2017 \\
\hline
\end{tabular}

1. "Before" Air Tightness Testing of Demonstration Building Envelope. At the start of the project, the demonstration side of the facility (1540A) underwent air barrier testing to establish the existing air leakage rate (measured as $\mathrm{cfm} / \mathrm{ft}^{2}$ of leakage through the building envelope @ $75 \mathrm{~Pa}$ ) for the demonstration facility (refer to Section 6.1 "Baseline Performance").

2. Prepare Concept Retrofit Design. Based on the results of "Before" air tightness testing, as-built drawings, and a survey of existing conditions, PERTAN prepared a concept design for building system improvements (im- 
proved building envelope, DOAS system and radiant heating/cooling system) (refer to Chapter 2, "Technology Description"). They also developed a concept instrumentation plan and data acquisition system design, which were submitted for Government review/comments.

3. Finalize Retrofit Design. After receiving Government review comments, PERTAN prepared a final demonstration design for building system improvements and a design for the instrumentation and data acquisition system.

4. Retrofit System Installation. PERTAN subcontracted with a general Contractor (Musser Mechanical, Mercersburg, PA) to install the retrofit design. This included system commissioning of the demonstration facility and repairing and recommissioning of the baseline facility to ensure that it was operating according to its original design intent. Other subcontractors installed instrumentation and a data acquisition system for measuring and recording operational data.

5. "After" Air Tightness Testing of Demonstration Building Envelope. "After" testing was performed to establish the air leakage rate for the improved demonstration facility (refer to Section 6.1, "Baseline Performance").

6. Identification, Repair of Mechanical System Deficiencies in Baseline Bldg 1540B. Numerous deficiencies were identified in the baseline Bldg $1540 \mathrm{~B}$ system, which were certain to impact the energy performance of Bldg 1540B. After trying unsuccessfully to get these deficiencies repaired by the Directorate of Public Works (DPW), we executed a contract modification to have the demonstration Contractor make the necessary repairs.

7. Recommissioning of Baseline Bldg 1540B: Following completion of repair work in Bldg $154 \mathrm{OB}$, the building was recommissioned to ensure that it was performing per its original design specifications.

8. Energy Monitoring: On completion of renovation, commissioning and installation of performance data collection systems in Bldgs 1540A\&B, PERTAN collected and analyzed performance data for a period of 12 months (refer to Section 5.5, "Sampling Protocol"). Because repair and recommissioning of Bldg 1540B was completed in Sep 2015, the Energy Monitoring period was extended through Sep 2016.

9. Data Analysis and Draft Final Report: On completion of the Energy Monitoring period, the Contractor completed the data analysis and prepared a draft final report.

10. Final Reports: After submittal and review of the draft Final Report, CERL incorporated ESTCP's comments into a Final Report and a C\&P Report (refer to Chapter 7, "Cost Assessment"). 


\subsection{Objective}

The objective of this project was to demonstrate the energy performance, occupant comfort and sustainability benefits of integrating three complementary technologies (improved building envelopes to minimize uncontrolled infiltration of unconditioned outdoor air, DOAS to accurately deliver properly conditioned outdoor air, and radiant heating/cooling systems) in a military facility. The findings from this project will not influence or change ASHRAE or other national standards by itself, but can add momentum to larger, collective research efforts concerning radiant cooling systems (e.g., the Center for the Built Environment's ongoing Radiant Systems Research, http://www.cbe.berkeley.edu/research/radiant-systems.htm) (UC Regents 2014)).

This project will help DoD to improve building energy performance by demonstrating the value and feasibility of achieving very airtight building envelopes for both new and existing facilities. Combined with DOASs to accurately control delivery of properly conditioned outdoor air, building interior humidity conditions can be controlled at levels that make radiant heating and cooling feasible. Improved building envelopes reduce the amount of outdoor air required to pressurize buildings while DOAS systems deliver properly conditioned outdoor air to meet occupant ventilation requirements. Radiant heating/cooling provides occupant comfort with less energy than conventional "all-air" systems. According to the 2015 ASHRAE Handbook: HVAC Applications (ASHRAE 2015), “... a conservative limit for no mold ever, on anything at any temperature, is below $60 \%$ RH.” Therefore, by maintaining less than $60 \% \mathrm{RH}$ inside the facility and reducing infiltration of unconditioned outdoor air, there should be a relatively negligible probability of mold and mildew problems in the building.

Validate: This project installed the subject technologies in one half of the study facility (Bldg 1540A) and the other half of the facility (Bldg 1540B) remained unrenovated to serve as a baseline. The energy performance of the renovated and baseline portions of the facility was recorded, analyzed, and compared. The relative economics of the two halves of the facility were also compared, including the first cost of demonstrated technologies vs. first cost of a conventional design, as well as the relative maintenance and energy costs. In addition, the relative comfort of the two facilities were compared. 
Findings and Guidelines. The insights gained from the demonstration illustrate the possibility of significantly improving the air tightness of existing building envelopes. By successfully controlling humidity in the building, we have demonstrated that it is possible to radiantly heat and cool a facility without increasing the risk of condensation on cool surfaces within the building.

With a calculated simple payback of 26.7 years, this project did not successfully demonstrate the cost effectiveness of radiant heating/cooling systems with respect to conventional all-air HVAC systems. Nevertheless, it may be that radiant systems could be found to be cost competitive with all-air HVAC systems as designers and installers gain experience with these systems and as the suppliers of radiant system components achieve increased sales volume. It is also possible that the energy performance of the demonstrated system could be further optimized to realize greater energy savings. Due to network security restrictions, it was very difficult for the Contractor to adjust system parameters to attempt to optimize performance.

In older facilities that may not have adequate interstitial space above the ceiling to facilitate installation of HVAC ductwork, radiant systems could prove to be a viable method of providing heating and cooling in these spaces.

Technology Transfer. This project demonstrated a novel approach to controlling environmental conditions in an active military facility in a hot and humid portion of the country. This technology will be transferred by articles on the Whole Building Design Guide (WBDG) website and by updating Unified Facilities Criteria (UFC) 3-410-01, Heating, Ventilating, and Air-Conditioning Systems (HQUSACE, NAVFAC, and AFCESA 2011). It will also be documented in an ERDC Technical Report and articles in publications such as the Army's Public Works Digest, The Military Engineer, and the ASHRAE Journal. We will also submit an article to Dr. Stanley Mumma's DOAS-Penn State University website (http://doas.psu.edu/).* Dr. Mumma is a highly published expert on radiant heating and cooling and DOAS systems.

\footnotetext{
* Dr. Stanley Mumma, of Penn State University, State College, PA, is a source of a wealth of information on dedicated outdoor air systems and radiant heating/cooling systems. See, for example: http://doas.psu.edu/ http://www.cbe.berkeley.edu/research/radiant_cooling.htm http://www.healthyheating.com/Page\%2055/Page_55_i_cooling_eq.htm
} 
Acceptance. This project showed that this technology, particularly radiant cooling, can be successfully used in the hot and humid southeastern United States. If it can work well in that portion of the country, and if it can ultimately be shown to be economically competitive (on a first cost basis) while reducing maintenance costs and satisfying occupant comfort requirements, it will overcome the reluctance of other DoD locations to try a technology that appears to be novel and unproven.

Additional Benefits. This project will benefit the radiant heating and cooling industry. Radiant heating enjoys a small niche in the industry, but would probably realize a significant increase if it could be shown that radiant heating and radiant cooling are both technically feasible and economically viable. Currently, there is little incentive to install a radiant heating system in a space if it is also necessary to install an all-air cooling system, which would require investment in two different systems.

Deliverables. Deliverables include an ERDC/CERL technical report, an article submitted to The Military Engineer (Society of American Military Engineers) and to the ASHRAE Journal. We will also submit articles to the Army's Public Works Digest and to Air Force and Navy equivalents.

\subsection{Background}

Current State of Technology in DoD. USACE issued Engineering and Construction Bulletin (ECB) 2009-29, Building Air Tightness Requirements, on 30 Oct 2009 (HQUSACE 2009). For all new Army construction projects and all major Army renovation construction projects after FY10, ECB 2009-29 required that building envelope air barrier material(s) must have an air permeance not to exceed $0.004 \mathrm{cfm} / \mathrm{ft}^{2}$ at 0.3 inches of water gauge (iwg) $\left[0.02 \mathrm{~L} / \mathrm{s}-\mathrm{m}^{2} @ 75 \mathrm{~Pa}\right.$ ] when tested in accordance with American Society for Testing and Materials (ASTM) E 2178 (ASTM 2013). It also required testing of the completed building to demonstrate building envelope air leakage of less than $0.25 \mathrm{cfm} / \mathrm{ft}^{2}\left(1.25 \mathrm{~L} / \mathrm{s}-\mathrm{m}^{2}\right)$ at a pressure differential of 0.3 iwg (75 Pa) in accordance with ASTM E779, Standard Test Method for Determining Air Leakage Rate by Fan Pressurization (ASTM 2003a) or ASTM E 1827, Standard Test Methods for Determining Air tightness of Buildings Using an Orifice Blower Door (ASTM 2011) 
DoD recognizes the importance of achieving airtight building envelopes as a means of reducing building energy consumption and minimizing the infiltration of moist air into the building interior. Subsequent to the Army's adoption of ECB 2009-29, the DoD issued UFC 3-101-01 (HQUSACE, NAVFAC, and AFCESA 2011). Per this Tri-Service document, the Army and Navy adopted the ECB 2009-29 requirements. For Air Force projects, the building air leakage rate shall not exceed $0.4 \mathrm{cfm} / \mathrm{ft}^{2}\left(2.00 \mathrm{~L} / \mathrm{s}-\mathrm{m}^{2}\right)$ when test results measured at a pressure differential of 0.2 iwg ( $50 \mathrm{~Pa}$ ) are extrapolated to 0.3 iwg (75 Pa).

USACE's experience with new construction has shown that meeting the requirement for envelope leakage not to exceed $0.25 \mathrm{cfm} / \mathrm{ft}^{2}$ at a pressure differential of $0.3 \mathrm{iwg}(75 \mathrm{~Pa}$ ) is quite achievable for new construction. A number of new construction projects have been documented with air leakage rates as low as $0.1 \mathrm{cfm} / \mathrm{ft}^{2}$ at a pressure differential of 0.3 iwg (75 Pa). It is, however, much more difficult to achieve air leakage rates this low on renovation projects, depending on the extent of the renovation work. Regardless of the challenge, benefits can still be realized. For example, research has demonstrated that improvements in window sealing can decrease building leakage 5 to 30\%. (U.S. Department of Energy 2016).

VAV systems often fail to deliver required quantities of ventilation air to occupied spaces as a building's cooling load is reduced. Central air handling units (AHUs) and fan coil units (FCUs) often lack the latent cooling capacity to adequately control building moisture levels, especially at reduced sensible cooling levels. As a result, DOASs are increasingly being used on new construction and renovation projects as they are recognized as being more capable of controlling the quantity and quality of ventilation air than other HVAC systems.

DOAS systems and improved building envelopes are complementary technologies. As building envelopes are tightened, it becomes more critical to ensure adequate quantities of ventilation air because uncontrolled infiltration of outdoor air cannot compensate for inadequate delivery of ventilation air by the HVAC system. DOAS systems are able to reliably provide required quantities of ventilation air under a variety of building operating conditions. In general with any HVAC system, a tighter building envelope minimizes air leakage, thereby allowing the DOAS system to be downsized to deliver sufficient outdoor air to maintain a slight positive pressure within the facility. 
Radiant heating systems are widely used in the DoD in shops, high bay maintenance facilities, hangars and other applications. They have been shown to heat such facilities more effectively than traditional forced air systems. By radiantly warming objects in a space rather than directly heating the air in the space, occupants perceive comfort in relation to the radiant temperature of their surroundings. Radiant heating systems are quieter and cleaner than forced convection systems in that they do not mechanically circulate air. Hydronic radiant heating systems can provide comfort at lower hot water temperatures than forced air heating systems, which improves the efficiency of the hot water generation system. In addition, it is more energy efficient to deliver a given quantity of heating energy hydronically (via a pump) than through forced air (via a fan).

Radiant cooling systems are not widely used in the U.S. construction industry although they have enjoyed increasing use in Europe and Australia. Like hydronic radiant heating systems, radiant cooling systems (which are inherently hydronic) are quieter and cleaner than forced air systems. They also require less energy to deliver a given amount of cooling capacity and can effectively provide occupant comfort while using chilled water that is warmer than the air of conventional forced air cooling systems.

Hydronic radiant heating/cooling systems have not penetrated the U.S. construction industry for at least a couple of reasons. First, the American construction industry is relatively unfamiliar with radiant heating/cooling systems. As a result, most designers are reluctant to use technologies that appear to be novel or unproven. Secondly, there is a well-founded concern that cool surfaces of radiant cooling systems could be subject to condensation. This project demonstrated that this possible problem can be avoided by combining a tight building envelope (to prevent uncontrolled infiltration of unconditioned outdoor air) with a DOAS system to control the moisture levels of outdoor air introduced to the building, hence the dewpoint of the air within the conditioned spaces can be maintained at levels that will not result in condensation on cooling surfaces.

Technology Opportunity. If adopted, the combination of these technologies could have a significant impact on DoD's mission accomplishment, energy costs, energy security and attainment of energy goals. DoD annually spends millions of dollars to renovate buildings that have been contaminated with mold and mildew. This project sought to demonstrate a 
way to reduce the potential for mold and mildew formation in existing buildings while efficiently and cost effectively heating and cooling these facilities and satisfying occupant comfort requirements. This project enables DoD to greatly reduce the high costs of remediating mold and mildew in military facilities while saving energy, thereby helping the DoD to meet energy performance mandates.

\subsection{Regulatory drivers}

\section{- Executive Orders:}

- Executive Order (EO) 13423 - NOTE: Revoked by EO 13693 on 19 Mar 2015.

- Agencies shall:

○ Reduce energy intensity by 3\% annually through the end of FY2015, or

- Reduce energy intensity by $30 \%$ by the end of FY2015, relative to an FY2003 baseline.

- Ensure that:

* New construction and major renovation of agency buildings complies with the Guiding Principles for Federal Leadership in High Performance and Sustainable Buildings.

* $15 \%$ of the existing Federal capital asset building inventory of the agency as of the end of FY2015 incorporates the sustainable practices in the Guiding Principles.

* EO 13514 - NOTE: Revoked by EO 13693 on 19 Mar 2015.

- Implement high performance sustainable Federal building design, construction, operation and management, maintenance, and deconstruction by:

* Ensuring all new Federal buildings entering the design phase in 2020 or later are designed to achieve zero net energy by 2030.

* Ensuring all new construction, major renovations, or repair or alteration of Federal buildings comply with the Guiding Principles for Federal Leadership in High Performance and Sustainable Buildings (USEPA 2006).

* Ensuring at least 15\% of existing agency buildings and leases (above 5,000 gross square feet) meet the Guiding Principles by FY2015 and that the agency makes annual progress towards $100 \%$ compliance across its building inventory. 
* Pursuing cost-effective, innovative strategies to minimize consumption of energy, water, and materials.

* Managing existing building systems to reduce the consumption of energy, water, and materials, and identifying alternatives to renovation that reduce existing asset deferred maintenance costs.

- EO 13693 - Agencies shall: Promote building energy conservation, efficiency, and management by reducing agency building energy intensity measured in British thermal units per gross square foot by $2.5 \%$ annually through the end of fiscal year 2025 (FY25), relative to the baseline of the agency's building energy use in FY15 and taking into account agency progress to date.

\section{- Legislative Mandates:}

- Energy Policy Act of 2005 (EPACT) - New Federal buildings shall be designed to require 30\% less energy than buildings designed in accordance with ASHRAE Standard 90.1-2004 (ASHRAE 2004) or the International Energy Code.

- Energy Independence and Security Act of 2007 (EISA) - New and renovated Federal buildings must reduce fossil fuel use by $55 \%$ (from 2003 levels) by 2010 , and $80 \%$ by 2020 . All new Federal buildings must be carbon-neutral by 2030 .

- Federal Policy: Federal Leadership in High Performance and Sustainable Buildings Memorandum of Understanding (MOU) (USEPA 2006).

- Energy Efficiency: For new construction, reduce the energy cost budget by $30 \%$ compared with the baseline building performance rating per ASHRAE Standard 90.1-2004 (ASHRAE 2004) . For major renovations, reduce the energy cost budget by $20 \%$ below the pre-renovation 2003 baseline.

- Ventilation and Thermal Comfort: Meet the requirements of ASHRAE Standard 55-2010, Thermal Environmental Conditions for Human Occupancy (ASHRAE 2010), including continuous humidity control within established ranges per climate zone, and ASHRAE Standard 62.1-2004, Ventilation for Acceptable Indoor Air Quality (ASHRAE 2004).

- Moisture Control: Establish and implement a moisture control strategy for controlling moisture flows and condensation to prevent building damage and mold contamination. 
- DoD Policy: “2016 Strategic Sustainability Performance Plan,” Energy Security MOU with the U.S. Department of Energy (USDOE) (OMB 2016).

- Service Policy: Army, Navy, Air Force.

- Regulations: Air Force Instructions.

- Guides: Whole Building Design Guide (WBDG, http://www.wbdg.org/).

- Specifications: ASHRAE, Leadership in Energy and Environmental Design (LEED). 


\section{Technology Description}

\subsection{Technology overview}

Bldg 1540A used two complementary technologies to manage occupant comfort, the DOAS and radiant ceiling panel systems. The DOAS system dehumidifies the outdoor air used to both ventilate the space and supply makeup air to replace air that was mechanically exhausted. The temperature of the conditioned space was managed by the radiant heat transfer from the heating/cooling water flowing through the radiant ceiling panels. Pumps supplied either heated or chilled water through the radiant ceiling panels depending on the system's demand for heating or cooling. Therefore, the panels either absorbed heat and cooled the space during chilled water flow, or emitted heat and warmed the space during hot water flow.

\subsection{Description}

Radiant heating systems have been around for centuries in the form of fireplaces, cast iron radiators, and other devices. Radiant heating systems have been incorporated into heated floors and gas-fired radiant heaters, which see widespread usage in shops and high bay facilities.

This project made use of a hydronic radiant heating/cooling system. The system consisted of metallic panels that were incorporated in a $2 \times 4 \mathrm{ft}$. grid ceiling system and metallic "cloud" panels suspended from the unfinished ceiling of a conference room and a training room. Hot or chilled water was piped through a serpentine copper tubing network that was thermally bonded to the upper surface of the metallic panel system. Insulation was applied above the panels in accordance with the manufacturer's recommendations. Radiant heat transfer with the room occurred primarily due to the $4^{\text {th }}$ power of the temperature difference between objects in the room and the surface of the radiant ceiling panels. Figure 2-1 shows a schematic of a typical hydronic radiant panel.

Figure 2-2 shows an upper surface view of a two-circuit radiant panel for installation in a ceiling grid. Figure 2-3 shows the finished surface side of a grid-mounted panel illustrating that the finished surface can be designed to match the surrounding suspended-ceiling system, in this case, to resemble an acoustic ceiling tile. 
Figure 2-1. Radiant heating/cooling panel for ceiling mount application.

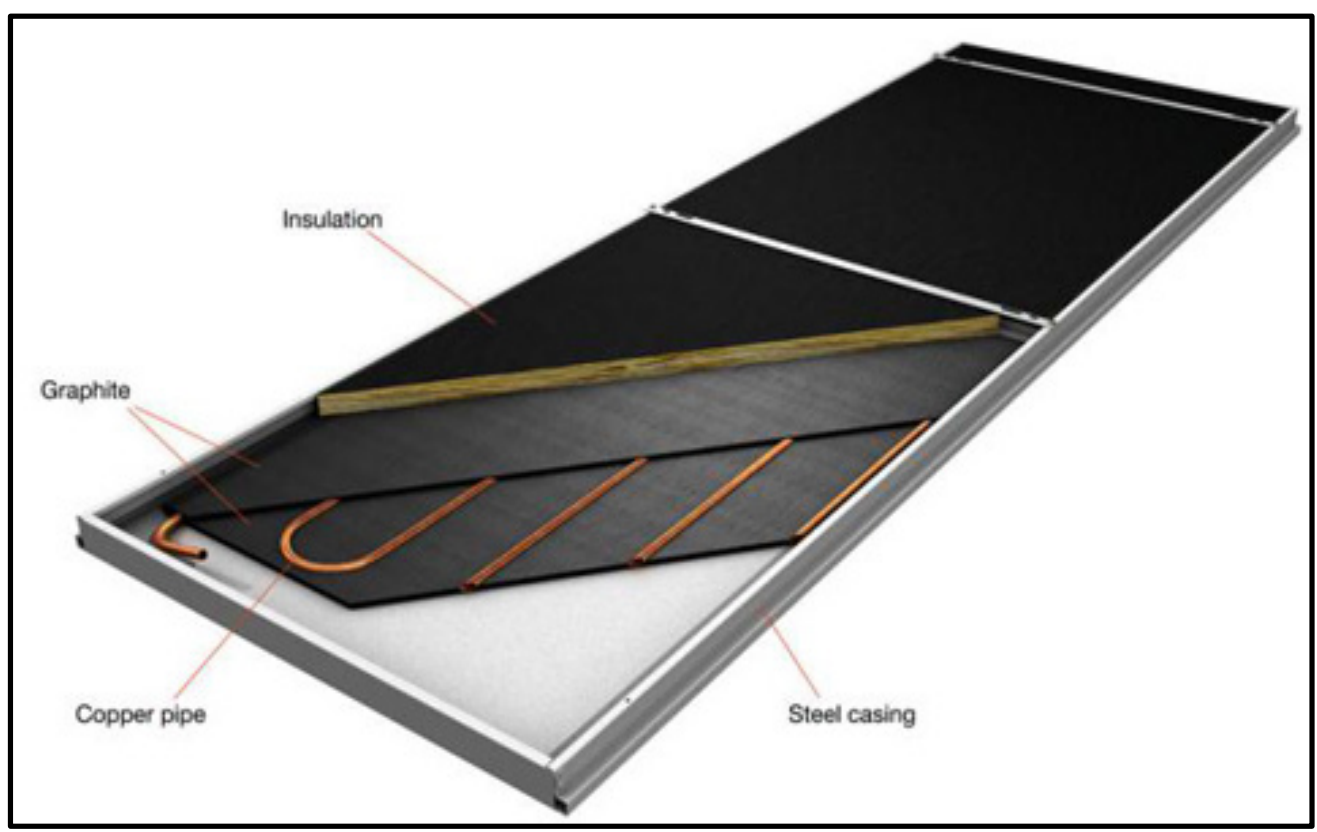

Figure 2-2. Upper surface view of a two-circuit radiant heating/cooling panel for suspendedceiling application.

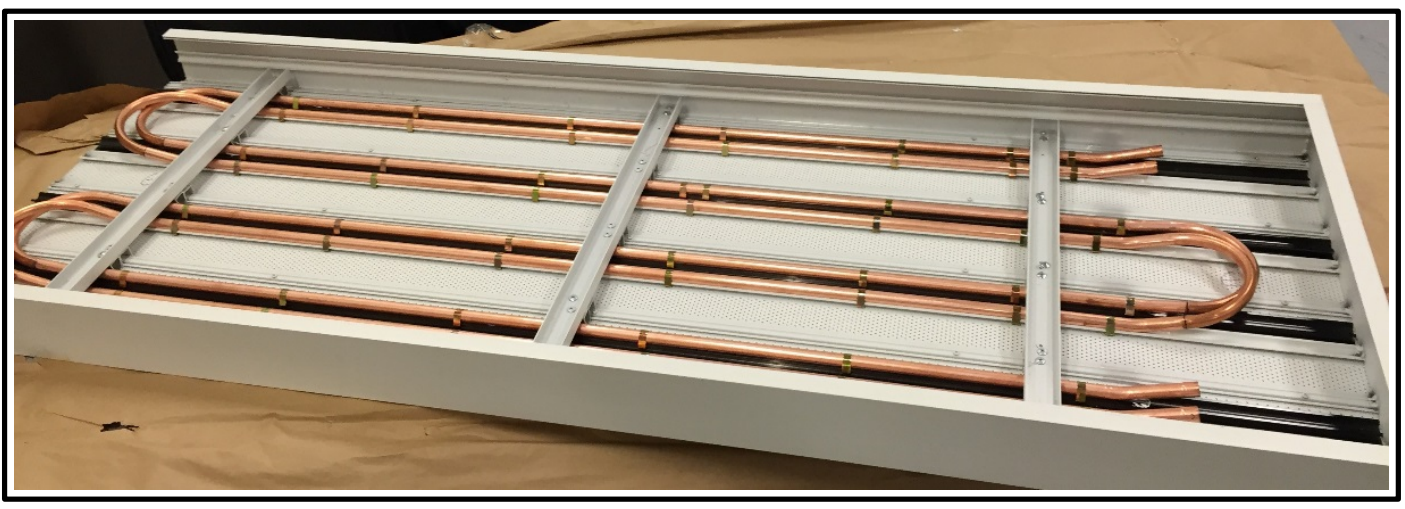

Figure 2-3. Finished surface view of a suspended-ceiling radiant panel.

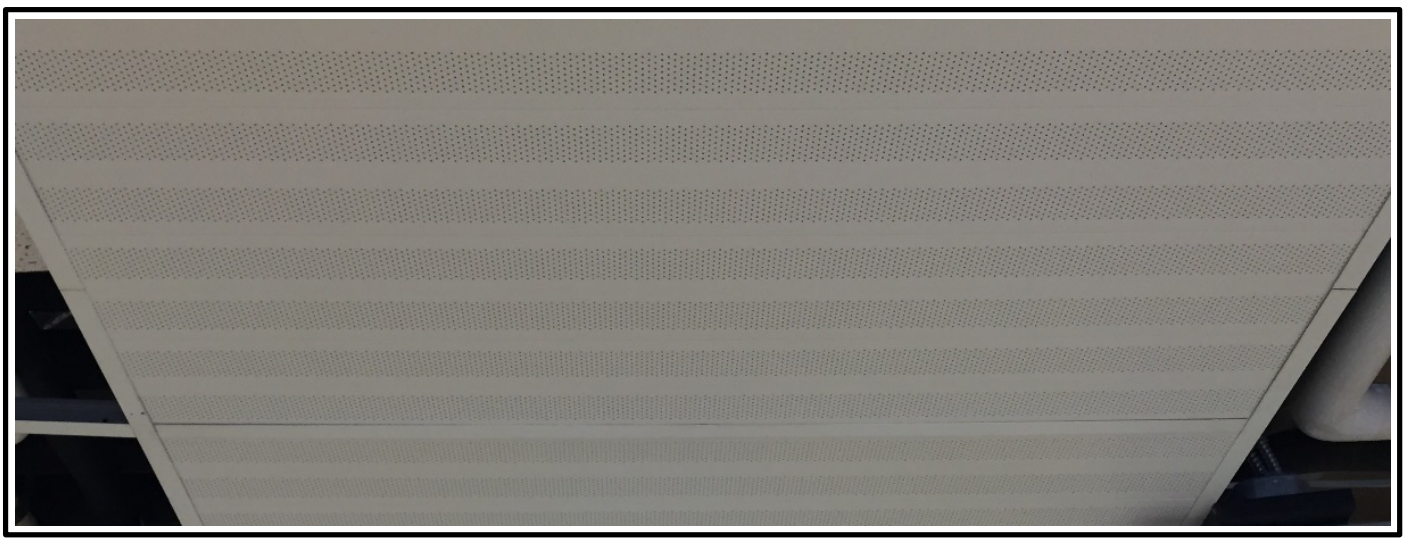


Two configurations of radiant panels were used on this project. In conditioned spaces with existing grid ceilings, 2x4-ft grid-mounted radiant panels were used. In conditioned spaces without an existing grid ceiling, "cloud" panels were suspended from the hard overhead ceiling. Depending on zone load requirements, some panels were two-circuit panels that incorporated separate heating and cooling tubing. In some spaces, additional "cooling-only" panels were installed to satisfy cooling requirements beyond the capacity of the two-circuit panels. Figures 2-4 and 2-5 show partial plan views of radiant panel installation in Bldg 1540A.

Note that a number of rooms in Bldg 1540 A were not retrofitted with radiant panels. In the Bldg 1540A side of Figure 2-6, the spaces were conditioned as follows:

- Purple spaces (admin, conference room, training) - radiant heating/cooling

- Yellow spaces (mechanical/electrical) - unconditioned

- Green spaces (locker room/restroom) - exhausted only

- Red spaces (arms storage) - existing unit heater, split DX Alternating Current (AC) system

- White spaces (general storage/work area) - existing hydronic unit heaters.

In the Bldg $1540 \mathrm{OB}$ side shown in Figure 2-6, the spaces were conditioned in the same manner except that the Purple spaces (admin, conference room) were conditioned with a DX VAV air handling unit with hot water reheat coils at the VAV boxes.

We deliberately elected not to install radiant heating/cooling in spaces in Bldg 1540 A that were not previously conditioned by its existing VAV air handling unit. First, it seemed to be unnecessary to attempt to condition spaces beyond what was already provided. Second, if we had installed heating and/or cooling in spaces that were not previously so provided, any attempts to compare the energy performance of the demonstrated system with that of the original system or with that of the baseline system in Bldg $1540 \mathrm{OB}$ would have become irrelevant. Finally, for budget purposes, we prioritized designing and installing a system that effectively conditioned spaces that were previously conditioned rather than attempting to condition the entire facility. 


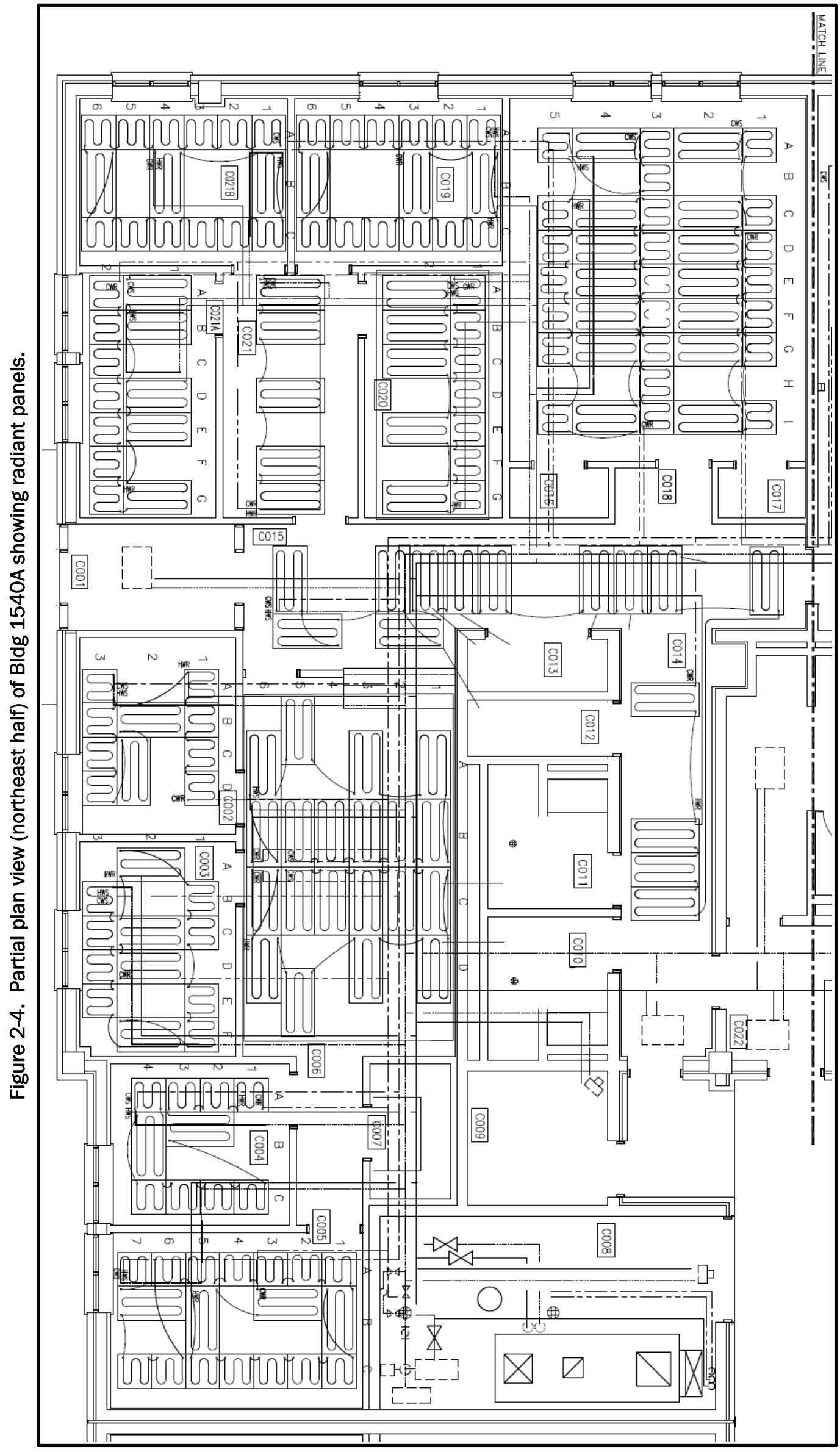




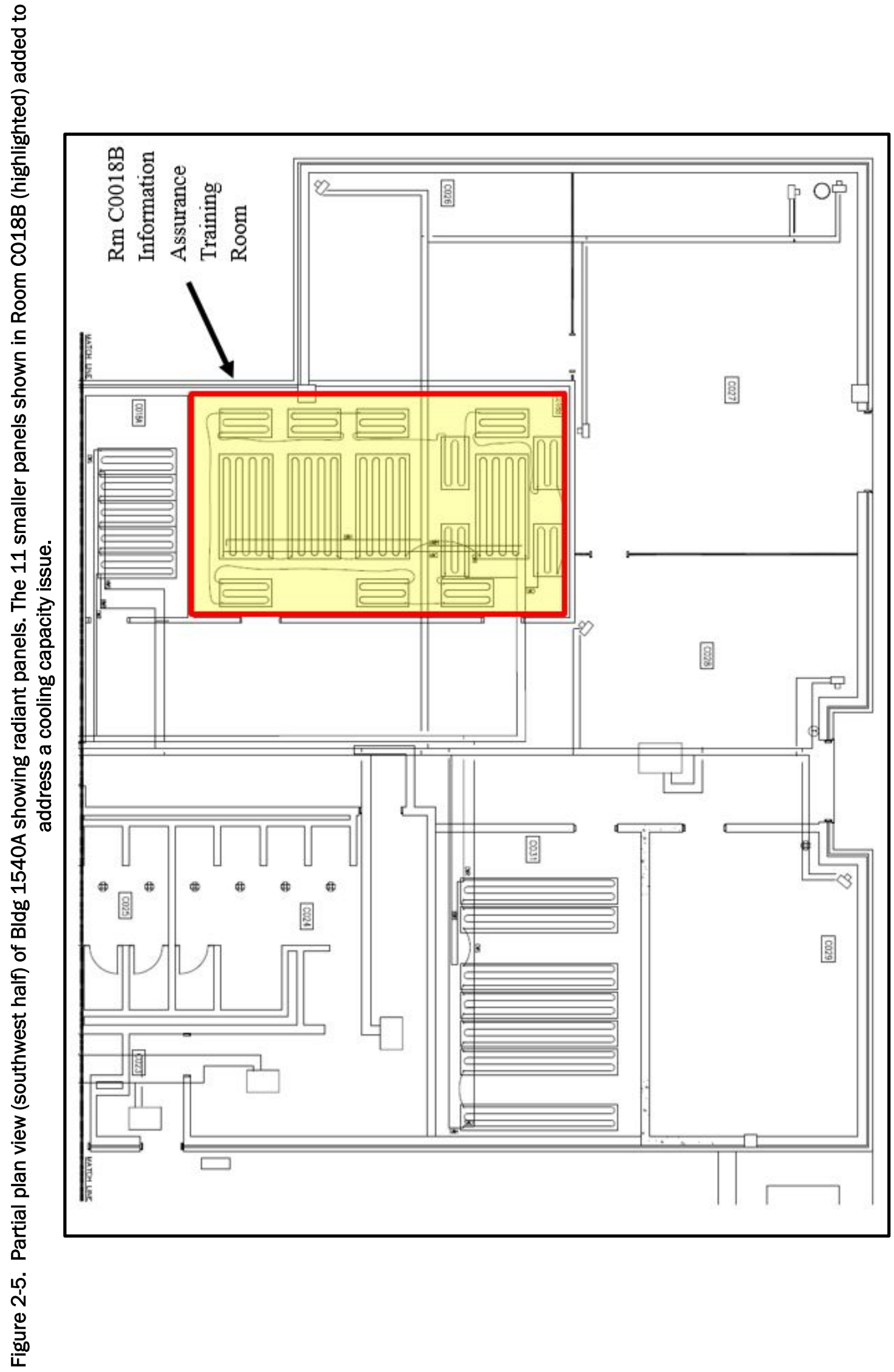




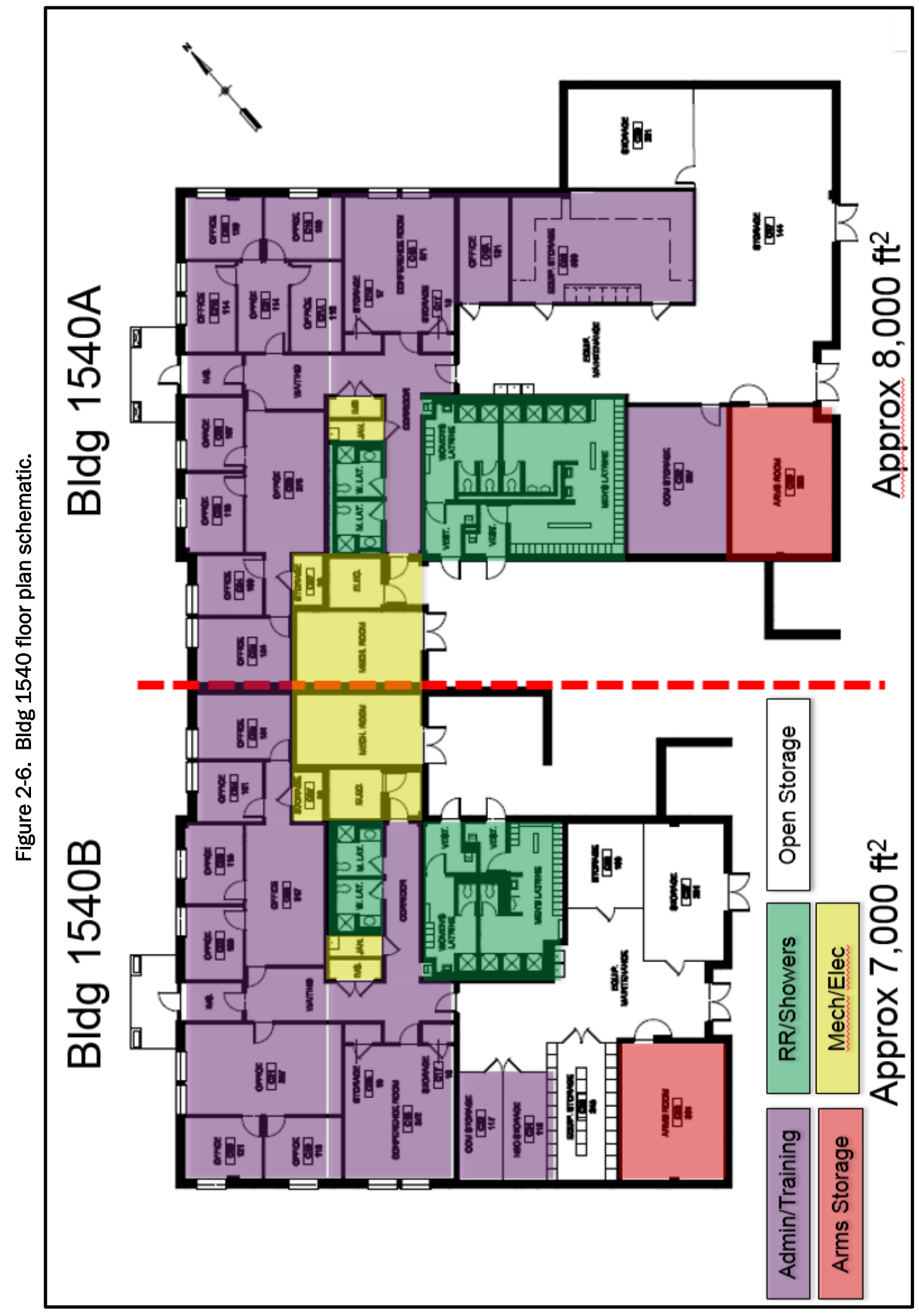


Certainly, electing not to cool the general storage/work area reduced the building's cooling load. On hot days, the warm temperatures in the general storage/work area would have induced additional cooling load on the adjacent fully conditioned spaces (conference room, Information Assurance training room, admin spaces), but it would be highly speculative to attempt to quantify the effect.

The radiant panel system is supplied with hot water from an existing boiler and chilled water from a new air-cooled chiller. Figure 2-7 shows the layout of the hot water system and Figure 2-8 shows a schematic of the chilled water system. Note that chilled water is delivered to the DOAS AHU's cooling coil at $42^{\circ} \mathrm{F}$ and leaves at $49^{\circ} \mathrm{F}$. Chilled water is then delivered to the three-way mixing valve where it is blended with return water from the radiant cooling panels. The chilled water is then delivered to the radiant cooling panels where it is supplied at $61^{\circ} \mathrm{F}$ and leaves at $66^{\circ} \mathrm{F}$. Cascading chilled water from the DOAS AHU's cooling coil improves system efficiency by providing a larger $\Delta \mathrm{T}$ to the chiller. Also, delivering warmer chilled water to the ceiling-mounted radiant cooling panels minimizes the risk of condensation on the cool surfaces of the panels by keeping the panel surfaces above the dewpoint temperature of the air within the conditioned spaces.

Figure 2-9 shows the DOAS AHU. This is a constant volume device that filters and preheats (if needed) outside air. The air then passes through an enthalpy wheel where it exchanges energy (sensible and latent) with building exhaust from the latrines. The ventilation air then passes through a deep cooling coil that cools and dehumidifies it before it enters the reheat coil where it is warmed to a neutral temperature before delivery to the occupied zones. 


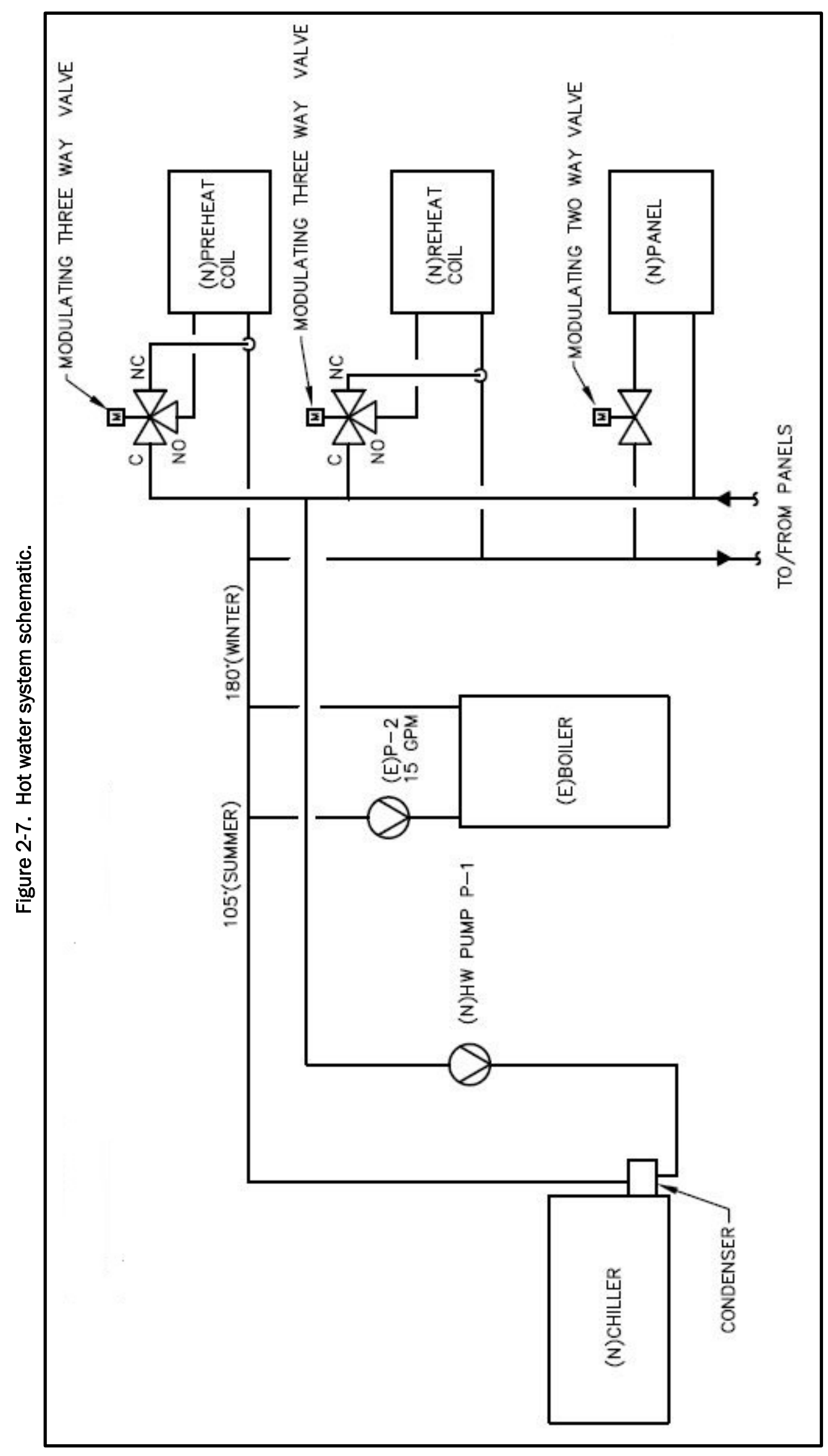




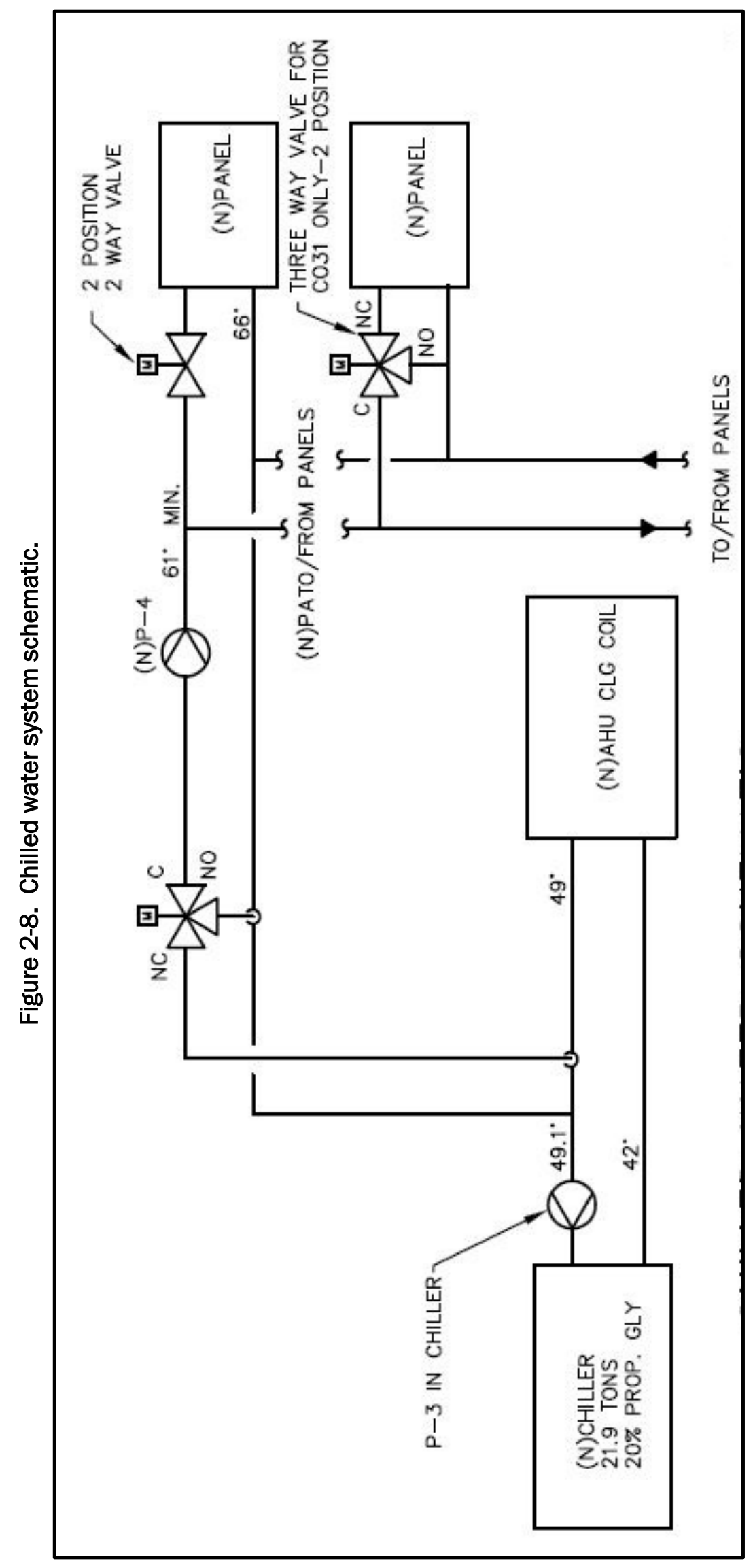




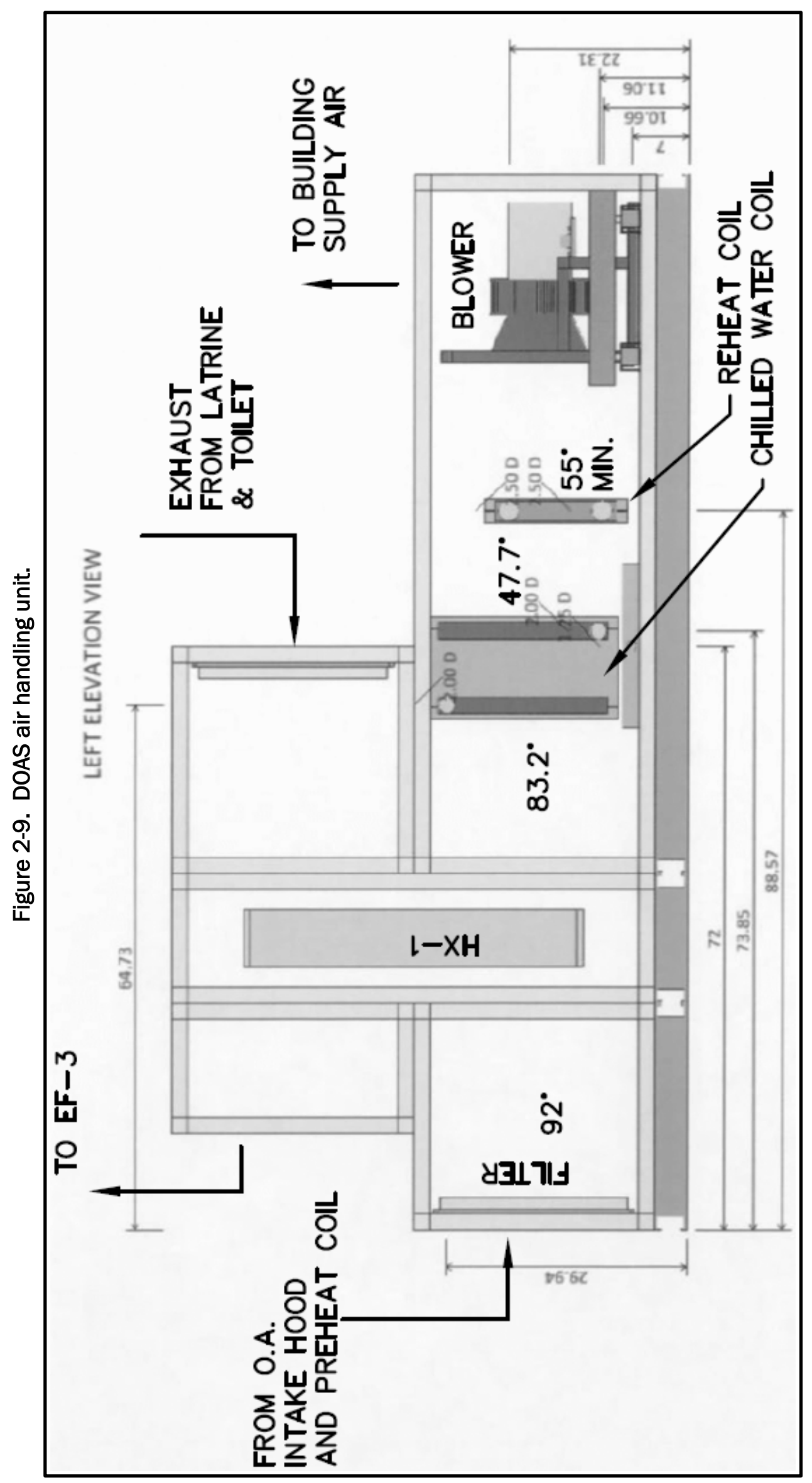


This technology has applicability to buildings that have tight envelopes and that have capability of controlling indoor humidity. It would not be applicable to buildings in humid climates with leaky building envelopes, or to buildings that were frequently operated with doors or windows open to the outdoor environment because such openings would allow unconditioned humid outdoor air to enter the building where it would condense on cool radiant panel surfaces. The technology may also be unsuitable for comfort cooling in zones with a very high cooling load as the radiant panels may not have sufficient cooling capacity to satisfy the load requirements. At average panel surface temperatures of $63.5^{\circ} \mathrm{F}\left(61^{\circ} \mathrm{F}\right.$ entering water temperature and $66^{\circ} \mathrm{F}$ leaving water temperature), the panels have a cooling capacity of 82 British Thermal Units (BTU) per $\mathrm{ft}^{2}$ (24.03 Watt$\mathrm{hr}$ per $\mathrm{ft}^{2}$ ). Of course, one could increase the cooling capacity by lowering the average panel surface temperature as long as the dewpoint temperature of the air within the conditioned spaces remains below the average panel surface temperature.

\subsubsection{Comparison to existing technology}

Radiant heating/cooling differs from "conventional" HVAC systems in its primary mode of heat transfer. Conventional HVAC systems primarily transfer heat by forced convection. They directly heat (or cool) the air supplied to a space. The supply air mixes with the room air so that by controlling the quantity (and/or temperature) of heated (or cooled) air delivered to the space, the mixed air temperature in the space is maintained at a level that the occupants perceive as comfortable. Radiant heating/cooling primarily transfers heat radiantly. Radiant systems use large surface areas maintained at a slightly warmer (or cooler) temperature than the skin temperature of the occupants to transfer heat to (and from) the occupants.

Because radiant heat transfer is directly proportional to the $4^{\text {th }}$ power of the temperature difference between two objects, it is not necessary to have a large temperature difference between two objects to transfer significant heat. As a result, radiant systems can operate effectively with cooler heating water (and warmer cooling water) than conventional forced convection systems. By being able to use cooler heating water (and warmer cooling water), it is possible to generate heating water and cooling water more efficiently. Depending on availability, it is possible to cascade water leaving a heating coil (or leaving a cooling coil) to take advantage of the heating 
(cooling) capacity of the water before returning it to the boiler (or chiller). When this arrangement is used, the boiler (or chiller) sees a larger $\Delta \mathrm{T}$, resulting in improved capacity and increased efficiency.

The radiant panel system was expected to perform better than the conventional fan coil HVAC system. According to the Dec 2013 ASHRAE Journal article "Cooling Load Calculations For Radiant Systems" (Bauman, Feng, and Schiavon 2013), an experimental study revealed "The radiant system has a higher cooling rate than the air system, meaning that it is faster to remove heat gains while maintaining equivalent comfort conditions. For the tested cases, 75 to $82 \%$ of the total heat gain was removed by the radiant system ... while for the air system, 61 to $63 \%$ was removed."

Radiant heating/cooling systems are made feasible by a tight building envelope and by use of a DOAS. This combination controls humidity levels within the building so that moisture and condensation problems do not occur on radiant cooling surfaces. Although all persons have experienced radiant heating/cooling (e.g., sitting in front of a fireplace or sitting near a large window on a sunny day or on a very cold evening), very few modern buildings in the United States attempt to actively control occupant comfort primarily through radiant heat transfer.

To enable the radiant system to operate effectively, the Contractor significantly improved the air tightness of the building envelope using minimally invasive sealant methods such as sealing with closed-cell spray polyurethane foam (ccSPF) and/or caulking with backer material where necessary. Our successful demonstration of this combination of envelope sealing technologies was quite challenging. Nevertheless, we believe it is an important capability to implement throughout DoD.

\subsubsection{Chronological summary}

This is a mature technology. It has been used extensively in Europe, but has not enjoyed much use in the United States. This is partly due to higher humidity and higher cooling needs in the United States compared with Europe; in the United States, there are concerns about condensation of moisture on cool surfaces, which can be a real issue if building humidity levels are not well controlled. Another concern has to do with the return on investment (ROI) of a radiant system vs. an all-air system. The perception 
has been that radiant systems are not as cost-effective as conventional allair systems. This project addressed both humidity control issues and ROI concerns.

\subsubsection{Future potential for DoD}

Radiant heating/cooling systems with DOAS can reduce energy consumption and could be very helpful in moving DoD a step closer to Net Zero Energy facilities. Radiant heating/cooling systems require less above-ceiling space than all-air systems, which require ducts and could prove to be quite useful in retrofit of existing buildings where space above the ceiling is very limited. Applications of radiant heating/cooling could be widespread to many types of facilities.

\subsection{Technology development}

Modern hydronic radiant technology has been used in various configurations for many years as an alternative to all-air HVAC systems to condition occupied spaces. Several authors over the decades attest to the research and deployment of radiant technology, predominantly in Europe, and the successfully operation of this technology and its systems. There are several International Standard Organization (ISO) and ASHRAE standards that have been developed to guide the design and installation of hydronic radiant ceiling systems. According to Mumma (2001), Europeans have deployed Ceiling Radiant Cooling Panels, in connection with DOAS, since the mid-1980s with little adoption in the United States although there are relatively few barriers prohibiting their adoption.

The type of linear radiant panel used on this project is a mature technology that has been used in Europe for many decades. These panels have most predominantly been deployed within Europe and Canada. In recent decades this configuration has been adopted in the United States as an alternative to all-air systems. The designer and manufacturer of these panels, Frenger Systemen BV, ${ }^{*}$ was founded in 1950 in the Netherlands. At the same time, the company installed their first heated ceiling application. In 1960 the first chilled ceiling was installed. Twa Panel Systems, Inc., the

* BV = Besloten Vennootschap (Dutch or “Limited Company") 
Frenger Panel manufacturer and distributor, was first established in 1986 to support the installation of this system in North America.

The radiant panel system is expected to perform better than the conventional HVAC system. According to the Dec 2013 ASHRAE Journal article "Cooling Load Calculations For Radiant Systems" (Bauman, Feng, and Schiavon 2013), an experimental study revealed "The radiant system has a higher cooling rate than the air system, meaning that it is faster to remove heat gains while maintaining equivalent comfort conditions. For the tested cases, $75 \%$ to $82 \%$ of the total heat gain was removed by the radiant system ... while for the air system, $61 \%$ to $63 \%$ was removed."

\subsection{Advantages and limitations of the technology}

\subsubsection{Performance advantages}

This combination of technologies may reduce overall energy consumption by delivering heating and cooling energy to occupied spaces more efficiently than all-air systems. Fan energy is a significant portion of HVAC energy. Hydronic delivery of thermal energy is more efficient because hydronic pumping costs are significantly less than fan energy costs. Due to the way humans perceive comfort, building occupants may experience comfort at slightly cooler space air temperatures during the heating season and slightly warmer space air temperatures during the cooling season with a radiant system.

\subsubsection{Cost advantages}

With a calculated simple payback of 26 years, this project did not successfully demonstrate that this technology is cost competitive from a combined first cost, installation cost, and operational cost basis compared with traditional all-air HVAC systems. Nevertheless, Guruprakash and Rumsey (2014) claimed to demonstrate a radiant system that had an installed cost slightly lower (less than $1 \%$ cost savings) than its traditional cooling system counterpart. The radiant cooling system in that study also used $38 \%$ less energy than its traditional HVAC counterpart. 


\subsubsection{Performance limitations}

A number of potential risks are associated with this technology:

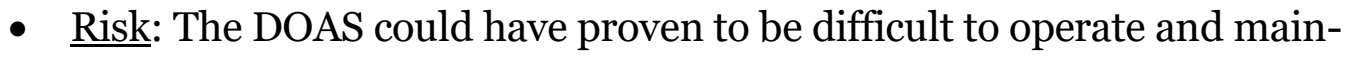
tain, or it could fail to adequately control humidity levels in the building.

Fortunately, we found the system to be easy to operate. DPW HVAC maintenance personnel were invited to witness the system commissioning process. They were pleased with the relative simplicity of the installed system. With over a year of operational experience, there have been few maintenance issues to date and the system has had no difficulty controlling humidity levels within the facility at suitable levels to maintain comfort and avoid condensation on cool surfaces.

- Risk: Building occupants might have left doors and windows open, deliberately or carelessly, allowing hot and humid air to enter the building and defeating the DOAS's ability to maintain humidity levels in the building.

This did not prove to be a problem. Bldg 1540 is a secured building and posted signs within the building direct that all doors be kept closed. The occupants understand and respect the need to keep doors closed for both security reasons and to avoid allowing infiltration of unconditioned humid air. Had this not been the case, there could have been a risk that humidity and condensation problems might have been a problem.

- Risk: Radiant heating/cooling systems may fail to satisfy occupants' comfort requirements.

For the most part, this was not a problem. However, there were problems of lack of cooling capacity in Information Assurance (IA) Training Room Co18B. The Contractor originally counted the occupancy of this room to be 11 persons (10 trainees and one instructor along with their computers, lighting, a projector, etc.), and designed the radiant panel system accordingly. After the building was reoccupied, they discovered that the actual occupancy was about 21 persons (20 trainees and one instructor). The occupants of this room complained of being too hot. Eventually, the Contractor designed a solution to this problem, which consisted of adding additional radiant cooling panels as ceiling spaced allowed. This solution 
was installed in Jan 2016. Additional cooling capacity in this zone improved the situation. From Feb 2016 onward, the average occupied temperature was $71^{\circ} \mathrm{F}$, and only infrequently escalated above $80^{\circ} \mathrm{F}$.

Figure 2-10 shows the temperature recorded in $\mathrm{Rm}$ Co18B for the 24-hr period ending at 4:55 pm on Tuesday, 23 Aug 2016. During this period, the temperature setpoint was $78^{\circ} \mathrm{F}$ and the outdoor air temperature ranged from about 58 to about $84^{\circ} \mathrm{F}$. During the same period, the room temperature stayed at or below the setpoint, varying between about 73 and $78^{\circ} \mathrm{F}$. It is encouraging to see that the room temperature stayed at or below the setpoint. The facility, to include Rm Co18B, was passively cooled by 8 hours of continuous exposure to outdoor conditions that were $18{ }^{\circ} \mathrm{F}$ cooler than the cooling setpoint.

Figure 2-10. Temperature display for IA Training Rm C018B for 24-hr period ending at 4:55 pm on 23 Aug 2016.

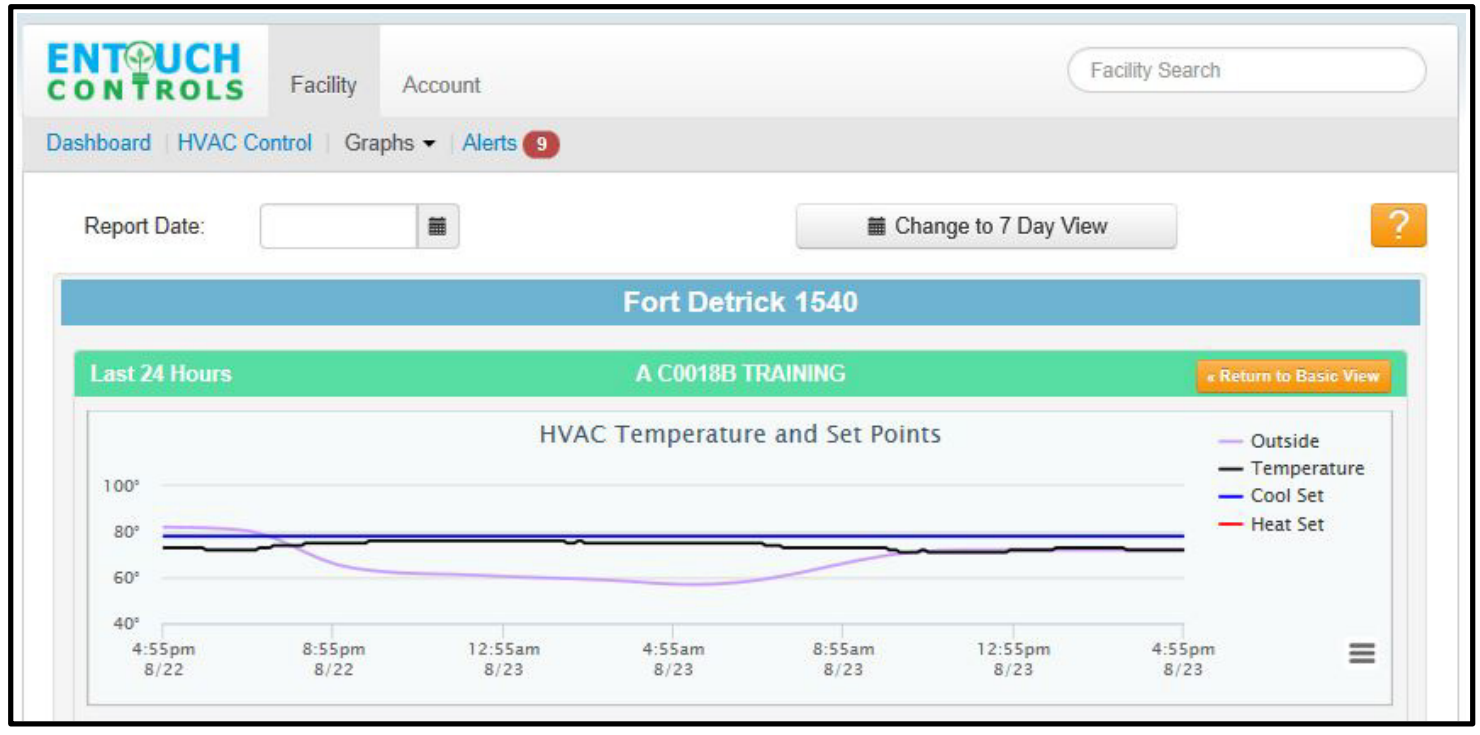

Figure 2-11 shows a display of room temperatures, outside temperatures and setpoint for the same room for the period 16-23 Aug 2016. Also displayed are outside temperatures and the cooling setpoint. Interestingly, the room temperature often seems to move in a direction opposite to that of the outside temperature. This illustrated the transient nature of a mechanically cooled building's heat exchange with the outdoors, as noted in the ASHRAE Handbook: Fundamentals (ASHRAE 1997): "(1) time lag in conductive [outdoor] heat gain through opaque exterior surfaces and (2) time delay by thermal storage in converting [outdoor] radiant heat gain [in the structure] to [an interior] cooling load". At night when the temperatures are below the 
HVAC setpoint the building is passively cooled from outside inward, and requires no HVAC operation. During the daytime, sunlight heats the previously cool thermal mass (the building), from outside inward. As the heat reaches the interior, the HVAC then actively and increasingly responds to the daytime heat gain and occupant activity.

Figure 2-11 also shows that the cooling setpoint was lowered to approximately $60{ }^{\circ} \mathrm{F}$ for a few hours on 17 Aug 2016 and was also lowered to about $70{ }^{\circ} \mathrm{F}$ for several hours on 19 Aug 2016. Considering that the Contractor had no capability to make remote system adjustments and that no Contractor personnel was on site on these dates, these setpoint changes indicated that occupant(s) had adjusted the thermostat.

Figure 2-11. Temperature display from Energy Monitoring System for IA Training Rm C018B for the 7-day period 16-23 Aug 2016.

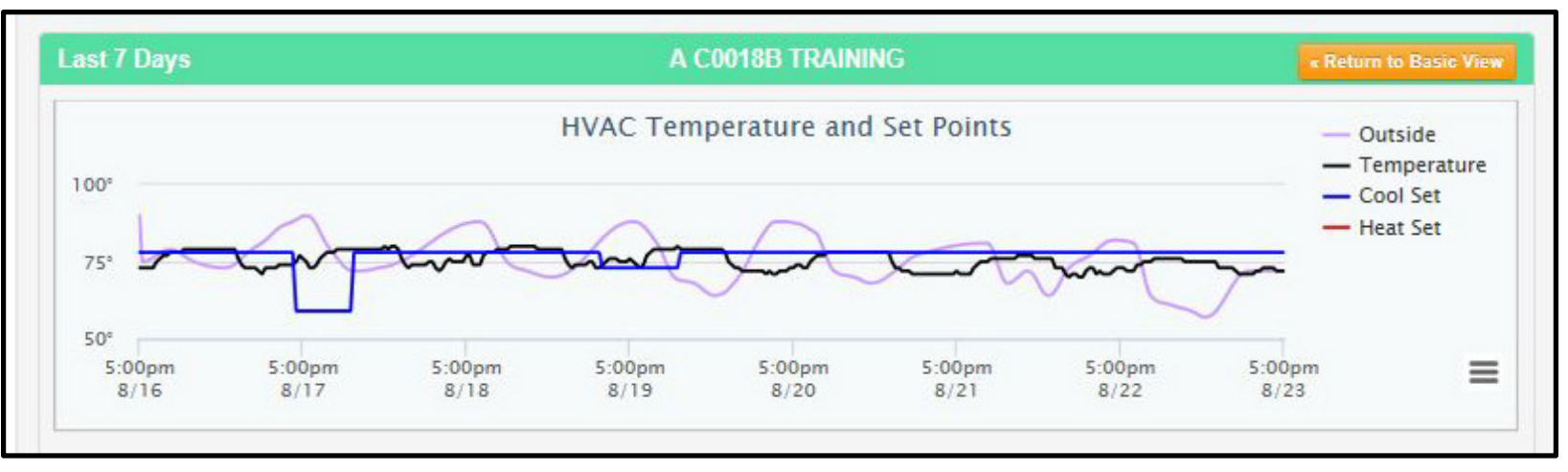

- $\quad$ Risk: The demonstrated system might not prove to be cost effective.

The first cost of the demonstration system was estimated to be $\$ 73,382$, which was more expensive than the first cost of a conventional VAV HVAC system. However, the yearly O\&M costs of the demonstration system were $\$ 220$, which was $\$ 1,320$ per year less than the O\&M costs of the conventional VAV HVAC system alternative. The resulting simple payback was calculated at 26.7 years for the demonstration system vs. a traditional all-air HVAC system. Section 7.3, "Cost Analysis and Comparison," analyzed these differences in detail.

- $\quad$ Risk: The demonstrated system might not prove to be socially acceptable.

Some occupants may not have felt that the demonstrated system maintained adequate comfort. We are aware of inadequate cooling problems in Information Assurance Training Room Co18B. Otherwise, we have 
had very little feedback on comfort conditions in Bldg 1540A. We have heard a number of anecdotal remarks from several persons associated with this building:

"Conference Rm C0028 is very comfortable." Major, $21^{\text {st }}$ Signal Brigade

"The room has been too hot."

IA Instructor - IA Training Rm C018B

"The overall building is very comfortable and very quiet."

USACE Construction Representative

"Overall, the building has been satisfactory. There have been complaints from the Chaplains [Rms C019, C020, C021, C021A and C021B] that they have been too hot."

Brigade Maintenance Officer, 21st Signal Brigade

We are unaware of any complaints during the heating season of persons experiencing cold feet and legs while sitting at a desk because their feet and legs were not directly exposed to heat radiating from a ceiling-mounted radiant heating/cooling system.

Other than the anecdotal remarks above, we have heard no complaints that occupants are unable to adequately control the comfort conditions in their own space. Occupants can adjust the temperature setpoints within DoD permitted levels - heating $70^{\circ} \mathrm{F}$ occupied, $55^{\circ} \mathrm{F}$ unoccupied, and cooling $75{ }^{\circ} \mathrm{F}$ occupied, $80^{\circ} \mathrm{F}$ unoccupied. A o-60 minute override timer integrated in the thermostat for Administration Room o06 Zone-2 will override the time schedule and cause the systems to operate for up to 60 minutes on a timed override. Otherwise, the thermostats will default to the preprogrammed temperature schedule during occupied hours (6:00 a.m. to 6:00 p.m.) and unoccupied hours (6:00 p.m. to 6:00 a.m.).

Although occupants could experience a sense of discomfort due to insufficient air movement in their space during the cooling season, we have not heard any complaints related to this issue.

Implementation issues are identified in Chapter 8 "Implementation Issues." 


\section{Performance Objectives}

Performance objectives are the primary criteria established by the investigator for evaluating this innovative technology. They provide the basis for evaluating the performance and costs of the technology. Meeting the following performance objectives is essential for successful demonstration and validation of the technology:

- Energy and Water Security: This technology will reduce energy intensity $\left(\mathrm{kWh} / \mathrm{ft}^{2}\right)$. It will have no direct effect on building or installation water consumption.

- Cost Avoidance: The technology will lead to reduced energy consumption. The technology will also result in a facility that is more resistant to the formation of mold and mildew, which has a major impact on the cost of operating and maintaining military facilities.

- Greenhouse Gas (GHG) Reduction: GHG emissions will be directly related to energy reductions for this facility.

Table 3-1 details the performance objectives for this demonstration. System economics were analyzed in accordance with the Department of Energy Building Life-Cycle Cost program.

Table 3-1. Performance objectives.

\begin{tabular}{|c|c|c|c|c|}
\hline $\begin{array}{l}\text { Performance } \\
\text { Objective }\end{array}$ & Metric & Data Requirements & Success Criteria & Results \\
\hline \multicolumn{5}{|c|}{ Quantitative performance objectives } \\
\hline $\begin{array}{l}\text { Reduced building } \\
\text { envelope air } \\
\text { leakage }\end{array}$ & $\begin{array}{l}\mathrm{cfm} / \mathrm{ft}^{2} \text { of air } \\
\text { leakage at } 75 \mathrm{~Pa}\end{array}$ & $\begin{array}{l}\text { Blower door test results } \\
\text { (cfm and corresponding } \\
\text { differential pressure (DP) } \\
\text { readings) }\end{array}$ & $\begin{array}{l}<0.15 \mathrm{cfm} / \mathrm{ft}^{2} \text { of air } \\
\text { leakage at } 75 \mathrm{~Pa}\end{array}$ & $\begin{array}{l}0.39 \mathrm{cfm} / \mathrm{ft}^{2} \text { of air } \\
\text { leakage at } 75 \mathrm{~Pa} \\
\text { Estimated } 0.27 \mathrm{cfm} / \mathrm{ft}^{2} \text { of } \\
\text { air leakage at } 75 \mathrm{~Pa} \text { with } \\
\text { improved fenestration } \\
\text { Objective not met. }\end{array}$ \\
\hline $\begin{array}{l}\text { Reduced energy } \\
\text { consumption }\end{array}$ & $\begin{array}{l}\text { Site Energy Use } \\
(\mathrm{kWh})\end{array}$ & $\begin{array}{l}\text { Thermal energy delivered } \\
\text { and mechanical systems } \\
\text { electrical usage }\end{array}$ & $\begin{array}{l}20 \% \text { reduction in heating, } \\
\text { cooling and ventilation } \\
\text { system energy }\end{array}$ & $\begin{array}{l}46 \% \text { reduction in overall } \\
\text { energy usage (electric }+ \\
\text { gas) } \\
\text { Objective met }\end{array}$ \\
\hline Cost effectiveness & $\begin{array}{l}\text { Simple Payback, } \\
\text { Savings-to- } \\
\text { Investment Ratio } \\
(\text { SIR) }\end{array}$ & $\begin{array}{l}\text { First costs, O\&M costs, } \\
\text { energy costs, and useful life }\end{array}$ & $\begin{array}{l}\text { Simple Payback: }<5 \text { yrs. } \\
\text { SIR: }>1.2\end{array}$ & $\begin{array}{l}\text { Simple Payback of } 26.7 \\
\text { yrs. } \\
\text { SIR of } 1.0 \\
\text { Objective not met. }\end{array}$ \\
\hline
\end{tabular}




\begin{tabular}{|c|c|c|c|c|}
\hline $\begin{array}{l}\text { Performance } \\
\text { Objective }\end{array}$ & Metric & Data Requirements & Success Criteria & Results \\
\hline \multicolumn{5}{|c|}{ Qualitative performance objectives } \\
\hline Improved comfort & $\begin{array}{l}\text { Occupant } \\
\text { satisfaction }\end{array}$ & $\begin{array}{l}\text { Space dry bulb temperature, } \\
\text { mean radiant temperature, } \\
\text { air speed, RH, activity level, } \\
\text { and clothing }\end{array}$ & $\begin{array}{l}\text { Temperatures and RH within } \\
\text { comfort criteria defined by } \\
\text { ASHRAE Standard 55-2010, } \\
\text { Section 5.2.1.1 “Graphic } \\
\text { Zone Comfort Method" }\end{array}$ & $\begin{array}{l}\text { The building satisfied } \\
\text { ASHRAE Standard 55- } \\
2010 \text { by maintaining an } \\
\text { average of } 70^{\circ} \mathrm{F} \text { and } \\
43 \% \mathrm{RH} \text {. } \\
\text { Objective met. }\end{array}$ \\
\hline $\begin{array}{l}\text { Reduced relative } \\
\text { mold/mildew } \\
\text { potential }\end{array}$ & $\begin{array}{l}\text { Mold and mildew } \\
\text { potential }\end{array}$ & $\begin{array}{l}\text { Interior humidity levels and } \\
\text { temperatures of "cold" } \\
\text { surfaces }\end{array}$ & $\begin{array}{l}\text { Measurement of interior } \\
\text { surfaces at or below } 80 \% \\
\text { surface RH }\end{array}$ & $\begin{array}{l}\text { The building's } 43 \% \text { RH } \\
\text { average was within } \\
\text { ASHRAE's recommended } \\
\text { range for the prevention } \\
\text { of mold growth. } \\
\text { Objective met }\end{array}$ \\
\hline $\begin{array}{l}\text { Easily operable } \\
\text { and maintainable }\end{array}$ & $\begin{array}{l}\text { Operability and } \\
\text { maintainability }\end{array}$ & $\begin{array}{l}\text { Maintenance records and } \\
\text { discussions W/ O\&M } \\
\text { personnel }\end{array}$ & $\begin{array}{l}\text { Maintainable by existing } \\
\text { staff, no special skills } \\
\text { required, less O\&M burden }\end{array}$ & Objective met \\
\hline
\end{tabular}

\subsection{Quantitative objective: Reduced building envelope air leakage}

- Definition: This objective refers to the amount of air that will infiltrate/exfiltrate through the building envelope when the building is pressurized/depressurized to a reference pressure differential of $75 \mathrm{~Pa}$ (o.3 iwg) with respect to the outdoor ambient environment.

- Purpose: Envelope air leakage is a very good indicator of the quality of construction of a building envelope and is directly related to the degree that the building will experience uncontrolled infiltration/exfiltration of unconditioned outdoor air. A tighter building envelope will require less energy to heat, cool, and dehumidify. It will also be easier to balance the HVAC system and will maintain better comfort conditions because it will be less affected by outdoor wind conditions. The Army's Engineer and Construction Bulletin (ECB) 2012-16, Building Air Tightness and Air Barrier Continuity Requirements (HQUSACE 2012a), addressed building air tightness requirements for new facilities and major retrofits of existing facilities. This project demonstrated that it is possible to effect significant air tightness improvements on existing facilities even without major deconstruction and replacement of building envelope components.

- Metric: The metric used was cfm of air leakage per unit area of the building envelope at a reference pressure of 0.3 iwg (75 Pa). For purposes of air barrier testing, the air barrier envelope area includes the area of all walls (including doors, windows and other "intentional openings"), the ceiling and the area of the floor. The leakage rate was expressed in units of " $\mathrm{cfm} / \mathrm{ft}^{2}$ at 75 Pa." 
- Data: The data required to calculate or evaluate this metric included:

- Wall, ceiling and floor areas.

- Differential pressure (Pa) and corresponding air flow rate (cfm).

- Analytical Methodology: Testing was conducted in accordance with the requirements of ASTM E779 (ASTM 2003a). Per this standard, "intentional openings" in the building envelope (such as bathroom vents, outdoor air louvers, exhaust louvers, etc.) were sealed. Then the building was positively (or negatively) pressurized using a blower door apparatus as discussed in Section 5.2, "Baseline Characterization." Building pressure was gradually ramped upward in increments of 5 to $10 \mathrm{~Pa}$ over the range of at least $25 \mathrm{~Pa}$ to $50 \mathrm{~Pa}$. At each increment, the differential pressure between the building's interior and the exterior ambient environment was recorded along with the flow rate $(\mathrm{cfm})$ of air required to achieve that pressure differential (equivalent to the air leakage at that pressure difference). This procedure resulted in five to 10 differential pressure and flow rate data points in both the positive and negative pressurization modes. The resulting data were fitted to an exponential curve and extrapolated to the reference pressure of $75 \mathrm{~Pa}$. The average of the results from the positive and negative pressurization modes was reported as the building envelope's leakage rate at $75 \mathrm{~Pa}$.

- Success Criteria: The building envelope leakage rate performance objective was $<=0.15 \mathrm{cfm} / \mathrm{ft}^{2}$ at $75 \mathrm{~Pa}$. While the Army and Navy require building envelopes to leak no more than $0.25 \mathrm{cfm} / \mathrm{ft}^{2}$ of building envelope at $75 \mathrm{~Pa}$ for new and major retrofit projects, the Army has shown that it is possible to achieve air tightness levels on new and major retrofit projects as low as $0.1 \mathrm{cfm} / \mathrm{ft}^{2}$. Setting the goal for this demonstration at $<=0.15 \mathrm{cfm} / \mathrm{ft}^{2}$ at $75 \mathrm{~Pa}$ for an existing building was a very aggressive goal considering that we did not intend to execute major intrusive changes to the existing building envelope.

- Results: Objective not met. As stated, this was an extremely aggressive performance objective. Per UFC 3-101-01 (HQUSACE, NAVFAC, and AFCESA 2011), building envelopes on new construction projects and major renovation projects for the Army and Navy must leak no more than $0.25 \mathrm{cfm} / \mathrm{ft}^{2}\left(1.25 \mathrm{~L} / \mathrm{s}-\mathrm{m}^{2}\right)$ when tested at a pressure differential of 0.3 iwg (75 Pa). For Air Force projects the building air leakage rate shall not exceed $0.4 \mathrm{cfm} / \mathrm{ft}^{2}\left(2.00 \mathrm{~L} / \mathrm{s}-\mathrm{m}^{2}\right)$ when test results measured at a pressure differential of 0.2 iwg (50 Pa) are extrapolated to 0.3 iwg (75 Pa). 
Note that these UFC criteria are for new construction or major renovation projects that offer ideal conditions for minimizing building envelope leakage. Even under these conditions, Contractors must carefully select and apply materials and pay close attention to construction details and workmanship to meet these criteria. Nevertheless, we have seen examples of new and major renovation projects in which building envelope leakage was reduced to $<=0.10 \mathrm{cfm} / \mathrm{ft}^{2}$ at a pressure differential of $0.3 \mathrm{iwg}$.

It is much more difficult to achieve such results with existing buildings, especially if the project does not involve major disruptive work on the building's exterior (such as complete removal of the exterior finish system and installation of a continuous air barrier). In this project, the exterior side of the building envelope was untouched.

Air barrier testing was performed by the Southern Independent Testing Agency, Inc. (SITA) of Lutz, FL. Initial building envelope pressurization testing was conducted on 21 Mar 2014 for both buildings, but it was determined that due to unfavorable weather conditions, Bldg 1540 A would need to be retested at a later date. This was accomplished on 8 May 2014.

Initial ("Before") testing and all follow-up ("After") testing was performed in accordance with ASTM E779 (ASTM 2003a). Initial results for Bldg $1540 \mathrm{~A}$ were $0.8157 \mathrm{cfm} / \mathrm{ft}^{2}$ at $0.3 \mathrm{iwg}$ (based on an envelope surface area of 19,492 $\mathrm{ft}^{2}$ ) and $1.1242 \mathrm{cfm} / \mathrm{ft}^{2}$ at 0.3 iwg for Bldg $1540 \mathrm{~B}$ (based on an envelope surface area of $14,476 \mathrm{ft}^{2}$ ). SITA's initial testing was followed by visual inspection and diagnostic evaluation in general accordance with ASTM E1186 (ASTM 2003b) by means of infrared thermography to identify air leakage paths. During the diagnostic evaluation, the building was pressurized to approximately $25 \mathrm{~Pa}(0.1 \mathrm{iwg})$ and the building was heated/cooled to achieve a minimum $\Delta \mathrm{T}$ of $10^{\circ} \mathrm{F}$ between interior and exterior conditions. SITA provided the following observations, which were applicable to both Bldgs 1540A\&B:

1. All exterior doors should be sealed due to significant heat transfer and leakage located on door perimeters.

2. Significant leakage was present throughout the existing air barrier. One major area of concern was the penetration where the supply and return ductwork leaves the mechanical rooms. 
3. On visual inspection above the ceiling, many breaches within the air barrier were evident. All penetrations required sealing and review to achieve the desired leakage rate.

After initial testing and diagnostic evaluation was performed, work was initiated to seal the envelope of Bldg 1540A. All work was done from the interior side of the envelope. The work involved locating and sealing numerous large and small cracks, penetrations, and openings using spray foam, gypsum board, and other materials. Figures 3-1 through 3-5 shows examples of envelope sealing measures.

Figure 3-1. Leakage sources at pipe penetrations and at framing systems.

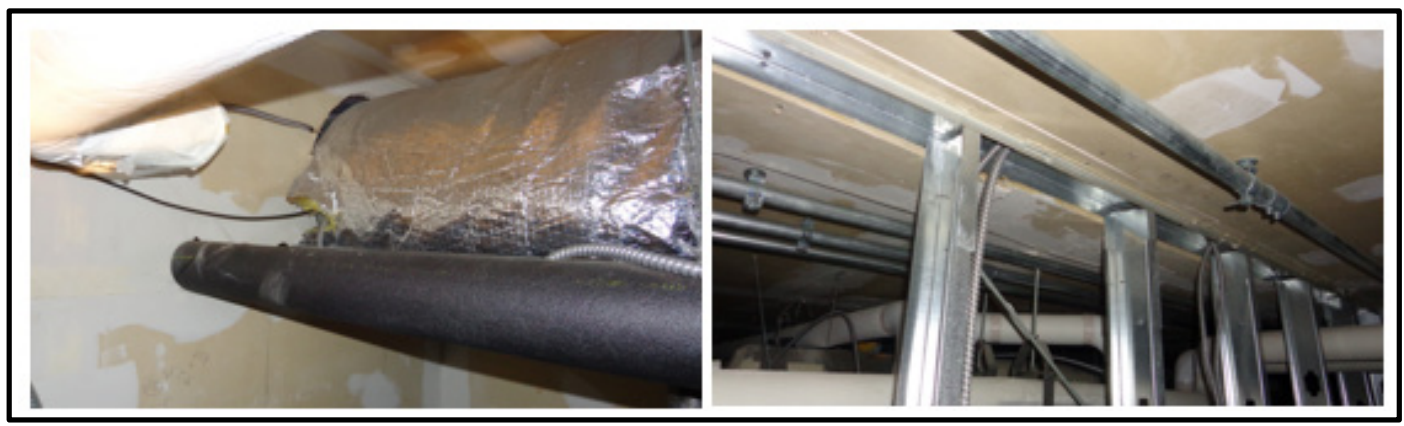

Figure 3-2. Leaks sealed at pipe hangers in “heated-only" portion of Bldg 1540A.




Figure 3-3. Sealing of conduit penetrations in cavity space above the suspended ceiling of Bldg 1540A (left) and at the mounting location of a $4 \times 4$ conduit box (right).

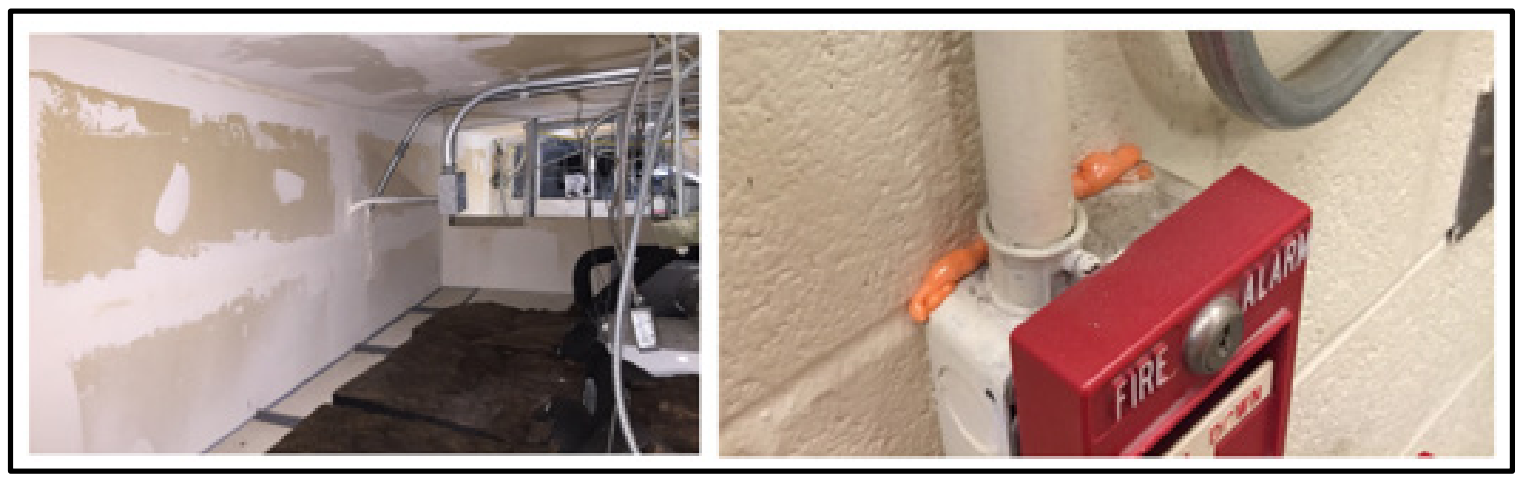

Figure 3-4. Sealing of leaks around an exhaust fan in the mechanical room.

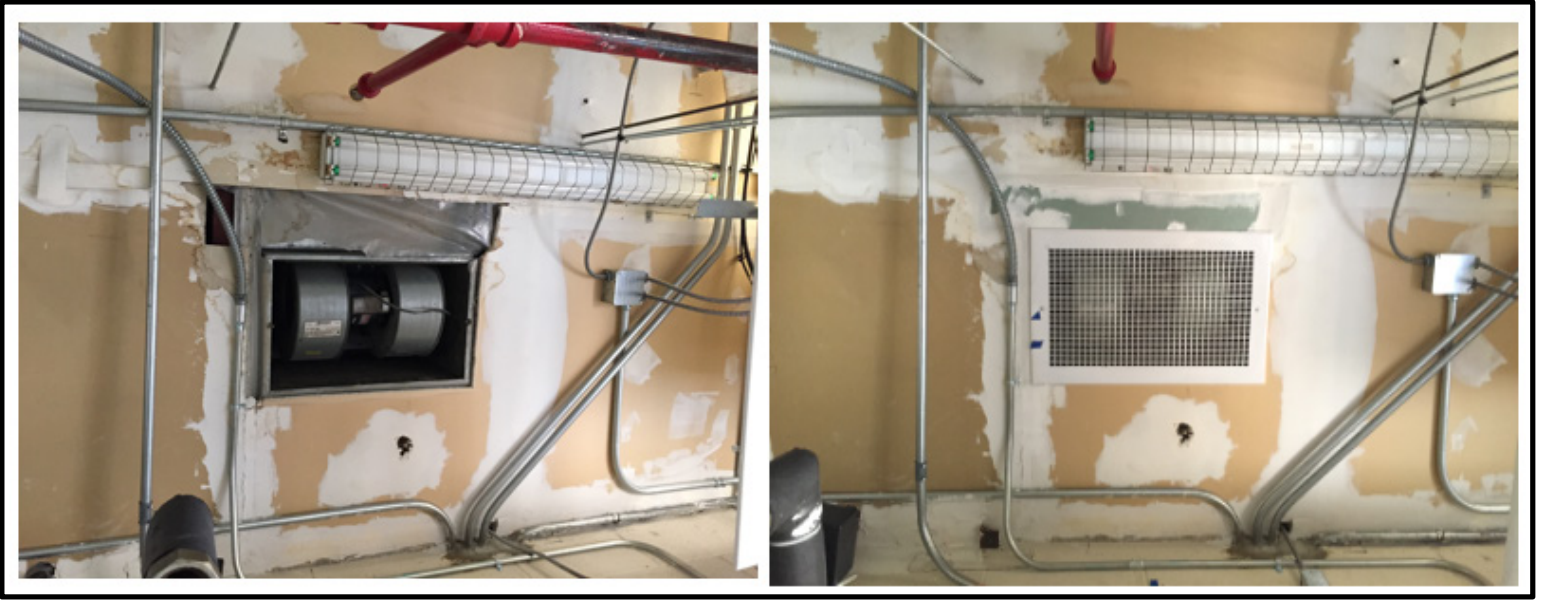

Figure 3-5. Sealing of a major opening above the hard ceiling above the men's latrine.




Throughout the project, the Contractor continued to locate and seal cracks and other penetrations and retested the envelope of Bldg 1540A several times. The Contractor performed post-sealing pressurization testing of Bldg 1540A during the week of 27 Apr 2015 to 1 May 2015 and found the leakiness to be greater than they had hoped. New deficiencies were discovered and subsequently repaired.

Once again, pressure testing of Bldg $1540 \mathrm{~A}$ was performed during the week of 10 Aug 2015. During this test, additional hidden air infiltration locations were discovered within the secured storage area. These deficiencies were repaired during a Jan 2016 site visit.

A final air barrier test of Bldg 1540A was performed during the week of 4 Jan 2016 to determine effects of additional repairs to areas found in the 10 Aug 2015 tests. The final reported envelope leakage rate for Bldg $1540 \mathrm{~A}$ was $0.39 \mathrm{cfm} / \mathrm{ft}^{2}$ at $75 \mathrm{~Pa}$. This leakage rate included the effects of air leakage through the 10 existing 4'x4' single hung windows (Figure 3-6), which were deemed to be quite leaky. Since repair or replacement of the windows was not within the scope of their work, the Contractor did not attempt to remediate leakage through the existing window systems and offered no suggestions on how the existing windows might be improved. Nevertheless, they estimated that, had the windows been upgraded or replaced with currently available window systems, the building's overall leakage rate would have been approximately $0.27 \mathrm{cfm} / \mathrm{ft}^{2}$ at $75 \mathrm{~Pa}$.

It is possible that the air tightness of these windows could be improved by repairing or replacing any air seals between the moveable sash and the window frame. However, it is likely that there is a greater potential for air leakage around the perimeter of the unit where the frame is installed in the rough opening. Prior to the last couple of decades, the construction industry didn't concern itself with building envelope air tightness to any great extent. As a result, window systems were often installed without much attention paid to achieving a tight air seal at this location. On some projects, this gap would be stuffed with fiberglass insulation or with an expanding foam insulation. Fiberglass insulation in this application is ineffective as an air seal and expanding foam insulation may fill the void between the window frame and the rough opening, but still allow air entry into the wall system. 
Figure 3-6. Single hung window (4x4-ft) in Bldg 1540A (typical of 10).

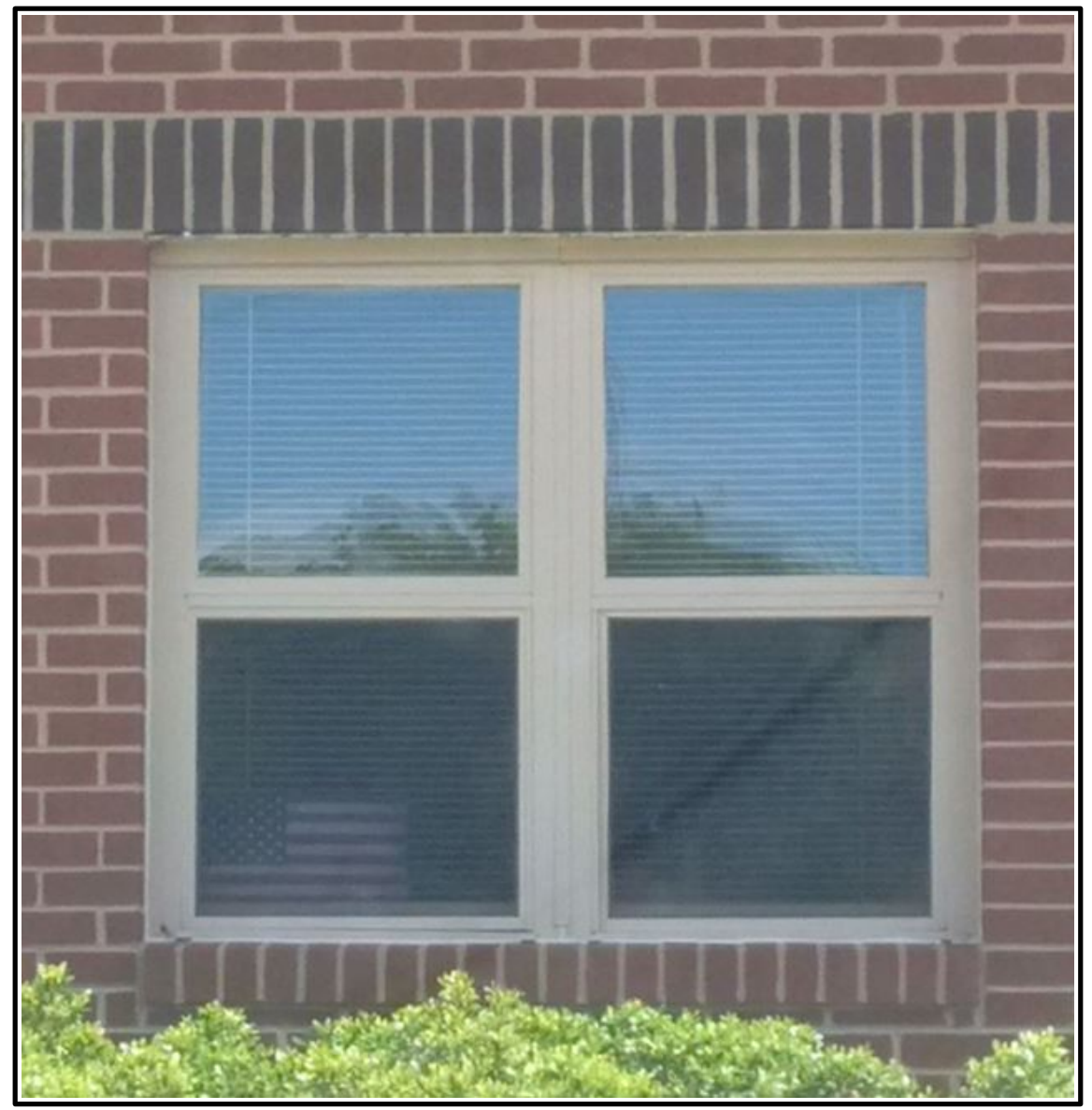

Current best practice is to tape the gap between the interior side of the window frame and the interior air barrier with a high quality, long lasting sealing tape. On the exterior side, windows should be sealed per the manufacturer's instructions. In order to seal these windows in accordance with current best practice would have involved major disruptive repair work on the interior and possibly the exterior sides of the windows.

Although the project did not meet its very aggressive performance objective of $<=0.15 \mathrm{cfm} / \mathrm{ft}^{2}$ at $75 \mathrm{~Pa}$, the $52 \%$ reduction in air leakage rate achieved by this effort was very significant and illustrates the kind of leakage reduction that is possible in many military buildings without impacting the building's exterior finish system. 


\subsection{Quantitative objective: Reduced energy consumption}

- Definition: This objective refers to the relative amount of energy required to heat, cool, and ventilate the demonstration building as compared with the baseline facility.

- Purpose: The primary purpose of the project was to demonstrate effective means of reducing facility energy consumption and help DoD installations meet Federal and Service requirements to reduce facility energy usage.

- Metric: Energy consumption associated with heating, cooling, and ventilation was measured and reported in terms (BTU) for gas usage and kilowatt-hours (kWh) for electricity usage. BTUs were converted to $\mathrm{kWh}$ when total energy usage was analyzed.

- Data: Thermal energy delivered, mechanical systems electrical usage, and whole building electrical usage.

- Analytical Methodology: Measurements of environmental conditions in Bldgs 1540A\&B were measured and recorded as well as energy consumption of each facility. Factors such as relative floor size, relative occupancy, and differences in activities within the two facilities were taken into consideration. With consideration that Bldg 1540 is not aligned on the cardinal North-South axis, the differences in building orientation created a minimal difference in the combined heat gain from windows and walls (within $4 \%$ ). The primary cause for differences in building envelope heat gain was due to roof area differences between Bldgs 1540A\&B. The roof area differences and their associated heat gains were proportional to their differences in square footage, with Bldg $1540 A$ being $36 \%$ larger than Bldg $1540 B$.

- Success Criteria: Success was contingent on the demonstration facility consuming $20 \%$ less energy than the baseline facility. Raw energy data from each of the facilities were adjusted to account for differences in the two facilities such as relative floor size.

- Results: Objective Met. Overall, Bldg 1540A used 16\% less energy than Bldg 1540B. Bldg 1540A consumed 33\% more electrical energy than Bldg 1540B; however, it also used 42\% less gas energy than Bldg 1540B. Two seasonal observations were made when comparing Bldgs 1540A\&B. First, while Bldg 1540A typically used more electrical energy than Bldg $1540 B$, this gap widened during the summer season. This was attributed to the multitude of components in the radiant panel system (chiller, DOAS, pumps, etc.) that consume electricity, and their 
year round operation (excluding the chiller). Second, during the fall and winter periods, the heating system in Bldg $1540 \mathrm{OB}$ demanded more energy from its boiler compared with Bldg 1540A. This single difference in boiler energy usage drove Bldg 1540B's total energy usage above 1540A's despite the fact that 1540A used more energy in its chiller, HVAC, and electrical systems. The energy savings recorded in Bldg $1540 \mathrm{~A}$ becomes even more appreciable after incorporating adjustments for the differences in each building's square footage. Bldg $1540 \mathrm{~B}$ used $30.67 \mathrm{kWh} / \mathrm{ft}^{2}$ while Bldg $1540 \mathrm{O}$ used $18.81 \mathrm{kWh} / \mathrm{ft}^{2}$. This represented a $39 \%$ energy savings for Bldg 1540 A on an energy usage per square footage basis compared with Bldg $1540 B$.

\subsection{Quantitative objective: Cost effectiveness}

- Definition: This objective refers to the relative life-cycle cost effectiveness of the demonstration system as compared with the baseline system, including first cost, operational cost and maintenance cost over its useful life.

- Purpose: Cost effectiveness is, or should be, the basis for all facilitiesrelated decisions. Typical economic break points for selecting one technology over a competing technology might be a 10-year simple payback and a SIR greater than 1.0.

- Metric: Simple Payback (SP), SIR.

- Data: Delta first costs, delta O\&M costs, delta energy costs, useful life.

- Analytical Methodology: We recorded the costs of installing the demonstration system and compared those costs with the estimated costs to install a conventional all-air HVAC system. In performing our analysis, we considered not only the actual costs of installing the demonstrated system, but projected the costs of installing such a system assuming that the technology were to become broadly accepted within the construction industry. Our analysis is applicable to both a renovation project replacing an existing all-air HVAC system or new construction because we were careful to exclude costs of demolition of existing ductwork, air handlers, VAV boxes and other associated costs in our analysis. As a result, whether for a renovation project or a new construction project, our cost analysis assumed a clean installation of the demonstrated system in a building with no existing systems or equipment hindering installation of the new system.

We recorded and compared the O\&M costs and the energy costs for 
both Bldgs 1540A\&B. We also estimated the useful life of the demonstration system for use in the SIR calculations.

- Success Criteria: SP of less than 5 years as compared with a comparable all-air HVAC system with an SIR on the delta costs greater than 1.2 .

- Results: Objective Not Met. The study indicated a 26.7 year SP and a 23.9 year discounted payback for the radiant panel with DOAS system. The SIR was calculated to be 1.o. Details of these calculations are provided in Section 7.3, "Cost Analysis and Comparison."

\subsection{Qualitative objective: Improved comfort}

- Definition: This objective dealt with the relative perceived comfort of the environment within Bldg 1540A before and after retrofit.

- Purpose: The ultimate purpose of conditioning buildings is to provide occupant comfort and satisfaction. It would be easy to save energy by conditioning buildings at levels that are not comfortable, or by not conditioning buildings at all. However, the purpose of buildings is to provide a place for people to live and work. Uncomfortable people cannot be expected to effectively carry out their mission.

- Metric: Comfort was determined per the criteria provided in ASHRAE Standard 55-2010, Thermal Environmental Conditions for Human Occupancy (ASHRAE 2010), Section 5.2.1.1 "Graphic Comfort Zone Method." Note that we also attempted to get occupant satisfaction feedback from Bldg 1540 occupants through a simple one-page survey. However, we got no responses to our survey.

- Data: Space dry bulb temperature and RH.

- Analytical Methodology: We monitored space temperature and RH in various locations within Bldg 1540A and compared them with the requirements shown in ASHRAE Std 55-2010, Section 5.2.1.1 "Graphic Comfort Zone Method" (ASHRAE 2010).

- Success Criteria: Temperature and RH fell within criteria as required by ASHRAE Std 55-2010, Section 5.2.1.1 "Graphic Comfort Zone Method" (ASHRAE 2010). This success criteria is not based on occupant satisfaction, an $80 \%$ occupant satisfaction metric, nor any criteria that implies occupant satisfaction.

- Results: Objective Met. For Bldg $1540 \mathrm{~A}, 95 \%$ of the daily temperatures (6 a.m. to 6 p.m.) ranged between 62 and $78^{\circ} \mathrm{F}$, averaging $70^{\circ} \mathrm{F}$. Similarly, $95 \%$ of the daily relative humidities ( 6 a.m. to 6 p.m.) ranged 
between 28 and 58\% RH, averaging 43\%. These parameters for Bldg 1540 A were predominantly within the standard's range of acceptability, demonstrating Bldg 1540A's compliance with ASHRAE Standard (STD) 55-2010 (ASHRAE 2010).

\subsection{Qualitative objective: reduced relative mold/mildew potential}

- Definition: This performance objective dealt with the relative reduced risk of developing mold and mildew in the demonstration facility vs. the baseline facility due to system improvements.

- Purpose: The DoD has spent millions of dollars trying to mitigate existing mold and mildew and to minimize or eliminate future mold and mildew formation in military facilities. It was important that the systems demonstrated in this project support the DoD's effort to achieve healthful facilities that are free of mold and mildew.

- Metric: Mold and mildew potential.

- Data: Interior RH levels.

- Analytical Methodology: Measurement of interior surfaces at or below $80 \%$ surface RH.

- Success Criteria: No condensation on "cold" surfaces; interior surfaces at or below $80 \%$ surface RH.

- Results: Objective Met. According to the 2015 ASHRAE Handbook: HVAC Applications, "a conservative limit for no mold ever, on anything at any temperature, is below 60\% RH" (ASHRAE 2015). Bldg $1540 \mathrm{~A}$ averaged $43 \% \mathrm{RH}$ during the occupied period (6 a.m. to 6 p.m.) demonstrating the HVAC system's success in mitigating microbial growth potential.

\subsection{Qualitative objective: Easily operable and maintainable}

- Definition: This objective is related to the frequency and extent of operational problems associated with the demonstrated systems and the degree of difficulty that maintenance personnel experience in addressing these problems.

- Purpose: Military installations are under increasing pressure to operate with fewer resources (dollars, personnel, etc.). Any proposed systems should be at least as easily operable and maintainable as existing systems.

- Metric: Operability and maintainability. 
- Data: Maintenance records, additional training requirements, discussions with O\&M personnel.

- Analytical Methodology: We were unable to monitor DPW maintenance records to determine the number of work orders executed to operate and maintain Bldgs $1540 A \& B$ as well as the relative cost and time required for O\&M in each facility.

- Success Criteria: Maintainable by existing staff, no special skills required, reduced O\&M burden as compared with the baseline facility.

- Results: Objective Met. An absence of reported O\&M-related issues appears to demonstrate the system's ease of operation and maintainability. The mechanical room components, consisting of a DOAS AHU, pumps and valves, are similar in complexity to a typical AHU and other components of a conventional system. The waterside components of a radiant panel system are similar to those of a chilled water fan coil system. However, the radiant panel systems are less complex than FCUs since they have no fans and require no filters. 


\section{Facility/Site Description}

\subsection{Facility/site selection criteria}

The following criteria were used to select the demonstration site.

- Geographic Criteria: We specifically sought a demonstration site that had both a significant heating season and a significant cooling season. In addition, we sought a location that was considered "wet" or "humid" as a means of addressing concerns that radiant cooling systems will necessarily experience condensation problems in humid areas.

- Facility Criteria: We sought a facility that was a reasonable size - big enough to be meaningful, but small enough to feasibly conduct a demonstration. We also wanted a facility that was in fairly good condition to avoid the massive costs of a major renovation project. A facility that was used for a residential (barracks) or administrative occupancy was also desirable to demonstrate an ability to satisfy typical occupant comfort requirements.

Another criteria was an ability to retrofit the selected building and have a similar building available to use as a baseline for comparison purposes. Fortunately, we found a single building that fit this requirement quite well. Fort Detrick's Bldg 1540 (Figures 4-1 and 4-2) below, is divided into two sub-facilities, Bldg $1540 \mathrm{~A}$ and Bldg $1540 \mathrm{OB}$, which were separated by a very short "common wall" as seen in Figure 4-2. This short plane of separation served as the building envelope demarcation line between Bldgs1540A\&B. Bldgs 1540A\&B are very similar in size, layout, and occupancy. Each half of the existing building had completely independent boilers, AHUs and cooling units so that it was possible to retrofit one side (1540A) without disrupting the mechanical systems of the other half of the building.

- Facility Representativeness: The selected building is typical of hundreds of other DoD buildings in a variety of respects. Bldg 1540 is a Base Realignment and Closure (BRAC) facility that is approximately 20 years old. It is a single-story admin/training facility similar in a number of respects to many DoD buildings of similar age, size, and usage. The building uses slab-on-grade construction with concrete masonry unit (CMU) walls with brick cladding and a standing seam pitched metal roof. Both sides used VAV air handlers to condition the occupied spaces. Finished rooms have gypsum walls with 2x4 lay-in grid ceilings. 
Figure 4-1. NE corner of Bldg 1540 (left) and SW corner of Bldg 1540 (right).



Figure 4-2. Floor plan of Bldg 1540A and Bldg 1540B.

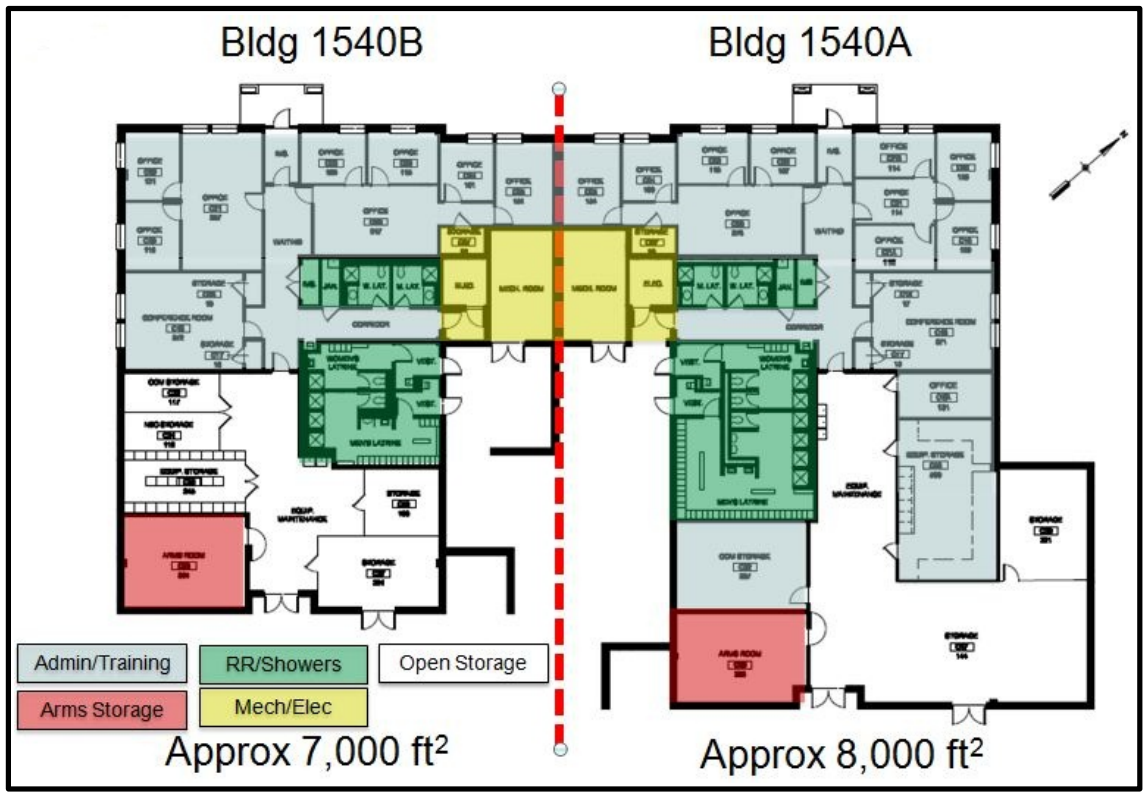

Figure 4-3. Illustration depicting assumed construction details of air gaps separating adjoining walls of Bldgs 1540A and 1540B.

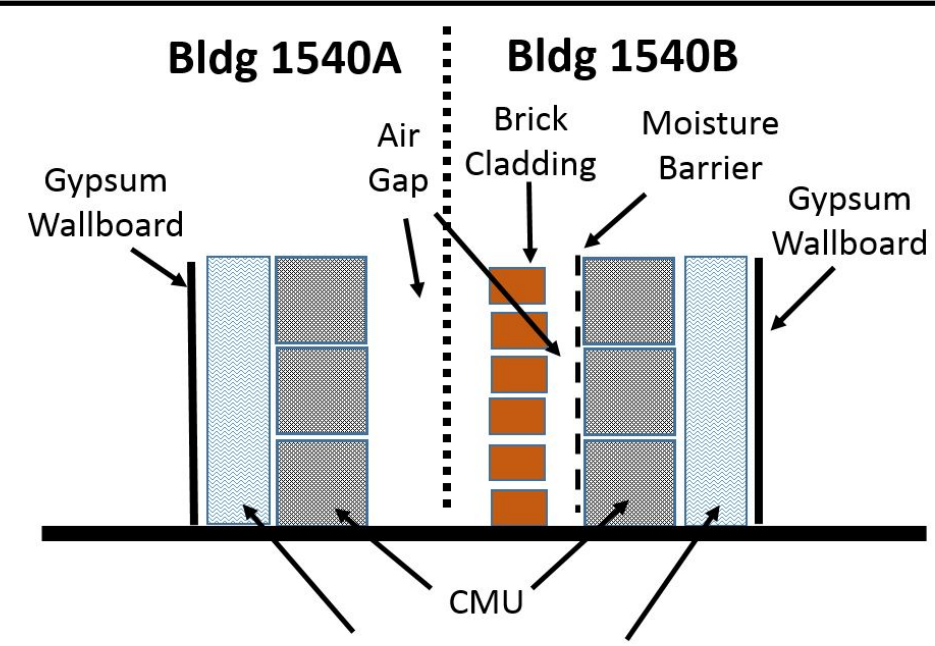

Steel studs and Fiberglass Insulation 
A question arose concerning the possibility of moisture transfer across this "common wall" between Bldgs 1540A and 1540B. Presumably, the interior of Bldg 1540A would need to be maintained at relatively drier indoor air conditions than Bldg $1540 \mathrm{OB}$ to avoid condensation of moisture on cool radiant panel surfaces. Assuming that Bldg $1540 \mathrm{OB}$ would not be maintained at similarly dry interior conditions, there would be a vapor pressure difference between conditions in Bldgs $1540 \mathrm{~A}$ and $1540 \mathrm{OB}$ that would tend to drive moisture across the "common wall" from Bldg 1540B to Bldg $1540 \mathrm{~A}$.

Bldg 1540 actually consists of two distinct buildings under a common roof. Bldg $1540 \mathrm{OB}$ was constructed first and Bldg $1540 \mathrm{O}$ was constructed some time later. We were unable to locate construction drawings showing the details of the adjacent exterior walls of these buildings and we avoided doing any exploratory deconstruction of the exterior wall of Bldg $1540 \mathrm{~A}$ to discover the details of these walls. Nevertheless, we believe that the "common wall" separating Bldg $1540 \mathrm{~A}$ and $1540 \mathrm{OB}$ actually consists of two separate exterior walls separated by air gaps as depicted in Figure 4-3.

Assuming that the air gaps between Bldgs $1540 \mathrm{~A}$ and $1540 \mathrm{~B}$ were quite "leaky" with respect to the outdoor ambient air, the "climate" in the air gaps would presumably approach that of the outdoor ambient conditions. If this were to be the case, moisture transport across this section of the exterior wall of Bldg 1540 A wouldn't be significantly different than for other portions of its exterior wall. Conversely, if the air gaps were quite "tight" with respect to the outdoor ambient air, conditions in the air gaps would fall somewhere between that of the conditions within Bldgs 1540A and $1540 B$. If so, this section of the exterior wall of Bldg 1540 A would experience a smaller vapor pressure differential than other portions of its exterior walls. As a result, we did not think that moisture transport across this short section of exterior would be a serious concern and we took no actions to mitigate it.

\subsection{Facility/site location and operations}

- Demonstration Site Description: Fort Detrick is located at Frederick, MD, approximately 49 miles northwest of Washington, DC, and about 45 miles west of Baltimore. The installation supports a number of research organizations including the National Institute of Health, the U.S. Department of Agriculture, a biodefense campus and others. 
The $21^{\text {st }}$ Signal Brigade is one of the major tenants of the installation. Installation operations primarily consist of administrative or research activities. There are no training ranges at Fort Detrick.

- Key Operations: Bldg 1540 is occupied by elements of the $21^{\text {st }}$ Signal Brigade and serves as an administrative and training building for the $514^{\text {th }}$ Signal Battalion. The building houses administrative staff, chaplain offices, conference rooms, an IA training classroom, arms storage rooms, large shower/locker rooms, and unfinished open storage/work areas.

- Command Support: The installation's DPW has been very supportive of this project. Fort Detrick's mission is largely to support research in a variety of areas. This willingness to experiment and try new things carries over into the daily operations of the installation engineers.

The occupants of the facility and their higher organization (21 ${ }^{\text {st }}$ Signal Brigade) have been very supportive. Bldg 1540's HVAC systems had not been functioning satisfactorily and the installation had been unable to correct the situation. The building occupants were not satisfied with comfort conditions in the building. The building had been very hot in the summer and humidity in the building had not been well controlled. This was evidenced by the fact that the occupants had installed dedicated dehumidifiers to prevent rusting of the weapons being stored in the Arms Storage Room.

- Communications: The Contractor's original communications plan was to disconnect the facility's Building Automation Systems (BASs) from the base-wide network and then to arrange with an on-Post internet service provider to provide internet service, allowing the Contractor to remotely access system performance data from the standalone BAS systems. This would have also allowed the Contractor a measure of remote control capability through the existing BAS systems. Unfortunately, the Contractor was unable to secure approval for this approach from the installation's Network Enterprise Command (NEC). The Contractor then suggested the possibility of installing a standalone Energy Monitoring System (EMS) that would have no physical connection to the existing BAS systems. The proposed EMS system (Figure 4-4) shared no data with the existing BAS systems, had no control capabilities, and communicated performance data to the Contractor via a cell phone connection. After lengthy coordination with the NEC, this system was ultimately approved. 
Figure 4-4. Screen capture of the online EnTouch energy management system platform for BIdg 1540.

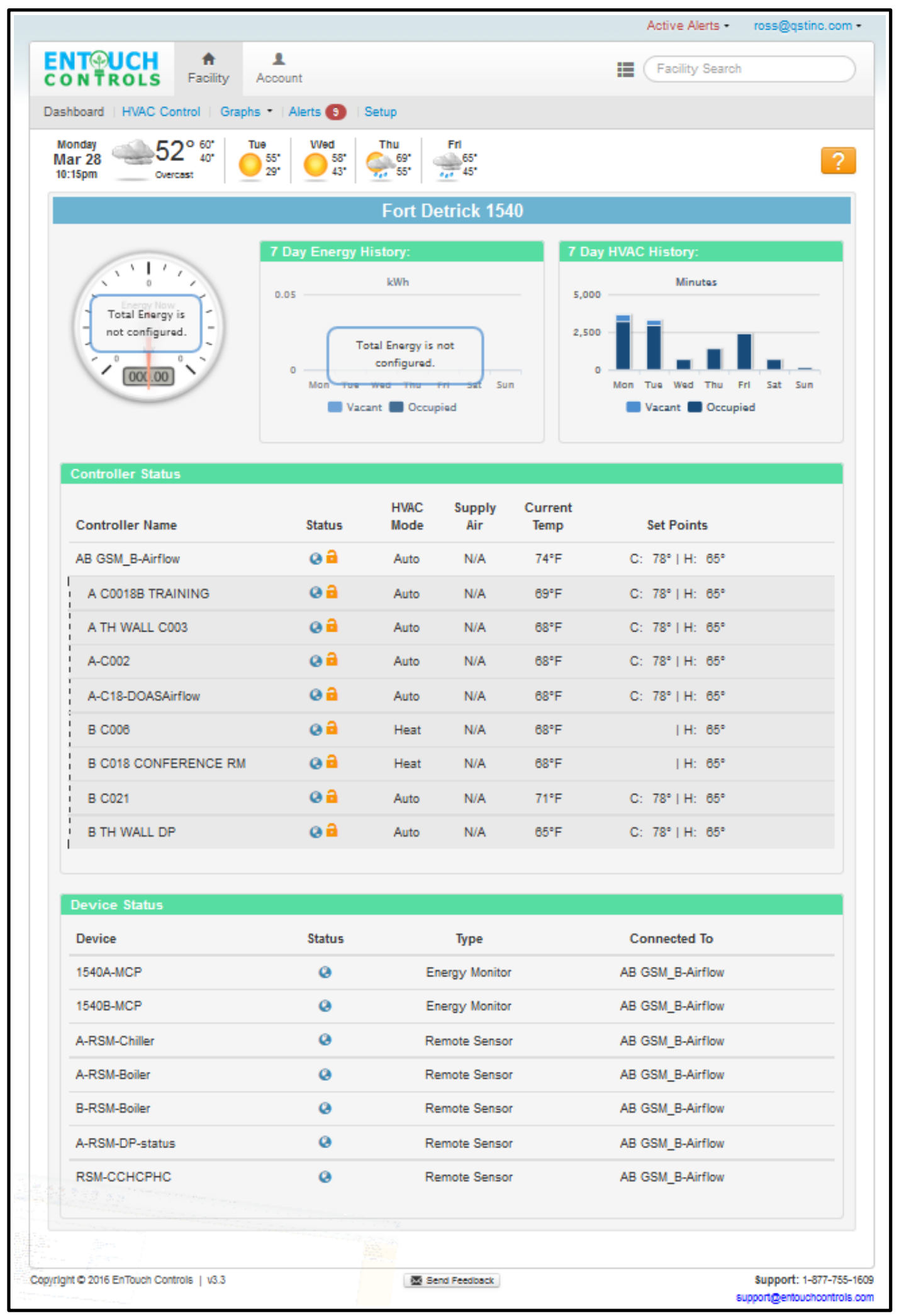


The inability to negotiate a more convenient means of remotely accessing system performance data with the NEC was unfortunate and costly in several ways. A good deal of time and effort was spent trying to negotiate a method of accessing data that would be acceptable to the NEC. The Contractor expended considerable unanticipated time and funds to purchase and install an EMS system that was completely separate but parallel to the existing BAS system. The Contractor's EMS system was not allowed to share connections to existing sensors with the existing BAS system. As a result, the data inputs to the EMS system were brand new redundant devices installed in parallel with perfectly functional existing devices.

Most significantly, the Contractor's inability to access the existing BAS system meant that the Contractor had no ability to make remote changes in setpoints or start/stop times, or to adjust sequences of operation. Combined with the fact that the Contractor was located in Tampa, FL, and the Fort Detrick DPW also had little or no ability to access the system through the existing BAS, the Contractor's ability to adjust system parameters was extremely limited.

- Location/Site Map: Bldg 1540 is located on Porter Street at the location shown in Figure 4-5.

Figure 4-5. Map of Fort Detrick showing location of Bldg 1540.

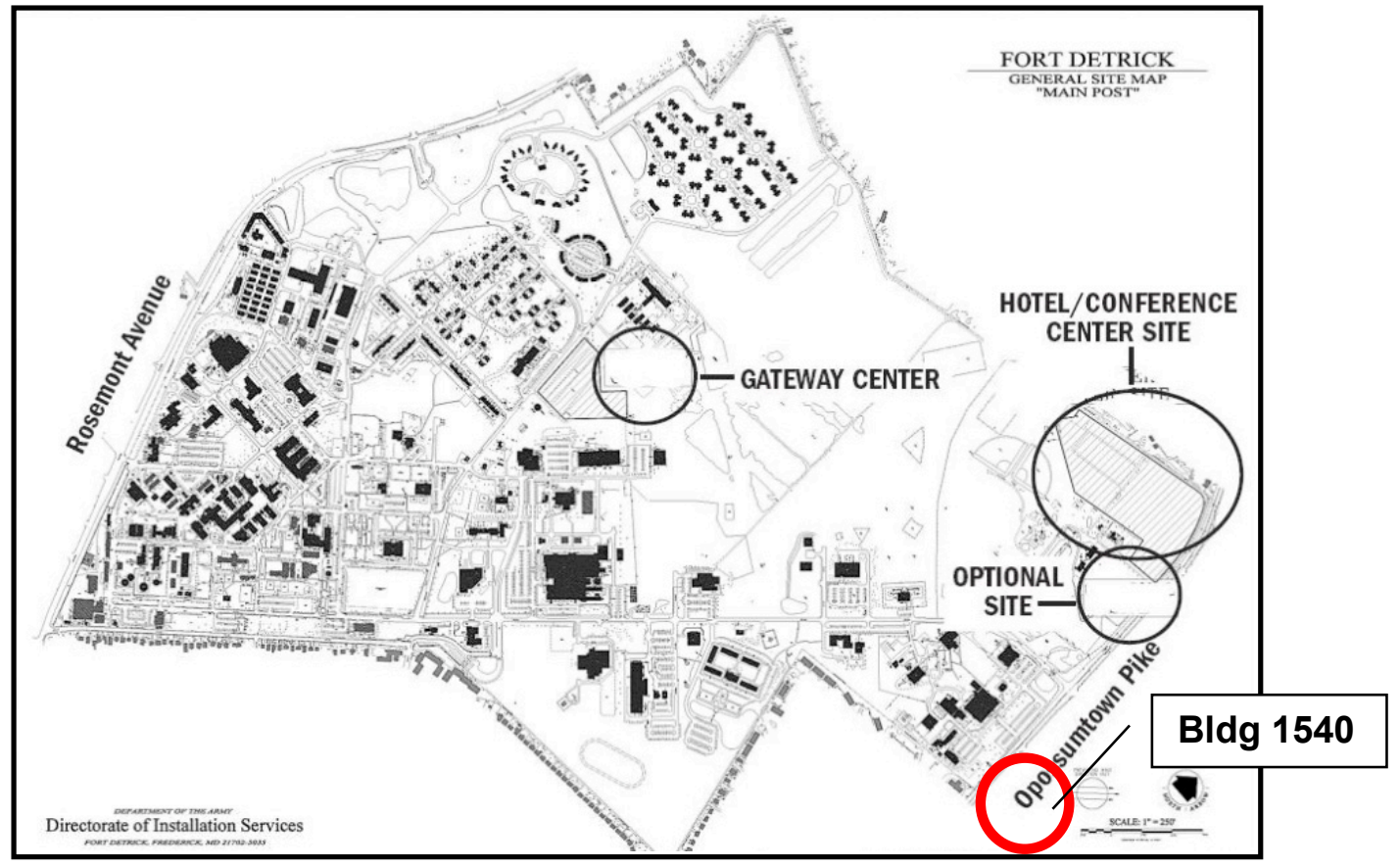


- Other Concerns: One issue that proved to be challenging was the fact that the IA training mission in Bldg $1540 \mathrm{~A}$ is a critical operation that cannot easily accommodate disruptions. Moreover, alternate locations at Fort Detrick to conduct this training while Bldg 1540A was being renovated were not readily available. Close coordination between the IA training staff and the Contractor was required. All of the occupants of Bldg 1540A were temporarily relocated during the renovation process. Occupants vacated the facility on $15 \mathrm{Jul} 2014$ and were allowed to reoccupy the facility on 11 May 2015.

Another issue that was somewhat difficult to address was that of complying with the Force Protection requirements of UFC 4-010-01, DoD Minimum Antiterrorism Standards for Buildings. (HQUSACE, NAVFAC, and AFCESA 2003) Appendix B, Paragraph B-4.1, Standard 16, "Air Intakes," is intended to minimize the opportunity for aggressors to easily place contaminants where they could be drawn into the air intakes of buildings. The most common means of satisfying this requirement is to elevate the outdoor air inlet to at least $10 \mathrm{ft}$ above ground level. This was the first approach considered by the Contractor. Unfortunately, due to the architecture of the existing exterior brick cladding and the wide roof overhang above the existing outdoor air inlet, there appeared to be no way to cost effectively provide an elevated outdoor air inlet through the mechanical room's exterior wall.

Per Standard 16, "Air Intakes," there is an alternative way of satisfying its requirements.

The requirements of this standard do not have to be applied when air intakes are located within an enclosed mechanical equipment yard or similar area with access control such as an enclosed courtyard.

The Contractor proposed satisfying the Standard 16 requirements by installing a chain link fence and gate enclosing the mechanical equipment yard. This would have been a relatively simple solution to the problem, but the installation Fire Department would not approve it because it could hinder emergency access to the back side of the building.

The Contractor then investigated the possibility of penetrating the standing seam metal roof and installing a vertical air intake above the roof. This 
approach would have required a specialized roofing Contractor to make this roof penetration. Also, because the building was relatively new, there was concern that any attempts to penetrate or alter the roof would void the roof warranty. Ultimately, it was determined that there was no longer a valid warranty on the roof. By this time, however, the Contractor had fortunately discovered that there was an existing roof penetration above the mechanical room that was large enough for their use and that was no longer being used for its original purpose. Ultimately, this roof penetration was used to accommodate a new outdoor air duct to the new DOAS AHU.

A second aspect of Antiterrorism/Force Protection (AT/FP) pertaining to this project is found in UFC 4-010-01 (HQUSACE, NAVFAC, and AFCESA 2003), Appendix B, Paragraph B-4.3, Standard 18, "Emergency Air Distribution Shutoff," which requires a means of rapidly shutting down air distribution systems and exhaust systems in response to an emergency situation, stating that:

For all new and existing buildings required to comply with these standards, provide an Emergency Shutoff Switch in the HVAC control system that can immediately shut down the air distribution and exhaust systems throughout the building and close all dampers leading to the outside ...

The switch must be capable of shutting down all required systems and closing all required dampers, even if the local hand/off/auto switch is in the hand position, within 30 seconds of switch activation. Locate the shutoff switch (or switches) to be easily accessible by building occupants by locating them similarly to mass notification system (MNS) local operating consoles (LOCs) (see UFC 4-021-01 [HQUSACE, NAVFAC, and AFCESA 2010] for additional information on MNS LOCs) so that the travel distance to the nearest shutoff switch will not be in excess of $200 \mathrm{ft}$ (61 m). Ensure that the shutoff switches are well labeled, and of a different color than fire alarm pull stations. 
Appendix B, Paragraph B-4.3.1, "Outside Air Intakes, Relief Air, and Exhausts" establishes leakage ratings for all dampers that must respond in an emergency situation, stating that:

... all outside air intakes, relief air, and exhaust openings with low leakage dampers that are automatically closed when the emergency air distribution shutoff switch is activated. The low leakage dampers will have maximum leakage rates of $3 \mathrm{cfm} / \mathrm{square}$ foot (15 liters/second/square meter) with a differential pressure of 1 in. of water gauge (250 Pa) across the damper.

Finally, Appendix B, Paragraph B-4.3.4, "HVAC Replacements and Upgrades" defines the criteria that determine whether the requirements of Standard 18 are required, as follows:

Where air handling equipment in heating, ventilating, and air-conditioning systems is being replaced or when they are being upgraded, all provisions of Standard 18 will be applied to the building in which the new HVAC system is being installed. This will apply regardless of the major investment trigger...

Based on Paragraph B-4.3.4, since the existing air handling equipment was being replaced, it was clear that the requirements of Standard 18 were in force, regardless of the magnitude of the project cost. As a result, the Contractor-provided dampers in compliance with the requirements of Paragraph B-4.3.1. These dampers were all interlocked to be activated by an Emergency Shutoff Switch that, when activated, shuts down all supply fans and exhaust fans and closes all dampers to the outdoors. Figure 4-6 shows the location of the Emergency Shutoff Switch.

Paragraph B-4.3 of UFC 4-010-01 (HQUSACE, NAVFAC, and AFCESA 2012) made mention of an MNS. We determined that there were no mass notification requirements applicable to this project and made no effort to incorporate an MNS in the facility. 


\subsection{Site-related permits and regulations}

- Regulations: There were no known regulations that impacted this project.

- Environmental Permits: There was no need for any environmental permits.

- Agreements: A memorandum of understanding between Fort Detrick and ERDC-CERL was signed in Dec 2012. Signatories included Fort Detrick's Garrison Commander and the ERDC-CERL Director.

Figure 4-6. Emergency shutoff switch location.

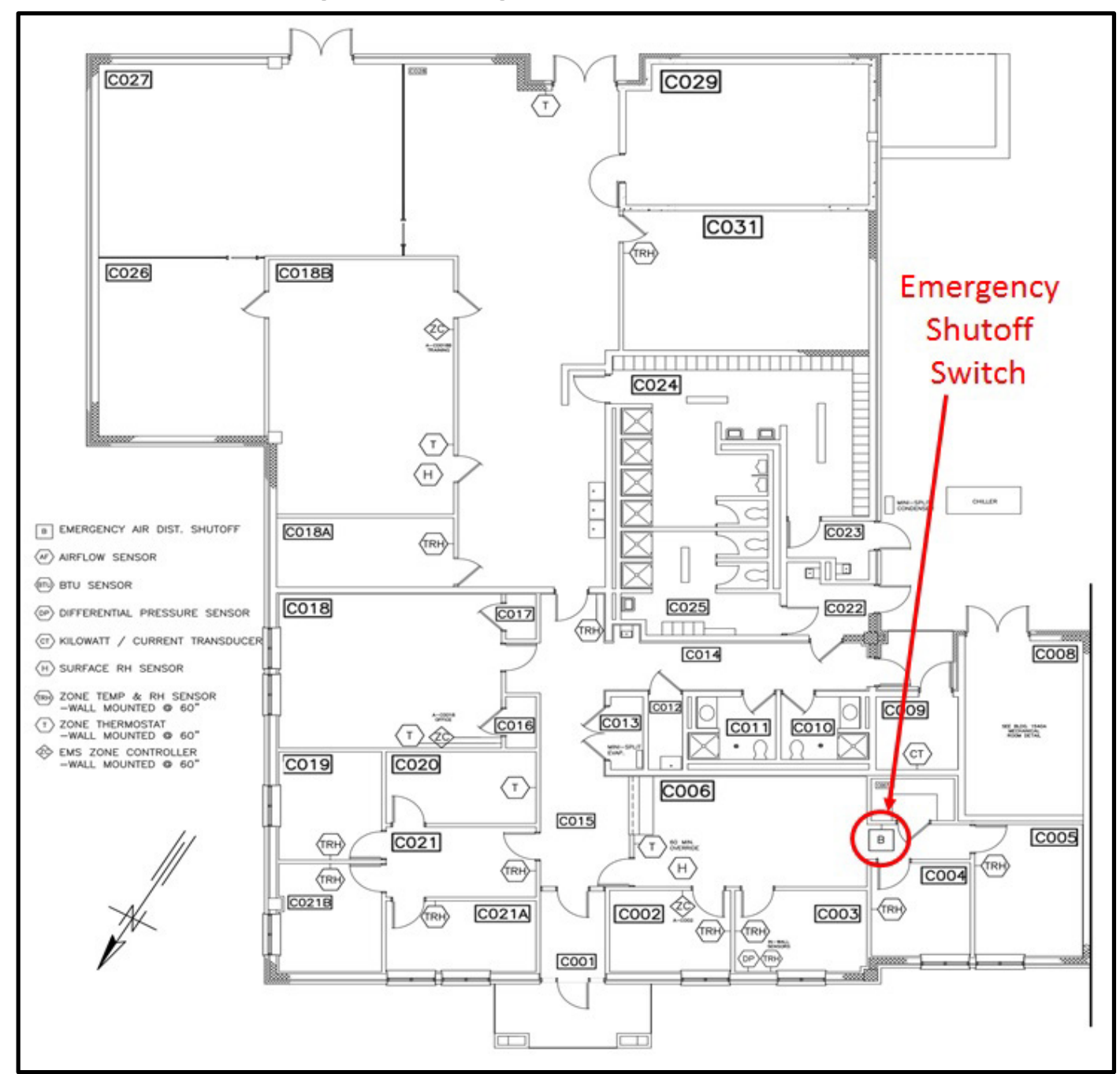




\section{Test Design}

- Fundamental Problem: This project attempted to demonstrate the feasibility and efficacy of integrating building envelope improvements with a DOAS system and a radiant heating/cooling system to effectively condition a military facility while reducing energy consumption and costs, avoiding condensation on cold surfaces within the facility and reducing relative mold and mildew potential. The goal of this demonstration was to provide a cost-effective alternative to the all-air approach to conditioning military buildings.

- Demonstration Questions: Questions posed by this demonstration included the following:

- Can the air tightness of existing building envelopes be substantially improved without major disruptive changes to the envelope system?

- Can a DOAS system with energy recovery efficiently and cost effectively provide adequate volumes of conditioned outdoor air to reduce the potential for mold and mildew in the building and prevent formation of condensation of moisture on cool surfaces?

- Can a radiant heating/cooling system satisfactorily condition a military facility?

- Will such an integrated system (improved building envelope, DOAS and radiant heating/cooling) be maintainable in a military environment?

- Approach: The approach taken was to identify an operational military facility of reasonable size and with an occupancy and function similar to a large number of existing military facilities. We sought a building in a portion of the United States where the installed systems would be challenged to adequately maintain comfortable and healthful interior conditions under hot and humid conditions as well as winter temperatures. We also looked for a building that had a similar building nearby or that could be subdivided into a demonstration portion and a similar baseline portion. Fort Detrick's Bldg 1540 fit these requirements quite well. The building was about 20 years old and was comparable in design, construction, construction quality, and maintained condition to many buildings of its vintage. The building was divided approximately in half by two floor-to-roof walls and an air gap that completely isolated the two halves of the facility. Each half of the facility had its own independent HVAC system, including boilers, direct expansion (DX) 
condensers, and DX VAV AHUs. Each half of the building had its own gas and electric meters. The only shared utility was domestic hot water, which was provided from a dedicated gas hot water heater in the $1540 \mathrm{OB}$ mechanical room. The energy required to generate domestic hot water was not accounted for in the heating energy requirements of Bldg 1540B. The two halves of the building had similar, but not identical, floor plans and occupancies.

On identifying the demonstration building, the Contractor collected energy performance baseline data and prepared a demonstration design for Bldg 1540A. The demonstration design was installed and both Bldgs $1540 A \& B$ were commissioned and instrumented for energy performance data collection. Because there were many mechanical system deficiencies identified in baseline Bldg $1540 \mathrm{~B}$, extensive repairs were made to bring this half of the building up to its design energy performance. Appendix $\mathrm{C}$ lists these deficiencies and the associated repairs.

- Required Data: The data necessary to perform this demonstration included:

- Envelope leakage data:

- "Before" envelope improvements, Bldg 1540A.

- "After" envelope improvements, Bldg 1540A.

- "Baseline" envelope leakage rate, Bldg 1540B.

- Electrical energy data:

- Total electrical energy, Bldg 1540A.

- HVAC electrical energy, Bldg 1540A.

- Total electrical energy, Bldg 1540B.

- HVAC electrical energy, Bldg 1540B.

- Thermal energy data:

- Total thermal energy, Bldg 1540A.

- Total thermal energy, Bldg 1540B.

- Thermal comfort data:

- Space temperature and RH, Bldg 1540A.

- Space temperature and RH, Bldg 1540B.

- Cost data:

- Cost of building envelope improvements, Bldg 1540A.

- Cost to install demonstrated HVAC systems, Bldg 1540A.

- Estimated cost to install a conventional HVAC system, Bldg 1540A.

- Cost to maintain HVAC systems, Bldg 1540A.

- Cost to maintain HVAC systems, Bldg 1540B. 
- Cost of energy, Bldg 1540A.

- Cost of energy, Bldg 1540B.

- Maintainability data:

- Number of HVAC work orders, Bldg 1540A.

- Number of HVAC work orders, Bldg 1540B.

- Number of HVAC work orders requiring special training or skills, Bldg 1540A.

- Local weather data:

- Dry bulb temperature and dewpoint temperature.

\subsection{Conceptual test design}

"Before" and "after" building envelope air tightness testing involved the following:

- Independent variable: Differential pressure (both positive and negative) across the building envelope. Differential pressure is measured in Pascals (Pa) or iwg. For our testing, the building envelope was subjected to differential pressures in the range of 25 to $75 \mathrm{~Pa}$. Testing was completed using the U.S. Army Corps of Engineers Air Leakage Test Protocol for Building Envelopes (HQUSACE 2012a) as a guideline.

- Dependent variable(s): Envelope air leakage rate (cfm). The envelope air leakage rate increased as the differential pressure increased.

- Controlled variable(s): The building envelope area ( $\left.\mathrm{ft}^{2}\right)$ was held constant throughout the testing. Also, all "intentional" building openings remained sealed throughout the testing process.

- Hypothesis: In situ sealing measures can be applied to the building envelope of a "typical" modern military facility to cost effectively improve the air tightness of the building envelope.

- Test Design: The air tightness of Bldg 1540A was tested before and after making physical improvements. The costs to implement the improvements were documented and analyzed to determine the cost effectiveness of the improvements in terms of energy cost savings.

- Test Phases: Air barrier testing was performed in accordance with the requirements of ASTM E779 (ASTM 2003a). "Before" testing was conducted to determine the baseline condition of Bldg $1540 \mathrm{~A}$ and to identify, locate, and characterize leaks. Based on this information, an approach was developed and implemented. After executing the build- 
ing envelope improvements, "after" testing was performed to determine the degree of improvement. The costs to design and execute the improvements were calculated and analyzed with respect to the projected energy savings and cost effectiveness.

Effectiveness of the DOAS was determined as follows:

- Independent variable: Outdoor ambient dry bulb temperature (DBT) and dewpoint temperature (DPT) are the independent variables.

- Dependent variable(s):

- Bldg $1540 A$ interior DBT $\left({ }^{\circ} \mathrm{F}\right)$.

- Bldg $1540 \mathrm{OA}$ interior DPT $\left({ }^{\circ} \mathrm{F}\right)$.

- Energy requirements of the DOAS system (kWh).

- Controlled variable(s):

- Bldg 1540A supply air flow DBT $\left({ }^{\circ} \mathrm{F}\right)$.

- Bldg 1540A supply air flow DPT $\left({ }^{\circ} \mathrm{F}\right)$.

- Exterior doors and windows were kept closed to prevent infiltration of unconditioned outdoor air.

- The DOAS supply air flow rate and exhaust air flow rate were fixed.

- Hypothesis: The DOAS system can deliver sufficient quantities of properly conditioned outdoor air to satisfy the ventilation requirements of Bldg 1540A and to keep the interior of the building dry enough to make Bldg 1540A less susceptible to mold/mildew problems than baseline Bldg 1540 B.

- Test Design: The outdoor ambient conditions (DBT and DPT), and the condition of the delivered air (DBT and DPT) were measured and recorded. Supply and exhaust air flow rates were fixed. Energy consumed by the DOAS unit was also measured and recorded.

- Test Phases: On installation and commissioning of the DOAS system, outdoor ambient conditions, delivered ventilation air conditions, and DOAS energy consumption were measured and recorded for 12 months.

Effectiveness of the radiant heating and cooling system was determined as follows:

- Independent variable: Outdoor ambient DBT.

- Dependent variable(s):

- DBT $\left({ }^{\circ} \mathrm{F}\right)$ in interior locations of Bldgs $1540 A \& B$. 
- Delivered heating and cooling energy (measured in BTU, then converted to $\mathrm{kWh}$ ):

- Bldg 1540A: Supply water temperature $\left({ }^{\circ} \mathrm{F}\right)$, return water temperature $\left({ }^{\circ} \mathrm{F}\right)$, and flow rate (gallons per minute [gpm]).

- Bldg 1540B: Supply air temperature $\left({ }^{\circ} \mathrm{F}\right)$, return air temperature $\left({ }^{\circ} \mathrm{F}\right)$, and flow rate $(\mathrm{cfm})$.

- Occupant comfort was determined in accordance with the criteria provided in ASHRAE Std 55-2010, Section 5.2.1.1 "Graphic Comfort Zone Method" (ASHRAE 2010)

- Controlled variable(s): Exterior doors and windows were kept closed to ensure that building temperature control was maintained via the radiant heating/cooling system. The use of portable heaters or fans to address personal comfort was discouraged.

- Hypothesis: The radiant heating/cooling system can be capable of maintaining comfort conditions in the various spaces. The system can be easily operable and maintainable and will be more energy efficient than an all-air system.

- Test Design: The outdoor ambient conditions (DBT and DPT) were measured and recorded. The indoor temperatures in occupied spaces were measured and recorded and the energy delivered by the radiant heating/cooling system was measured and recorded.

- Test Phases: On installation and commissioning of the radiant heating/cooling system, outdoor ambient conditions and indoor temperatures in various spaces and radiant heating/cooling energy were measured and recorded for 12 months.

\subsection{Baseline characterization}

This Section defines baseline information necessary for the test design. Data and data interpretation are provided in other sections. Specifics pertaining to baseline performance and cost comparisons can be found in Sections 6.1, "Baseline Performance" and 7.3 "Cost Analysis and Comparison," respectively.

- Reference Conditions: Energy data to be collected include:

- Building air tightness data:

- Bldg 1540A baseline air tightness data.

- Bldg 1540A post improvement air tightness data.

- Building environmental conditions: 
- Bldg 1540A temperatures and RH (various locations).

- Bldg 1540B temperatures and RH (various locations).

- Building energy consumption:

- Bldg 1540A gas and electric energy consumption.

- Bldg 1540B gas and electric energy consumption.

- Relative first costs:

- Labor and material costs to install demonstrated system.

- Estimated labor and materials costs to install conventional system.

- Relative O\&M costs:

- Labor and materials costs to operate and maintain demonstrated system.

- Labor and materials costs to operate and maintain baseline system.

- Baseline Collection Period:

- Bldg 1540A baseline air tightness data - 1 day.

- Bldg 1540B baseline energy performance data - 12 months.

- Bldg 1540B baseline interior environmental performance data - 12 months.

- Bldg 1540B baseline O\&M data - 12 months.

- Existing Baseline Data: No existing baseline data is known to exist.

- Baseline Estimation: The cost to install a conventional system in Bldg 1540A was estimated using RS Means.

- Baseline Occupancy: It was also necessary to account for the relative occupancy of Bldgs 1540A\&B. Although the building sizes are quite similar, we found that the occupancy of Bldg 1540 A was significantly higher than for Bldg $1540 \mathrm{OB}$. Although it was not feasible to get an accurate day-to-day count of the number of occupants of each building, it appeared that Bldg $154 \mathrm{OB}$ typically had 10 or fewer occupants and Bldg 1540 A had 20 or more occupants, especially when IA training classes were in session. These students also brought with them additional computers that added to the cooling load in Bldg 1540A. We also noted that Bldg 1540A had much larger male and female shower rooms, which necessitated considerably higher exhaust (and, hence, ventilation) rates.

- Building Orientation: Another consideration is that Bldg 1540's orientation does not lie on a true North-South axis. The differences in building orientation created minimal difference in the combined heat gain from windows and walls (within $4 \%$ ). The primary cause for differences in building envelope heat gain is due to their differences in roof area. The roof area differences and their associated heat gains are 
proportional to their differences in square footage with Bldg $1540 \mathrm{~A}$ being 36\% larger than Bldg 1540 B.

- Data Collection Equipment. The air barrier testing apparatus (Figure 5-1) consisted of a calibrated blower door system that was installed in the doorway of the facility being tested. The system accurately measured the air being blown into/drawn out of the building while simultaneously measuring the pressure differential $(\Delta \mathrm{P})$ across the building envelope. By measuring a number of paired volume/ $\Delta \mathrm{P}$ data points, it was possible to calculate the leakage rate per unit of envelope surface area at a reference differential pressure of $75 \mathrm{~Pa}$. Small, inexpensive temperature and RH dataloggers (Figures 5-2 to 5-4) were easily deployed where needed. Existing utility gas and electric meters (Figures $5-5$ and 5-6) were used to measure energy consumption.

Figure 5-1. Air barrier testing apparatus.

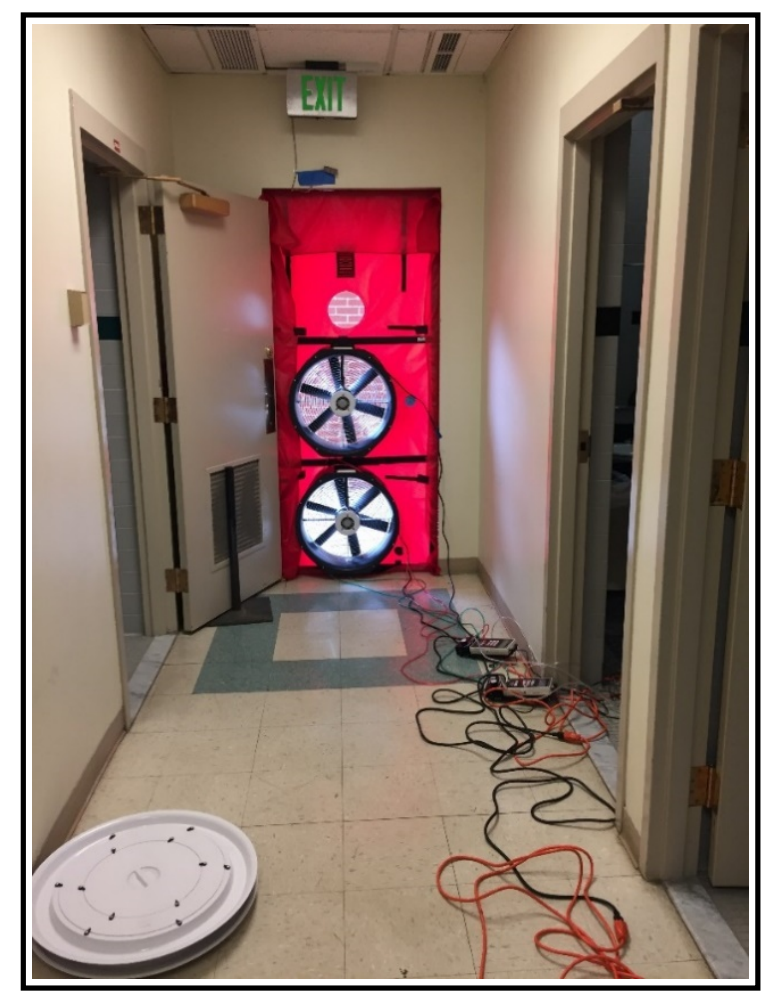


Figure 5-2. Typical EnTouch EMS zone thermostat and temperature/humidity logger.

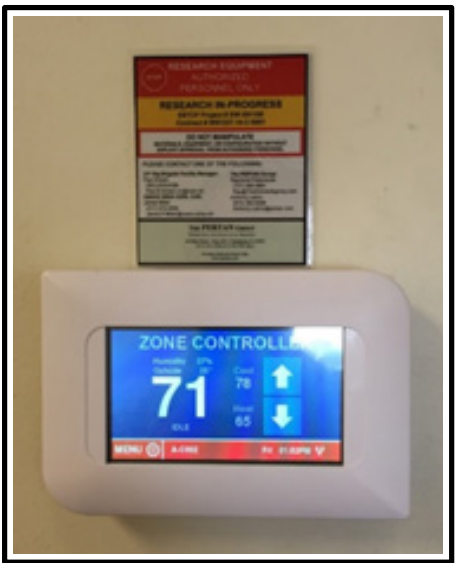

Figure 5-4. Typical room thermostat and RH sensor.

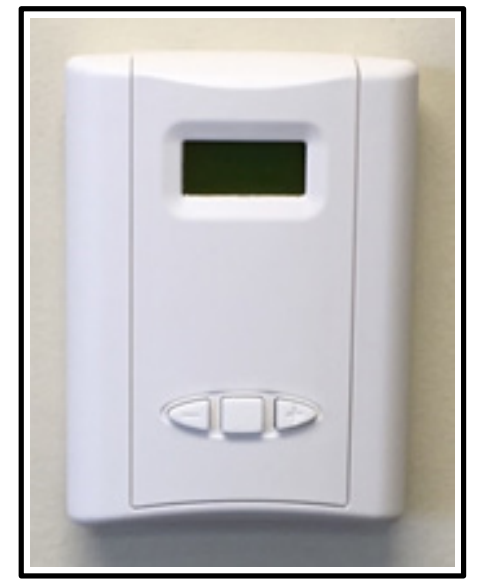

Figure 5-6. Existing utility gas meter for BIdg 1540B.

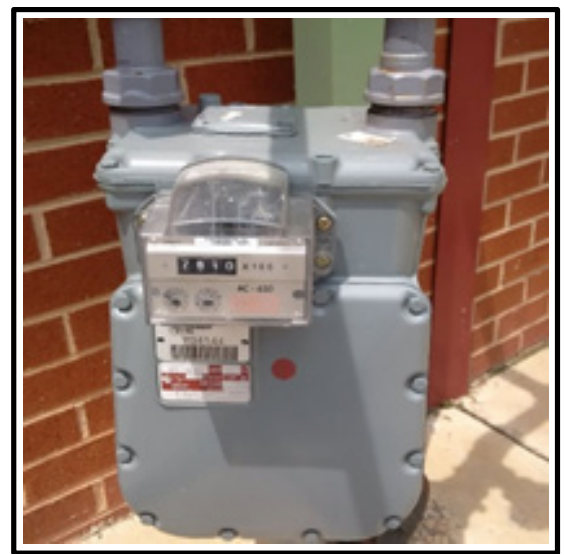

Figure 5-3. Typical temperature and $\mathrm{RH}$ dataloggers.

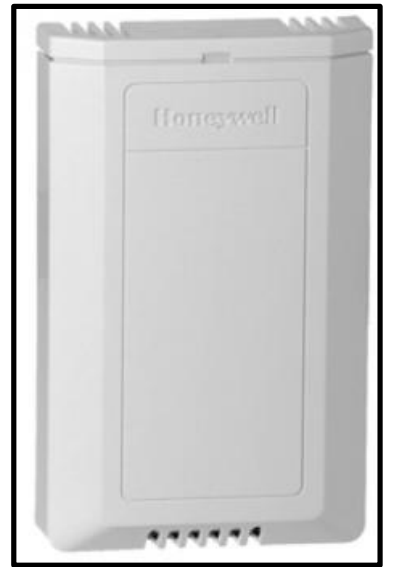

Figure 5-5. Existing utility gas meter for Bldg 1540A.

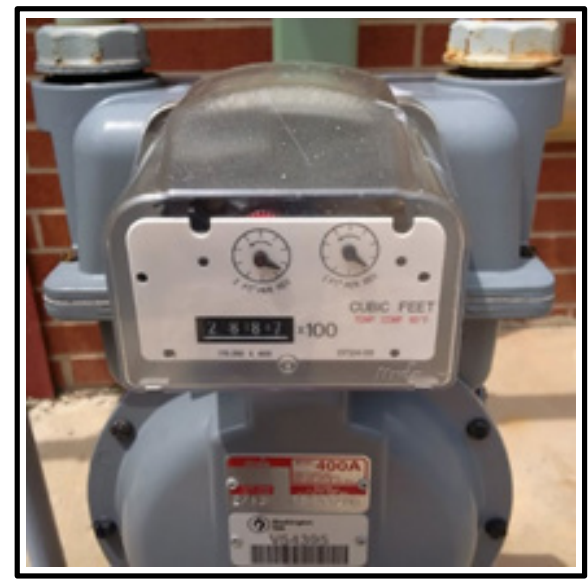




\subsection{Design and layout of system components}

\subsubsection{AHUs and/or fan coil units}

Table 5-1 lists the test and balance findings on AHUs and/or FCUs.

Table 5-1. Test and balance findings on AHUs and/or FCUs.

\begin{tabular}{|l|c|c|c|c|c|c|}
\hline Unit & Design CFM & Actual CFM & $\%$ of Design & Design OSA & Actual OSA & $\%$ Of Design \\
\hline AHU-1 & 1,625 & 1,659 & $102 \%$ & 1,625 & 1,659 & $102 \%$ \\
\hline FCU-1 & 530 & 370 & $70 \%$ & - & - & - \\
\hline${ }^{*}$ Outside Air & \multicolumn{7}{|l|}{} \\
\hline
\end{tabular}

\subsubsection{Exhaust fans}

Table 5-2 lists the test and balance findings on exhaust fans.

Table 5-2. Test and balance findings on exhaust fans.

\begin{tabular}{|c|c|c|c|}
\hline Exhaust Fan (EF)\# & Design CFM & Actual CFM & $\%$ Of Design \\
\hline 1 & 1,270 & $(1)$ & - \\
\hline 2 & 160 & 92 & $58 \%$ \\
\hline & 1,100 & 1,102 & $100 \%$ \\
\hline
\end{tabular}

Two configurations of radiant panels were used on this project. In conditioned spaces with existing grid ceilings, 2x4 ft grid-mounted radiant panels were used. In conditioned spaces without an existing grid ceiling, "cloud" panels were suspended from the hard overhead ceiling. Depending on zone load requirements, some panels were two-circuit panels that incorporated separate heating and cooling tubing. In some spaces, additional "cooling-only" panels were installed to satisfy cooling requirements beyond the capacity of the two-circuit panels.

Figures 5-7 and 5-8 show partial plan views of radiant panel installation in Bldg 1540A. Note that a number of rooms did not receive radiant panels, including:

- Figure 5-7:

- $\mathrm{Co23}, \mathrm{Co24}$ (men's latrine/shower, existing hot water cabinet unit heaters and exhaust).

- Co22, Co25 (women's latrine/shower, existing hot water cabinet unit heaters and exhausted). 
- Co26, C027, Co28 (open storage, existing hot water unit heaters only).

- Co29 (arms storage, existing hot water unit heater and DX split AC unit).

- Figure 5-8:

- Co10/Co11 (men's/women's latrines, exhausted only)

- Coo8 (mechanical room, existing hot water unit heater and exhaust)

- Coog (electrical room, unconditioned).

Figure 5-7. Partial plan view (southwest half) of Bldg 1540A showing radiant panels. Rm C018B (highlighted) shows 11 additional smaller panels installed to address a cooling capacity issue.

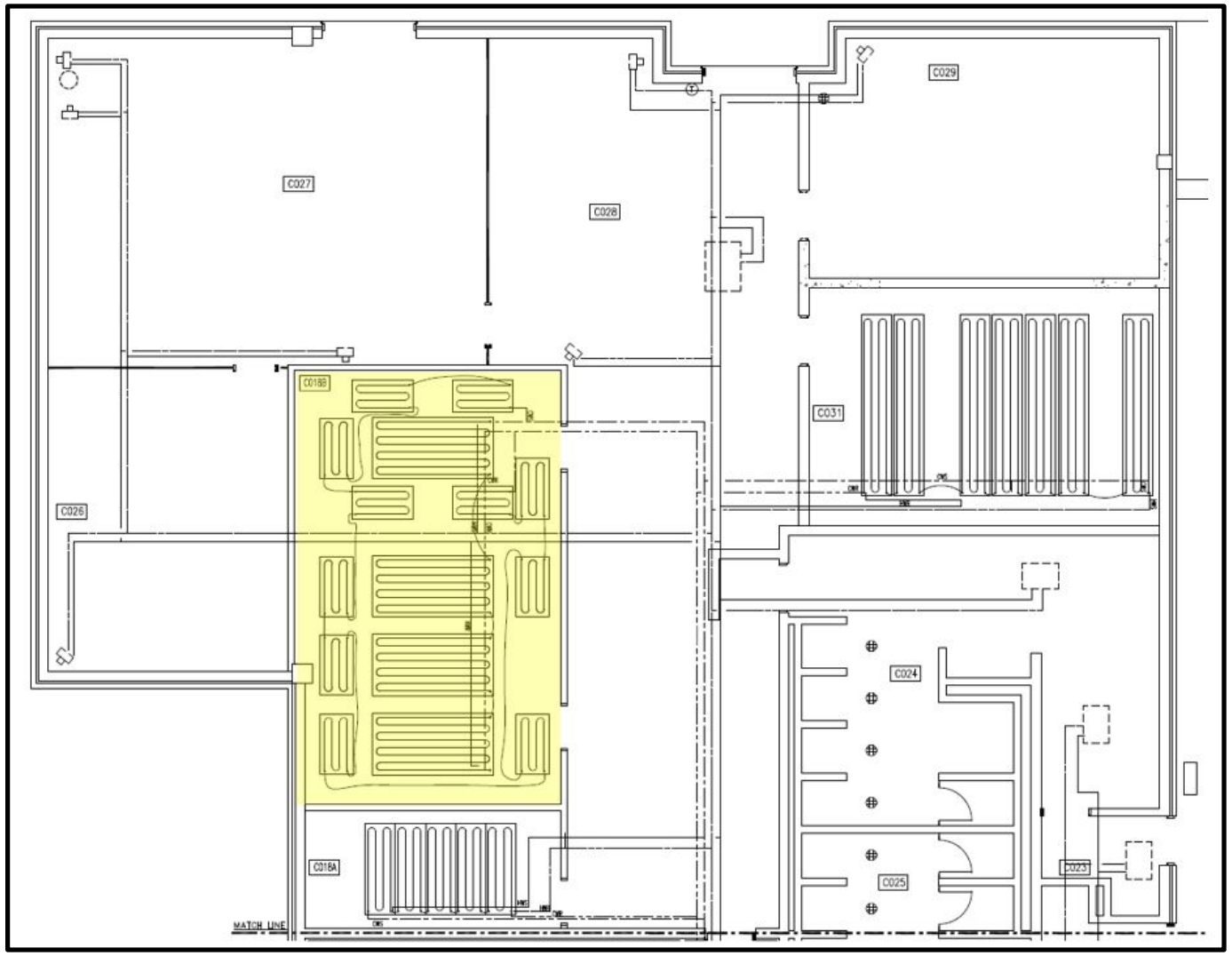


Figure 5-8. Partial plan view (northeast half) of Bldg 1540A showing radiant panels.

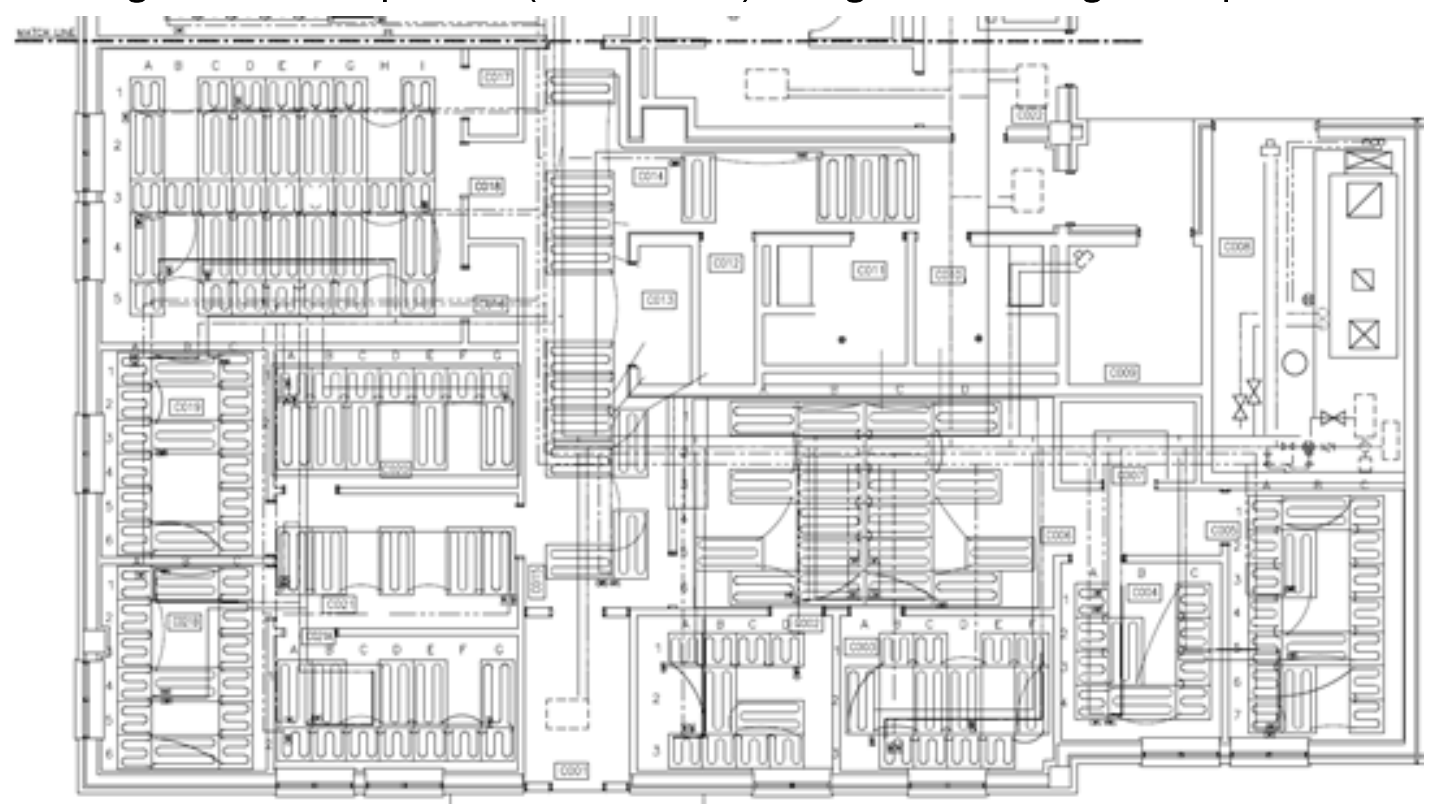

The radiant panel system was supplied with hot water from an existing boiler and chilled water from a new air-cooled chiller. Figure 5-9 shows the layout of the hot water system and Figure 5-10 shows a schematic of the chilled water system. Note that chilled water was delivered to the DOAS AHU's cooling coil at $42{ }^{\circ} \mathrm{F}$ and left at $49^{\circ} \mathrm{F}$. It was then delivered to the three-way mixing valve where it was blended with return water from the radiant cooling panels. The chilled water was then delivered to the radiant cooling panels where it was supplied at $61^{\circ} \mathrm{F}$ and left at $66^{\circ} \mathrm{F}$. Cascading chilled water from the DOAS AHU's cooling coil improved system efficiency by providing a larger $\Delta \mathrm{T}$ to the chiller. Also, delivering warmer chilled water to the ceiling-mounted radiant cooling panels minimized the risk of condensation on the cool surfaces of the panels by keeping the panel surfaces above the DPT of the air in the conditioned spaces. 
Figure 5-9. Hot water system schematic.

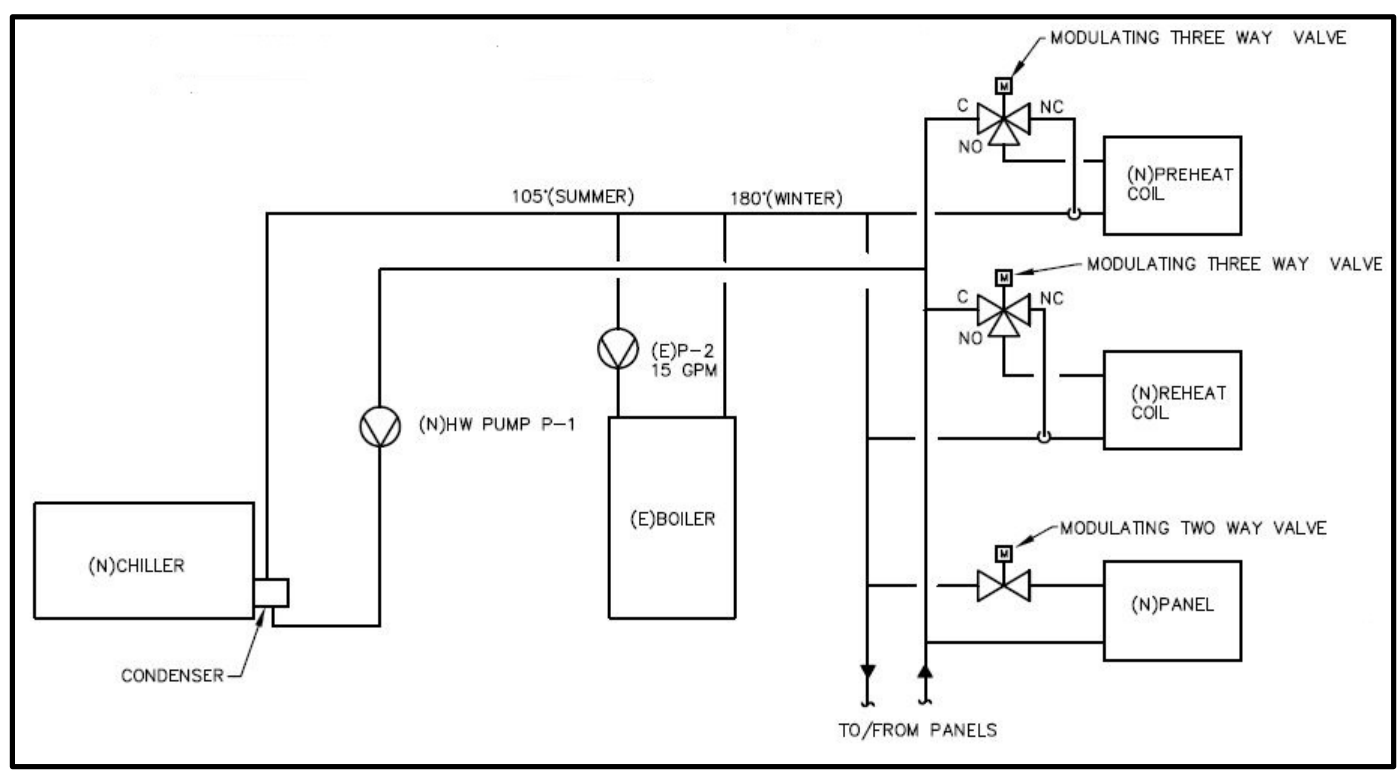

Figure 5-10. Chilled water system schematic.

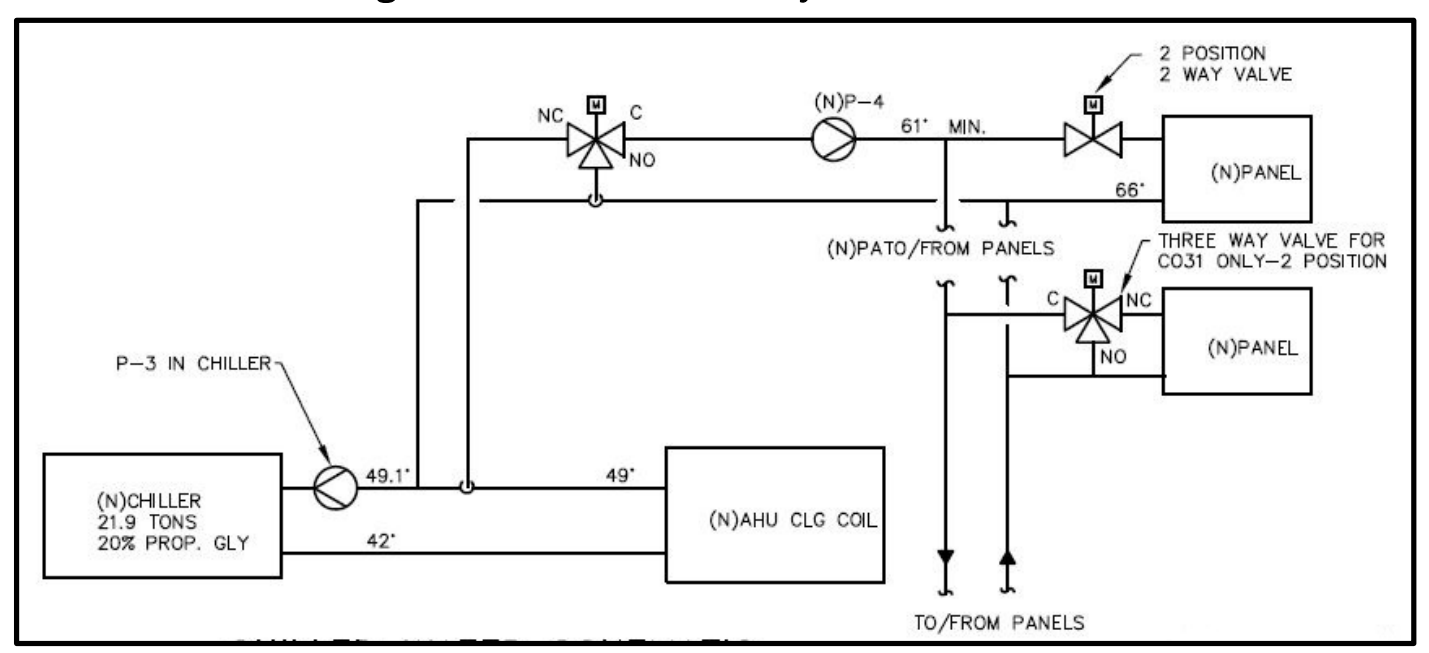

Figure 5-11 shows the DOAS AHU. This was a constant volume device that filtered and preheated (if needed) outside air. The air then passed through an enthalpy wheel where it exchanged energy with building exhaust from the latrines. The ventilation air then passed through a deep cooling coil that cooled and dehumidified it before it entered the reheat coil where it was warmed to a neutral temperature before delivery to the occupied zones. 
Figure 5-11. DOAS air handling unit.

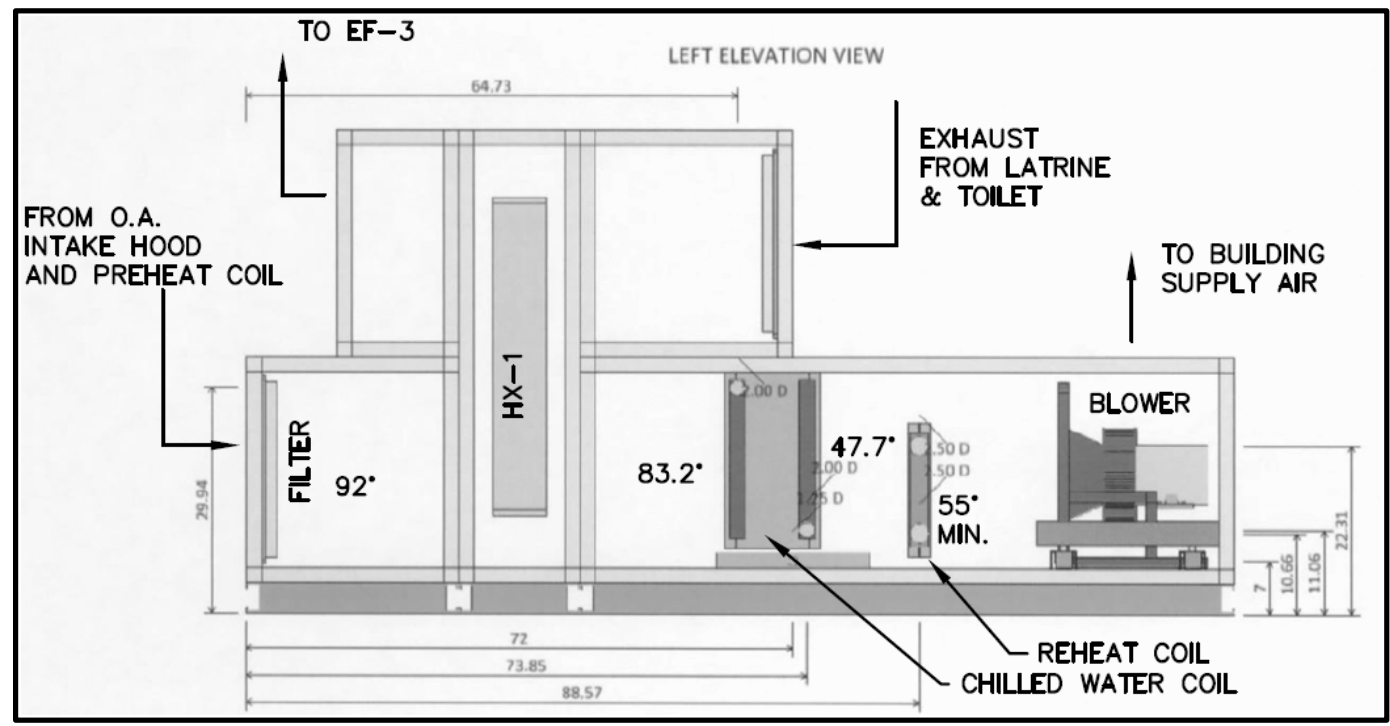

\subsection{Operational testing}

- Operational Testing of Cost and Performance: Energy and cost performance data were collected through the course of 12 months of operation under typical outdoor ambient conditions and normal building occupancy. Throughout the course of the year, it was possible to collect performance data during extreme weather events, systems shut downs, periods of high and low occupancy, etc.

- Modeling and Simulation: This project did not include modeling and simulation of this building.

- Timeline: Operational testing began soon after project kickoff. The Contractor performed "before" testing of the building envelope to determine the relative tightness of the existing building. Based on this information, the Contractor designed an approach to improve the building envelope.

The Contractor began measuring and recording energy consumption of the baseline facility and demonstration facility during the retrofit design phase to obtain baseline energy usage. Post-retrofit testing of the building envelope of the demonstration facility was performed to determine the effectiveness of building envelope sealing activities. On completion of installation of the retrofit systems, energy performance monitoring of the demonstration facility and of the baseline facility was initiated and continued for 12 months through Sep 2016. 
- Technology Transfer or Decommissioning: The Fort Detrick Energy Manager and the $21^{\text {st }}$ Signal Brigade's Facility manager were kept informed throughout the design, installation, testing, and evaluation of this project. Fort Detrick DPW employees were invited to witness and participate in commissioning of this system. All system documentation was turned over to the DPW on project completion. Per prior correspondence with the Director of Public Works, Fort Detrick has no intention to request that the demonstration system be removed at the conclusion of this project and is prepared to provide written acceptance of the demonstration system on receipt of the final deliverable (i.e., the Final Report).

\subsection{Sampling protocol}

Table 5-3 details the elements of the data sampling, recording, and storage protocol for this demonstration.

Table 5-3. Data sampling, recording, and storage protocol.

\begin{tabular}{|c|c|c|c|c|c|}
\hline Parameter & Data Collector & Data Recording & $\begin{array}{l}\text { Data Storage } \\
\text { and Backup }\end{array}$ & $\begin{array}{l}\text { Data Collection } \\
\text { Diagram }\end{array}$ & $\begin{array}{c}\text { Non-Standard } \\
\text { Data }\end{array}$ \\
\hline $\begin{array}{l}\text { Building air } \\
\text { tightness } \\
\text { testing }\end{array}$ & $\begin{array}{l}\text { Building } \\
\text { envelope air } \\
\text { tightness testing } \\
\text { Contractor }\end{array}$ & $\begin{array}{l}\text { Automatic data } \\
\text { recording by test } \\
\text { apparatus }\end{array}$ & $\begin{array}{l}\text { Data stored in } \\
\text { test instrument }\end{array}$ & $N A^{*}$ & NA \\
\hline Temperature & $\begin{array}{l}\text { Demo } \\
\text { Contractor }\end{array}$ & Temp loggers & $\begin{array}{l}\text { Remote data } \\
\text { access }\end{array}$ & NA & NA \\
\hline $\begin{array}{l}\text { Relative } \\
\text { humidity }\end{array}$ & $\begin{array}{l}\text { Demo } \\
\text { Contractor }\end{array}$ & $\mathrm{RH}$ loggers & $\begin{array}{l}\text { Remote data } \\
\text { access }\end{array}$ & NA & NA \\
\hline $\begin{array}{l}\text { Gas } \\
\text { consumption }\end{array}$ & DPW personnel & Manual recording & $\begin{array}{l}\text { Paper } \\
\text { and/electronic } \\
\text { records }\end{array}$ & NA & NA \\
\hline $\begin{array}{l}\text { Electric } \\
\text { consumption }\end{array}$ & DPW personnel & Manual recording & $\begin{array}{l}\text { Paper } \\
\text { and/electronic } \\
\text { records }\end{array}$ & NA & NA \\
\hline First costs & $\begin{array}{l}\text { Demo } \\
\text { Contractor }\end{array}$ & Invoices & $\begin{array}{l}\text { Paper } \\
\text { and/electronic } \\
\text { records }\end{array}$ & NA & NA \\
\hline O\&M costs & DPW personnel & Work orders & $\begin{array}{l}\text { Paper } \\
\text { and/electronic } \\
\text { records }\end{array}$ & NA & NA \\
\hline $\begin{array}{l}\text { Occupant } \\
\text { satisfaction }\end{array}$ & $\begin{array}{l}\text { Demo } \\
\text { Contractor }\end{array}$ & $\begin{array}{l}\text { Temp loggers, } \\
\text { Humidity loggers }\end{array}$ & $\begin{array}{l}\text { Data stored in } \\
\text { test instrument }\end{array}$ & NA & NA \\
\hline
\end{tabular}




\subsubsection{Instrumentation plan}

Table 5-4 and 5-5 list the elements instrumentation plan for Bldgs 1540A and $1540 B$, respectively.

Table 5-4. Bldg 1540A instrumentation plan.

\begin{tabular}{|c|c|c|c|c|}
\hline Parameter & $\begin{array}{l}\text { Data } \\
\text { Measurement } \\
\text { Method }\end{array}$ & $\begin{array}{l}\text { Data } \\
\text { Measurement } \\
\text { Frequency }\end{array}$ & Data Measurement Location & $\begin{array}{c}\text { Data } \\
\text { Analysis } \\
\text { Method }\end{array}$ \\
\hline $\begin{array}{l}\text { Boiler Flow } \\
\text { Rate }\end{array}$ & $\begin{array}{l}\text { Electronic, Badger } \\
\text { Meter }\end{array}$ & Hourly & $\begin{array}{l}\text { Immersed in-line with boiler water } \\
\text { flow }\end{array}$ & $\begin{array}{l}\text { Numerical } \\
\text { tabulation } \\
\text { and plotting }\end{array}$ \\
\hline $\begin{array}{l}\text { Boiler Water } \\
\text { Temperature }\end{array}$ & $\begin{array}{l}\text { Electronic, Badger } \\
\text { Meter }\end{array}$ & Hourly & $\begin{array}{l}\text { On the exterior of the supply and } \\
\text { return boiler water pipes }\end{array}$ & $\begin{array}{l}\text { Numerical } \\
\text { tabulation } \\
\text { and plotting }\end{array}$ \\
\hline $\begin{array}{l}\text { Chiller Flow } \\
\text { Rate }\end{array}$ & $\begin{array}{l}\text { Electronic, Badger } \\
\text { Meter }\end{array}$ & Hourly & $\begin{array}{l}\text { Immersed in-line with chiller water } \\
\text { flow }\end{array}$ & $\begin{array}{l}\text { Numerical } \\
\text { tabulation } \\
\text { and plotting }\end{array}$ \\
\hline $\begin{array}{l}\text { Chiller Water } \\
\text { Temperature }\end{array}$ & $\begin{array}{l}\text { Electronic, Badger } \\
\text { Meter }\end{array}$ & Hourly & $\begin{array}{l}\text { On the exterior of the supply and } \\
\text { return chilled water pipes }\end{array}$ & $\begin{array}{l}\text { Numerical } \\
\text { tabulation } \\
\text { and plotting }\end{array}$ \\
\hline $\begin{array}{l}\text { Electricity } \\
\text { Usage }\end{array}$ & Electronic & 24 hour intervals & $\begin{array}{l}\text { Main, Chiller, Chilled Water Pumps } \\
3 \text { and 4, Hot Water Pump 2, } \\
\text { Pump 1, DOAS Unit Fan, DOAS HX, } \\
\text { EF-3, FCU-1 }\end{array}$ & $\begin{array}{l}\text { Numerical } \\
\text { tabulation } \\
\text { and plotting }\end{array}$ \\
\hline $\begin{array}{l}\text { Air } \\
\text { Temperature }\end{array}$ & Electronic & $\begin{array}{l}5 \text { minute } \\
\text { intervals }\end{array}$ & $\begin{array}{l}\text { DOAS Cooling Coil Temperature } \\
\text { and Heating Coil Temperature, } \\
\text { Entering and Leaving Preheat Coil, } \\
\text { A-Inside Wall, DOAS-A-HX-EX In } \\
\text { and Out, Outside, Rooms: A- } \\
\text { C018B Training, A-TH Wall C003, } \\
\text { A-C002, AC18-DOAS Airflow }\end{array}$ & $\begin{array}{l}\text { Numerical } \\
\text { tabulation } \\
\text { and plotting }\end{array}$ \\
\hline Air Humidity & Electronic & $\begin{array}{l}5 \text { minute } \\
\text { intervals }\end{array}$ & $\begin{array}{l}\text { Outside, Rooms: A-C018B } \\
\text { Training, A-TH Wall C003, A-C002, } \\
\text { AC18-DOAS Airflow }\end{array}$ & $\begin{array}{l}\text { Numerical } \\
\text { tabulation } \\
\text { and plotting }\end{array}$ \\
\hline Pressure & Electronic & $\begin{array}{l}5 \text { minute } \\
\text { intervals }\end{array}$ & 1540A Conditioned Space & $\begin{array}{l}\text { Observed in } \\
\text { system } \\
\text { alarms }\end{array}$ \\
\hline $\begin{array}{l}\text { Data } \\
\text { Transmission }\end{array}$ & $\begin{array}{l}\text { Electronic } \\
\text { (isolated system), } \\
\text { EnTouch }\end{array}$ & $\begin{array}{l}5 \text { minute } \\
\text { intervals }\end{array}$ & 1540A Mechanical Room & $\begin{array}{l}\text { Monthly } \\
\text { observation }\end{array}$ \\
\hline
\end{tabular}


Table 5-5. Bldg 1540B instrumentation plan.

\begin{tabular}{|l|l|l|l|l|}
\hline Parameter & $\begin{array}{l}\text { Data } \\
\text { Measurement } \\
\text { Method }\end{array}$ & $\begin{array}{l}\text { Data } \\
\text { Measurement } \\
\text { Frequency }\end{array}$ & Data Measurement Location & $\begin{array}{l}\text { Data Analysis } \\
\text { Method }\end{array}$ \\
\hline $\begin{array}{l}\text { Boiler Flow } \\
\text { Rate }\end{array}$ & $\begin{array}{l}\text { Electronic, } \\
\text { Badger Meter }\end{array}$ & Hourly & $\begin{array}{l}\text { Immersed in-line with boiler } \\
\text { water flow }\end{array}$ & $\begin{array}{l}\text { Numerical } \\
\text { tabulation } \\
\text { and plotting }\end{array}$ \\
\hline $\begin{array}{l}\text { Boiler Water } \\
\text { Temperature }\end{array}$ & $\begin{array}{l}\text { Electronic, } \\
\text { Badger Meter }\end{array}$ & Hourly & $\begin{array}{l}\text { On the exterior of the supply } \\
\text { and return boiler water pipes }\end{array}$ & $\begin{array}{l}\text { Numerical } \\
\text { tabulation } \\
\text { and plotting }\end{array}$ \\
\hline $\begin{array}{l}\text { Electricity } \\
\text { Usage }\end{array}$ & Electronic & $\begin{array}{l}24 \text { hour } \\
\text { intervals }\end{array}$ & $\begin{array}{l}\text { Main, Hot Water (HW) Pump, } \\
\text { DX AHU-4 Fan, DX AHU-4 } \\
\text { Condensing Unit, FCU-4, Vault } \\
\text { DH/EF }\end{array}$ & $\begin{array}{l}\text { Numerical } \\
\text { tabulation } \\
\text { and plotting }\end{array}$ \\
\hline $\begin{array}{l}\text { Air } \\
\text { Temperature }\end{array}$ & Electronic & $\begin{array}{l}5 \text { minute } \\
\text { intervals }\end{array}$ & $\begin{array}{l}\text { AHU-B-Supply, Rooms: AB GSM } \\
\text { B-Airflow, B-COO6, B-CO18 } \\
\text { Conference Room, B-C021, B- } \\
\text { TH Wall DP }\end{array}$ & $\begin{array}{l}\text { Numerical } \\
\text { tabulation } \\
\text { and plotting }\end{array}$ \\
\hline Air Humidity & Electronic & $\begin{array}{l}5 \text { minute } \\
\text { intervals }\end{array}$ & $\begin{array}{l}\text { Rooms: AB GSM B-Airflow, B- } \\
\text { CO06, B-CO18 Conference } \\
\text { Room, B-CO21, B-TH Wall DP }\end{array}$ & $\begin{array}{l}\text { Numerical } \\
\text { tabulation } \\
\text { and plotting }\end{array}$ \\
\hline Data \\
Transmission & $\begin{array}{l}\text { Electronic } \\
\text { (isolated } \\
\text { system), } \\
\text { EnTouch }\end{array}$ & $\begin{array}{l}5 \text { minute } \\
\text { intervals }\end{array}$ & $\begin{array}{l}\text { 1540B Mechanical Room } \\
\text { Monthly } \\
\text { observation }\end{array}$ \\
\hline
\end{tabular}

\subsubsection{Data acquisition plan}

\subsubsection{System overview}

The data communication system and acquisition plan was implemented through a Contractor-provided EMS. The EMS consisted of the EnTouch One System and its wireless components, which was completely separate and not connected in any way to the existing Invensys BAS. The EnTouch system provided the following capabilities needed to satisfy the data collection efforts of this endeavor: metering capabilities (to monitor several system performance metrics), data acquisition/collection and storage, and a method for off-loading data to the Contractor. Figure 5-12 shows a diagram of the system.

At the time of this project, the existing BAS was not connected to the installation-wide network. This project did not affect the network connection status of the existing BAS system; and the Contractor-provided EMS system did not access, share or communicate information with the existing 
BAS or any other Fort Detrick data systems. The EMS only communicated through the Contractor-provided cellular connection, which was solely maintained and managed by the Contractor. Since the proposed EMS will not be necessary or required for normal building operation, when the project is completed and all of the required data are recorded, the proposed EMS will be turned off, removed, and/or abandoned in place on project completion, as determined and directed by the Government.

\subsubsection{Data collection}

Remote monitoring and downloading of data (logs and trends) were achieved through a Global System for Mobile Communications (GSM) cellular connection via an internal device. The EnTouch One Energy Management System (Figure 5-12 and Table 5-6) had an on-board cellular phone connection that connected to EnTouch's data servers (the "Cloud") where the logger and sensor data were downloaded and collected into a personal computer (PC) spreadsheet program. This cellular communication process eliminated the requirement for traditional internet or land line telephone connections. The data were stored at the EnTouch (2017) website, uww.entouchgo.com. 


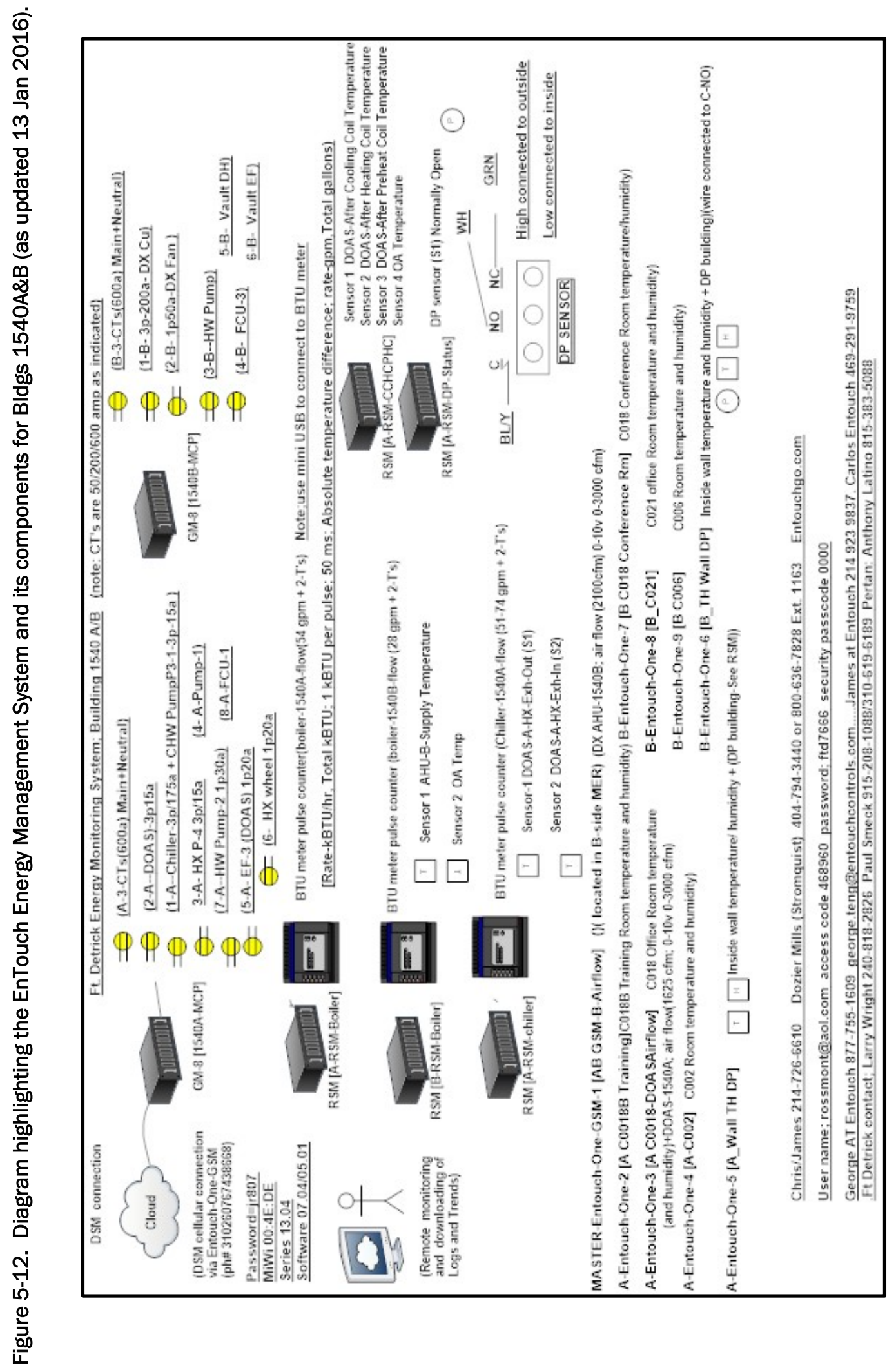


The EMS had individual points that monitored and collected data on the following metrics (which have been outlined in-depth below):

- Energy Consumption - Electrical (kWh) and Thermal (BTU, converted to $\mathrm{kWh}$ ).

- Electrical data points were monitored via current transformer (CT) clamps and voltage measurements inside the main and branch circuit panels in each electrical room.

- Thermal data points were monitored via BTU pulse meters (flow + temperatures) using supply and return water temperature sensors and a flow meter in the thermal distribution piping. This did not include domestic hot water supply.

- Outside Temperature and Humidity $\left({ }^{\circ} \mathrm{F}\right.$ and $\left.\% \mathrm{RH}\right)$.

- Points were monitored via temperature and humidity sensors.

- Interior Room Temperature and $\mathrm{RH}$ of three selected rooms ( ${ }^{\circ} \mathrm{F}$ and \% $\mathrm{RH})$.

- Points were monitored via temperature and humidity sensors.

- DP at two locations.

- These instruments measured the pressure difference (Pa) between the exterior ambient air pressure and the air pressure within the building. These data indicated whether the building pressurization was 'positive' or 'negative.' If the building interior pressure was less than the outside pressure, or 'negative,' untreated outdoor air would infiltrate into the conditioned spaces. If the building interior pressure was greater than the outside pressure, or 'positive', conditioned air would exfiltrate to the exterior. These data provided a better understanding of the additional ventilation air heating or cooling loads that the mechanical system had to accommodate, in addition to the plug loads and occupant loads.

Throughout the data-monitoring period, a monthly energy performance report used the $\mathrm{kWh}$ and BTU (converted to $\mathrm{kWh}$ ) data to establish the total energy use of the two buildings. These data were in turn used as a metric to compare the differences in energy use of the two HVAC systems. 
Table 5-6. Acronym list for the EnTouch Energy Management System diagram.

\begin{tabular}{|l|l|}
\hline Term & \multicolumn{1}{|c|}{ Definition } \\
\hline AHU & Air Handling Unit \\
\hline BTU & British Thermal Unit \\
\hline CHW & Chilled Water Supply \\
\hline CT & Current Transformer Sensor \\
\hline DH & Dehumidifier \\
\hline DOAS & Dedicated Outdoor Air System \\
\hline DP & Differential Pressure \\
\hline DX & Direct Expansion Air-Conditioning System \\
\hline EF & Exhaust Fan \\
\hline FCU & Fan Coil Unit \\
\hline HW & Hot Water \\
\hline HX & Heat Exchanger \\
\hline OA & Outside Air \\
\hline P & Pump \\
\hline
\end{tabular}

\subsubsection{Energy monitoring points, Bldg $1540 A$}

Appendix D to this report includes datasheets for instruments listed in this Section.

Demonstration facility Bldg 1540A was renovated with new mechanical equipment including an air-cooled chiller and chilled water pump, DOAS, radiant panels, and controls. Overall gas and electric consumption data were provided by utility company meters:

1. kWh (electric) [Note: The EMS system had individual points that tracked each of the following device data points. These points were monitored via CT clamps and voltage measurements inside the main and branch circuit panels in Electrical Room Coo9.]:

2. 1540A Main Total (total building power) This was the total $\mathrm{kWh}$ for the building that provided more granular datasets than a single monthly electric utility meter reading.

3. Chiller + CHW pump P-3.

4. CHW pump P-4.

5. HW Pump P-2.

6. Pump P-1.

7. DOAS unit fan. 
8. DOAS HX.

9. EF-3.

10. FCU-1.

11. BTU (thermal) [Note: Points were monitored via BTU pulse meters (flow + supply/return temperatures) in the piping. This did not include domestic hot water supply. The existing boiler and hot water pump in 1540A were retained. Chilled and hot water were in a closed system. See Section 2.2, "Description," for sensor layout and mechanical room layouts.]:

12. Chiller - included chilled water flow rate, supply and return water temperature sensors.

13. Boiler - included hot water flow rate, supply and return water temperature sensors.

14. Flow (airflow) [Note: This point was monitored via an airflow meter located in the supply ductwork of the DOAS unit.].

15. Temperature and Relative Humidity $\left({ }^{\circ} \mathrm{F}, \% \mathrm{RH}\right)$ [Note: Points were monitored via temperature and relative humidity sensors.]:

16. DOAS unit HX supply and return temperatures.

17. Inside wall temperature and relative humidity (near room CoO3) - building envelope sensor (a similar $\mathrm{T} / \mathrm{RH}$ measurement was taken inside the wall of 1540B).

18. Room temperature and $\mathrm{RH}$, Room CoO18 (office).

19. Room temperature and RH, Room Co18B (IA training).

20. Room temperature and $\mathrm{RH}$, Room $\mathrm{CoO} 2$ (office).

21. Pressure Differential (status):

22. Building DP alarm (located near room Coo3, alarmed if building pressurization went negative).

23. Ambient:

24. Outside temperature and humidity were per local weather data service (the EnTouch system uses local National Oceanic and Atmospheric Administration [NOAA] reported data)

\subsubsection{Energy monitoring system, Bldg 1540A}

The installation of the project's EMS within Bldg 1540A began in Nov 2014 and was substantially completed by Jan 2015. Figures 5-13 to 5-17 show some components of the installed EMS system. 
Figure 5-13. EMS panel with monitoring devices installed.

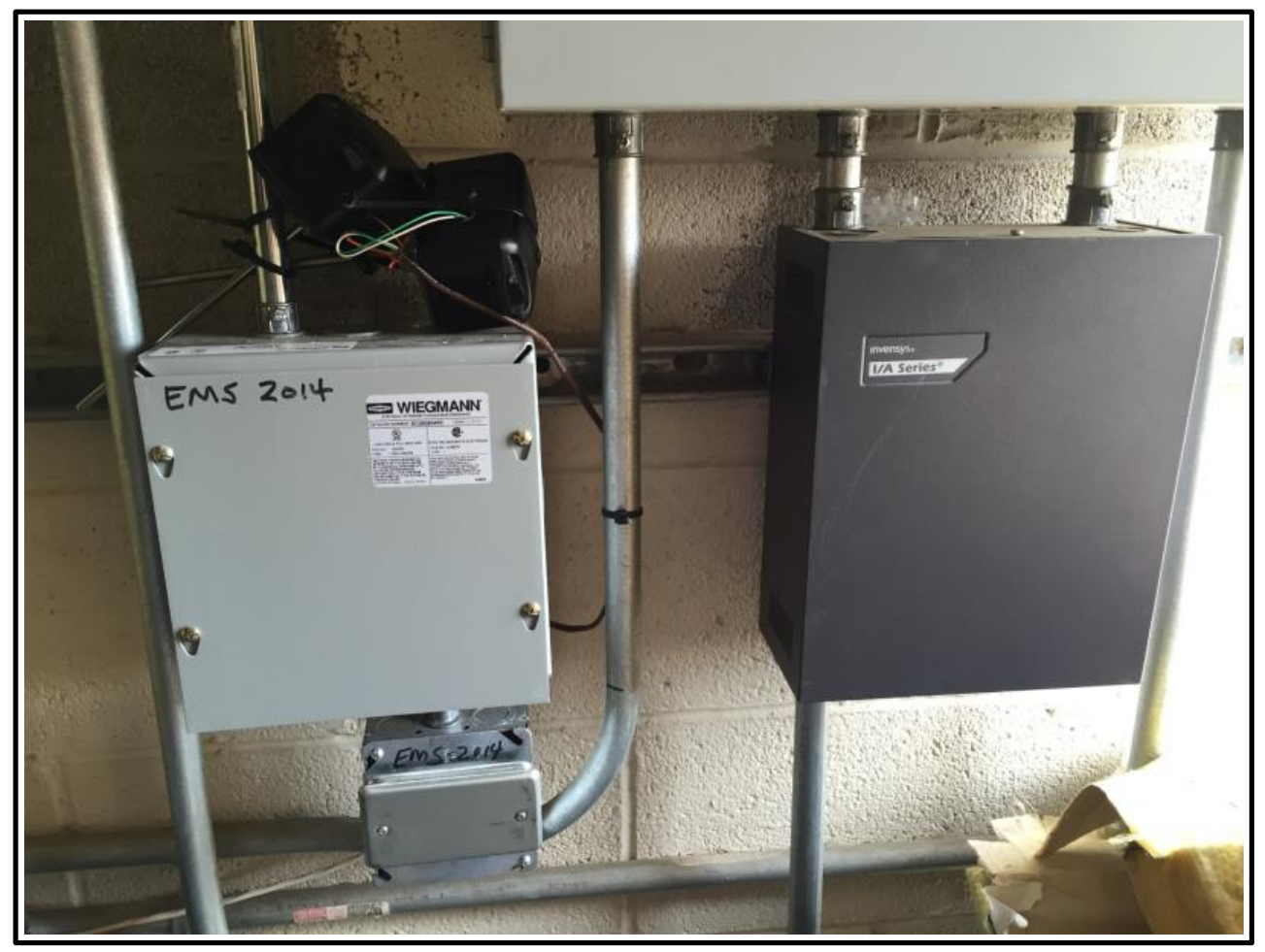

Figure 5-14. Boiler BTU meter connected to programming software.

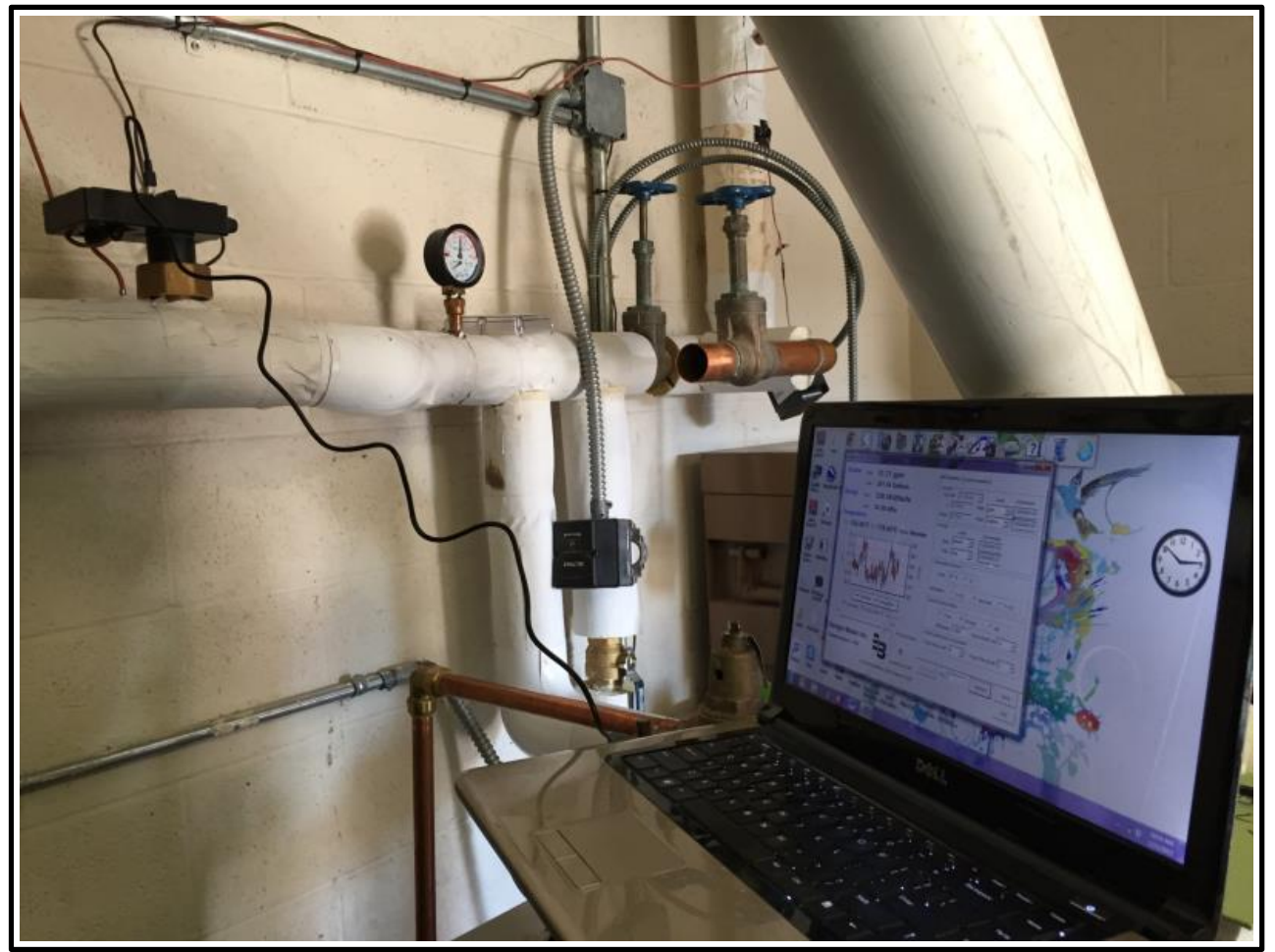


Figure 5-15. Boiler BTU meter as installed.

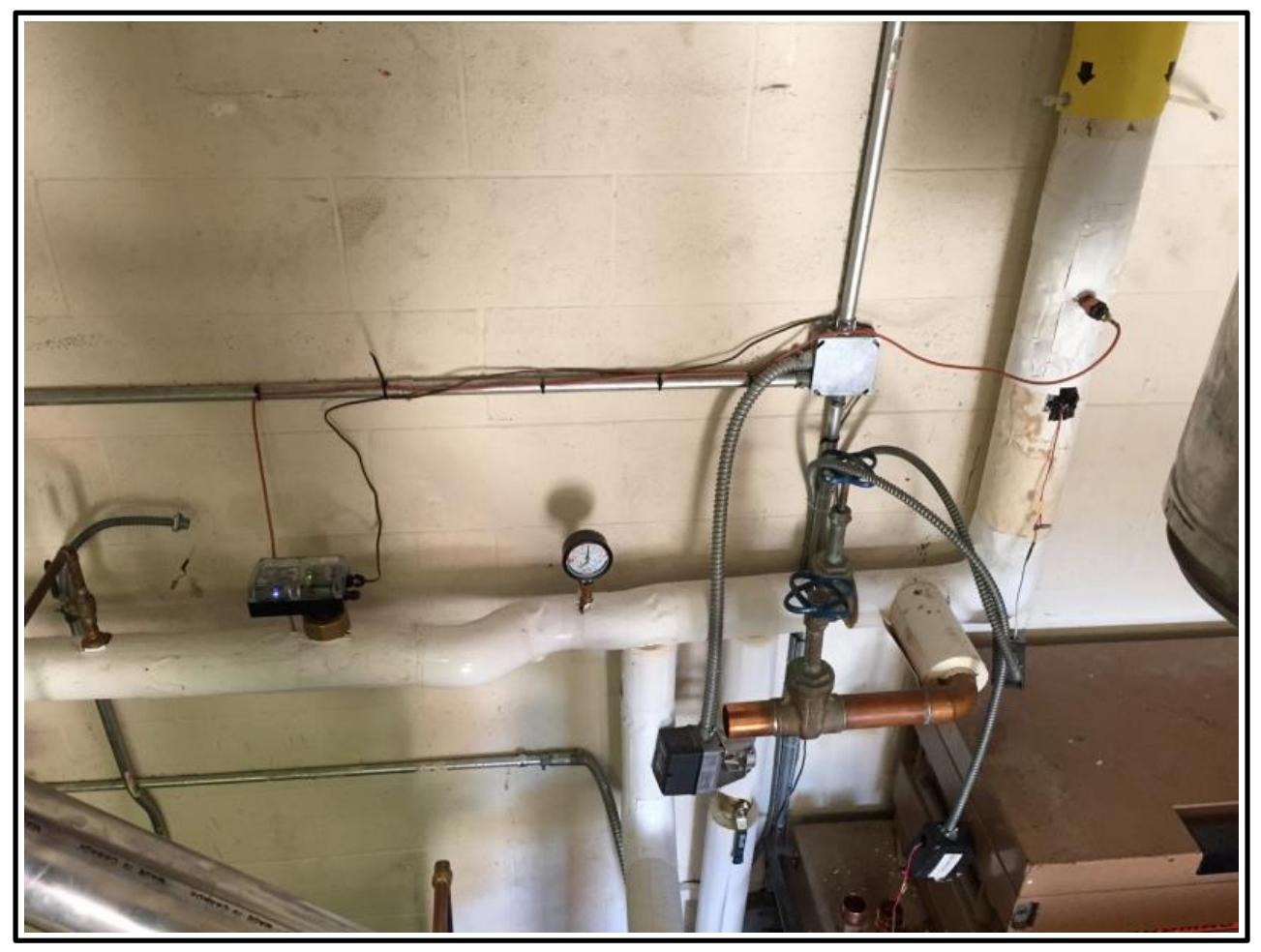

Figure 5-16. Building envelope DP sensor and wall temperature/RH sensors installed above office $\mathrm{C003.}$

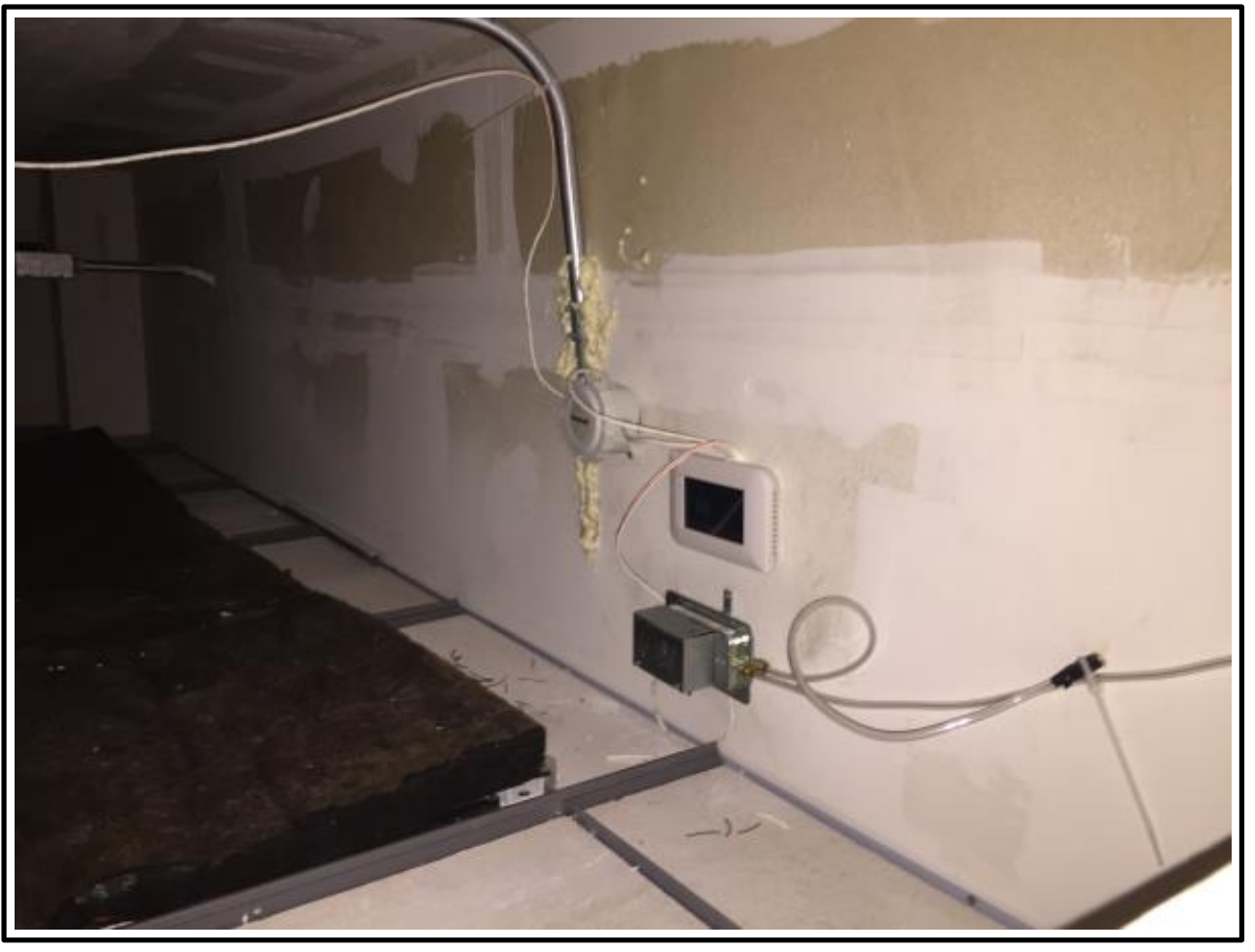


Figure 5-17. Building envelope DP sensor (high side inside room, low side outside building) and wall temperature/RH sensor installed above office $\mathrm{C0O3.}$

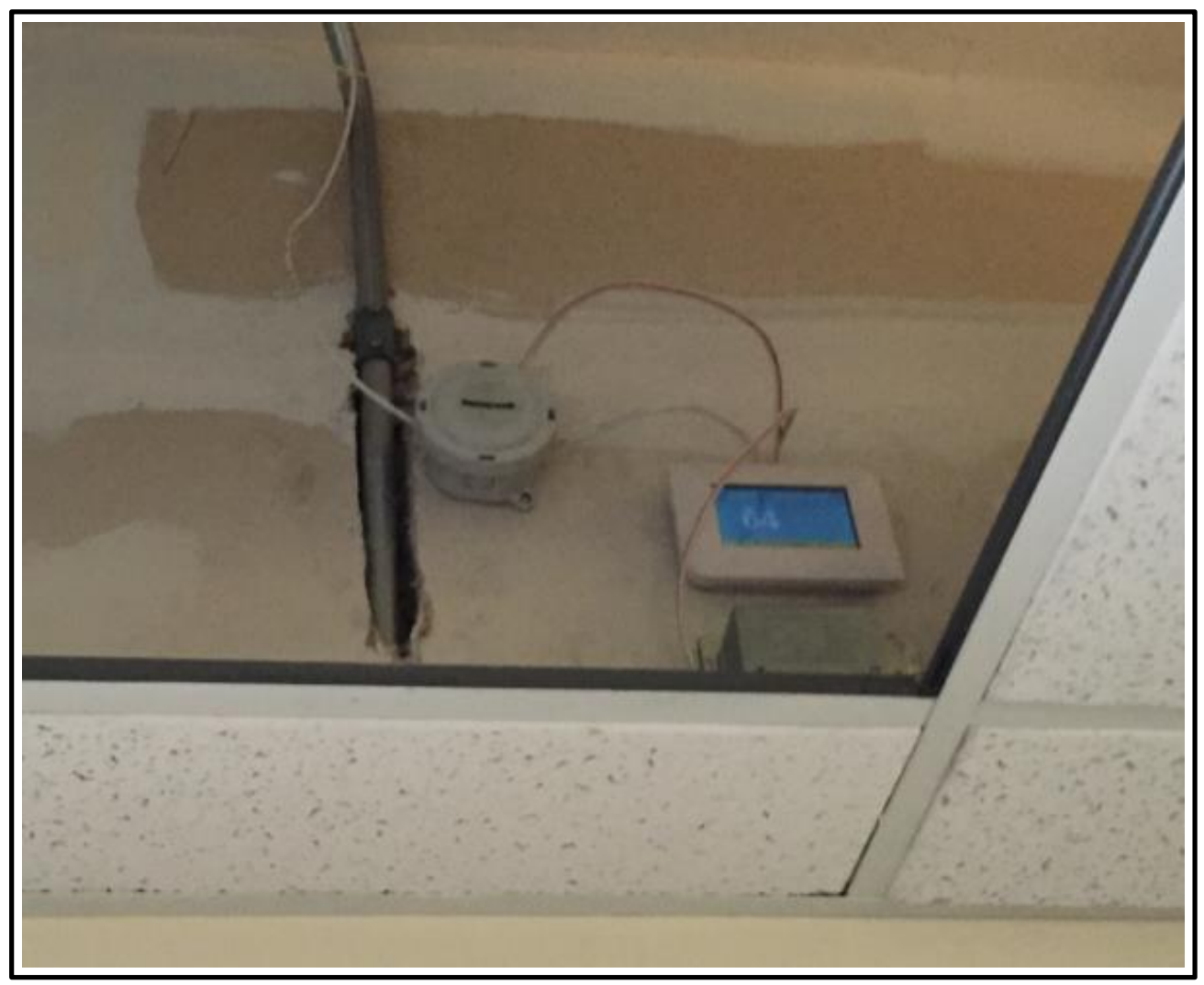

5.5.2.5 Energy monitoring points, Bldg 1540B

The existing mechanical systems in Bldg $1540 \mathrm{OB}$ were retained "as-is" and served as the project control. No new equipment or controls were added or modified. Overall gas and electric consumption data were provided by utility company meters.

1. kWh (electric) [Note: Points were monitored via CT clamps and voltage measurements inside the main and branch circuit panels in the electrical room.]:

2. Bldg $1540 \mathrm{OB}$ Main Total (total building power).

3. HW Pump.

4. DX AHU-4 fan.

5. DX AHU-4 condensing unit.

6. FCU-3.

7. Vault Dehumidifier / Exhaust Fan (different from the A-side).

8. BTU (thermal) [Note: Points were monitored via BTU pulse meters (flow + temperatures) in the hot water piping.]: 
9. Boiler - included common hot water flow, supply and return water temperature sensors.

10. Flow (airflow) [Note: Point was monitored via an airflow meter located in the supply ductwork of AHU-4.].

11. Temperature and Relative Humidity $\left({ }^{\circ} \mathbf{F}, \% \mathbf{R H}\right)$ [Note: Points were monitored via temperature and humidity sensors.]:

12. AHU-4 supply air temperature.

13. Outside air temperature (the outdoor air temperature measured at the site generally tracked the outdoor air temperature recorded by NOAA at the Frederick Municipal Airport, although there were some differences due to the distance between the project site and the airport).

14. Inside wall temperature and $\mathrm{RH}$ (near room Coo6) - building envelope sensor.

15. Room temperature and RH, Room Coo6 (office).

16. Room temperature and $\mathrm{RH}, \mathrm{Room} \mathrm{CoO} 18$ (conference).

17. Room temperature and RH, Room Co21 (office).

18. Differential Pressure (status):

19. Differential pressure alarm (alarm on negative pressurization) for the building (near room Coo6).

20.Ambient Temperature and RH:

21. Outside temperature and humidity per local weather data service.

\subsubsection{Energy monitoring system, Bldg $1540 B$}

The installation of the project's EMS within Bldg 1540B began Nov 2014, and was substantially completed by Jan 2015. Figures 5-18 to 5-24 show some components of the EMS installation. 
Figure 5-18. EMS master monitoring device with Global System for Mobile Communications (GSM) communication device.

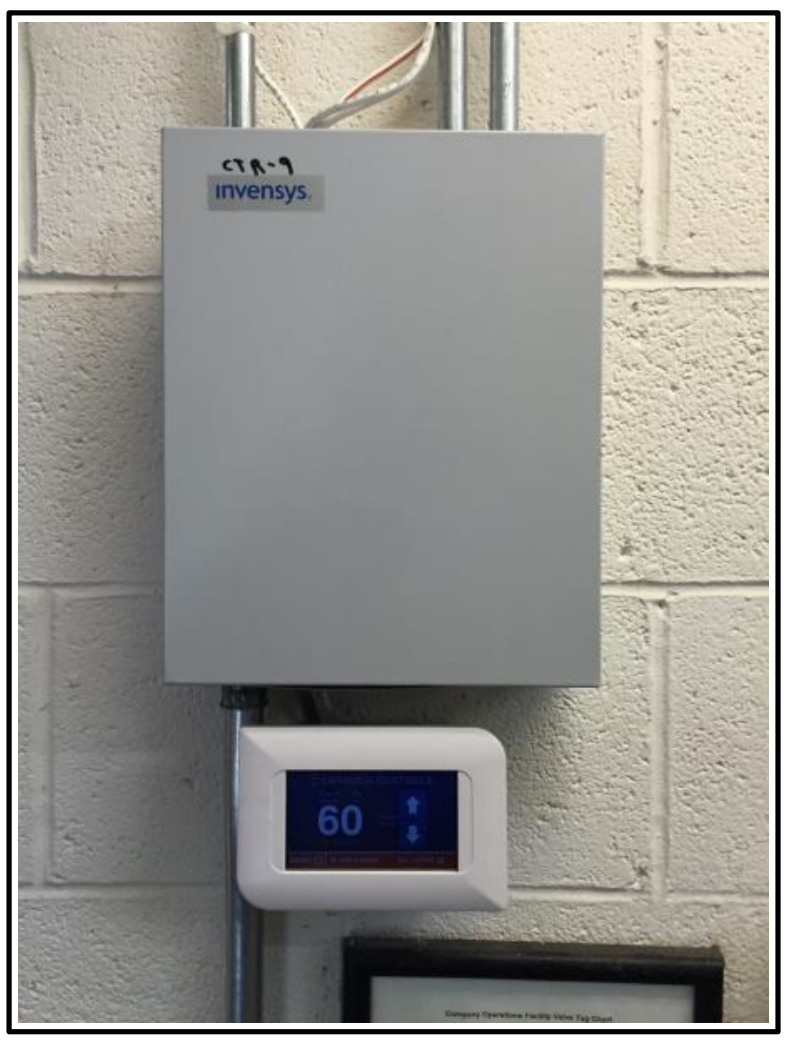

Figure 5-19. EMS Controller.

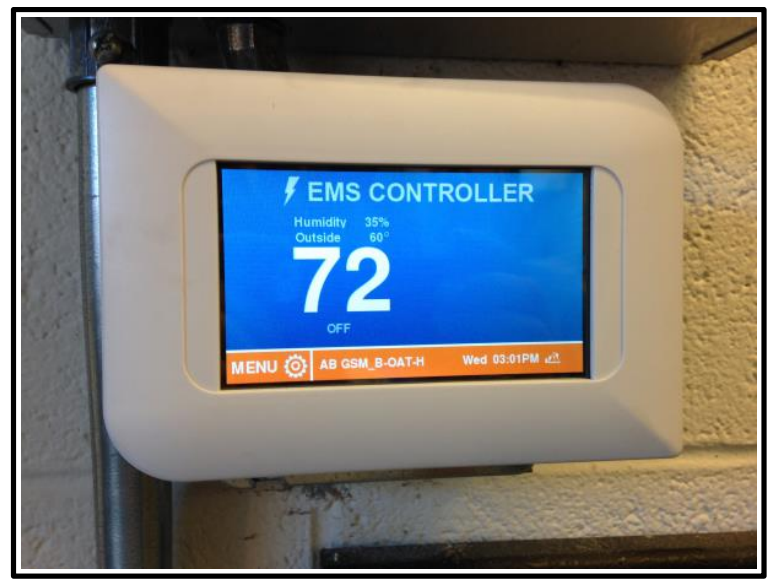


Figure 5-20. EMS installation within the BIdg 1540B mechanical room, showing EMS controller and outside air (OA) temperature sensor.

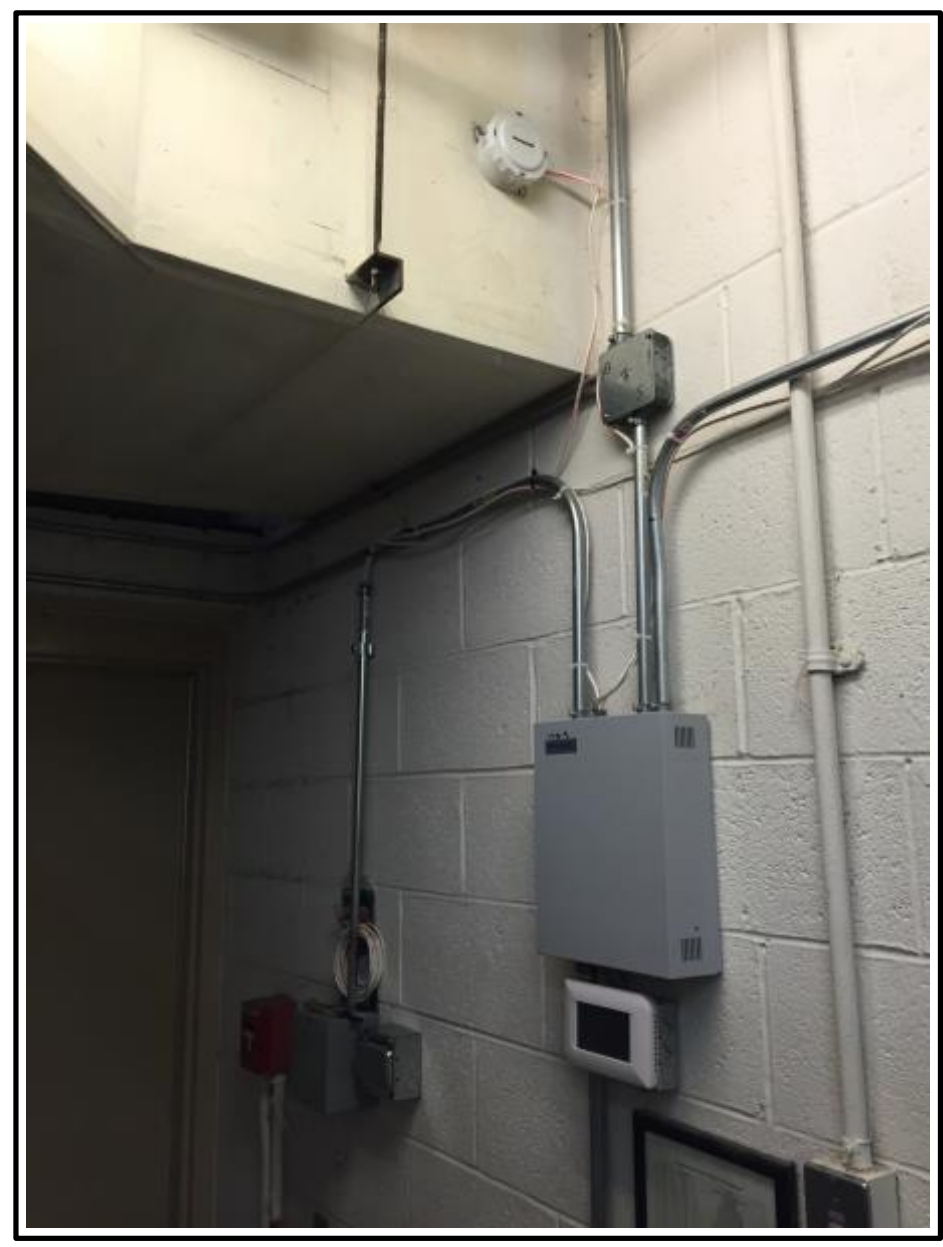

Figure 5-21. Air flow sensor located in AHU-4 supply air.

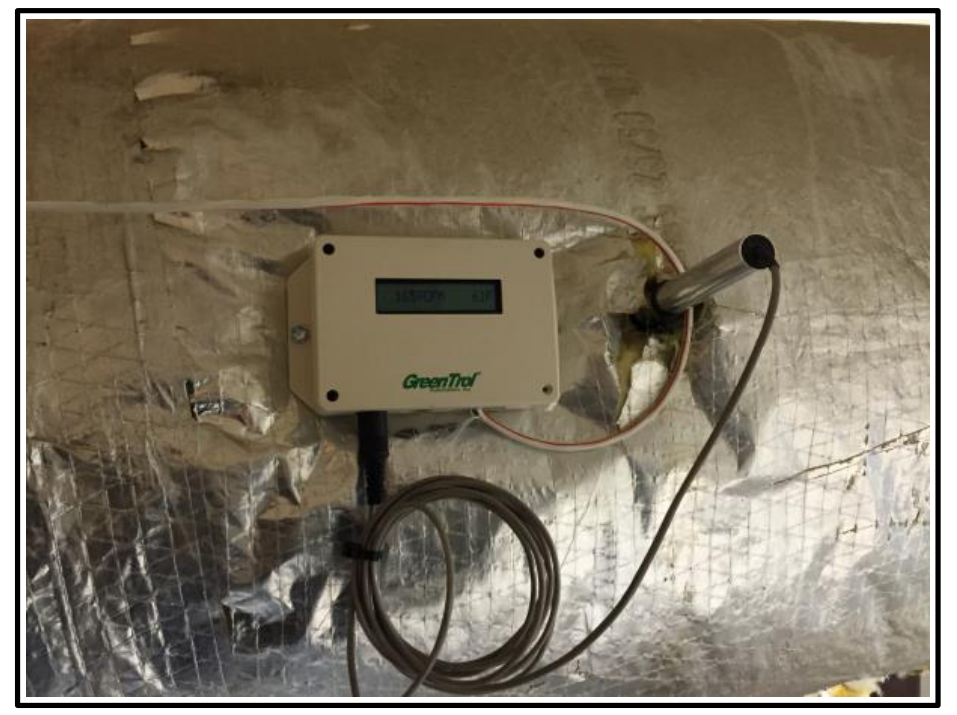


Figure 5-22. Outside air temperature sensor.

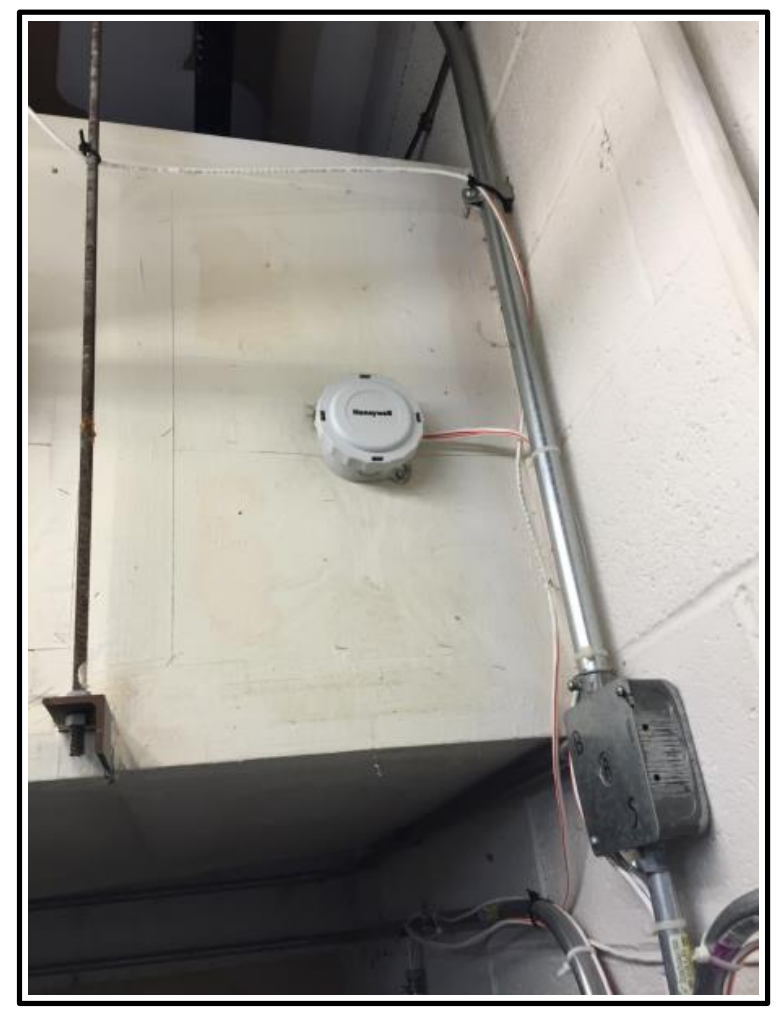

Figure 5-23. Supply air temperature AHU-4 duct sensor.

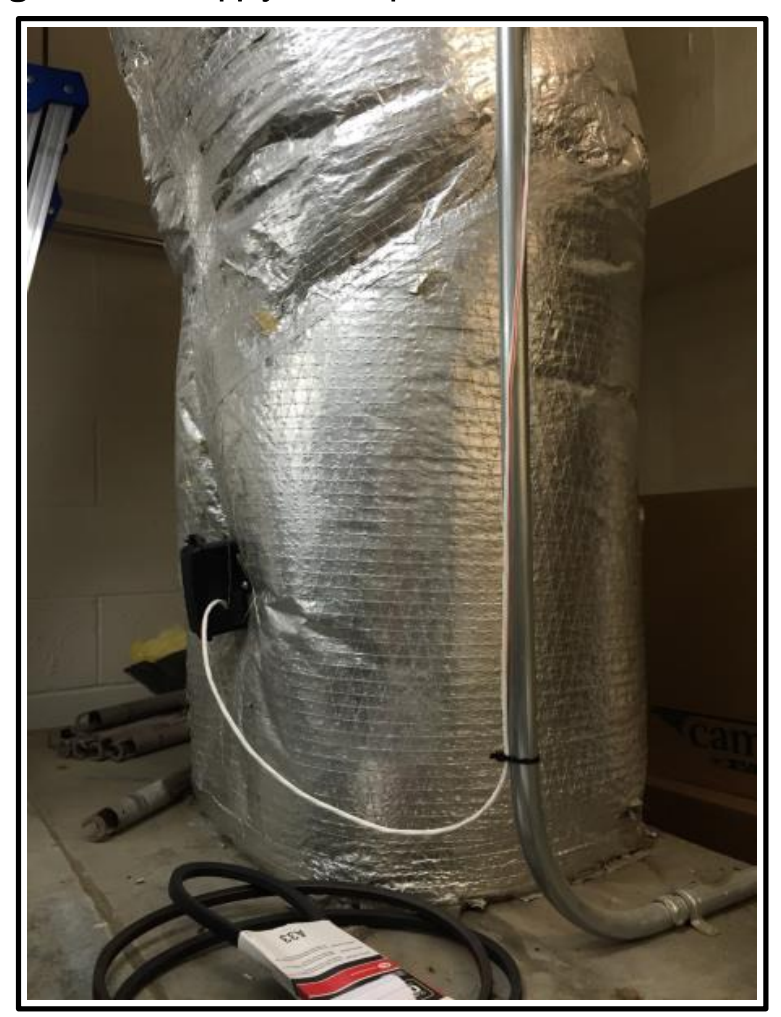


Figure 5-24. BTU meter located on Bldg 1540B boiler.

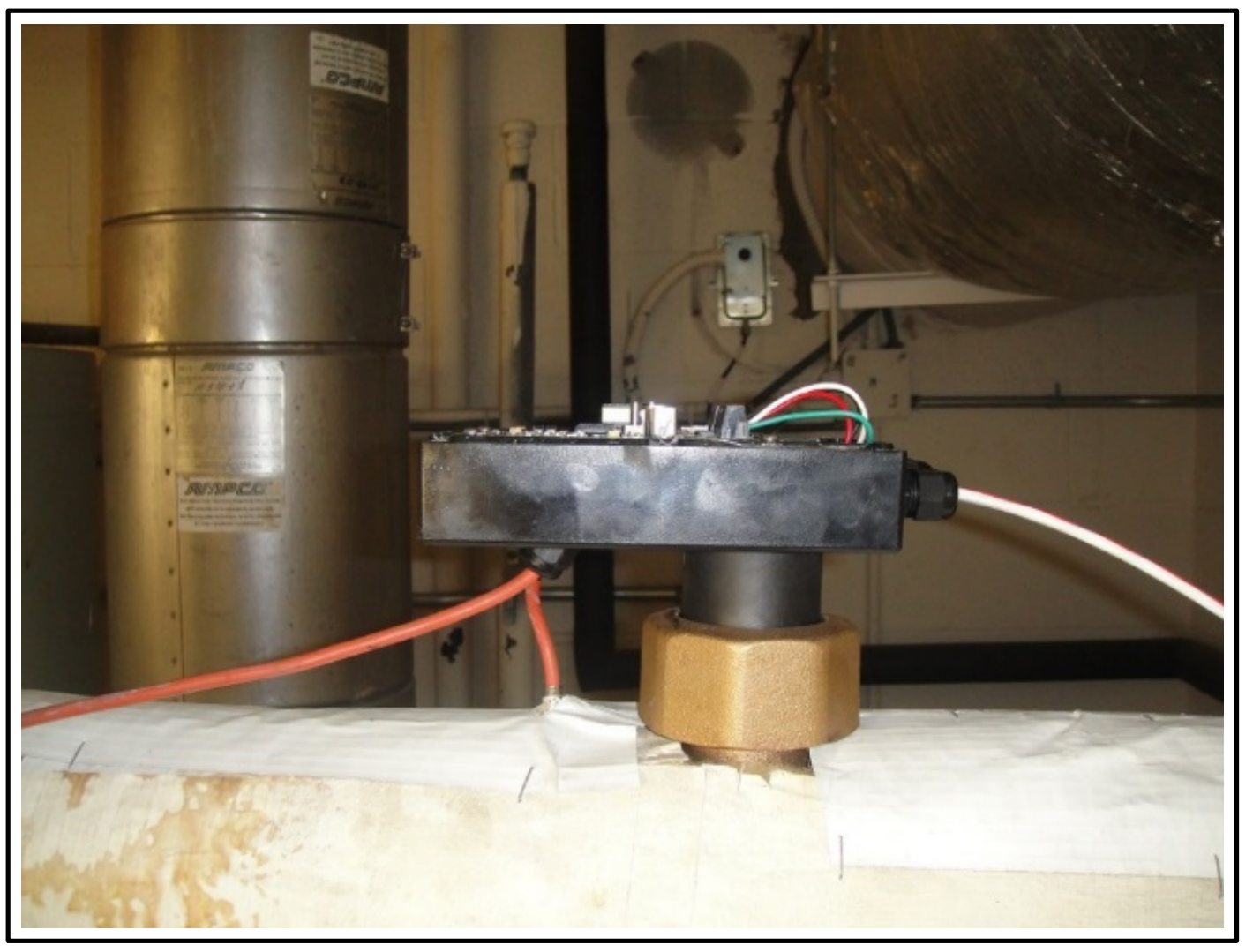

\subsubsection{General note}

For both buildings, electrical sub-meters were not installed on boilers, FCU's, Unit Heaters (UHs), CUH's, EF's, and packaged terminal air conditioners (PTACs). Gas flow monitoring was not included and domestic hot water heating monitoring points were not included.

\subsubsection{Sensor layout}

Figures 5-25 and 5-26 display the sensor layouts for Bldgs 1540A\&B, respectively. 
Figure 5-25. Sensor layout in Bldg 1540A.

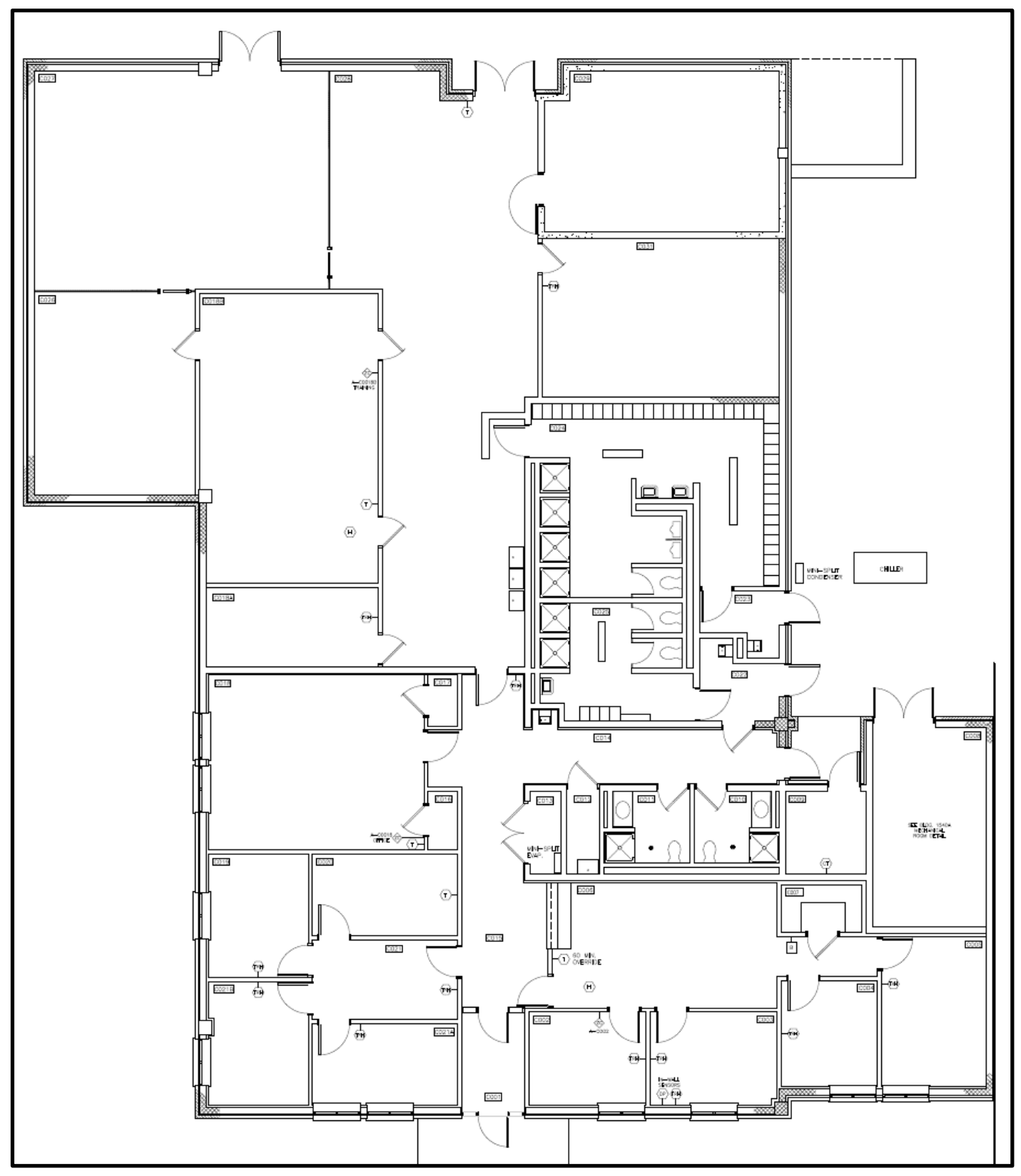


Figure 5-26. Sensor layout in Bldg 1540B.

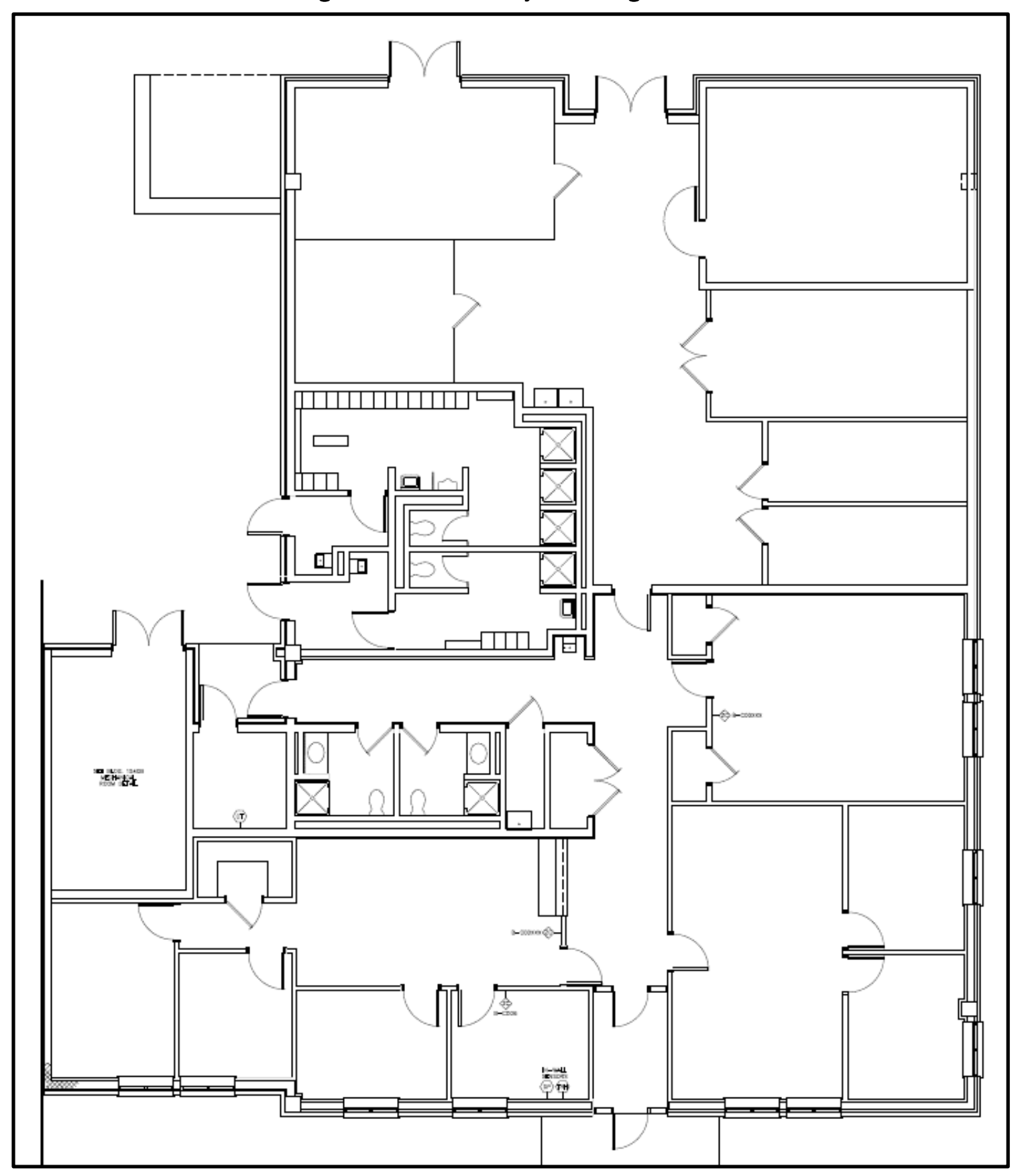




\subsection{Sampling results}

Table 5-7 provides an overview of the data sampling, recording, and storage protocol for this demonstration. Chapter 6, "Performance Assessment," and its subsections provide data on the parameters detailed in Table 5-7 (excluding costs). Chapter 7, "Cost Assessment," and its subsections provide cost-related data.

Table 5-7. Data sampling, recording and storage protocol.

\begin{tabular}{|l|l|l|l|c|c|}
\hline Parameters & Data Collector & Data Recording & $\begin{array}{l}\text { Data Storage } \\
\text { and Backup }\end{array}$ & $\begin{array}{c}\text { Data } \\
\text { Collection } \\
\text { Diagram }\end{array}$ & $\begin{array}{c}\text { Non- } \\
\text { Standard } \\
\text { Data }\end{array}$ \\
\hline $\begin{array}{l}\text { Building air } \\
\text { tightness testing }\end{array}$ & $\begin{array}{l}\text { Building envelope } \\
\text { air tightness } \\
\text { testing Contractor }\end{array}$ & $\begin{array}{l}\text { Automatic data } \\
\text { recording by test } \\
\text { apparatus }\end{array}$ & $\begin{array}{l}\text { Data stored in } \\
\text { test instrument }\end{array}$ & NA & NA \\
\hline Temperature & Demo Contractor & Temp loggers & $\begin{array}{l}\text { Remote data } \\
\text { access }\end{array}$ & NA & NA \\
\hline Relative humidity & Demo Contractor & RH loggers & $\begin{array}{l}\text { Remote data } \\
\text { access }\end{array}$ & NA & NA \\
\hline Gas consumption & DPW personnel & Manual recording & $\begin{array}{l}\text { Paper } \\
\text { and/electronic } \\
\text { records }\end{array}$ & NA & NA \\
\hline $\begin{array}{l}\text { Electrical } \\
\text { consumption }\end{array}$ & DPW personnel & Manual recording & $\begin{array}{l}\text { Paper } \\
\text { and/electronic } \\
\text { records }\end{array}$ & NA & NA \\
\hline First costs & Demo Contractor & Invoices & $\begin{array}{l}\text { Paper } \\
\text { and/electronic } \\
\text { records }\end{array}$ & NA & NA \\
\hline $\begin{array}{l}\text { O\&M costs } \\
\text { satisfaction }\end{array}$ & DPW personnel & Work orders & $\begin{array}{l}\text { Paper } \\
\text { and/electronic } \\
\text { records }\end{array}$ & NA & NA \\
\hline
\end{tabular}

\subsection{Equipment calibration and data quality issues}

\section{- Equipment Calibration:}

- Blower door apparatus (for testing building envelope air tightness) - to be calibrated by the building envelope air tightness testing Contractor.

- Temperature and RH instruments - factory calibrated.

- Gas meters - factory calibrated.

- Electric meters - factory calibrated. (Installed sensors had their factory calibration checked at the time of installation.) 
- Quality Assurance Sampling: Temperature and RH data were transmitted in real time to the Contractor's office where it could be reviewed and inspected as frequently as necessary to ensure that all sensors were functioning properly and transmitting plausible data. Gas and electric meter data were checked on a monthly basis to ensure that the meters were functioning correctly.

- Post-Processing Statistical Analysis: Datasets were inspected to determine the quality of the collected data. Any missing data points were filled in by interpolation with surrounding data points, if reasonable. When numerous data points appeared to be missing, it was not appropriate or feasible to fill in these points. In such cases, it was necessary to flag such time periods for special consideration.

Occasional outlier points were considered to be anomalous and were adjusted to conform to the preceding and succeeding data. Extended series of outliers were an indication of unexpected conditions in the sensed environment. Such situations warranted investigation to determine the cause of the anomaly and, if necessary, to take actions to correct it or otherwise account for it. 


\section{Performance Assessment}

This chapter summarizes the data analysis process the investigators used for each performance objective. Section 6.8, "Performance Review" presents and reviews the collected data.

\subsection{Baseline performance}

A major objective of this project was to compare the baseline (pre-retrofit) energy performance of Bldg $1540 \mathrm{OA}$ to its post-retrofit performance and to baseline facility Bldg 1540B. We requested access to Fort Detrick DPW's utility records and received the following data for Bldg 1540 for FY2O13.

Table 6-1. FY2013 utilities data for Bldg 1540 from Fort Detrick's DPW.

\begin{tabular}{|c|c|c|c|c|c|c|}
\hline \multirow[b]{2}{*}{ Date } & \multicolumn{3}{|c|}{ Bldg 1540A } & \multicolumn{3}{|c|}{ Bldg 1540B } \\
\hline & Elec (kWh) & Gas (therm) & Gas (kWh) & Elec (kWh) & Gas (therm) & Gas (kWh) \\
\hline Oct-12 & 6790.1 & 655.9 & 19,223 & 9316.7 & 530.4 & 15,544 \\
\hline Nov-12 & 4460.4 & 727.9 & 21,333 & 6174 & 679 & 19,900 \\
\hline Dec-12 & 3719.7 & 871.1 & 25,529 & 5205 & 784.6 & 22,994 \\
\hline Jan-13 & 4463.6 & 828.6 & 24,284 & 5980 & 779.2 & 22,836 \\
\hline Feb-13 & 4948 & 796.8 & 23,352 & 6956 & 536.6 & 15,726 \\
\hline Mar-13 & 3744 & 757.4 & 22,197 & 5090 & 332.9 & 9,756 \\
\hline Apr-13 & 6742 & 684.8 & 20,070 & 8532 & 460.2 & 13,487 \\
\hline May-13 & 8704 & 457 & 13,393 & 9201 & 430.4 & 12,614 \\
\hline Jun-13 & 15269 & 287.6 & 8,429 & 13313 & 235.1 & 6,890 \\
\hline Jul-13 & 7203 & & 0 & 7313 & & 0 \\
\hline Aug-13 & 0 & 231.3 & 6,779 & 0 & 22.9 & 671 \\
\hline Sep-13 & 0 & & 0 & 0 & & 0 \\
\hline TOTALS & 66,044 & 6,298 & 184,588 & 77,081 & 4,791 & 140,419 \\
\hline TOTALS & \multicolumn{3}{|l|}{$250,632 \mathrm{kWh}$} & \multicolumn{3}{|l|}{$217,500 \mathrm{kWh}$} \\
\hline EUI & \multicolumn{3}{|c|}{$32.9 \mathrm{kWh} / \mathrm{ft}^{2}$ (based on $7,618 \mathrm{ft}^{2}$ ) } & \multicolumn{3}{|c|}{$38.9 \mathrm{kWh} / \mathrm{ft}^{2}\left(\right.$ based on $\left.5,590 \mathrm{ft}^{2}\right)$} \\
\hline
\end{tabular}


Based on total building areas of 7,618 $\mathrm{ft}^{2}$ (Bldg 1540A) and 5,590 $\mathrm{ft}^{2}$ (Bldg $1540 B$ ), the calculated Energy Use Intensity (EUI) was $32.9 \mathrm{kWh} / \mathrm{ft}^{2}$ for Bldg $1540 \mathrm{OA}$ and $38.9 \mathrm{kWh} / \mathrm{ft}^{2}$ for Bldg $1540 \mathrm{~B}$. Note that there are gaps in the data for both buildings for the months of July, August and September. We are not sure how to address these gaps.

We also hoped to collect several months of operational data in the pre-retrofitted Bldg 1540A while it was occupied under normal operations. Although the Contractor submitted their proposed Energy Monitoring plan on 15 Apr 2014, their proposed system was not approved by the Fort Detrick NEC until 10 Jul 2014. Meanwhile, the Bldg 1540A occupants had vacated the building in early July 2014.

After getting NEC approval, the Energy Monitoring System was ordered, installed and operational by early Sep 2014. As a result, we were unable to collect any pre-retrofit, occupied performance data in Bldg 1540A using our installed Energy Monitoring System as we had hoped. In the end, we used the Energy Monitoring System to collect 24 consecutive months of data for both Bldg $1540 \mathrm{OA}$ and $1540 \mathrm{OB}$. We used this data to compare the first 12 months of Bldg 1540A energy performance data to the first 12 months of Bldg $1540 \mathrm{OB}$ energy performance data and to the second 12 months of Bldg 1540A energy performance data. We also compared the first 12 months and the second 12 months of energy performance data for Bldg 1540B. The second 12 months of Bldg $1540 \mathrm{OB}$ data are significant in that we completed repairing and recommissioning Bldg 1540B's mechanical systems just before the start of this second 12-month data collection period.

During the first 9 months of our energy performance data collection, Bldg $1540 \mathrm{~A}$ underwent a variety of phases related to the renovation process. Tables 6-2 to 6-4 list the electricity and gas utility usage for Bldgs 1540A\&B during this first 12-month period (Sep 2014 thru Aug 2015). The Bldg 1540A phases were: (1) an unoccupied, pre-retrofit period (highlighted in pink), (2) an unoccupied retrofit period (highlighted in yellow), and (3) a reoccupied post-retrofit period (highlighted in blue). Section 6.8, "Performance Review," includes comparisons of, and interpretations drawn from this data. 
Table 6-2. Energy related baseline parameters for Bldgs 1540A\&B.

\begin{tabular}{|l|c|c|c|c|}
\hline Building & $\begin{array}{l}\text { Preliminary Envelope } \\
\text { Air Leakage }\end{array}$ & $\begin{array}{l}\text { Electricity Usage } \\
\text { Sep 2014 thru Aug } \\
\mathbf{2 0 1 5}\end{array}$ & $\begin{array}{l}\text { Gas Usage } \\
\text { Sep 2014 thru Aug } \\
\mathbf{2 0 1 5}\end{array}$ & $\begin{array}{l}\text { Total Energy Usage } \\
\text { Sep 2014 thru Aug } \\
\mathbf{2 0 1 5}\end{array}$ \\
\hline $1540 \mathrm{~A}$ & $0.82 \mathrm{CFM} 75 / \mathrm{ft}^{2}$ & $97,210 \mathrm{kWh}$ & 5,121 Therms & $247,292 \mathrm{kWh}$ \\
\hline $1540 \mathrm{~B}$ & $1.12 \mathrm{CFM} 75 / \mathrm{ft}^{2}$ & $51,822 \mathrm{kWh}$ & 6,068 Therms & $229,658 \mathrm{kWh}$ \\
\hline
\end{tabular}

Table 6-3. First 12-month energy performance monitoring period for Bldgs 1540A\&B (Sep 2014 thru Aug 2015).

\begin{tabular}{|c|c|c|c|c|c|c|}
\hline \multirow[b]{2}{*}{ Month } & \multicolumn{3}{|c|}{ Bldg 1540A } & \multicolumn{3}{|c|}{ Bldg 1540B } \\
\hline & $\begin{array}{l}\text { Electric } \\
(\mathrm{kWh})\end{array}$ & $\begin{array}{c}\text { Gas } \\
\text { (therms) }\end{array}$ & $\begin{array}{l}\text { Gas } \\
(\mathrm{kWh})\end{array}$ & $\begin{array}{c}\text { Electric } \\
\text { (kWh) }\end{array}$ & $\begin{array}{c}\text { Gas } \\
\text { (therms) }\end{array}$ & $\begin{array}{l}\text { Gas } \\
(\mathrm{kWh})\end{array}$ \\
\hline Sep 2014 & 7,893 & 248 & 7,268 & 4,332 & 432 & 12,661 \\
\hline Oct 2014 & 4,980 & 403 & 11,811 & 6,317 & 373 & 10,932 \\
\hline Nov 2014 & 4,980 & 816 & 23,915 & 6,071 & 710 & 20,808 \\
\hline Dec 2014 & 8,506 & 957 & 28,047 & 6,366 & 754 & 22,098 \\
\hline Jan 2015 & 10,010 & 894 & 26,201 & 6,679 & 792 & 23,211 \\
\hline Feb 2015 & 9,177 & 881 & 25,820 & 6,152 & 957 & 28,047 \\
\hline Mar 2015 & 20,165 & 447 & 13,100 & 677 & 606 & 17,760 \\
\hline Apr 2015 & 358 & 104 & 3,048 & 45 & 495 & 14,507 \\
\hline May 2015 & 1,263 & 82 & 2,403 & 5,779 & 423 & 12,397 \\
\hline Jun 2015 & 12,010 & 115 & 3,370 & 2,234 & 259 & 7,591 \\
\hline Jul 2015 & 10,083 & 83 & 2,432 & 3,374 & 133 & 3,898 \\
\hline Aug 2015 & 7,785 & 91 & 2,667 & 3,796 & 133 & 3,898 \\
\hline Total & 97,210 & 5,121 & 150,082 & 51,822 & 6,068 & 177,806 \\
\hline Totals & \multicolumn{3}{|c|}{$247,292 \mathrm{kWh}$} & \multicolumn{3}{|c|}{$229,628 \mathrm{kWh}$} \\
\hline EUI & \multicolumn{3}{|c|}{$32.5 \mathrm{kWh} / \mathrm{ft}^{2}\left(\right.$ based on $\left.7,618 \mathrm{ft}^{2}\right)$} & \multicolumn{3}{|c|}{$41.8 \mathrm{kWh} / \mathrm{ft}^{2}\left(\right.$ based on $\left.5,590 \mathrm{ft}^{2}\right)$} \\
\hline Color Key & \multicolumn{2}{|c|}{$\begin{array}{l}\text { Pre-Retrofit Period } \\
\text { (unoccupied) }\end{array}$} & \multicolumn{2}{|c|}{ Retrofit Period (unoccupied) } & \multicolumn{2}{|c|}{$\begin{array}{l}\text { Post-Retrofit Period } \\
\text { (reoccupied) }\end{array}$} \\
\hline
\end{tabular}

Note that Bldg 1540 B was continuously occupied throughout the duration of this project. Also, the first 12 months of data were collected prior to completing mechanical system repairs and recommissioning of Bldg $1540 \mathrm{OB}$. 
Table 6-4. Second 12-month energy performance monitoring period for Bldgs 1540A\&B (post retrofit, occupied, Sep 2015 thru Aug 2016).

\begin{tabular}{|c|c|c|c|c|c|c|}
\hline & \multicolumn{3}{|c|}{ Bldg 1540A } & \multicolumn{3}{|c|}{ Bldg 1540 B } \\
\hline Month & $\begin{array}{c}\text { Electric } \\
\text { (kWh) }\end{array}$ & $\begin{array}{c}\text { Gas } \\
\text { (therms) }\end{array}$ & $\begin{array}{c}\text { Gas } \\
(\mathrm{kWh})\end{array}$ & $\begin{array}{l}\text { Electric } \\
\text { (kWh) }\end{array}$ & $\begin{array}{c}\text { Gas } \\
\text { (therms) }\end{array}$ & $\begin{array}{l}\text { Gas } \\
(\mathrm{kWh})\end{array}$ \\
\hline Sep 2015 & 8,087 & 49 & 1,436 & 5,359 & 139 & 4,074 \\
\hline Oct 2015 & 6,203 & 166 & 4,865 & 4,449 & 323 & 9,466 \\
\hline Nov 2015 & 5,711 & 231 & 6,770 & 4,096 & 411 & 12,045 \\
\hline Dec 2015 & 5,370 & 251 & 7,356 & 4,540 & 485 & 14,214 \\
\hline Jan 2016 & 5,163 & 529 & 15,503 & 4,853 & 771 & 22,596 \\
\hline Feb 2016 & 4,665 & 425 & 12,456 & 4,621 & 697 & 20,427 \\
\hline Mar 2016 & 4,664 & 228 & 6,682 & 4,929 & 445 & 13,042 \\
\hline Apr 2016 & 5,233 & 158 & 4,631 & 4,665 & 281 & 8,235 \\
\hline May 2016 & 6,326 & 100 & 2,931 & 4,296 & 225 & 6,594 \\
\hline Jun 2016 & 8,086 & 32 & 938 & 4,830 & 43 & 1,260 \\
\hline Jul 2016 & 8,719 & 29 & 850 & 5,990 & 10 & 293 \\
\hline Aug 2016 & 9,809 & 31 & 909 & 6,235 & 12 & 352 \\
\hline TOTALS & 78,036 & 2,228 & 65,326 & 58,864 & 3,842 & 112,598 \\
\hline TOTALS & \multicolumn{3}{|c|}{$143,362 \mathrm{kWh}$} & \multicolumn{3}{|c|}{$171,462 \mathrm{kWh}$} \\
\hline EUI & \multicolumn{3}{|c|}{$18.8 \mathrm{kWh} / \mathrm{ft}^{2}\left(\right.$ based on $\left.7,618 \mathrm{ft}^{2}\right)$} & \multicolumn{3}{|c|}{$30.67 \mathrm{kWh} / \mathrm{ft}^{2}\left(\right.$ based on $\left.5,590 \mathrm{ft}^{2}\right)$} \\
\hline
\end{tabular}

The second 12 months of data (above) were collected after completing mechanical system repairs and recommissioning of Bldg $1540 \mathrm{OB}$.

One Action Item raised by ESTCP's Technical Review Panel was to quantify and discuss the impact of solar heat gains on the different sides of the building. The centerline of the wall dividing Bldgs 1540A\&B was oriented along a nearly northwest-southeast axis as shown in Figure 6-1. As oriented, Bldg $1540 \mathrm{~A}$ and $1540 \mathrm{~B}$ had equal roof and wall surface areas facing northwest, Bldg 1540A had significantly more roof and wall surface area facing northeast and southeast than Bldg $154 \mathrm{OB}$ and it had slightly less roof and wall surface area facing southwest than Bldg $1540 \mathrm{OB}$. With respect to solar heat gain, southwest facing surface areas would be the most significant, followed by southeast facing surface areas. In Figure 6-1 one can see 
also that the southwest side of Bldg $1540 \mathrm{~B}$ appears to be shaded by a number of mature trees while the southwest side of Bldg $1540 \mathrm{~A}$ faces a paved open courtyard.

Considering these differing relative surface areas and differing orientations, combined with significant shading of the southwest facing walls of Bldg $154 \mathrm{OB}$, it is very difficult to estimate the impact of the building's orientation on the relative energy usage of the demonstration side and the baseline side of the building. We do not believe that relative energy usage was significantly affected by building orientation, but the only way to arrive at a credible estimate of the effect on the relative energy usage would be to model the building, preferably using an hour-by-hour modeling tool such as EnergyPlus $^{\mathrm{TM}}$. No such modeling was conducted as part of this project.

Figure 6-1. Satellite view of BIdgs 1540A\&B (maps.google.com).

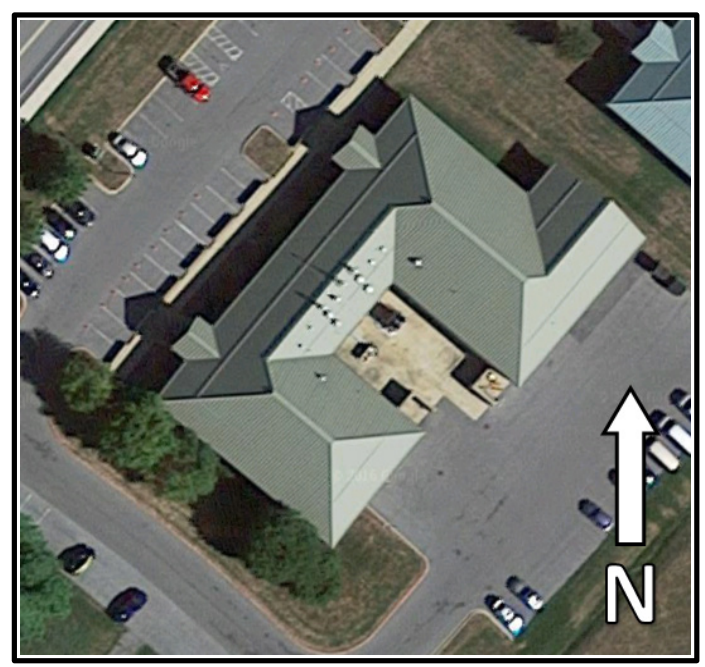

\subsection{Reduced building envelope air leakage}

- Performance Objective Analysis Overview: Building envelope air leakage was performed in accordance with the U.S. Army Corps of Engineers Air Leakage Test Protocol for Building Envelopes (HQUSACE 2012b), which was based on ASTM E779 Standard Test Method for Determining Air Leakage Rate by Fan Pressurization (ASTM 2003a).

- Statistical Methodologies: The methodology uses an unweighted $\log$-linearized linear regression technique, where $Q$ is the airflow rate, in $\mathrm{m} 3 / \mathrm{s}(\mathrm{ft} 3 / \mathrm{min})$, and $d P$ is the differential pressure in Pa. In determining the fit to a prescribed equation, the confidence intervals of the derived air leakage coefficient $C$ and pressure exponent $\mathrm{n}$ are calculated 
according to a procedure defined by this Standard. $C$ and $n$ are calculated separately for pressurization and depressurization. If the pressure exponent is less than 0.5 or greater than 1 , then the test is invalid and must be repeated.

- Graphical Methodologies: Graphical methodologies were not used.

- Modeling and Simulation: Modeling or simulation were not performed as part of this project.

- Sensitivity Analysis: Confidence limits for the derived values were determined from the data using the methodology specified in the Standard. The confidence limits of a combined pressurization and depressurization are based on a simple average of pressurization and depressurization values.

- Industry Standards: ASTM E779 (ASTM 2003a) is the industry standard for this procedure.

- Internal Validity: Test equipment was calibrated, all intentional building envelope openings were sealed, and occupants were prohibited from entering or leaving the building during data collection periods. Data were examined to identify any anomalies that would indicate a possible need to repeat the test.

- External Validity: This methodology is broadly applicable to all military installations, regardless of building type, climate zone or other factors.

\subsection{Reduced energy consumption}

- Performance Objective Analysis Overview: Relative energy performance of the retrofitted Bldg 1540A was compared with the baseline energy performance of Bldg 1540B. The electrical and gas energy required to heat, cool and ventilate both buildings was analyzed and compared.

- Statistical Methodologies: No statistical analysis was performed.

- Graphical Methodologies: Plots of relative energy consumption as a function of time were employed. Other plots illustrated relative energy performance as a function of outdoor weather conditions.

- Modeling and Simulation: We did not perform modeling or simulation as part of this project.

- Sensitivity Analysis: Building operations during normal daily and seasonal changes in outdoor ambient conditions enabled analysis of the building's sensitivity to outdoor weather conditions in comparison to energy consumption of the baseline facility. 
- Anecdotal Perspectives: We discussed with energy managers and maintenance personnel their general observations about the function of the retrofitted facility. We also noted typical temperature settings in Bldgs 1540A\&B necessary to maintain comfort and any significant changes in occupancy or activities within the baseline and retrofitted facilities that might impact relative energy performance.

- Industry Standards: We referenced ASHRAE's Performance Measurement Protocols for Commercial Buildings: Best Practice Guide (ASHRAE 2012b), and ASHRAE's Guideline 14-2014, Measurement of Energy, Demand, and Water Savings (ASHRAE 2014) or similar guidance.

- Internal Validity: We measured energy consumption similarly on both sides of the demonstration building to ensure that the energy required to heat, cool, and ventilate both sides was accurately portrayed. Energy consumption meters were calibrated and checked on a regular basis.

We had no effective means of tracking significant differences or changes in occupancy or activities in the baseline and retrofitted facilities to account for the effect of occupants. On our various site visits, however, we noted that occupants appeared to be keeping exterior doors and windows closed at all times.

External Validity: We believe that these integrated technologies are feasible and applicable to all but the most extremely humid locations. These technologies should be ideally suited to dry climates (i.e., locations with low outdoor DPTs) because the ventilation air dehumidification load would be minimal. In such locations, the dehumidification capacity of the DOAS system could be greatly reduced or possibly eliminated altogether. This would reduce the first cost of the system and simultaneously lower the operating cost as well. In such locations, with low outdoor humidity levels, there would be decreased risk of condensation on radiant cooling surfaces. As a result, it might be safe to operate the radiant cooling panels at lower surface temperatures without risk of condensation. If so, this would increase the cooling capacity of the panels and possibly further decrease first costs.

In hot locations, these technologies would remain technically feasible as long as it would be possible to install sufficient cooling surface area to satisfy the cooling load requirement. In making this determination, the designer would need to consider the expected DPTs within the space and adjust the panel surface temperature accordingly. A panel 
surface temperature reduction of only a few degrees would significantly increase the system's cooling capacity. For example, in a room with a mean radiant temperature of $78^{\circ} \mathrm{F}$ and a panel surface temperature of $62{ }^{\circ} \mathrm{F}$, lowering the panel's surface temperature by $2{ }^{\circ} \mathrm{F}$ would increase the radiant cooling capacity by $12 \%$.

These technologies would be quite ideal in locations where the design heating load was significantly larger than the design cooling load. In the heating mode, the $\Delta \mathrm{T}$ between the hot water supply and return temperatures is much greater than the $\Delta \mathrm{T}$ between the chilled water supply and return temperatures. As a result, a given radiant panel surface area would have much more heat transfer capacity in the heating mode than in the cooling mode. If the cooling load were substantially smaller than the heating load, the total radiant panel surface could be significantly downsized, making the first cost of the overall radiant heating and cooling system much less expensive.

Radiant heating systems are already being used in large open bay systems such as hangars, garages, and maintenance facilities. These facilities are typically not cooled. Occupancies that are expected to benefit from the combination of radiant heating and cooling would include administrative and barracks facilities. In all applications, adequate provision must be made for delivery of properly conditioned ventilation air.

\subsection{Cost effectiveness}

- Performance Objective Analysis Overview: We tracked the costs to install the proposed systems and to operate and maintain them, to include the cost of energy. These costs were compared with the costs to install, operate and maintain a conventional system in the same building. Costs associated with demolition of the previously existing all-air HVAC system were excluded from this analysis so that the included costs were similar to what might be experienced in a new construction project.

- Graphical Methodologies: Cost data for the demonstrated systems vs. a conventional system were presented in a tabular format.

- Modeling and Simulation: We did not perform modeling or simulation as part of this project.

- Sensitivity Analysis: Sensitivity analysis to determine the impact of increases (or decreases) in system component costs, differing local utility rates and differing climate conditions was not performed. 
- Anecdotal Perspectives: We were unable to obtain a good breakdown of the construction Contractor's perspective of the relative costs of these technologies vs. more conventional technologies. We were unable to get feedback from the Fort Detrick DPW on the relative costs to maintain the demonstrated system vs. a more conventional system.

- Industry Standards: RS Means cost data were used as a reference of comparison of costs to purchase and install these systems.

- Internal Validity: We made sure that the costs attributed to the demonstrated systems did not include the costs of ancillary systems such as sensors and data collection systems that would not be included in a normal construction project. We also attempted to reasonably adjust the purchase and installation costs of the demonstrated systems to account for the fact that the first costs for these systems would be expected to fall if they were to become more widely used.

- External Validity: Cost effectiveness of this technology at other locations will need to consider local utility rates and labor rates in addition to local climate conditions. In a very dry, temperate climate, it might be possible to successfully implement this technology with very little dehumidification capacity and reduced heating and cooling capacity. Conversely, in a humid location with extreme peak heating and increased cooling and dehumidification requirements, use of these technologies might be prohibitively expensive.

- Building Life-Cycle Cost Program: To address the System Economics Performance Objective, the USDOE's Life-Cycle Cost tool was used.

\subsection{Improved comfort}

- Performance Objective Analysis Overview: Comfort was analyzed with reference to ASHRAE Standard 55-2010, Thermal Environmental Conditions for Human Occupancy, Section 5.2.1.1 "Graphic Zone Comfort Method" (ASHRAE 2010).

- Statistical Methodologies: No statistical analyses were performed.

- Graphical Methodologies: A time dependent scatter plot was used (section 6.8.2). A stock chart was also modified to accommodate the display of temperature and humidity ranges.

- Modeling and Simulation: We did not perform modeling or simulation as part of this project. 
- Sensitivity Analysis: We did not perform a sensitivity analysis to determine how occupant comfort might be impacted by unusual outdoor temperature or humidity conditions.

- Anecdotal Perspectives: We attempted to perform a survey of occupants of Bldgs 1540A\&B, but the occupants were not responsive to the survey. We did, however, hear about a complaint of uncomfortably warm conditions in Bldg 1540A's Room Co18B (the Information Assurance training classroom). In response to this complaint, the Contractor installed additional cooling panels in the ceiling of this room in an attempt to alleviate the lack of adequate cooling capacity. Subsequently, we had a brief discussion with the instructor in this classroom. He said that the temperatures in the classroom were still too hot and that they had brought in a portable cooling unit to blow cool air into the classroom.

- This problem does not necessarily indicate a failure of the radiant cooling technology per se. The Contractor's initial design was for an expected classroom cooling load of one instructor, 10 students, their computers, a projector, and the room's lighting. After the occupants returned to the building, we found that the cooling load had essentially doubled (one instructor, 20 students, their computers, a projector, and the room's lighting). As a result, the original radiant cooling system design for this space was wholly undersized to handle the space's actual cooling load. The Contractor worked with the radiant panel manufacturer to attempt to address the problem with the installation of a few additional panels. However, without a major reworking of the entire system in Co18B (piping, valves, rearrangement of originally installed radiant cooling panels, and additional panels), it was not possible to gain the additional cooling capacity to satisfy the room's added cooling load. One can see from Figure 5-7 that most of the available ceiling space is currently taken with the installed panels. Apparently the radiant panel manufacturer had some further ideas to increase the cooling capacity, to include mounting cooling panels on the upper walls of the space. It might have been possible to satisfactorily address the problem with further system changes, but this was not attempted. An important takeaway is that any HVAC system is only as good as the heating/cooling load estimates upon which it is based. If actual loads are significantly different than the original design, adding additional capacity can be very challenging. 
It is also possible that the occupants' use of this room may have exacerbated their cooling problem. We noted that the occupants often operated the room with both of its doors open to the unconditioned high ceilinged storage area. This would have allowed heat from this uncooled space to infiltrate the classroom space, adding to its cooling load.

It should also be noted that it was basically impossible for the Contractor to remotely control the temperature of the chilled water delivered to the radiant panels. Because the Contractor was not allowed to remotely control chilled water temperatures and other system parameters, and because they were being very careful to maintain radiant panel temperatures above the space DPT, it was not practical for the Contractor to "play" with chilled water temperatures to see if that would resolve the temperature issue in this space. For example, assuming a mean radiant temperature in the space of $78^{\circ} \mathrm{F}$ and a mean cooling panel surface temperature of $63.5{ }^{\circ} \mathrm{F}$, reducing the cooling panel's surface temperature by just $2{ }^{\circ} \mathrm{F}$ (to $61.5^{\circ} \mathrm{F}$ ) would increase the panel's cooling capacity by $12 \%$.

Other than this unresolved problem in Room Co18B, we had heard only positive comments concerning comfort in the remainder of Bldg 1540A. We discussed this with DPW personnel, who said they were unaware of any other issues related to comfort in the building.

- Industry Standards: ASHRAE Standard 55-2010, Thermal Environmental Conditions for Human Occupancy (ASHRAE 2010).

- Internal Validity: We discouraged the use of personal electric heaters, personal fans, opened windows and doors, or other means for people to control their personal comfort. We made sure that the temperature and humidity sensors used to ascertain comfort per ASHRAE Standard 55 (ASHRAE 2010) were properly calibrated, located appropriately, and providing credible data.

- External Validity: Other than the problem of comfort issues in Room Co18B noted above, we verified that the system provides comfort in accordance with ASHRAE Standard 55 (ASHRAE 2010), assuming that the system is designed and installed with adequate heating, cooling, dehumidification, and ventilating capacity. 


\subsection{Reduced relative $\mathrm{mold} / \mathrm{mildew}$ potential}

- Performance Objective Analysis Overview: Of the three necessary ingredients for the formation and growth of mold and mildew (spores, food source, an acceptable temperature range and adequate moisture in the food source), the only one that we can realistically control is the moisture content of the food source. Therefore, our analysis focused on the ability of the retrofitted facility to maintain humidity in the building at levels that will keep building elements and building contents dry enough to discourage mold and mildew formation and growth.

- Statistical Methodologies: No statistical analysis was performed.

- Graphical Methodologies: We did not use graphical methodologies to analyze this item.

- Modeling and Simulation: We did not perform modeling or simulation as part of this project.

- Sensitivity Analysis: No sensitivity analysis was planned.

- Anecdotal Perspectives: No interviews were conducted.

- Industry Standards: "Water activity" describes the amount of water adsorbed by a specified material when it is in equilibrium with air at a given RH. Two material samples of equal mass but dissimilar sorption characteristics would contain differing absolute masses of water at the same water activity level. In other words, a water activity of 0.75 would correspond to the moisture content of a material with a given sorption characteristic when exposed to and in equilibrium with air at a $\mathrm{RH}$ of $75 \%$. Since most building materials and building contents are not susceptible to mold growth at water activity levels below 0.75 , our goal was to ensure that no building materials or building contents experienced a water activity greater than 0.75 .

- Internal Validity: We ensured that temperature and RH data loggers were properly calibrated and delivering accurate data. We also located these devices in the areas that were most susceptible to development of mold and mildew.

- External Validity: This performance objective is fully applicable to other locations because it is dependent on maintaining the proper internal environmental conditions that should be attainable with a properly designed system. 


\subsection{Easily operable and maintainable}

- Performance Objective Analysis Overview: Because this project replaced a conventional mechanical system, our goal was to demonstrate that the retrofit system was at least as easily operable and maintainable as the existing system. Operability and maintainability was to be determined through the analysis of frequency and extent of operational problems associated with the demonstrated systems and the degree of difficulty that maintenance personnel experience in addressing these problems in comparison to the O\&M of the conventional system within the baseline facility.

- Statistical Methodologies: O\&M data are sufficiently sparse to be statistically insignificant.

- Graphical Methodologies: Graphical methodologies were not used.

- Modeling and Simulation: We did not perform modeling or simulation as part of this project.

- Sensitivity Analysis: No sensitivity analysis was performed.

- Anecdotal Perspectives: We engaged the O\&M staff during commissioning of the demonstrated systems. The O\&M personnel who participated in the commissioning of the systems expressed their satisfaction with the relative simplicity of the installed systems.

Subsequent to turnover of the system, we attempted to discuss with the installation energy manager and the O\&M staff their experiences working with the demonstrated system. As this was an unfamiliar technology, it would have been helpful to identify areas of misunderstanding or concepts that needed to be explained so that maintenance staff could more easily operate and maintain the systems. We were able to discuss maintenance issues with the DPW's Chief of Operations after about 2 years of operational experience. He said that he was unaware of any significant issues or problems with the system. In the absence of information to the contrary, we believe that the demonstrated system was as at least as operable and maintainable as the conventional VAV system that it replaced.

- Industry Standards: We are unaware of any related industry standards.

- Internal Validity: We were unable to analyze operability and maintainability for internal validity.

- External Validity: We were unable to evaluate external validity of this performance objective. 


\subsection{Performance review}

\subsubsection{Overview of performance review}

The data listed Table 6-5 give an overview of the performance objectives of this demonstration.

\subsubsection{Thermal comfort}

The Graphical Zone Method of ASHRAE STD 55-2010 (ASHRAE 2010) provides a plotted area of temperature and humidity combinations where $80 \%$ of occupants in mechanically cooled spaces will be comfortable performing low exertion activities (typing, filing, etc.) (Figure 6-2). The upper and lower temperature bounds in this standard are $82{ }^{\circ} \mathrm{F}$ in the summer and $67^{\circ} \mathrm{F}$ in the winter. For Bldg 1540A, 95\% of the daily temperatures (6 a.m. to 6 p.m.) ranged between 62 and $78{ }^{\circ} \mathrm{F}$, averaging $70^{\circ} \mathrm{F}$ (Figure 6-3). Similarly, $95 \%$ of the daily relative humidities ( 6 a.m. to 6 p.m.) ranged between 28 and 58\% RH, averaging 43\%. These parameters for Bldg 1540A were predominantly within the standard's plotted area of acceptability, demonstrating Bldg 1540A's compliance with ASHRAE STD 55-2010 (ASHRAE 2010). Interior temperatures during unoccupied periods were cooler than the Standard's $67^{\circ} \mathrm{F}$ lower boundary due to the $55^{\circ} \mathrm{F}$ night temperature setpoint. Although interior temperatures never fell to the $55^{\circ} \mathrm{F}$ night setback temperature, they were often below $67^{\circ} \mathrm{F}$ at the start of the "occupied" period ( 6 a.m. to 6 p.m.) in the winter months (Figure 6-4, Table 6-6). 


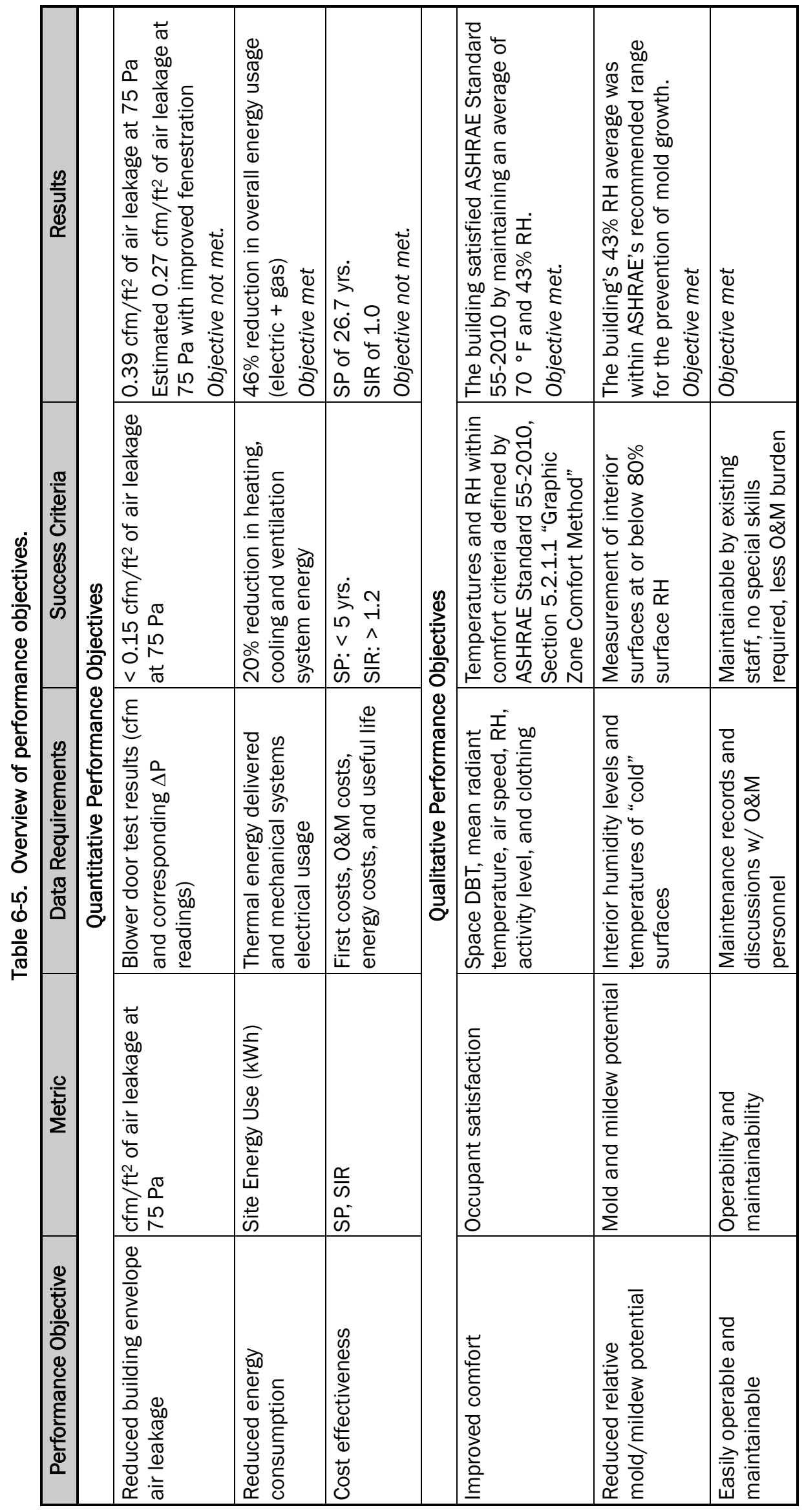




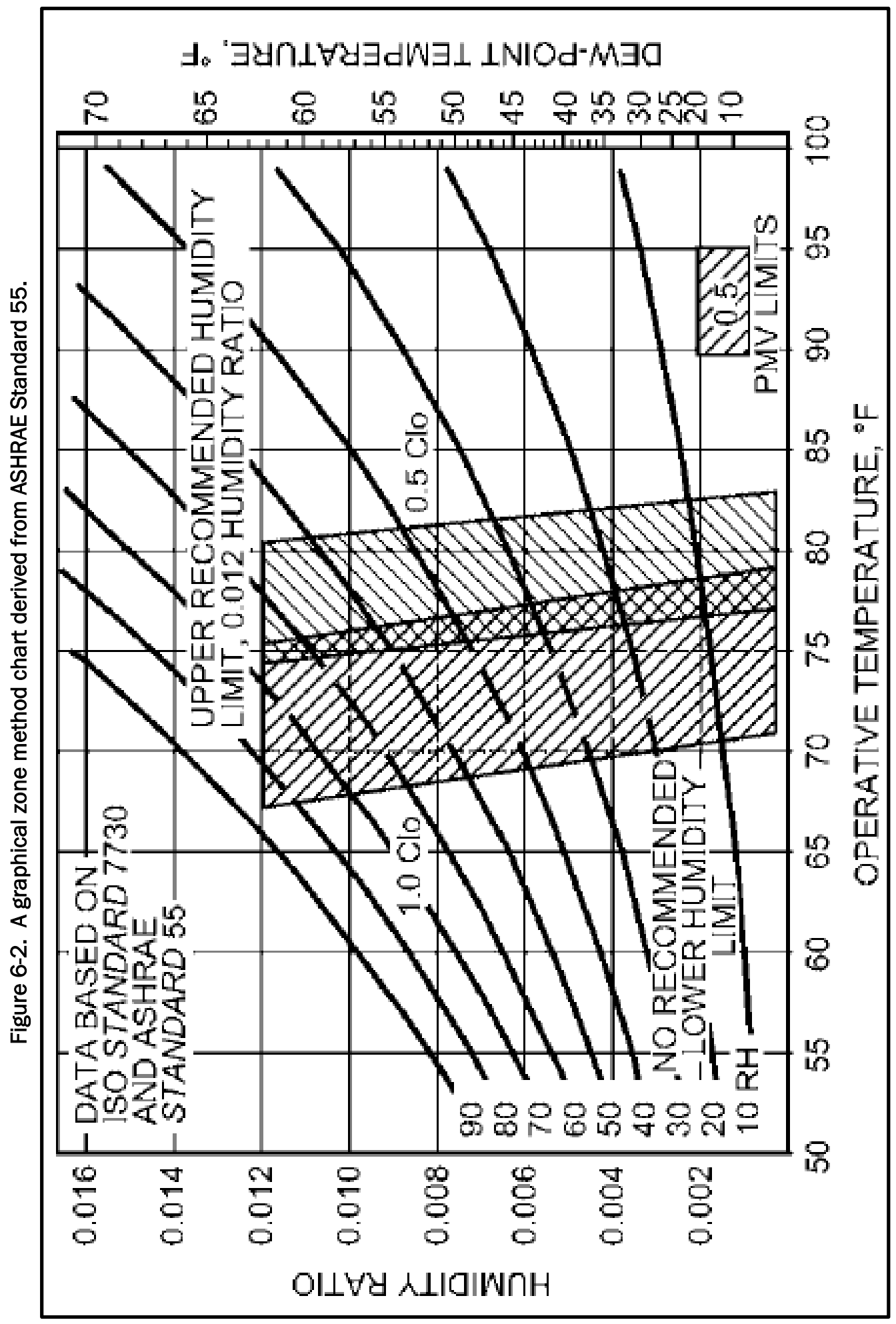




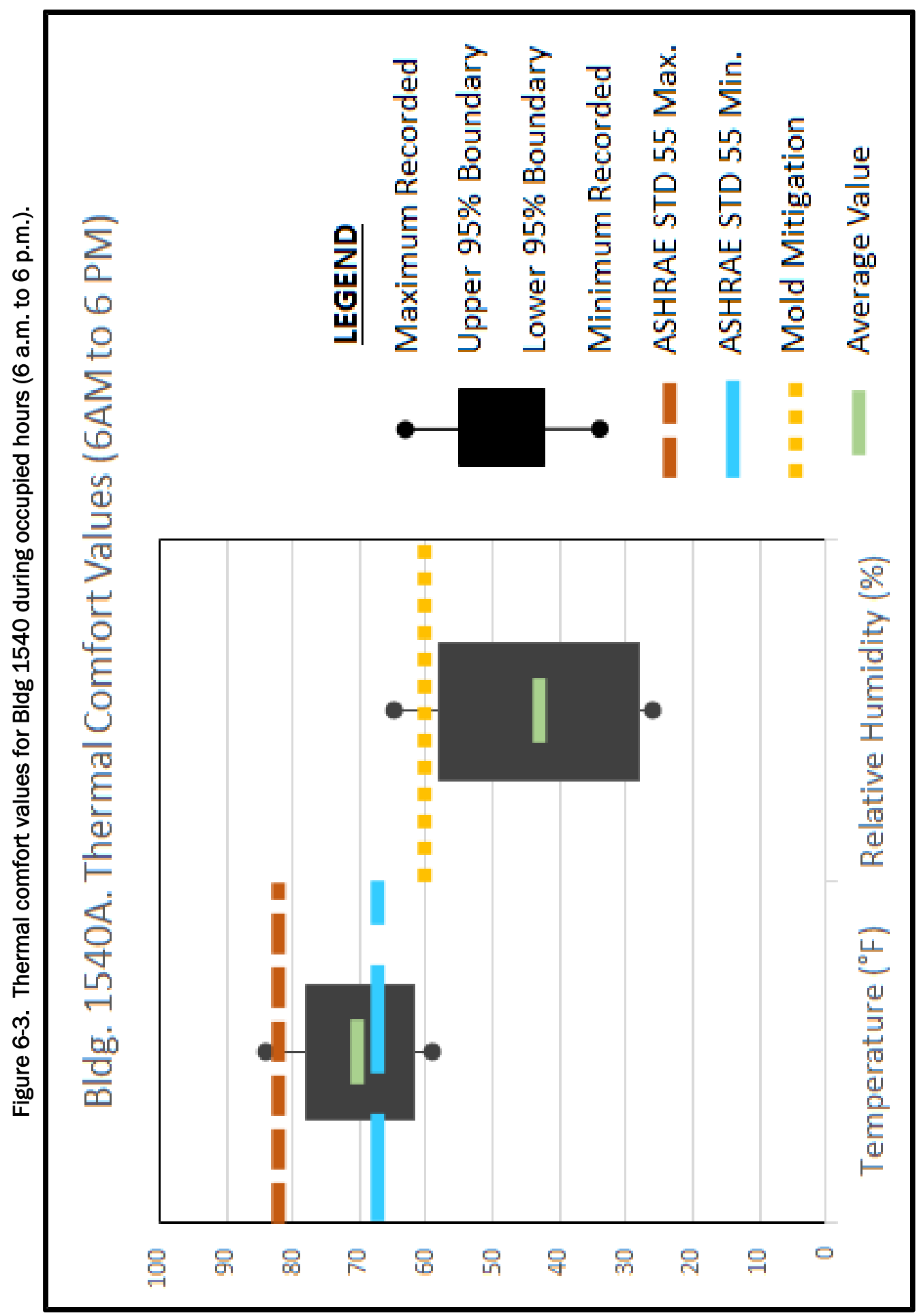




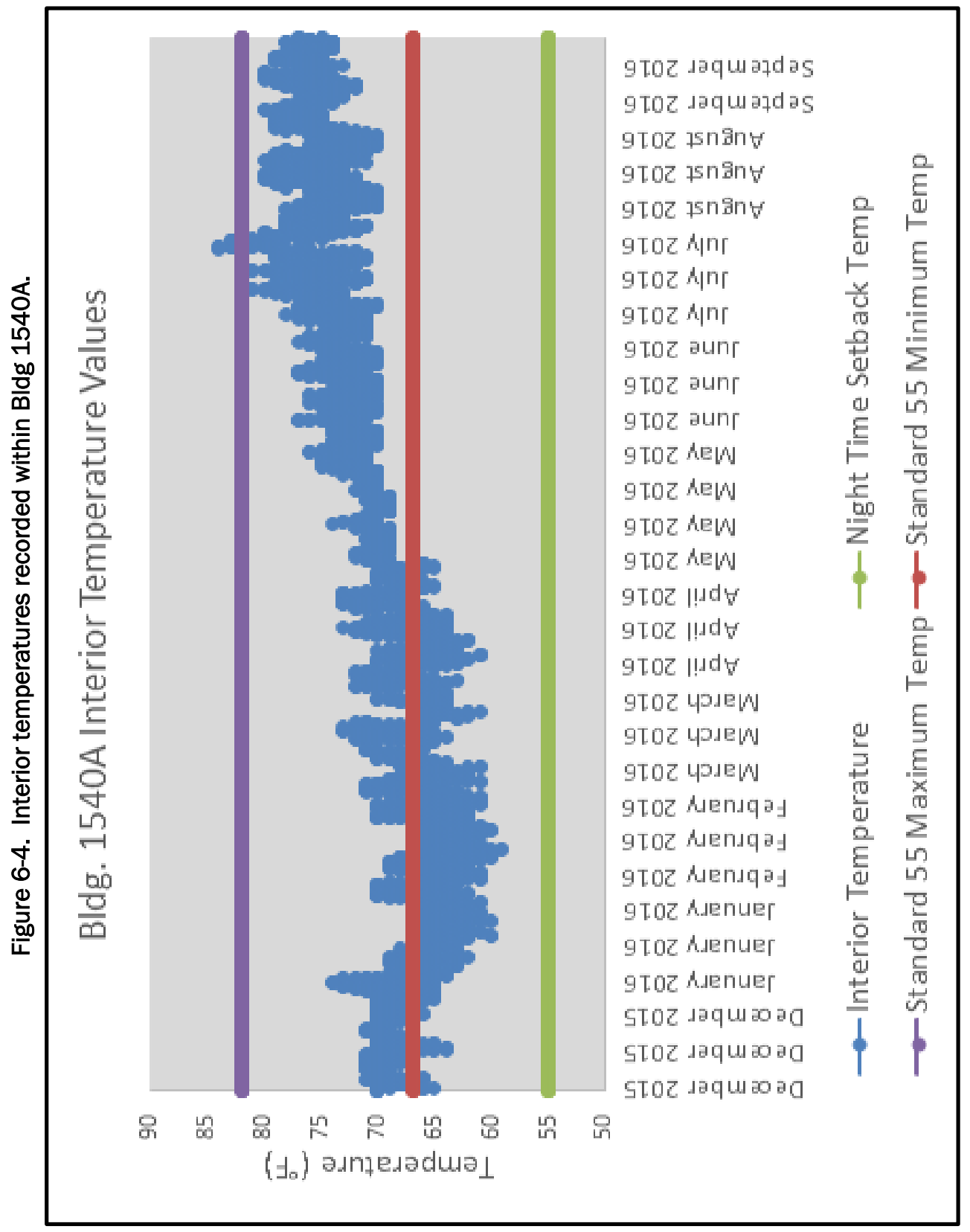


Table 6-6. Monthly outdoor temperatures and interior thermal comfort ranges.

\begin{tabular}{|l|c|c|c|c|c|}
\hline Month & $\begin{array}{c}\text { Outside } \\
\text { Temperature }\end{array}$ & $\begin{array}{c}\text { 1540A Interior } \\
\text { Temperature }\end{array}$ & $\begin{array}{c}\text { 1540A } \\
\text { Interior } \\
\mathrm{RH}\end{array}$ & $\begin{array}{c}\text { 1540B Interior } \\
\text { Temperature }\end{array}$ & $\begin{array}{c}\text { 1540B } \\
\text { Interior } \\
\mathrm{RH}\end{array}$ \\
\hline Sep 2015 & $77^{\circ} \mathrm{F}$ & $\mathrm{N} / \mathrm{A}$ & $\mathrm{N} / \mathrm{A}$ & $\mathrm{N} / \mathrm{A}$ & $\mathrm{N} / \mathrm{A}$ \\
\hline Oct 2015 & $65^{\circ} \mathrm{F}$ & $\mathrm{N} / \mathrm{A}$ & $\mathrm{N} / \mathrm{A}$ & $\mathrm{N} / \mathrm{A}$ & $\mathrm{N} / \mathrm{A}$ \\
\hline Nov 2015 & $56^{\circ} \mathrm{F}$ & $55^{\circ} \mathrm{F}-78^{\circ} \mathrm{F}$ & $26 \%-59 \%$ & $\mathrm{~N} / \mathrm{A}$ & $\mathrm{N} / \mathrm{A}$ \\
\hline Dec 2015 & $53^{\circ} \mathrm{F}$ & $64^{\circ} \mathrm{F}-75^{\circ} \mathrm{F}$ & $29 \%-66 \%$ & $\mathrm{~N} / \mathrm{A}$ & $\mathrm{N} / \mathrm{A}$ \\
\hline Jan 2016 & $30^{\circ} \mathrm{F}$ & $60^{\circ} \mathrm{F}-74^{\circ} \mathrm{F}$ & $27 \%-47 \%$ & $\mathrm{~N} / \mathrm{A}$ & $\mathrm{N} / \mathrm{A}$ \\
\hline Feb 2016 & $35^{\circ} \mathrm{F}$ & $59^{\circ} \mathrm{F}-71^{\circ} \mathrm{F}$ & $25 \%-45 \%$ & $\mathrm{~N} / \mathrm{A}$ & $\mathrm{N} / \mathrm{A}$ \\
\hline Mar 2016 & $48^{\circ} \mathrm{F}$ & $61^{\circ} \mathrm{F}-73^{\circ} \mathrm{F}$ & $33 \%-52 \%$ & $\mathrm{~N} / \mathrm{A}$ & $\mathrm{N} / \mathrm{A}$ \\
\hline Apr 2016 & $50^{\circ} \mathrm{F}$ & $61^{\circ} \mathrm{F}-73^{\circ} \mathrm{F}$ & $30 \%-54 \%$ & $69^{\circ} \mathrm{F}-74^{\circ} \mathrm{F}$ & $29 \%-57 \%$ \\
\hline May 2016 & $63^{\circ} \mathrm{F}$ & $64^{\circ}-75^{\circ} \mathrm{F}$ & $35 \%-57 \%$ & $69^{\circ} \mathrm{F}-76^{\circ} \mathrm{F}$ & $33 \%-65 \%$ \\
\hline Jun 2016 & $72^{\circ} \mathrm{F}$ & $70^{\circ} \mathrm{F}-77^{\circ} \mathrm{F}$ & $40 \%-57 \%$ & $70^{\circ} \mathrm{F}-77^{\circ} \mathrm{F}$ & $40 \%-60 \%$ \\
\hline Jul 2016 & $78^{\circ} \mathrm{F}$ & $70^{\circ} \mathrm{F}-85^{\circ} \mathrm{F}$ & $40 \%-60 \%$ & $71^{\circ} \mathrm{F}-80^{\circ} \mathrm{F}$ & $49 \%-68 \%$ \\
\hline Aug 2016 & $78^{\circ} \mathrm{F}$ & $70^{\circ} \mathrm{F}-81^{\circ} \mathrm{F}$ & $41 \%-58 \%$ & $71^{\circ} \mathrm{F}-82^{\circ} \mathrm{F}$ & $54 \%-69 \%$ \\
\hline
\end{tabular}

\subsubsection{Microbial growth potential}

In addition to thermal comfort, ASHRAE has also published recommendations for indoor humidity levels for mitigating mold growth and promoting human health. According to the 2015 ASHRAE Handbook: HVAC Applications (ASHRAE 2015), “... a conservative limit for no mold ever, on anything at any temperature, is below 60\% RH." Furthermore, the 2012 ASHRAE Handbook on HVAC Systems and Equipment (ASHRAE 2012c) details an optimum humidity range for human comfort and health between 30 and 60\% RH (Figure 6-5). Bldg 1540A averaged 43\% RH during the occupied period ( 6 a.m. to 6 p.m.) demonstrating the HVAC system's success in mitigating microbial growth potential. These accomplishments validated the ability for a properly designed radiant panel and DOAS system combination to maintain temperature and humidity for indoor health and comfort. 
Figure 6-5. The optimum humidity range for human comfort and health (30 to $60 \%$ ), as published in the 2012 ASHRAE Handbook on HVAC Systems and Equipment.

\begin{tabular}{|l|l|l|l|l|l|l|l|l|l|l|l|}
\hline \multicolumn{7}{|c|}{ Decrease in bar width indicates decrease in effect } \\
\hline BACTERIA & & & & & & & & & & \\
\hline
\end{tabular}

\subsubsection{Comparison with baseline energy Performance}

This project demonstrated energy savings for Bldg 1540A's radiant system over the original all-air system. Overall energy consumption (electric + gas) in Bldg 1540A for the period Sep 2015 through Aug 2016 decreased 42\% compared with the prior 12 months (Sep 2014 through Aug 2015) (Figure 6-6 and Table 6-7). This was due to a 20\% decrease in electricity usage, and a 56\% decrease in gas usage (Figures 6-7 and 6-8). Section 6.8.5 compares the energy performance of Bldgs 1540A\&B.

Table 6-7. Monthly electric and gas usage data for BIdg 1540A during the periods of Sep 2014 through Aug 2015 and Sep 2015 through Aug 2016. Also shown are monthly HDD and CDD (base 60).

\begin{tabular}{|l|r|r|r|r|r|r|r|c|c|}
\hline & \multicolumn{4}{|c|}{ Sep 2014 through Aug 2015 } & \multicolumn{4}{c|}{ Sep 2015 through Aug 2016 } \\
\hline Month & HDD60 & CDD60 & Electric (kWh) & Gas (Therms) & Month & HDD60 & CDD60 & $\begin{array}{c}\text { Electric } \\
\text { (kWh) }\end{array}$ & $\begin{array}{c}\text { Gas } \\
\text { (therms) }\end{array}$ \\
\hline Sep 2014 & 5.4 & 282.5 & 7,893 & 248 & Sep 2015 & 0 & 266.4 & 8,087 & 49 \\
\hline Oct 2014 & 56.6 & 77.8 & 4,980 & 403 & Oct 2015 & 201.3 & 13.8 & 6,203 & 166 \\
\hline Nov 2014 & 442.9 & 3.1 & 4,980 & 816 & Nov 2015 & 319.1 & 18.3 & 5,711 & 231 \\
\hline Dec 2014 & 614.4 & 0 & 8,506 & 957 & Dec 2015 & 422.6 & 5.6 & 5,370 & 251 \\
\hline Jan 2015 & 886.5 & 0 & 10,010 & 894 & Jan 2016 & 911.7 & 0 & 5,163 & 529 \\
\hline Feb 2015 & 943.7 & 0 & 9,177 & 881 & Feb 2016 & 713.1 & 0 & 4,665 & 425 \\
\hline Mar 2015 & 624.1 & 0 & 20,165 & 447 & Mar 2016 & 363.3 & 15.3 & 4,664 & 228 \\
\hline Apr 2015 & 167.3 & 29.3 & 358 & 104 & Apr 2016 & 264.4 & 22.7 & 5,233 & 158 \\
\hline
\end{tabular}




\begin{tabular}{|l|r|r|r|r|r|r|r|c|c|}
\hline & \multicolumn{4}{|c|}{ Sep 2014 through Aug 2015 } & \multicolumn{5}{c|}{ Sep 2015 through Aug 2016 } \\
\hline Month & HDD 60 & CDD60 & Electric (kWh) & Gas (Therms) & Month & HDD60 & CDD60 & $\begin{array}{c}\text { Electric } \\
(\mathbf{k W h})\end{array}$ & $\begin{array}{c}\text { Gas } \\
\text { (therms) }\end{array}$ \\
\hline May 2015 & 11.7 & 282 & 1,263 & 82 & May 2016 & 87.4 & 119.8 & 6,326 & 100 \\
\hline Jun 2015 & 2.9 & 371.1 & 12,010 & 115 & Jun 2016 & 0 & 359.9 & 8,086 & 32 \\
\hline Jul 2015 & 0 & 496.9 & 10,083 & 83 & Jul 2016 & 0 & 544.6 & 8,719 & 29 \\
\hline Aug 2015 & 0 & 438.1 & 7,785 & 91 & Aug 2016 & 0 & 542.7 & 9,809 & 31 \\
\hline Total & 3755.5 & 1980.8 & 97,210 & 5,121 & Total & 3282.9 & 1909.1 & 78,036 & 2,229 \\
\hline Total & & & \multicolumn{2}{|c|}{247,292} & Total & & & & 143,362 \\
\hline
\end{tabular}

In Table 6-7, note that Bldg 1540A was unoccupied during the shaded months while the demonstration system was being installed. Table 6-7 also includes Heating Degree Days (HDD) and Cooling Degree Days (CDD) using a balance point of $60^{\circ} \mathrm{F}$. Weather data were obtained from a Global Surface Observation Data (GSOD) data file from the Frederick Municipal Airport, which is approximately 1 mile to the Southeast of Bldg 1540. The data consist of daily averages of DBT data, dew point temperature data, and several other weather data parameters. HDD and CDD calculations are based on daily average DBT data only. From a quick review of Table $6-7$, one can see that there were $14 \%$ more HDDs and $4 \%$ more CDDs in the period of Sep 2014 to Aug 2015 than for the period Sep 2015 to Aug 2016. These greater HDDs and CDDs are not significant enough to account for the considerably more electrical and gas energy consumed in the period of Sep 2014 to Aug 2015.

In reviewing Table 6-7, it is puzzling to note that, although Bldg $1540 \mathrm{~A}$ was unoccupied from Sep 2014 to May 2015 (as the building was being renovated and commissioned), it still had comparable or greater electrical usage during several months in this period than during the same months in the following year; also, recorded gas usage during most months was greater than gas usage in the same months of the following year. The Contractor went to great efforts to account for these anomalies, including checking the calibration of meters and instrumentation and reviewing sequences of operation and operational schedules and verifying conversion factors on gas meters.

It is possible that construction contractor activities consumed an inordinate amount of electricity during the unoccupied period, but this is considered to be unlikely. The Contractor also detected and corrected a boiler controls problem that allowed the boiler to stay fired during unoccupied 
periods even though no spaces had fallen below the night thermostat setting. They also detected that various room temperature setpoints had been adjusted downward on a number of occasions. This was especially intriguing since the Contractor themselves had no means to make such adjustments without hiring the installation's controls contractor to make these changes. This anomaly remained unresolved.

Figure 6-6. Bldg 1540A total energy usage (electric + gas) for the period Sep 2015 to Aug 2016 vs. the period Sep 2014 to Aug 2015.

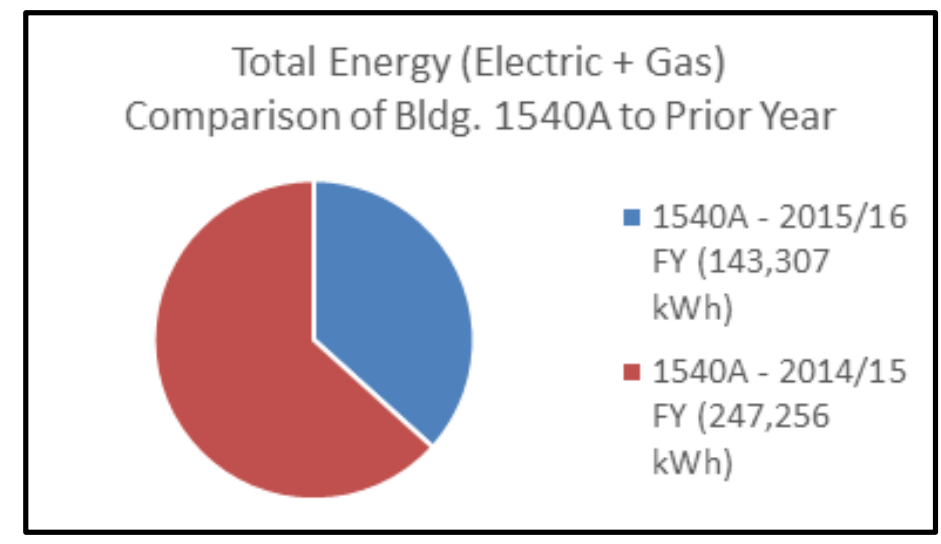

Figure 6-7. BIdg 1540A realized a 20\% decrease in electrical usage for the period Sep 2015 to Aug 2016 vs. the period Sep 2014 to Aug 2015.

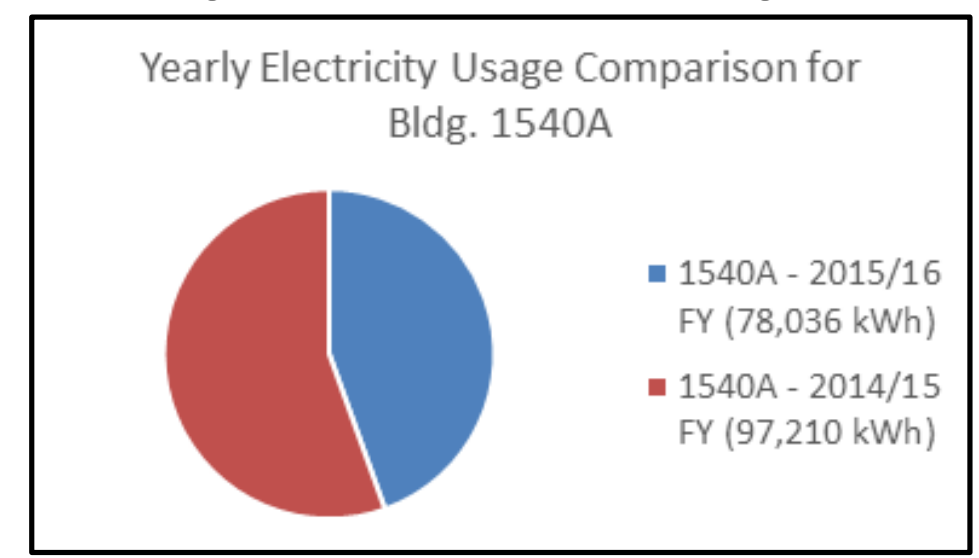


Figure 6-8. Bldg 1540A realized a 56\% decrease in gas usage for the period Sep 2015 to Aug 2016 vs. the period Sep 2014 to Aug 2015.

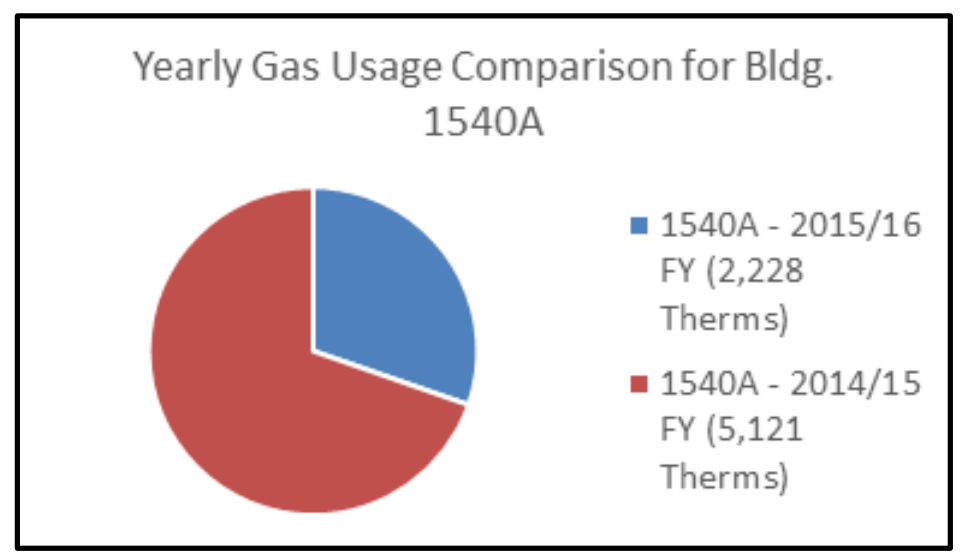

Bldg 1540B's energy usage shared similarities with the previous year. Overall energy consumption (electric + gas) in Bldg $1540 \mathrm{OB}$ decreased $25 \%$ compared with the prior year (2014/2015 FY) (Figure 6-9 and Table 6-8). This was due to a $14 \%$ increase in electricity usage being offset by a $37 \%$ decrease in gas usage (Figures 6-10 and 6-11).

Table 6-8. Bldg 1540B monthly electric and gas usage data for the periods of Sep 2014 through Aug 2015 and Sep 2015 through Aug 2016.

\begin{tabular}{|l|c|c|l|c|c|}
\hline Month & $\begin{array}{c}\text { Electric } \\
(\mathbf{k W h})\end{array}$ & $\begin{array}{c}\text { Gas } \\
\text { (therms) }\end{array}$ & \multicolumn{1}{|c|}{ Month } & $\begin{array}{c}\text { Electric } \\
(\mathbf{k W h})\end{array}$ & Gas (therms) \\
\hline Sep 2014 & 4,332 & 432 & Sep 2015 & 5,359 & 139 \\
\hline Oct 2014 & 6,317 & 373 & Oct 2015 & 4,449 & 323 \\
\hline Nov 2014 & 6,071 & 710 & Nov 2015 & 4,096 & 411 \\
\hline Dec 2014 & 6,366 & 754 & Dec 2015 & 4,540 & 485 \\
\hline Jan 2015 & 6,679 & 792 & Jan 2016 & 4,853 & 771 \\
\hline Feb 2015 & 6,152 & 957 & Feb 2016 & 4,621 & 697 \\
\hline Mar 2015 & 677 & 606 & Mar 2016 & 4,929 & 445 \\
\hline Apr 2015 & 45 & 495 & Apr 2016 & 4,665 & 281 \\
\hline May 2015 & 5,779 & 423 & May 2016 & 4,296 & 225 \\
\hline Jun 2015 & 2,234 & 259 & Jun 2016 & 4,830 & 43 \\
\hline Jul 2015 & 3,374 & 133 & Jul 2016 & 5,990 & 10 \\
\hline Aug 2015 & 3,796 & 133 & Aug 2016 & 6,235 & 12 \\
\hline Total & 51,822 & 6,068 & Total & 58,863 & 3,842 \\
\hline Total & $229,686 \mathrm{kWh}$ & & \multicolumn{2}{|c|}{$171,461 \mathrm{kWh}$} \\
\hline
\end{tabular}


The decreased energy usage in baseline Bldg $1540 \mathrm{~B}$ is also somewhat difficult to explain. As with Bldg 1540A, the 14\% more HDDs and 4\% more CDDs in the period of Sep 2014 to Aug 2015 than for the period Sep 2015 to Aug 2016 do not appear to be sufficient to explain the building's reduced energy usage from Sep 2015 to Aug 2016. One possible explanation for the reduced energy usage might be that the repairs and recommissioning work (see Appendix B) completed in Aug 2015 improved the building's overall energy efficiency. Although some energy efficiency improvements may have resulted, it seems unlikely that the building would have seen such a significant improvement in energy efficiency. A more plausible explanation would seem to be that occupancy and/or activities within Bldg $154 \mathrm{OB}$ were significantly reduced during the latter period as compared to the prior year. We were unable to verify relative occupancies or activity levels between these two periods.

Figure 6-9. Bldg 1540B total energy usage (electric + gas) for the period Sep 2015 to Aug 2016 vs. the period Sep 2014 to Aug 2015.

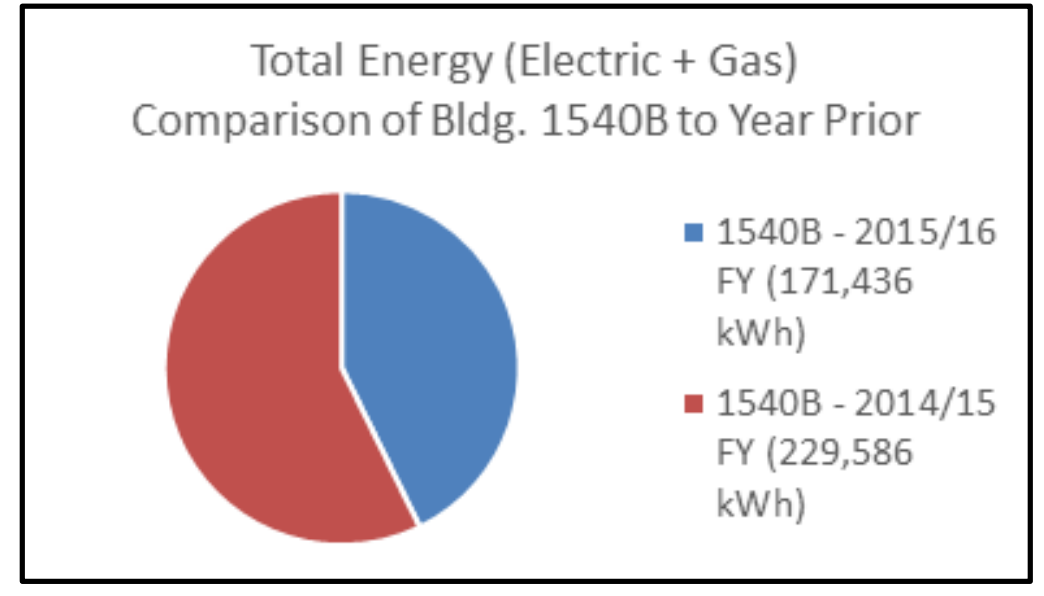

Figure 6-10. Bldg 1540B realized a 14\% increase in electrical usage for the period Sep 2015 to Aug 2016 vs. the period Sep 2014 to Aug 2015.

\section{Yearly Electricity Usage Comparison for} Bldg. 1540B

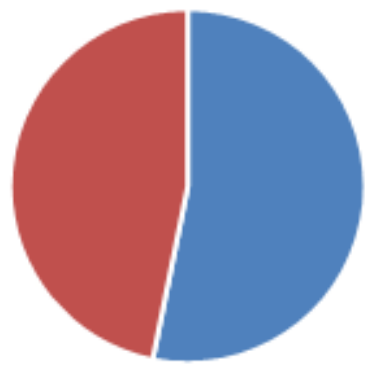

- 1540B - 2015/16 $\mathrm{FY}(58,864 \mathrm{kWh})$ 
Figure 6-11. Bldg 1540B realized a 37\% decrease in gas usage for the period Sep 2015 to Aug 2016 vs. the period Sep 2014 to Aug 2015.

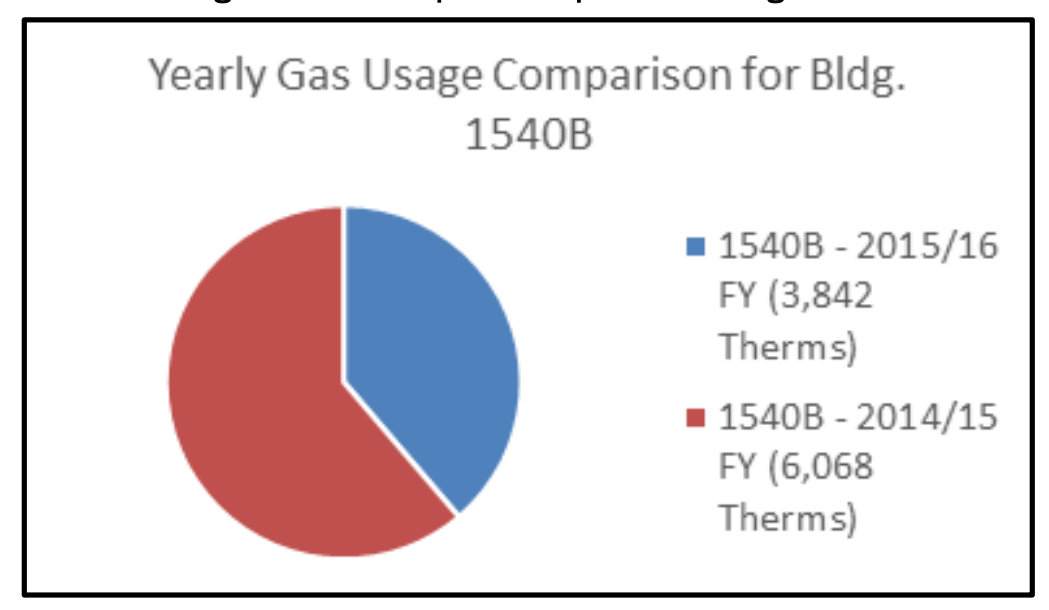

\subsubsection{Energy performance comparison of BIdgs 1540A\&B for monitoring periods Sep 2014 to Aug 2015 and Sep 2015 to Aug 2016}

Table 6-9 lists electricity and gas utility usage for Bldgs 1540A\&B during the post-retrofit monitoring period (Sep 2015 to Aug 2016). Overall, Bldg 1540A used 16\% less energy than Bldg 1540B (Figure 6-12). Bldg 1540A consumed 33\% more electrical energy than Bldg 1540B (Figure 6-13), however, Bldg $1540 \mathrm{O}$ also used $42 \%$ less gas energy than Bldg $1540 \mathrm{OB}$ (Figure 6-14). Two seasonal observations were made when comparing Bldgs 1540A\&B. First, while Bldg 1540A typically used more electrical energy than Bldg $1540 B$, this gap widened during the summer season. This was attributed to the multitude of components in the radiant panel system (chiller, DOAS, pumps, etc.) that consume electricity and that operate year round (with the exception of the chiller). Second, during the fall and winter periods, the heating system in Bldg $1540 \mathrm{OB}$ demanded more energy from its boiler compared with Bldg 1540A. This single difference in boiler energy usage drove Bldg 1540B's total energy usage above 1540A's despite $1540 A$ using more energy in its chiller, HVAC, and electrical systems. The energy savings recorded from Bldg $1540 \mathrm{~A}$ becomes even more appreciable after incorporating adjustments for the differences in each building's square footage. Bldg $1540 \mathrm{~B}$ used $30.67 \mathrm{kWh} / \mathrm{ft}^{2}$ while Bldg $1540 \mathrm{~A}$ used $18.81 \mathrm{kWh} / \mathrm{ft}^{2}$. This represented a $39 \%$ energy savings for Bldg $1540 \mathrm{~A}$ on an energy usage per square footage basis compared with Bldg $1540 \mathrm{~B}$. 
Table 6-9. Post-retrofit monitoring period (Sep 2015 to Aug 2016) electricity and gas utility usage for Bldgs 1540A\&B.

\begin{tabular}{|l|c|c|c|c|}
\hline & \multicolumn{3}{|l|}{ Bldg 1540A } & \multicolumn{2}{l|}{ Bldg 1540 B } \\
\hline Month & $\begin{array}{c}\text { Electric } \\
(\mathrm{kWh})\end{array}$ & $\begin{array}{c}\text { Gas } \\
\text { (therms) }\end{array}$ & $\begin{array}{c}\text { Electric } \\
(\mathrm{kWh})\end{array}$ & $\begin{array}{c}\text { Gas } \\
\text { (therms) }\end{array}$ \\
\hline Sep 2015 & 8,087 & 49 & 5,359 & 139 \\
\hline Oct 2015 & 6,203 & 166 & 4,449 & 323 \\
\hline Nov 2015 & 5,711 & 231 & 4,096 & 411 \\
\hline Dec 2015 & 5,370 & 251 & 4,540 & 485 \\
\hline Jan 2016 & 5,163 & 529 & 4,853 & 771 \\
\hline Feb 2016 & 4,665 & 425 & 4,621 & 697 \\
\hline Mar 2016 & 4,664 & 228 & 4,929 & 445 \\
\hline Apr 2016 & 5,233 & 158 & 4,665 & 281 \\
\hline May 2016 & 6,326 & 100 & 4,296 & 225 \\
\hline Jun 2016 & 8,086 & 32 & 4,830 & 43 \\
\hline Jul 2016 & 8,719 & 29 & 5,990 & 10 \\
\hline Aug 2016 & 9,809 & 31 & 6,235 & 12 \\
\hline Total & 78,036 & 2,228 & 58,864 & 3,842 \\
\hline Total (kWh) & 143,307 & & 171,436 & \\
\hline
\end{tabular}

Figure 6-12. Fiscal year 2015/2016 overall energy usage comparison for Bldgs 1540A\&B (electricity + gas). Overall, Bldg 1540A used 20\% less energy than Bldg 1540B.

Overall Energy Usage Comparison (Electricity + Gas)

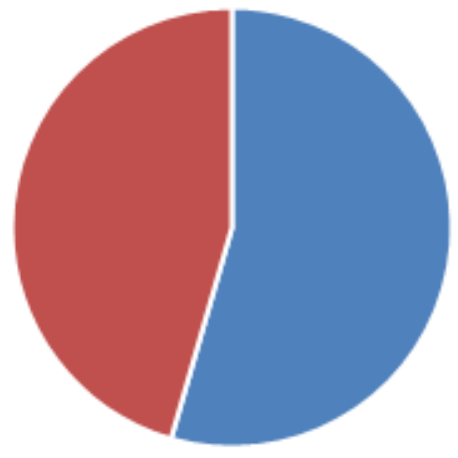

- 1540 B $(171,436$ $\mathrm{kWh}$ )

- 1540 A $(143,307$ kWh) 
Figure 6-13. Fiscal year 2015/2016 electricity usage comparison for Bldgs 1540A\&B. BIdg 1540A consumed 30\% more electrical energy than BIdg 1540B.

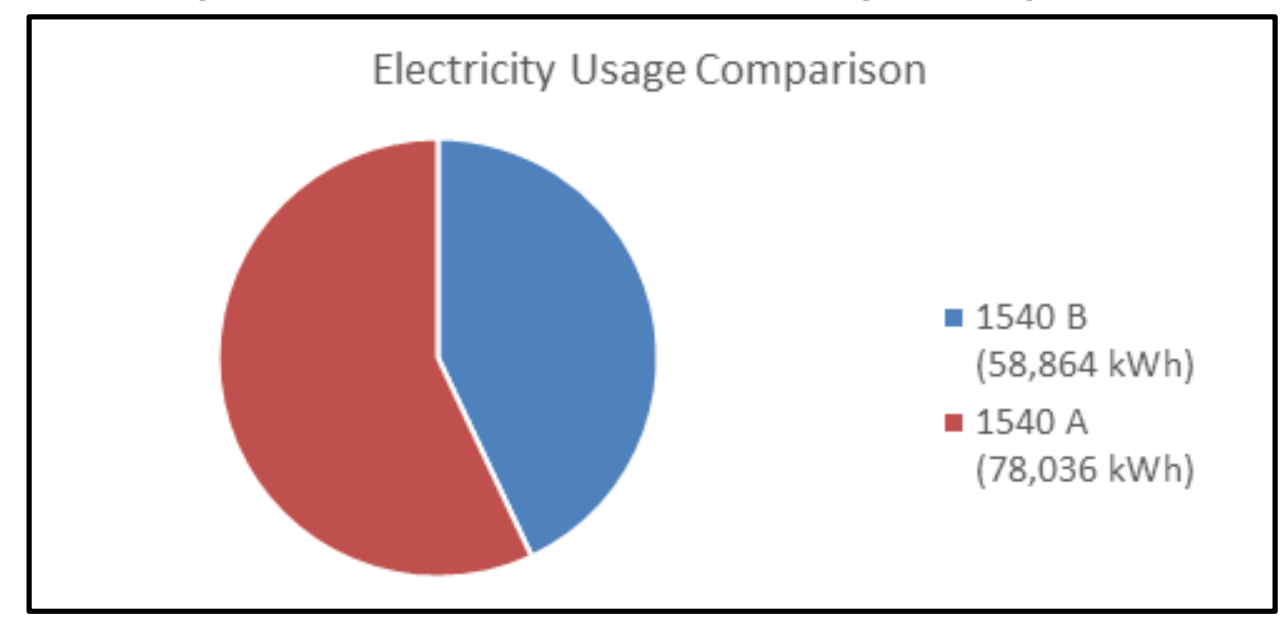

Figure 6-14. Fiscal year 2015/2016 gas utility usage comparison for Bldgs 1540A\&B. BIdg 1540A consumed 43\% less gas energy than Bldg 1540B.

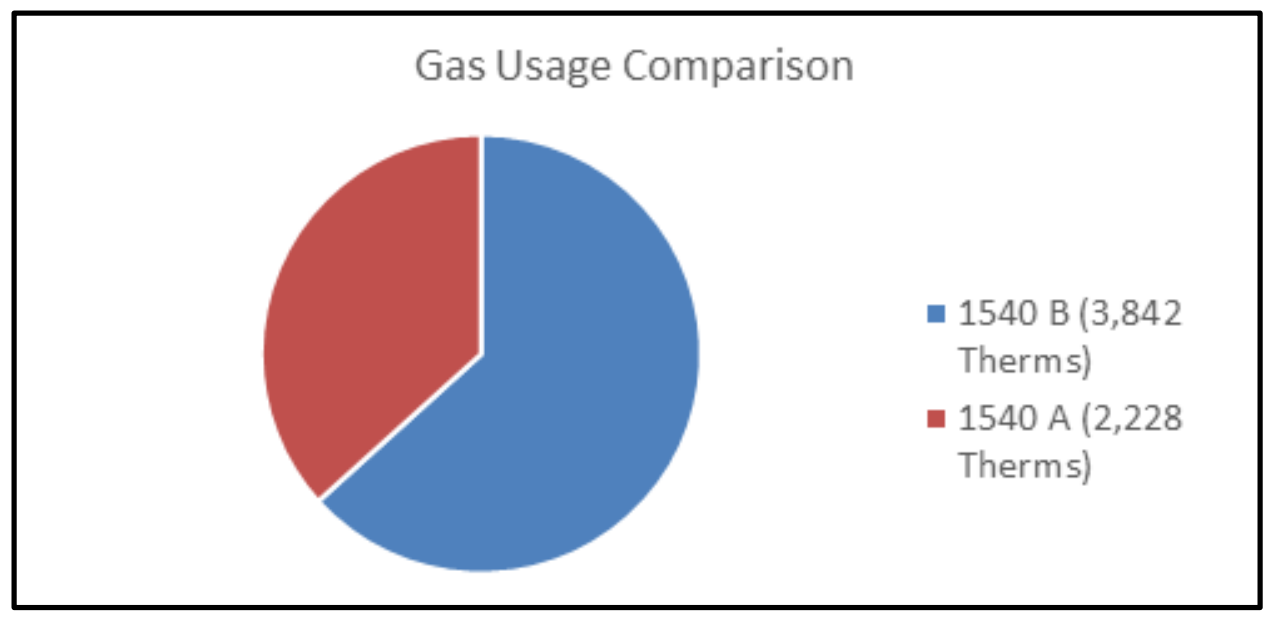

Table 6-10. Summary table of energy performance.

\begin{tabular}{|l|c|c|c|c|c|c|c|c|}
\hline & \multicolumn{4}{|c|}{ Bldg 1540A } & \multicolumn{3}{c|}{ Bldg 1540B } \\
\hline & Elec (kWh) & Gas (kWh) & $\begin{array}{c}\text { Total } \\
(\mathrm{kWh})\end{array}$ & EUI & $\begin{array}{c}\text { Elec } \\
(\mathrm{kWh})\end{array}$ & Gas (kWh) & $\begin{array}{c}\text { Total } \\
(\mathrm{kWh})\end{array}$ & EUI \\
\hline FY2013 DPW Data & 66,044 & 184,588 & 250,632 & 32.9 & 77,081 & 140,419 & 217,500 & 38.9 \\
\hline $\begin{array}{l}\text { Demonstration Data } \\
\text { Sep 2014-Aug 2015 }\end{array}$ & 97,210 & 150,082 & 247,292 & 32.5 & 51,822 & 177,806 & 229,628 & 41.1 \\
\hline $\begin{array}{l}\text { Demonstration Data } \\
\text { Sep 2015-Aug 2016 }\end{array}$ & 78,036 & 65,326 & 143,362 & 18.8 & 58,864 & 112,598 & 171,462 & 30.7 \\
\hline
\end{tabular}




\subsubsection{Operations and maintenance}

In discussions with the installation's Operations and Maintenance Chief, he stated that he was unaware of any maintenance issues with the installed system. An absence of O\&M-related issues demonstrated the system's ease of operation and maintainability. The waterside components of a radiant panel system are similar to those of a hot/chilled water fan coil system. However, the fact that a radiant panel system has no need for FCUs results in a system with fewer moving parts and filters.

\subsubsection{Distinct building issues and differences}

Additional differences between Bldgs 1540A\&B include:

1. A much greater volume of conditioned outside air is required for Bldg 1540A, primarily driven by its much larger latrine size and the fact that the current ventilation rate was based on current ASHRAE standards.

2. The fully conditioned area (heated and cooled) area (square feet) of Bldg $1540 \mathrm{~A}$ is 1.63 times greater than that of Bldg $1540 \mathrm{OB}$. The total area of Bldg $1540 \mathrm{~A}$ is 1.36 times larger than Bldg $1540 \mathrm{OB}$.

3. The total wall length separating heated-only spaces from fully conditioned spaces is nearly 1.4 times greater for Bldg $1540 \mathrm{~A}$ than for Bldg $1540 \mathrm{~B}$.

4. The envelope of Bldg $1540 \mathrm{~A}$ encloses a volume (cubic feet) that is 1.36 times larger than that of Bldg $1540 \mathrm{~B}$.

5. The mission in Bldg 1540A is different from that of Bldg 1540B. In particular, Bldg 1540A has the Information Assurance training mission, which appears to have ongoing classes of approximately 20 students and their computers. Bldg $1540 \mathrm{~B}$ does not appear to have anything comparable as far as operational intensity. Also, Bldg 1540A has a much larger shower/locker room.

\subsubsection{Other issues}

1. During periods of cool nighttime temperatures, Bldg 1540 A temperatures did not fall to the $55^{\circ} \mathrm{F}$ nighttime setback temperature during unoccupied mode. The programming for the $55^{\circ} \mathrm{F}$ night setback temperature was verified during a Jan 2016 site visit. It was also discussed with Control Systems, Inc., Fort Detrick's controls contractor, in Mar 2016, at which time the BAS was reprogrammed so that the boilers should not operate when the indoor temperatures are above $55^{\circ} \mathrm{F}$ during unoccupied periods. Therefore, the system appears to have been influenced/manipulated onsite 
by occupants during the after-hours period (6:00 p.m. to 6:00 a.m.). Despite the Mar 2016 reprogramming efforts by the controls Contractor, the HVAC system did not reach the nighttime setback temperature as intended.

2. We also noted that:

3. There is one heating VAV coil in Bldg $1540 \mathrm{OB}$ that has been nonfunctional for the past 7 months. This could account for an approximate $5-10 \%$ absence of heating energy from Bldg $154 \mathrm{OB}$. The VAV coil concern is on a DPW repair list awaiting corrective action.

4. The mechanical air handling equipment serving Bldg $1540 \mathrm{OB}$ is substantially smaller than the comparable system in Bldg 1540A.

5. In Bldg 1540A, the dehumidification discharge air temperature setpoint was raised from 45 to $50^{\circ} \mathrm{F}$. Additionally, the Entering Air Humidity sensor was programmed with a $10 \% \mathrm{RH}$ deadband. These adjustments were made because it was suspected that the DOAS reheat was a major energy consumer during the cooling season.

6. In Mar 2016, the BAS programming / logic of Bldgs $1540 A \& B$ was modified so that the boilers would not operate when the indoor space temperature is above $55^{\circ} \mathrm{F}$ during unoccupied periods. 


\section{Cost Assessment}

- Building Life-Cycle Costing: Completed using "User Friendly" Building Life-Cycle Costing (Addison 1999), a Department of Energy funded program that is a derivative of efforts described in the National Institute of Standards and Technology (NIST) Handbook 135 (Fuller and Petersen 1995).

- Life-Cycle Cost Table: See Table 7-1.

- Life-Cycle Cost Elements: See Table 7-1.

- Life-Cycle Cost Timeframe: The life-cycle cost estimate was conducted during the course of the project. First costs (material and equipment purchases and installation labor) were compiled during the course of system installation that occurred within approximately the first 8 months of the project. Operational costs, including energy costs and O\&M costs, were gathered during the 12-month data collection period.

\subsection{Cost model}

Table 7-1. Cost model for the demonstrated system.

\begin{tabular}{|l|l|c|}
\hline Cost Element & Data Tracked During the Demonstration & $\begin{array}{l}\text { Estimated } \\
\text { Costs }\end{array}$ \\
\hline Hardware capital costs & $\begin{array}{l}\text { Estimates made based on component costs for } \\
\text { demonstration. This includes, but is not limited } \\
\text { to: boiler, chiller, control systems, hardware, } \\
\text { plumbing, pumps, and radiant panels. }\end{array}$ & \$220,632 \\
\hline Installation costs & $\begin{array}{l}\text { Labor required to install equipment and } \\
\text { materials. }\end{array}$ & $\$ 110,000$ \\
\hline Consumables & $\begin{array}{l}\text { Estimates based on rate of consumable use } \\
\text { during the field demonstration. }\end{array}$ & $\$ 0$ \\
\hline $\begin{array}{l}\text { Facility operational } \\
\text { costs }\end{array}$ & Reduction in energy required vs. baseline data. & $\$ 2,746$ \\
\hline Maintenance & $\begin{array}{l}\text { Frequency of required maintenance. } \\
\text { Labor and material per maintenance action. }\end{array}$ & $\$ 220$ \\
\hline Hardware lifetime & $\begin{array}{l}\text { Estimate based on components degradation } \\
\text { during demonstration. }\end{array}$ & 0 Years \\
\hline Operator training & Estimate of training costs. & $\$ 2,500$ \\
\hline
\end{tabular}




\subsection{Cost drivers}

HVAC systems are sized and selected based on external loads (e.g., building location, orientation, and enclosure details), internal loads (e.g., occupants, equipment, and appliances), infiltration, and unique system requirements and building quality (ASHRAE 2015). The largest anticipated cost driver for a retrofit project would be the installation of a continuous air barrier within the facility. This project selected a building with an existing interior air barrier that needed to be extensively repaired and completed for purposes of this project. Nevertheless, if the facility had no air barrier to begin with, it would have added a large cost to this project to install a new air barrier.

A second major cost driver could be the required mechanical room space to install the DOAS. The DOAS AHU is configured to be approximately $50 \%$ taller than a conventional AHU to accommodate the desiccant energy recovery wheel. Care should be taken in selecting an existing mechanical equipment room so that it can accommodate the physically larger DOAS equipment. Chapter 5, "Test Design," and Appendix B, "Equipment Schedules," provide equipment-related information. Chapter 4, "Facility/Site Description," provides site information.

\subsection{Cost analysis and comparison}

A life-cycle cost analysis was performed comparing the project installation cost including materials and equipment costs, labor costs, energy costs and operation and maintenance costs. The radiant panel system with DOAS was compared with a Conventional Chilled/hot water VAV system such as existed at Bldg $1540 \mathrm{~A}$ before implementation of this demonstration project. The costs associated with a modern Conventional Chilled/hot water VAV system were estimated using RS Means.

Costs included:

- Base: (conventional chilled/hot water VAV system)

- Estimated first cost of system (using RS Means): $\$ 259,250$

- Estimated yearly utility cost (derived from scaling $1540 B$ consumption): $\$ 9,717$

- Yearly maintenance costs: $\$ 1,540$.

- Alternate: (radiant panel system with DOAS)

- Actual first cost of system: $\$ 332,632$ 
- Actual first year utility cost: $\$ 6,971$

- Yearly maintenance costs: $\$ 220$.

Assumptions were:

- USDOE/Federal Energy Management Program (FEMP) Fiscal Year: 2015

- Real Discount Rate for Capital Costs: 3.0\%

- Real Discount Rate for Operations Costs: 3.0\%

- Study Period (years covered by the Life-Cycle Cost [LCC] analysis): 25

- Number of Years before Project Occupancy or Operation: o

- USDOE Fuel Price Escalation Region: 3

- Analysis Sector: 2.

The present value life-cycle costs for 25 years were:

- Base: (conventional chilled/hot water VAV system): $\$ 470,796$

- Alternate: (radiant panel system with DOAS): $\$ 468,087$.

Our study indicated a 26.7 year SP and a 23.9 year discounted payback for the radiant panel system with DOAS. ASHRAE research has documented radiant equipment in service for more than 20 years (ASHRAE 2017). Therefore, the 23.9 year SP and 26.7 year discounted payback timelines are plausible.

Efforts were made to improve the condition of both buildings (Table 7-2). The $\$ 3,500.00$ spent in labor and materials to improve the air tightness of Bldg 1540 A yielded $\$ 87.58$ in annual energy savings (electric + gas). The SP on these sealing efforts is 40.0 years. A total of $\$ 48,996$ was invested in the retrocommissioning of Bldg 1540B. Comparison of the 2014/2015 and 2015/2016 fiscal years revealed that the retrocommissioning efforts yielded similar electrical energy usage to the prior year, but a $37 \%$ decrease in gas usage. This gas energy savings yields a $\$ 1,870$ annual benefit, with a 26.2 year SP. Accounting for the annual finances associated with envelope leaks did not materially change the life-cycle cost analysis (Table 7-3).

On a first cost basis, the radiant panel system with DOAS installed was $\$ 73,382$ (28\%) more expensive than the Conventional Chilled/Hot Water VAV System $(\$ 332,632$ and $\$ 259,250$, respectively). For rudimentary scaling purposes this translates to a $\$ 43.66 / \mathrm{ft}^{2}$ for the radiant panel system 
with DOAS and $\$ 34.03 / \mathrm{ft}^{2}$ for the Conventional Chilled/Hot Water VAV System (Table 7-4). Ultimately, the radiant panel system with DOAS produces a $\$ 2,709$ present value life-cycle savings over a 25-year period compared with the Conventional Chilled/Hot Water VAV System (Table 7-5 through Table 7-7). Therefore, the cost savings metric (less than 1\%) does not sufficiently distinguish radiant panel system with DOAS from the Conventional Chilled/Hot Water VAV System. However, the performance benefits of the radiant panel system with DOAS compared with the Conventional Chilled/Hot Water VAV System detailed in Chapter, 6 "Performance Assessment," provide motivation for adopting the radiant panel system.

Table 7-2. Financial overview of the efforts made to improve the condition of Bldgs 1540A\&B.

\begin{tabular}{|l|l|r|r|c|}
\hline Building & Effort & Investment & Annual Savings & $\begin{array}{l}\text { Payback } \\
\text { (Years) }\end{array}$ \\
\hline 1540A & Improve air tightness of building envelope & $\$ 3,500$ & $\$ 87.58$ & 40.0 \\
\hline 1540B & Retrocommissioning & $\$ 48,996$ & $\$ 1,870$ & 26.2 \\
\hline
\end{tabular}

Table 7-3. Annual finances associated with envelope leaks in Bldg 1540A.

\begin{tabular}{|l|c|c|c|}
\hline Location & $\begin{array}{c}\text { Annual Heating Cost } \\
\text { Due to Leaks }\end{array}$ & $\begin{array}{c}\text { Annual Cooling Cost } \\
\text { Due to Leaks }\end{array}$ & Total Cost \\
\hline Bldg 1540A (05/08/2014) & $\$ 312.00$ & $\$ 50.15$ & $\$ 362.15$ \\
\hline Bldg 1540A (08/13/2015) & $\$ 224.42$ & $\$ 36.07$ & $\$ 260.49$ \\
\hline $\begin{array}{l}\text { Bldg 1540A (resulting from Sealing } \\
\text { Efforts) }\end{array}$ & Heating Savings & Cooling Savings & Total Savings \\
\hline $\begin{array}{l}\text { Bldg 1540A (if window leaks } \\
\text { eliminated) }\end{array}$ & $\$ 67.58$ & $\$ 14.08$ & $\$ 101.66$ \\
\hline
\end{tabular}

Table 7-4. A comparison of materials and labor first costs between radiant panel and conventional HVAC systems.

\begin{tabular}{|l|c|c|}
\hline Parameter & $\begin{array}{c}\text { Radiant Panel } \\
\text { System }\end{array}$ & $\begin{array}{c}\text { Conventional HVAC } \\
\text { System }\end{array}$ \\
\hline Materials & $\$ 222,632.00$ & $\$ 136,884.00$ \\
\hline Labor & $\$ 110,000.00$ & $\$ 122,366.00$ \\
\hline Total & $\$ 332,632.00$ & $\$ 259,250.00$ \\
\hline Total per Square Foot & $\$ 43.66 / \mathrm{ft}^{2}$ & $\$ 34.03 / \mathrm{ft}^{2}$ \\
\hline
\end{tabular}


Table 7-5. Life-cycle cost analysis (Tbl. 1 of 3).

\begin{tabular}{|c|c|c|c|c|c|c|}
\hline \multirow[b]{3}{*}{ Case } & \multirow[b]{3}{*}{ Description } & \multicolumn{2}{|c|}{ One-Time Costs } & \multicolumn{3}{|c|}{ Total Utility } \\
\hline & & 1st Year & LCC & $\begin{array}{l}1 \text { st } \\
\text { Year }\end{array}$ & Undiscounted LCC & LCC \\
\hline & & $\$$ & $\begin{array}{c}\text { PhotoVoltaic } \\
\text { (PV) \$ }\end{array}$ & $\$$ & PV \$ & PV \$ \\
\hline Base & Conventional HVAC & $\$ 259,250$ & $\$ 259,250$ & $\$ 9,717$ & $\$ 269,000$ & $\$ 184,730$ \\
\hline Alt 1 & Radiant Panels & $\$ 332,632$ & $\$ 332,632$ & $\$ 6,971$ & $\$ 191,263$ & $\$ 131,624$ \\
\hline \multicolumn{7}{|c|}{ Life-Cycle Savings } \\
\hline Alt 1 & Radiant Panels & $(\$ 73,382)$ & $(\$ 73,382)$ & $\$ 2,746$ & $\$ 77,737$ & $\$ 53,105$ \\
\hline
\end{tabular}

Table 7-6. Life-cycle cost analysis (Tbl. 2 of 3).

\begin{tabular}{|c|c|c|c|c|c|c|}
\hline \multirow[b]{3}{*}{ Case } & \multirow[b]{3}{*}{ Description } & \multicolumn{2}{|c|}{ Maintenance } & \multirow{3}{*}{$\begin{array}{c}\text { Total } \\
\begin{array}{c}\text { Undiscounted } \\
\text { LCC }\end{array} \\
\text { PV \$ }\end{array}$} & \multirow{3}{*}{$\begin{array}{l}\text { Total } \\
\text { LCC } \\
\text { PV \$ }\end{array}$} & \multirow{3}{*}{$\begin{array}{c}\text { Net } \\
\text { Savings }\end{array}$} \\
\hline & & 1st Year & LCC & & & \\
\hline & & $\$$ & PV \$ & & & \\
\hline Base & Conventional HVAC & $\$ 1,540$ & $\$ 26,816$ & $\$ 566,750$ & $\$ 470,796$ & $\mathrm{n} / \mathrm{a}$ \\
\hline Alt 1 & Radiant Panels & $\$ 220$ & $\$ 3,831$ & $\$ 529,395$ & $\$ 468,087$ & $\mathrm{n} / \mathrm{a}$ \\
\hline \multicolumn{7}{|c|}{ Life-Cycle Savings } \\
\hline Alt 1 & Radiant Panels & $\$ 1,320$ & $\$ 22,985$ & $\$ 37,355$ & $\$ 2,709$ & $\$ 2,709$ \\
\hline
\end{tabular}

Table 7-7. Life-cycle cost analysis (Tbl. 3 of 3).

\begin{tabular}{|c|c|c|c|c|c|c|c|}
\hline \multirow[b]{2}{*}{ Case } & \multirow[b]{2}{*}{ Description } & $\begin{array}{l}\text { Simple } \\
\text { Payback }\end{array}$ & $\begin{array}{l}\text { Discounted } \\
\text { Payback }\end{array}$ & $\begin{array}{c}\text { Investment } \\
\text { Related }\end{array}$ & $\begin{array}{l}\text { Operations } \\
\text { Related }\end{array}$ & $\begin{array}{l}\text { Saving-to- } \\
\text { Invest. Ratio }\end{array}$ & $\begin{array}{c}\text { Adjusted } \\
\text { Internal } \\
\text { Rate of } \\
\text { Return }\end{array}$ \\
\hline & & Years & Years & PV \$ & PV \$ & SIR & AIRR $^{*}$ \\
\hline Base & $\begin{array}{l}\text { Conventional } \\
\text { HVAC }\end{array}$ & $\mathrm{n} / \mathrm{a}$ & $\mathrm{n} / \mathrm{a}$ & $\$ 259,250$ & $\$ 211,546$ & $\mathrm{n} / \mathrm{a}$ & $\mathrm{n} / \mathrm{a}$ \\
\hline Alt 1 & Radiant Panels & $\mathrm{n} / \mathrm{a}$ & $\mathrm{n} / \mathrm{a}$ & $\$ 332,632$ & $\$ 135,455$ & $\mathrm{n} / \mathrm{a}$ & $\mathrm{n} / \mathrm{a}$ \\
\hline \multicolumn{7}{|c|}{ Life-Cycle Savings } & \\
\hline Alt 1 & Radiant Panels & 26.7 & 23.9 & $\$ 73,382$ & $\$ 76,091$ & 1.0 & $3.1 \%$ \\
\hline
\end{tabular}




\section{Implementation Issues}

\subsection{Issues}

This demonstration project used a typical existing DoD facility to validate the performance of an integrated system of an improved building envelope, a DOAS, and a radiant heating and cooling system. The project assumed that the facility's original construction was performed in reasonable accordance with the original design intent. Therefore, it was imperative that the building be actually constructed in accordance with the original design intent and that the existing building be accurately depicted in asbuilt construction documents. Locating the original design documents proved to be a difficult task and we were frustrated to learn that there were no as-built documents.

The demonstration facility incorporated an air barrier system built with drywall encompassing the entire interior of the building. Much of this drywall air barrier system was hidden from view by installed HVAC equipment and interior partitions so as to prevent thorough inspection of the existing drywall air barrier system.

During removal of the existing HVAC equipment we discovered that the ceiling of the existing drywall air barrier system had been penetrated by numerous construction trades and never resealed to prevent air infiltration. In fact, two areas of the existing drywall air barrier in the wall adjacent to the mechanical equipment room were never closed where the supply and return air ductwork passed through the mechanical room enclosure into the occupied spaces. Apparently these two areas were never sealed during the original construction. These deficiencies were identified when tests on the existing air barrier system were unable to achieve proper pressurization.

After performing an initial air barrier test and being unable to pressurize the building due to excessive envelope penetrations, we sealed numerous ceiling drywall air barrier penetrations and two other large drywall air barrier penetrations. Upon repeating the air barrier tests, the building once again failed to achieve proper pressurization. This time, we determined that wall and ceiling air barriers located in an almost inaccessible location behind a hard drywall interior ceiling of the locker rooms had never been completed as required by the original design construction documents. This location (shown 
in Figure 3-5) allowed direct uncontrolled infiltration of outdoor air into the interior of the building. When this area was eventually sealed, air barrier tests were able to achieve proper pressurization of the building to determine the baseline air tightness of the original design intent.

\subsection{Lessons Learned}

- In planning retrofit projects, one should not assume that existing construction complies with the original design intent.

- In future construction projects, after the building envelope construction has been completed, air barrier tests should be performed to demonstrate that the building has been properly sealed before installing interior finishes.

During initial HVAC system testing, we found that the existing control system was undocumented, hindering our ability to perform in situ tests of the existing HVAC system. To overcome this handicap, we located and used the original HVAC controls subcontractor to determine the control points and proper operation of the HVAC controls system. When the HVAC system tests were performed, we determined that various system components were not operating properly and that they required additional DPW maintenance to get the existing HVAC system operating in accordance with the design intent. As this research effort was originally proposed for execution at a different Army installation, the project was not planned in advance with Fort Detrick's DPW. Therefore, maintenance personnel and system's components were not programmed or coordinated in advance. Additional unanticipated coordination with the DPW and the installation was required to accommodate this request before implementation of the Energy Monitoring System.

- For retrofit projects, one should not assume that the existing HVAC system complies with the original design intent.

Our original design concept for the Energy Monitoring System assumed that a new base-wide utility monitoring and control system (UMCS) being installed by Fort Detrick would be available for our use to remotely monitor data points for this HVAC demonstration project. However, we learned that current network security requirements disallowed our access to Army data, including building operational data. As a result, an unplanned standalone Energy Monitoring System had to be designed 
and implemented within the confines of our project budget and schedule. Our Energy Monitoring System allowed us to remotely access system operational data, but gave us no ability to remotely control or adjust our systems. This problem was further exacerbated by the fact that even Fort Detrick's DPW had no ability to make system adjustments on our behalf. Any control system changes or adjustments had to be separately procured through Fort Detrick's control system contractor. These network security restrictions cost our project a lot of time and money that could have been used more productively elsewhere. They also severely limited our ability to adjust system parameters, setpoints and schedules in an effort to optimize system performance.

- Network security policies will probably require installation of standalone data acquisition systems to remotely obtain operational data on future demonstration projects. Also, it will probably be impossible to remotely adjust or control demonstrated systems.

During the design of the demonstration HVAC system, interior occupant loads were based on existing program requirements and the existing number of occupants in the space. For example, the student count in the IA training room (Co18B) was initially determined to be 10 students in the classroom. However, during design and/or construction, the classroom program was doubled to accommodate 20 students. This necessitated redesign and renovation of the classroom HVAC radiant panels including installation of additional radiant cooling panels to accommodate the cooling load of 20 additional students and their corresponding computer equipment.

- Unanticipated programming requirements may change occupancy loads during an ongoing project.

- As with any other HVAC system, the ability of a radiant heating and cooling system to accommodate unanticipated additional loads is limited to the excess capacity designed into the system. Consider providing oversized supply and return piping from zones which might be subject to increased loads.

When conducting demonstration projects involving buildings, the number of building occupants and their day-to-day activities can significantly affect results. This was problematic for this project because we had no means of tracking the number of people using the buildings on a daily basis or of knowing what kind of activities were occurring. 
We had excellent support from the Unit's maintenance officer, but he was already seriously overworked so we tried to limit asking for his assistance to only the most essential matters.

- Onsite support by a person who has the time, flexibility, and technical knowledge to make observations, report findings, coordinate with local personnel, and make minor adjustments or corrections can be very valuable.

We had great difficulty accessing background energy consumption data because Fort Detrick facilities were not metered on a building-by-building basis. Currently Fort Detrick is executing a separate program to install a new base-wide networked UMCS system to monitor and collect facility data, including Bldg 1540. Unfortunately, the lack of available energy performance data for Bldg 1540 forced us to make very rudimentary assumptions of Bldg 1540's energy performance before this project. Although we were able to get monthly utilities data from Fort Detrick, the data had unexplained gaps, which reduced the value of the datasets.

- Quality historic energy data may not be available for baseline comparisons.

The energy consumption of the radiant heating and cooling system is greatly affected by the amount of ventilation air required to offset exhaust air and positively pressurize the facility. Currently there is no accepted industry method to precisely calculate this requirement. The volume of outside air required above building exhaust quantities is based on the experience and judgment of the designer. In actual use, we recommend adjustment of outside air volumes to that required to satisfy the actual ventilation and pressurization requirements of the building.

- Outside air flow should be adjusted to that required to satisfy the actual ventilation and pressurization requirements of the building.

This project used the existing gas utility meters installed at each half of the building to measure gas consumption. An onsite USACE employee emailed us a photograph of each meter's display at the start of each month. Since we had no ability to make remote adjustments of system parameters, schedules, or set points, this may have been adequate for our needs. However, if we had had an ability to remotely control the system, it would have been helpful to be able to measure and record gas usage in near real time.

- When attempting to optimize system performance, near real time data is essential. 
In addition to estimating the outside air requirement, it is necessary to specify the dehumidification coil's leaving air temperature in the DOAS system to satisfy the anticipated humidity load of the building. This is usually based on the experience and judgment of the designer. In this project, we had planned to adjust the dehumidification coil leaving air temperature to determine the actual leaving air temperature required to satisfy the actual humidity load of the building. Unfortunately, since our Energy Monitoring System was prohibited from having any control capabilities, we were unable to adjust this parameter. We recommend adjusting the dehumidification coil's leaving air temperature to satisfy the actual humidity load of the building. This capability could save considerable energy.

- The DOAS dehumidification coil's leaving air temperature should be adjusted to satisfy the actual humidity load of the building.

All the equipment and design expertise required to implement the use of these technologies is already in place from an industry perspective. Current design requirements are well acknowledged by HVAC designers. Commercial installation by HVAC installers is straightforward although not typically specified by HVAC designers.

No potential regulations or special permits are required to use these technologies. The required equipment is standard commercial off-the-shelf (COTS) and does not require customization or custom build procedures.

End-users have been reluctant to use radiant heating and cooling since it represents a paradigm shift in their normal application of HVAC technology. A common concern is that this technology cannot adequately cool or dehumidify to satisfy occupant comfort. This project demonstrated that radiant systems are capable of satisfying occupants' space heating and cooling requirements.

Another common concern is that a radiant cooling system will experience condensation on the cool surface of the radiant panels. By properly dehumidifying ventilation air through the DOAS system, by having a tight building envelope, and by maintaining the surface temperatures of the radiant panels above the DPT of the air within the space, we demonstrated that it is possible to implement radiant cooling without risk of condensation problems within the facility.

Typical decision-making factors include "known" technology and avoiding risky ("unknown") technologies. However, common "known" HVAC 
technologies are high risk with respect to maintenance costs. In an era of decreasing maintenance budgets and reduced maintenance staffing, radiant heating and cooling systems, which are relatively maintenance free, thus require reduce maintenance costs and personnel.

\subsection{Other possible Lessons Learned to consider}

- Above-ceiling access could be a future problem with grid-mounted radiant panel systems; however, this issue can be overcome with additional coordination of fire, electrical, and mechanical services located within the ceiling to consolidate as best as possible.

- For retrofit applications, it is best to plan to replace the entire existing ceiling grid system. Attempting to work around existing fire sprinklers and light fixture locations proved to be very difficult. In some cases, "cloud" radiant panels might be a good option (vs. grid-mounted radiant panels) as they would give the designer and installers some flexibility in mounting the cloud radiant panels. This might also facilitate future above-ceiling access.

- An accurate estimate of the number of individuals who typically occupy a given space is crucial for proper load calculations of the radiant system. 


\section{Appendix A: Points of Contact}

\begin{tabular}{|c|c|c|c|}
\hline Point of Contact & Organization & Phone \& E-mail & Role in Project \\
\hline James P. Miller & U.S. Army ERDC-CERL & $\begin{array}{l}\text { 217-373-4566 } \\
\text { James.P.Miller@usace.army.mil }\end{array}$ & $\begin{array}{l}\text { Project Manager, } \\
\text { Contracting Officer's } \\
\text { Representative }\end{array}$ \\
\hline Patrick Tanner & The PERTAN Group & $\begin{array}{l}\text { 217-351-4330, x201 } \\
\text { patrick.tanner@pertan.com }\end{array}$ & Principal \\
\hline Anthony Latino & The PERTAN Group & $\begin{array}{l}\text { 217-356-1348 } \\
\text { anthony.latino@pertan.com }\end{array}$ & Project Manager \\
\hline $\begin{array}{l}\text { Raymond } \\
\text { Patenaude }\end{array}$ & The PERTAN Group & $\begin{array}{l}\text { 727-369-0881 } \\
\text { ray@TheHolmesAgency.com }\end{array}$ & Technical Lead \\
\hline $\begin{array}{l}\text { Ross } \\
\text { Montgomery }\end{array}$ & The PERTAN Group & $\begin{array}{l}\text { 941-729-4496 } \\
\text { rossmont@aol.com }\end{array}$ & $\begin{array}{l}\text { Commissioning } \\
\text { Provider }\end{array}$ \\
\hline $\begin{array}{l}\text { Christopher } \\
\text { Martinez }\end{array}$ & The PERTAN Group & chrismartinez@tampabay.rr.com & Energy Consultant \\
\hline $\begin{array}{l}\text { Gary Stenlund, } \\
\text { P.E. }\end{array}$ & $\begin{array}{l}\text { Engineering Professionals, } \\
\text { Inc. }\end{array}$ & $\begin{array}{l}\text { 813-251-6848 } \\
\text { stenlund@engrpros.com }\end{array}$ & $\begin{array}{l}\text { Design Engineer of } \\
\text { Record }\end{array}$ \\
\hline Paul Smeck & $\begin{array}{l}\text { Fort Detrick, 21st Signal } \\
\text { Brigade }\end{array}$ & $\begin{array}{l}\text { 301-619-6189 } \\
\text { Paul.D.Smeck.civ@mail.mil }\end{array}$ & $\begin{array}{l}\text { Bldg } 1540 \text { User's } \\
\text { Representative }\end{array}$ \\
\hline Chris Nygard & $\begin{array}{l}\text { Fort Detrick DPW, Energy } \\
\text { Manager }\end{array}$ & $\begin{array}{l}\text { 301-619-0506 } \\
\text { christian.p.nygard.civ@mail.mil }\end{array}$ & $\begin{array}{l}\text { Installation Energy } \\
\text { Manager }\end{array}$ \\
\hline Carl B. Pritchard & Fort Detrick DPW, Director & $\begin{array}{l}\text { 301-619-2454 } \\
\text { carl.b.pritchard.civ@mail.mil }\end{array}$ & DPW \\
\hline Glenn Murphey & USACE Baltimore District & Glenn.N.Murphey@usace.army.mil & Construction Inspector \\
\hline Katie Brown & USACE Baltimore District & Katharine.L.Brown@usace.army.mil & $\begin{array}{l}\text { Commissioning } \\
\text { Specialist }\end{array}$ \\
\hline Sarah Medepalli & ESTCP & $\begin{array}{l}\text { 703-610-2158 } \\
\text { sarah.medepalli@noblis.org }\end{array}$ & Technical Monitor \\
\hline
\end{tabular}




\section{Appendix B: Equipment Schedules}

Table B-1. Bldg 1540A mechanical equipment schedule.

\begin{tabular}{|c|c|c|c|c|c|}
\hline Item \# & Description & Brand & Model & Location & Circuit \# \\
\hline AHU-1 & Air Handling Unit & Daikin & $\begin{array}{l}\text { CAH006GDG } \\
\text { C }\end{array}$ & COO8-MER & 2 \\
\hline B-1 & Boiler (existing) & HydroTherm & $\mathrm{KN}-4$ & C008-MER & 12 \\
\hline $\mathrm{CH}-1$ & Chiller & Carrier & 30RAP020 & Mech Courtyard & 1 \\
\hline $\mathrm{CUH}-1$ & Cabinet Unit Heater & EXISTING & & C001-Vestibule & 14 \\
\hline CUH-2 & Cabinet Unit Heater & EXISTING & & C022-W. Vestibule & 14 \\
\hline CUH-3 & Cabinet Unit Heater & EXISTING & & C023-M. Vestibule & 14 \\
\hline $\mathrm{CUH}-5$ & Cabinet Unit Heater & EXISTING & & C025-W. Latrine & 14 \\
\hline CUH-6 & Cabinet Unit Heater & EXISTING & & C024-M. Latrine & 14 \\
\hline $\mathrm{CUH}-7$ & Cabinet Unit Heater & EXISTING & & C024-M. Latrine & 16 \\
\hline $\mathrm{CUH}-8$ & Cabinet Unit Heater & EXISTING & & C014-Corridor & 18 \\
\hline $\mathrm{DH}-1$ & & & & & 9 \\
\hline EF-1 & $\begin{array}{l}\text { Mechanical Room Exhaust } \\
\text { Fan }\end{array}$ & EXISTING & & C008-MER & 7 \\
\hline EF-2 & Electrical Room Exhaust Fan & EXISTING & & c009-Elect Room & 7 \\
\hline EF-3 & AHU/Latrine Exhaust Fan & Cook & 135SQN-hp & C008-MER & 6 \\
\hline FCU-1 & $\begin{array}{l}\text { Fan Coil Unit; only supplies } \\
\text { heating }\end{array}$ & EXISTING & & C028-Loading Area & 5 \\
\hline Glycol Sys & Glycol System & $\begin{array}{l}\text { Advantage } \\
\text { Controls }\end{array}$ & GF & COO8-MER & 23 \\
\hline $\mathrm{HX}-1$ & Energy Recovery Wheel & Daikin & ECW 364-3A & C008-MER AHU & 15 \\
\hline LP-1 & $\begin{array}{l}\text { Electrical Sub-Distribution } \\
\text { Panel }\end{array}$ & EXISTING & & c009-Elect Room & 11 \\
\hline MS-1 & $\begin{array}{l}\text { Mini-Split System for } \\
\text { Comm/Information } \\
\text { Technology (IT) Closet }\end{array}$ & Daikin & $\begin{array}{l}\text { INDOOR- } \\
\text { FTXS12LVJU } \\
\text { OUTDOOR- } \\
\text { RXS12LVJU }\end{array}$ & $\begin{array}{l}\text { Mech } \\
\text { Courtyard/C013 }\end{array}$ & $24 \& 26$ \\
\hline P-1 & Pump & Bell \& Gossett & $\begin{array}{l}\text { B\&G SERIES } \\
801-1 / 2 \times \\
1-1 / 2 \times 9- \\
1 / 2\end{array}$ & C008-MER & 4 \\
\hline $\mathrm{P}-2$ & Pump & EXISTING & & C008-MER & 17 \\
\hline$P-3$ & Pump - located within Chiller & Carrier & & Mech Courtyard & 1 \\
\hline P-4 & Pump & Bell \& Gossett & $\begin{array}{l}\text { B\&G SERIES } \\
801-1 / 2 \times \\
1-1 / 2 \times 7 B\end{array}$ & C008-MER & 3 \\
\hline UH-1 & Unit Heater & Existing & & CO08-MER & 16 \\
\hline $\mathrm{UH}-2$ & Unit Heater & Existing & & c009-Elect Room & 16 \\
\hline UH-4 & Unit Heater & Existing & & C029-Arms Vault & 16 \\
\hline UH-5 & Unit Heater & Existing & & C028-Loading Area & 18 \\
\hline
\end{tabular}




\begin{tabular}{|l|l|l|l|l|l|}
\hline Item \# & Description & Brand & Model & Location & Circuit \# \\
\hline UH-6 & Unit Heater & Existing & & C028-Loading Area & 18 \\
\hline UH-7 & Unit Heater & Existing & & C027-Gen. Storage & 18 \\
\hline UH-8 & Unit Heater & Existing & & CO27-Gen. Storage & 18 \\
\hline UH-9 & Unit Heater & Existing & & C027-Gen. Storage & 18 \\
\hline UH-10 & Unit Heater & Existing & & C026-Gen. Storage & 18 \\
\hline VAV & ALL REMOVED & & & & \\
\hline
\end{tabular}

Table B-2. Air handler unit schedule.

\begin{tabular}{|c|c|c|}
\hline \multicolumn{3}{|l|}{ Air Handling Unit Schedule } \\
\hline Mark & AHU & AHU-1 \\
\hline Supply Air & CFM & 1625 \\
\hline Outside Air & CFM & 1625 \\
\hline Static Pressure In. H2O & EXT./TOTAL & $1.0 / 2.7$ \\
\hline Max. Fan Speed & RPM & 3300 \\
\hline Motor & Horsepower (hp) & 2.0 \\
\hline Fan Wheel Type & - & Plenum \\
\hline Filter & - & MERV8 \\
\hline Electrical & $\mathrm{V} / \varnothing / \mathrm{Hz}$ & $208 V / 3 \varnothing$ \\
\hline Location & - & Mech. Room \\
\hline Manufacturer & - & DAIKIN \\
\hline Model & - & CAH006GDGC \\
\hline Area Served & - & Offices \\
\hline \multicolumn{3}{|l|}{ Cooling Coil } \\
\hline Total Capacity & BTUH & 114,750 \\
\hline Sensible Capacity & BTUH & 63,000 \\
\hline Cooling Coil & Rows/Fins & $11 \mathrm{FPI}$ \\
\hline Cooling Coil Max. Face Vel. & feet/minute (FPM) & 286 \\
\hline Cooling Coil Max. Press. Drop & IN. $\mathrm{H}_{2} \mathrm{O}$ & 0.45 \\
\hline Entering Air Temp. (Db/Wb) & ${ }^{\circ} \mathrm{F} /{ }^{\circ} \mathrm{F}$ & $83.2 / 70.8$ \\
\hline Leaving Air Temp. (Db/Wb) & ${ }^{\circ} \mathrm{F} /{ }^{\circ} \mathrm{F}$ & $47.7 / 47.5$ \\
\hline Chilled Water Flow & GPM & 33.2 \\
\hline Chilled Water Temp. (Entering/Leaving) & ${ }^{\circ} \mathrm{F} /{ }^{\circ} \mathrm{F}$ & $42 / 49$ \\
\hline Max. Water Press. Drop & FT. $\mathrm{H}_{2} \mathrm{O}$ & 8.2 \\
\hline \multicolumn{3}{|l|}{ Heating } \\
\hline Total Capacity & BTUH & 57,275 \\
\hline Heating Coil & ROWS/FINS & $2 / 13 \mathrm{FPI}$ \\
\hline Heating Coil Max. Face Vel. & FPM & 433 \\
\hline Heating Coil Max. Press. Drop & IN. $\mathrm{H}_{2} \mathrm{O}$ & 0.29 \\
\hline Entering Air Temp. & ${ }^{\circ} \mathrm{F}$ & 48 \\
\hline Leaving Air Temp. & ${ }^{\circ} \mathrm{F}$ & 80 \\
\hline
\end{tabular}




\begin{tabular}{|c|c|c|}
\hline \multicolumn{3}{|l|}{ Air Handling Unit Schedule } \\
\hline Hot Water Flow & GPM & 11.4 \\
\hline Hot Water Temp. (Entering/Leaving) & ${ }^{\circ} \mathrm{F} /{ }^{\circ} \mathrm{F}$ & $105 / 94.9$ \\
\hline Max. Water Press. Drop & FT. $\mathrm{H}_{2} \mathrm{O}$ & 1.3 \\
\hline Notes & - & $1,2,3$ \\
\hline \multicolumn{3}{|l|}{ 20\% Prop. Glycol } \\
\hline \multicolumn{3}{|c|}{ Disconnect Switch By Div. 16. Factory Variable Speed Drive (VSD) for Fan and HX. } \\
\hline
\end{tabular}

Table B-3. Air-cooled scroll chiller schedule.

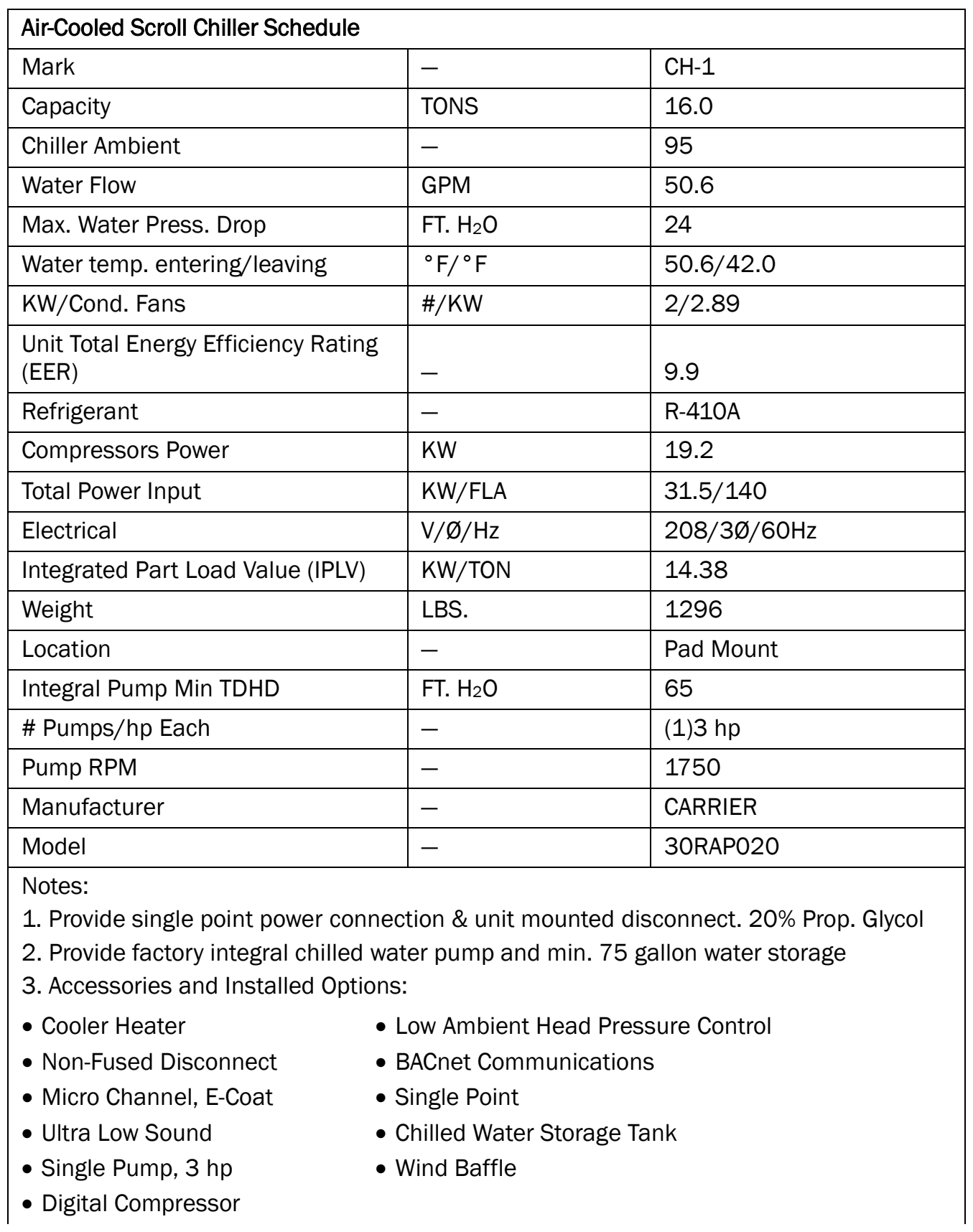


Table B-4. Enthalpy heat exchanger schedule.

\begin{tabular}{|c|c|c|c|c|}
\hline \multicolumn{5}{|c|}{ Enthalpy Heat Exchanger Schedule } \\
\hline \multicolumn{2}{|c|}{ HX-1 (SUMMER OPERATION) } & \multirow{2}{*}{$\begin{array}{l}\text { Outside Air } \\
1651 \text { CFM }\end{array}$} & \multirow{2}{*}{$\begin{array}{l}\text { Wheel } \\
0.8\end{array}$} & \multirow{2}{*}{\begin{tabular}{|l|} 
Supply Air \\
1625 CFM
\end{tabular}} \\
\hline Airflow & SCFM* & & & \\
\hline Temperature & ${ }^{\circ} \mathrm{F} \mathrm{db} / \mathrm{wb}$ & $92 / 77$ & IN.W.C. & $83.2 / 70.8$ \\
\hline Humidity Ratio & GR/LB & 116 & 523 & 92 \\
\hline Static Pressure & IN.W.C. & -0.25 & FPM & 1.05 \\
\hline \multirow{2}{*}{\multicolumn{2}{|c|}{ Heat Recovered }} & - & - & 43,900 \\
\hline & & Exhaust Air & Wheel & Building Air \\
\hline Airflow & SCFM & 1126 CFM & 0.5 & $1100 \mathrm{CFM}$ \\
\hline Temperature & ${ }^{\circ} \mathrm{F} \mathrm{db} / \mathrm{wb}$ & $90.0 / 75.7$ & IN.W.C. & $77 / 65$ \\
\hline Humidity Ratio & GR/LB & 115 & - & 79 \\
\hline Static Pressure & IN.W.C. & 1.0 & $1 / 2 \mathrm{hp}$ & -0.5 \\
\hline Notes & - & DAIKIN & 1. & MOD. ECW 364-3A \\
\hline
\end{tabular}

Table B-5. Preheat coil schedule.

\begin{tabular}{|l|l|l|l|l|l|}
\hline \multicolumn{5}{|l|}{ Preheat Coil Schedule } \\
\hline COIL \# & CFM & BTUH & SIZE & WATER GPM $\left(180^{\circ}-160^{\circ}\right)$ & \# REQUIRED \\
\hline 1 & 1625 & 71,700 & $24 X 15$ & 7.4 & 1 \\
\hline
\end{tabular}

Table B-6. Fan schedule.

\begin{tabular}{|c|c|c|c|c|}
\hline \multicolumn{5}{|l|}{ Fan Schedule } \\
\hline Tag & - & (E)EF-1 & (E)EF-2 & (N)EF-3 \\
\hline Service & - & Mech. & Elect. & Latrines \\
\hline Air Quantity & CFM & 1270 & 160 & 1,100 \\
\hline Ext. Static Press. & IN. $\mathrm{H}_{2} \mathrm{O}$ & $1 / 4$ & $1 / 4$ & 1.2 \\
\hline Fan Type & - & Prv & Prv & In-Line \\
\hline Drive & - & Existing & Existing & Belt \\
\hline Sones & - & Existing & Existing & 15.0 \\
\hline Motor & H.P./WATTS & $1 / 2$ & $1 / 12$ & $1 / 2$ \\
\hline Fan Speed & RPM & Existing & Existing & 1639 \\
\hline Power & $\mathrm{V} / 1 \varnothing$ & $115 \mathrm{~V} / 1 \varnothing$ & $115 V / 1 \varnothing$ & $115 \mathrm{~V} / 1 \varnothing$ \\
\hline Control & - & T-Stat & T-Stat & W/AHU-1 \\
\hline Location & - & Roof & Roof & Mech. \\
\hline Manufacturer & - & Existing & Existing & Cook \\
\hline Model & - & Existing & Existing & 135SQN-hp \\
\hline Notes & & 1 & 1 & 2 \\
\hline \multicolumn{2}{|c|}{ 1. Existing Fan To Remain. } & & & \\
\hline
\end{tabular}




\section{Fan Schedule}

2. Complete with Disconnect Switch, Vibration Isolators, Motor Operated Low Leakage Damper and Actuator, Spring Return, and Interlock to AHU-1 Operation.

Table B-7. Hood schedule.

\begin{tabular}{|l|l|l|l|l|l|l|l|l|}
\hline \multicolumn{2}{|l}{ Hood Schedule } \\
\hline Qty & Mark & $\begin{array}{l}\text { Throat } \\
\text { Size }\end{array}$ & $\begin{array}{l}\text { Hood } \\
\text { Size }\end{array}$ & Height & CFM & $\begin{array}{l}\text { Throat } \\
\text { Velocity }\end{array}$ & $\begin{array}{l}\text { Press. } \\
\text { Drop }\end{array}$ & Accessories \\
\cline { 2 - 6 } & L x W & L x W & H & & & \\
\hline 1 & $\begin{array}{l}\text { OA Int. } \\
\text { Hood }\end{array}$ & $42 \times 12$ & $78 \times 36$ & 14 & 1625 & 464 & 0.02 & 3 \\
\hline
\end{tabular}

Table B-8. Minimum code required outside air ventilation rates.

\begin{tabular}{|c|c|c|c|c|c|c|c|c|c|c|c|c|c|c|}
\hline \multicolumn{15}{|c|}{ Minimum Code Required Outside Air Ventilation Rates (per ASHRAE Standard 62.1-2010) } \\
\hline Area Served & $\begin{array}{c}\text { Occup. } \\
\text { Cat. }\end{array}$ & $\begin{array}{l}\text { Default } \\
\text { Occupant } \\
\text { Density }\end{array}$ & $\begin{array}{c}\text { Net } \\
\text { Area } \\
\text { Az }\end{array}$ & $\begin{array}{c}\text { Area } \\
\text { Outdoor } \\
\text { Air Rate } \\
\text { Ra }\end{array}$ & $\begin{array}{l}\text { Code } \\
\text { Req'd } \\
\text { Based } \\
\text { On Floor } \\
\text { Area }\end{array}$ & & $\begin{array}{c}\text { \# People } \\
\text { Pz }\end{array}$ & $\begin{array}{l}\text { People } \\
\text { Outdoor Air } \\
\text { Rate } \\
\text { Rp }\end{array}$ & \begin{tabular}{|c|} 
Code \\
Req'd Oa \\
Based \\
On \\
People
\end{tabular} & $\begin{array}{c}\text { Code Req'd } \\
\text { OA } \\
\text { Total } \\
\text { VBz } \\
\text { AzRa+PzRp }\end{array}$ & & $\begin{array}{c}\text { Zone Air } \\
\text { Distrib. } \\
\text { Effec. } \\
\text { Ez }\end{array}$ & & $\begin{array}{c}\text { Total Oa } \\
\text { Req'd by } \\
\text { Code } \\
\text { Voz }\end{array}$ \\
\hline & & $\begin{array}{c}\mathrm{P} / 1000 \\
\mathrm{SF}\end{array}$ & SF & CFM/SF & CFM & & Person(s) & CFM/person & CFM & CFM & & & & CFM \\
\hline Office & Office & Count & 1470 & 0.06 & 88 & + & 20 & 5 & 100 & 188 & / & 0.8 & $=$ & 235 \\
\hline $\begin{array}{l}\text { Conf/ } \\
\text { Training }\end{array}$ & Conf & Count & 1256 & 0.06 & 75 & + & 22 & 5 & 110 & 185 & / & 0.8 & $=$ & 231 \\
\hline \multicolumn{13}{|l|}{ Total Req'd } & $=$ & 466 \\
\hline \multicolumn{13}{|c|}{ Total Provided } & $=$ & 1625 \\
\hline
\end{tabular}

Table B-9. Pump schedule.

\begin{tabular}{|c|c|c|c|c|c|c|c|c|c|}
\hline \multicolumn{10}{|c|}{ Pump Schedule } \\
\hline Symbol & Type & Service & Location & $\begin{array}{l}\text { Flow } \\
\text { (gpm) }\end{array}$ & $\begin{array}{c}\text { Total } \\
\text { Head } \\
\text { (ft) }\end{array}$ & $\mathrm{Rpm}$ & $\begin{array}{l}\text { Power } \\
\text { (hp) }\end{array}$ & $\begin{array}{c}\text { Elect. } \\
(\mathrm{V} / \varnothing / \mathrm{Hz})\end{array}$ & Model \\
\hline P-1 & In-Line & Hot Water & c008 & 45 & 60 & 1750 & $3 \mathrm{hp}$ & $208 / 3 / 60$ & $\begin{array}{l}\text { B\&G Series } 80 \\
1-1 / 2 \times 1-1 / 2 \times 9-1 / 2\end{array}$ \\
\hline P-2 & In-Line & $\begin{array}{l}\text { Boiler } \\
\text { Loop }\end{array}$ & c008 & 15 & 10 & 1750 & $1 / 4 \mathrm{hp}$ & $115 / 1 / 60$ & Existing \\
\hline P-3 & In-Ch-1 & Ch Water & Chiller & 50.6 & 65 & 1750 & $3 \mathrm{hp}$ & $208 / 3 / 60$ & In Chiller \\
\hline P-4 & In-Line & Ch Water & c008 & 15.1 & 46 & 1750 & $3 / 4 \mathrm{hp}$ & $208 / 3 / 60$ & $\begin{array}{l}\text { B\&G Series } 80 \\
1-1 / 2 \times 1-1 / 2 \times 7 B\end{array}$ \\
\hline
\end{tabular}

Table B-10. Expansion tank schedule.

\begin{tabular}{|c|c|c|c|c|c|}
\hline \multicolumn{6}{|c|}{ Expansion Tank Schedule } \\
\hline Tag & Location & $\begin{array}{c}\text { Total Volume } \\
\text { (gal) }\end{array}$ & $\begin{array}{c}\text { Accept. Vol. } \\
\text { (gal) }\end{array}$ & Type & Remark \\
\hline ET-1 & C008 & 10 & 5 & Diaphragm & Horizontal Mounted \\
\hline ET-2 & C008 & 10 & 5 & Diaphragm & Horizontal Mounted \\
\hline
\end{tabular}


Table B-11. Boiler schedule (existing).

\begin{tabular}{|c|c|c|}
\hline \multicolumn{3}{|l|}{ Existing Boiler Schedule } \\
\hline Mark & - & B-1 \\
\hline Service & - & Heating \\
\hline Type & - & Cast Iron \\
\hline \multicolumn{3}{|l|}{ Burner Data } \\
\hline Type & - & Forced \\
\hline Fuel & - & Nat. Gas \\
\hline Output & MBTUH & 369 \\
\hline Input & MBTUH & 399 \\
\hline Fuel Consumption & $\mathrm{CFH}$ & 399 \\
\hline \multicolumn{3}{|l|}{ Boiler Data } \\
\hline Working Pressure & PSIG & 60 \\
\hline Test Pressure & PSIG & 100 \\
\hline Minimum Heating Surface & SQ.FT. & Existing \\
\hline Minimum Efficiency & $\%$ & $90 \%$ \\
\hline \multicolumn{3}{|l|}{ Electrical Data } \\
\hline Power & $(\mathrm{V} / \varnothing / \mathrm{Hz})$ & $150 V / 1 \varnothing$ \\
\hline Model & Hydrotherm & $\mathrm{KN}-4$ \\
\hline Notes & & To Remain \\
\hline \multicolumn{3}{|c|}{$\begin{array}{l}\text { Combustion air required: } 399,000 \text { BTUH gas input divided BY } 1 \text { SQ.IN/3,000 BTUH } \\
\text { equals } 133 \text { sq.in. opening. } 864 \text { sq.in. opening provided. }\end{array}$} \\
\hline
\end{tabular}

Table B-12. Fan coil unit schedule (existing).

\begin{tabular}{|c|l|l|l|l|l|l|}
\hline \multicolumn{2}{|l|}{ Existing Fan Coil Unit Schedule } \\
\hline \multirow{2}{*}{$\begin{array}{l}\text { Nominal Airflow } \\
\text { Tag }\end{array}$} & $\begin{array}{l}\text { Rating } \\
\text { (CFM) }\end{array}$ & $\begin{array}{l}\text { Minimum } \\
\text { (BTUH) }\end{array}$ & $\begin{array}{l}\text { EWT } \\
\left({ }^{\circ} \text { F) }\right.\end{array}$ & $\begin{array}{l}\text { Water Flow } \\
\text { (GPM) }\end{array}$ & $\begin{array}{l}\text { Power } \\
\text { (hp) }\end{array}$ & $\begin{array}{l}\text { Elect. } \\
\text { (V/ס/Hz) }\end{array}$ \\
\hline FCU-1 & 530 & 34,490 & 180 & 3.4 & $1 / 4$ & $115 / 1 / 60$ \\
\hline
\end{tabular}

Table B-13. Cabinet unit heater schedule (existing).

\begin{tabular}{|c|c|c|c|c|c|c|c|c|c|}
\hline \multicolumn{10}{|c|}{ Existing Cabinet Unit Heater Schedule } \\
\hline \multirow[b]{2}{*}{ Symbol } & \multirow[b]{2}{*}{$\begin{array}{l}\text { Capacity } \\
\text { (BTUH) }\end{array}$} & \multirow[b]{2}{*}{$\begin{array}{l}\text { EAT } \\
\left({ }^{\circ} \mathrm{F}\right)\end{array}$} & \multirow[b]{2}{*}{$\begin{array}{l}\text { EWT } \\
\left({ }^{\circ} \mathrm{F}\right)\end{array}$} & \multirow[b]{2}{*}{$\begin{array}{l}\text { LWT } \\
\left({ }^{\circ} \mathrm{F}\right)\end{array}$} & \multirow{2}{*}{$\begin{array}{l}\text { Water } \\
\text { Flow } \\
\text { (GPM) }\end{array}$} & \multicolumn{2}{|c|}{ Fan Motor } & \multirow[b]{2}{*}{ Type } & \multirow[b]{2}{*}{ Location } \\
\hline & & & & & & hp & $\begin{array}{l}\text { Elect. } \\
(\mathrm{V} / \varnothing / \mathrm{Hz})\end{array}$ & & \\
\hline CUH-1 & 6140 & $55^{\circ}$ & $180^{\circ}$ & $160^{\circ}$ & 0.63 & $1 / 12$ & $115 / 1 / 60$ & C.C. MOUNT & $\mathrm{co01}$ \\
\hline CUH-2 & 6140 & $68^{\circ}$ & $180^{\circ}$ & $160^{\circ}$ & 0.63 & $1 / 12$ & $115 / 1 / 60$ & R.C. MOUNT & $\mathrm{CO} 22$ \\
\hline CUH-3 & 11270 & $68^{\circ}$ & $180^{\circ}$ & $160^{\circ}$ & 1.6 & $1 / 12$ & $115 / 1 / 60$ & R.C. MOUNT & $\mathrm{CO23}$ \\
\hline CUH-5 & 850 & $68^{\circ}$ & $180^{\circ}$ & $160^{\circ}$ & 0.1 & $1 / 12$ & $115 / 1 / 60$ & R.C. MOUNT & W. TOILET \\
\hline CUH-6 & 850 & $68^{\circ}$ & $180^{\circ}$ & $160^{\circ}$ & 0.1 & $1 / 12$ & $115 / 1 / 60$ & R.C. MOUNT & M. TOILET \\
\hline CUH-7 & 850 & $68^{\circ}$ & $180^{\circ}$ & $160^{\circ}$ & 0.1 & $1 / 12$ & $115 / 1 / 60$ & R.C. MOUNT & M. TOILET \\
\hline CUH-8 & 11270 & $68^{\circ}$ & $180^{\circ}$ & $160^{\circ}$ & 1.6 & $1 / 12$ & $115 / 1 / 60$ & C.C. MOUNT & $\mathrm{C} 014$ \\
\hline
\end{tabular}


Table B-14. Unit heater schedule (existing).

\begin{tabular}{|c|c|c|c|c|c|c|c|c|c|}
\hline \multicolumn{10}{|c|}{ Existing Unit Heater Schedule } \\
\hline \multirow[b]{2}{*}{ Symbol } & \multirow[b]{2}{*}{$\begin{array}{l}\text { Capacity } \\
\text { (BTUH) }\end{array}$} & \multirow[b]{2}{*}{$\begin{array}{l}\text { EAT } \\
\left({ }^{\circ} \mathrm{F}\right)\end{array}$} & \multirow[b]{2}{*}{$\begin{array}{l}\text { EWT } \\
\left({ }^{\circ} \mathrm{F}\right)\end{array}$} & \multirow[b]{2}{*}{$\begin{array}{l}\text { LWT } \\
\left({ }^{\circ} \mathrm{F}\right)\end{array}$} & \multirow{2}{*}{$\begin{array}{l}\text { Water } \\
\text { Flow } \\
\text { (GPM) }\end{array}$} & \multicolumn{2}{|c|}{ Fan Motor } & \multirow[b]{2}{*}{ Type } & \multirow[b]{2}{*}{ Location } \\
\hline & & & & & & hp & $\begin{array}{l}\text { Elect. } \\
\text { (V/Ø/Hz) }\end{array}$ & & \\
\hline UH-1 & 27320 & $55^{\circ}$ & $180^{\circ}$ & $160^{\circ}$ & 3.5 & $1 / 20$ & $115 / 1 / 60$ & VERTICAL & $\mathrm{c008}$ \\
\hline $\mathrm{UH}-2$ & 3415 & $55^{\circ}$ & $180^{\circ}$ & $160^{\circ}$ & 0.8 & $1 / 25$ & $115 / 1 / 60$ & HORIZONTAL & 6009 \\
\hline $\begin{array}{l}\text { UH-3 } \\
\text { (REMOVED) }\end{array}$ & 3415 & $55^{\circ}$ & $180^{\circ}$ & $160^{\circ}$ & 0.8 & $1 / 25$ & $115 / 1 / 60$ & HORIZONTAL & 6031 \\
\hline UH-4 & 3415 & $55^{\circ}$ & $180^{\circ}$ & $160^{\circ}$ & 0.8 & $1 / 25$ & $115 / 1 / 60$ & HORIZONTAL & C029 \\
\hline UH-5 & 3415 & $55^{\circ}$ & $180^{\circ}$ & $160^{\circ}$ & 0.8 & $1 / 25$ & $115 / 1 / 60$ & HORIZONTAL & $\mathrm{CO} 28$ \\
\hline UH-6 & 10245 & $55^{\circ}$ & $180^{\circ}$ & $160^{\circ}$ & 1.0 & $1 / 20$ & $115 / 1 / 60$ & HORIZONTAL & $\mathrm{CO} 28$ \\
\hline UH-7 & 6830 & $55^{\circ}$ & $180^{\circ}$ & $160^{\circ}$ & 0.95 & $1 / 20$ & $115 / 1 / 60$ & HORIZONTAL & $\mathrm{CO} 27$ \\
\hline UH-8 & 3415 & $55^{\circ}$ & $180^{\circ}$ & $160^{\circ}$ & 0.8 & $1 / 25$ & $115 / 1 / 60$ & HORIZONTAL & $\mathrm{CO} 27$ \\
\hline UH-9 & 3415 & $55^{\circ}$ & $180^{\circ}$ & $160^{\circ}$ & 0.8 & $1 / 25$ & $115 / 1 / 60$ & HORIZONTAL & $\mathrm{CO} 27$ \\
\hline $\mathrm{UH}-10$ & 3415 & $55^{\circ}$ & $180^{\circ}$ & $160^{\circ}$ & 0.8 & $1 / 25$ & $115 / 1 / 60$ & HORIZONTAL & $\mathrm{CO} 26$ \\
\hline
\end{tabular}

Table B-15. Radiant panel cooling schedule.

\begin{tabular}{|c|c|c|c|c|c|c|c|c|c|c|c|}
\hline \multicolumn{12}{|c|}{ Manufacturer: TWA } \\
\hline \multicolumn{2}{|c|}{ Panel Type } & \multicolumn{2}{|c|}{ Description } & $\begin{array}{c}\text { Coil } \\
\text { Passes }\end{array}$ & $\begin{array}{c}\text { Output } \\
\text { (BTUH)/ft) }\end{array}$ & \multicolumn{2}{|c|}{ TWA Panel Code } & $\begin{array}{l}\text { Nominal } \\
\text { Width } \\
\text { (in.) }\end{array}$ & \multicolumn{2}{|c|}{$\begin{array}{l}\text { Min Flow Rate } \\
\text { (GPM) }\end{array}$} & 0.8 \\
\hline \multicolumn{2}{|l|}{ RP-1 } & \multicolumn{2}{|l|}{ Cloud } & 8 & 96 & \multicolumn{2}{|c|}{ SHSASASASASASASASASH } & 48 & \multicolumn{2}{|l|}{$\Delta \mathrm{T}\left({ }^{\circ} \mathrm{F}\right)$} & 5.0 \\
\hline \multicolumn{2}{|l|}{ RP-1 Cloud } & \multicolumn{2}{|l|}{ Cloud } & 4 & 48 & \multicolumn{2}{|c|}{ SHSPSPSPSPSH } & 24 & \multicolumn{2}{|c|}{$\begin{array}{l}\text { Mean Fluid Temp } \\
\left({ }^{\circ} \mathrm{F}\right)\end{array}$} & 63.5 \\
\hline \multicolumn{2}{|l|}{ RP-2/D } & \multicolumn{2}{|l|}{ Linear } & 4 & 48 & \multicolumn{2}{|c|}{ MOD } & 24 & \multicolumn{2}{|c|}{ Room Temp $\left({ }^{\circ} \mathrm{F}\right)$} & 75 \\
\hline \multicolumn{2}{|l|}{$\mathrm{RP}-2 / \mathrm{S}$} & \multicolumn{2}{|l|}{ Linear } & 4 & 48 & \multicolumn{2}{|c|}{ MOD } & 24 & & & \\
\hline \multicolumn{2}{|l|}{ RP-4/D } & \multicolumn{2}{|l|}{ Linear } & 4 & 48 & \multicolumn{2}{|c|}{ MOD } & 24 & & & \\
\hline \multicolumn{2}{|l|}{$\mathrm{RP}-4 / \mathrm{S}$} & \multicolumn{2}{|l|}{ Linear } & 4 & 48 & \multicolumn{2}{|c|}{ MOD } & 24 & & & \\
\hline \multicolumn{2}{|l|}{$\mathrm{RP}-5 / \mathrm{D}$} & \multicolumn{2}{|l|}{ Linear } & 4 & 48 & \multicolumn{2}{|c|}{ SHSASASASASH } & 24 & & & \\
\hline \multicolumn{2}{|l|}{ RP-5/S } & \multicolumn{2}{|l|}{ Linear } & 4 & 48 & \multicolumn{2}{|c|}{ SHSASASASASH } & 24 & & & \\
\hline Room \# & & el Type & Panel Ta & $\begin{array}{l}\text { Wall-Wa } \\
\text { Length } \\
\text { (in) }\end{array}$ & $\begin{array}{c}\text { Active Lengt } \\
\text { (ft) }\end{array}$ & $\begin{array}{l}\text { Actual } \\
\text { Output } \\
\text { (BTU) }\end{array}$ & $\begin{array}{l}\text { \# of Coil } \\
\text { Passes }\end{array}$ & $\begin{array}{c}\text { \# of } \\
\text { Circuits }\end{array}$ & $\begin{array}{c}\text { Panel } \\
\text { Install } \\
\text { Type }\end{array}$ & $\begin{array}{l}\text { Flow } \\
\text { Rate } \\
\text { (gpm) }\end{array}$ & $\begin{array}{c}\text { Press. } \\
\text { Drop } \\
\text { (ft of } \\
\text { Head) }\end{array}$ \\
\hline $\mathrm{COO2}$ & RP-2 & & $\mathrm{A} 1$ & 24 & 2.00 & 96 & 4 & 1 & T-BAR & 0.46 & 0.44 \\
\hline & RP-2 & & A3 & 24 & 2.00 & 96 & 4 & & & & \\
\hline & $\mathrm{RP}-2$ & & B1 & 24 & 2.00 & 96 & 4 & & & & \\
\hline & RP- - & & B2 & 48 & 4.00 & 192 & 4 & & & & \\
\hline & RP-2 & & B3 & 24 & 2.00 & 96 & 4 & & & & \\
\hline & $\mathrm{RP}-2$ & & C1 & 24 & 2.00 & 96 & 4 & & & & \\
\hline & $\mathrm{RP}-\mathrm{C}$ & & $\mathrm{C} 2$ & 48 & 4.00 & 192 & 4 & & & & \\
\hline & RP-2 & & C3 & 24 & 2.00 & 96 & 4 & & & & \\
\hline & $\mathrm{RP}-2$ & & D1 & 24 & 2.00 & 96 & 4 & & & & \\
\hline & RP-2 & & D3 & 24 & 2.00 & 96 & 4 & & & & \\
\hline $\mathrm{co0} 3$ & RP- -5 & & A2 & 48 & 4.00 & 192 & 4 & 1 & T-BAR & 0.61 & 0.94 \\
\hline & RP-2 & & B1 & 24 & 2.00 & 96 & 4 & & & & \\
\hline
\end{tabular}




\begin{tabular}{|c|c|c|c|c|c|c|c|c|c|c|}
\hline Room \# & Panel Type & Panel Tag & $\begin{array}{l}\text { Wall-Wall } \\
\text { Length } \\
\text { (in) }\end{array}$ & \begin{tabular}{|} 
Active Length \\
(ft)
\end{tabular} & $\begin{array}{l}\text { Actual } \\
\text { Output } \\
\text { (BTU) }\end{array}$ & $\begin{array}{l}\text { \# of Coil } \\
\text { Passes }\end{array}$ & $\begin{array}{c}\text { \# of } \\
\text { Circuits }\end{array}$ & $\begin{array}{c}\text { Panel } \\
\text { Install } \\
\text { Type }\end{array}$ & $\begin{array}{l}\text { Flow } \\
\text { Rate } \\
\text { (gpm) }\end{array}$ & $\begin{array}{c}\text { Press. } \\
\text { Drop } \\
\text { (ft Of } \\
\text { Head) }\end{array}$ \\
\hline & RP-2/D & B3 & 24 & 2.00 & 96 & 4 & & & & \\
\hline & RP-2/D & $\mathrm{C} 1$ & 24 & 2.00 & 96 & 4 & & & & \\
\hline & RP-4/S & C2 & 48 & 4.00 & 192 & 4 & & & & \\
\hline & RP-2/D & C3 & 24 & 2.00 & 96 & 4 & & & & \\
\hline & RP-2/D & $\mathrm{D} 1$ & 24 & 2.00 & 96 & 4 & & & & \\
\hline & $\mathrm{RP}-4 / \mathrm{S}$ & D2 & 48 & 4.00 & 192 & 4 & & & & \\
\hline & RP-2/D & D3 & 24 & 2.00 & 96 & 4 & & & & \\
\hline & RP-2/S & E1 & 24 & 2.00 & 96 & 4 & & & & \\
\hline & RP-2/D & E3 & 24 & 2.00 & 96 & 4 & & & & \\
\hline & RP-4/D & F2 & 48 & 4.00 & 192 & 4 & & & & \\
\hline \multirow[t]{10}{*}{ Co04 } & RP-2/D & A1 & 24 & 2.00 & 96 & 4 & \multirow[t]{10}{*}{1} & \multirow[t]{10}{*}{ T-BAR } & \multirow[t]{10}{*}{0.46} & \multirow[t]{10}{*}{0.44} \\
\hline & RP-2/S & $\mathrm{A} 2$ & 24 & 2.00 & 96 & 4 & & & & \\
\hline & $\mathrm{RP}-2 / \mathrm{S}$ & A3 & 24 & 2.00 & 96 & 4 & & & & \\
\hline & RP-2/D & A4 & 24 & 2.00 & 96 & 4 & & & & \\
\hline & RP-4/D & B2 & 48 & 4.00 & 192 & 4 & & & & \\
\hline & RP-4/D & B3 & 48 & 4.00 & 192 & 4 & & & & \\
\hline & RP-2/D & $\mathrm{C} 1$ & 24 & 2.00 & 96 & 4 & & & & \\
\hline & $\mathrm{RP}-2 / \mathrm{S}$ & $\mathrm{C} 2$ & 24 & 2.00 & 96 & 4 & & & & \\
\hline & $\mathrm{RP}-2 / \mathrm{S}$ & C3 & 24 & 2.00 & 96 & 4 & & & & \\
\hline & RP-2/D & C4 & 24 & 2.00 & 96 & 4 & & & & \\
\hline \multirow[t]{18}{*}{ c005 } & RP-2/D & $\mathrm{A} 1$ & 24 & 2.00 & 96 & 4 & \multirow[t]{18}{*}{1} & \multirow[t]{18}{*}{ T-BAR } & \multirow[t]{18}{*}{0.84} & \multirow[t]{18}{*}{2.21} \\
\hline & $\mathrm{RP}-2 / \mathrm{S}$ & A2 & 24 & 2.00 & 96 & 4 & & & & \\
\hline & RP-2/D & A3 & 24 & 2.00 & 96 & 4 & & & & \\
\hline & $\mathrm{RP}-2 / \mathrm{S}$ & A4 & 24 & 2.00 & 96 & 4 & & & & \\
\hline & RP-2/D & A5 & 24 & 2.00 & 96 & 4 & & & & \\
\hline & RP-2/S & A6 & 24 & 2.00 & 96 & 4 & & & & \\
\hline & RP-2/D & A7 & 24 & 2.00 & 96 & 4 & & & & \\
\hline & $\mathrm{RP}-4 / \mathrm{S}$ & $\mathrm{B} 1$ & 48 & 4.00 & 192 & 4 & & & & \\
\hline & RP-4/S & B3 & 48 & 4.00 & 192 & 4 & & & & \\
\hline & RP-4/S & B5 & 48 & 4.00 & 192 & 4 & & & & \\
\hline & RP-4/D & B7 & 48 & 4.00 & 192 & 4 & & & & \\
\hline & RP-2/D & $\mathrm{C} 1$ & 24 & 2.00 & 96 & 4 & & & & \\
\hline & $\mathrm{RP}-2 / \mathrm{S}$ & $\mathrm{C} 2$ & 24 & 2.00 & 96 & 4 & & & & \\
\hline & RP-2/D & C3 & 24 & 2.00 & 96 & 4 & & & & \\
\hline & RP-2/S & C4 & 24 & 2.00 & 96 & 4 & & & & \\
\hline & RP-2/D & $\mathrm{C} 5$ & 24 & 2.00 & 96 & 4 & & & & \\
\hline & RP-2/S & C6 & 24 & 2.00 & 96 & 4 & & & & \\
\hline & $\mathrm{RP}-2 / \mathrm{D}$ & $\mathrm{C} 7$ & 24 & 2.00 & 96 & 4 & & & & \\
\hline \multirow[t]{7}{*}{ c006 } & RP-4/D & A1 & 48 & 4.00 & 192 & 4 & \multirow[t]{7}{*}{1} & \multirow[t]{7}{*}{ T-BAR } & \multirow[t]{7}{*}{0.77} & \multirow[t]{7}{*}{1.71} \\
\hline & RP-4/S & A3 & 48 & 4.00 & 192 & 4 & & & & \\
\hline & RP-4/S & A4 & 48 & 4.00 & 192 & 4 & & & & \\
\hline & RP-4/D & A6 & 48 & 4.00 & 192 & 4 & & & & \\
\hline & $\mathrm{RP}-4 / \mathrm{S}$ & B1 & 48 & 4.00 & 192 & 4 & & & & \\
\hline & RP-4/S & B2 & 48 & 4.00 & 192 & 4 & & & & \\
\hline & RP-4/S & B3 & 48 & 4.00 & 192 & 4 & & & & \\
\hline
\end{tabular}




\begin{tabular}{|c|c|c|c|c|c|c|c|c|c|c|}
\hline Room \# & Panel Type & Panel Tag & $\begin{array}{l}\text { Wall-Wall } \\
\text { Length } \\
\text { (in) }\end{array}$ & \begin{tabular}{|} 
Active Length \\
(ft)
\end{tabular} & $\begin{array}{l}\text { Actual } \\
\text { Output } \\
\text { (BTU) }\end{array}$ & $\begin{array}{l}\text { \# of Coil } \\
\text { Passes }\end{array}$ & $\begin{array}{c}\text { \# of } \\
\text { Circuits }\end{array}$ & $\begin{array}{c}\text { Panel } \\
\text { Install } \\
\text { Type }\end{array}$ & $\begin{array}{l}\text { Flow } \\
\text { Rate } \\
\text { (gpm) }\end{array}$ & $\begin{array}{c}\text { Press. } \\
\text { Drop } \\
\text { (ft Of } \\
\text { Head) }\end{array}$ \\
\hline & RP-4/S & B4 & 48 & 4.00 & 192 & 4 & & & & \\
\hline & RP-4/S & B5 & 48 & 4.00 & 192 & 4 & & & & \\
\hline & RP-4/S & B6 & 48 & 4.00 & 192 & 4 & & & & \\
\hline & RP-4/S & C1 & 48 & 4.00 & 192 & 4 & \multirow[t]{10}{*}{1} & \multirow[t]{10}{*}{ T-BAR } & \multirow[t]{10}{*}{0.77} & \multirow[t]{10}{*}{1.71} \\
\hline & RP-4/S & $\mathrm{C} 2$ & 48 & 4.00 & 192 & 4 & & & & \\
\hline & $\mathrm{RP}-4 / \mathrm{S}$ & C3 & 48 & 4.00 & 192 & 4 & & & & \\
\hline & RP-4/S & C4 & 48 & 4.00 & 192 & 4 & & & & \\
\hline & RP-4/S & $\mathrm{C} 5$ & 48 & 4.00 & 192 & 4 & & & & \\
\hline & RP-4/S & C6 & 48 & 4.00 & 192 & 4 & & & & \\
\hline & RP-4/D & D1 & 48 & 4.00 & 192 & 4 & & & & \\
\hline & RP-4/S & D3 & 48 & 4.00 & 192 & 4 & & & & \\
\hline & $\mathrm{RP}-4 / \mathrm{S}$ & D4 & 48 & 4.00 & 192 & 4 & & & & \\
\hline & RP-4/D & D6 & 48 & 4.00 & 192 & 4 & & & & \\
\hline \multirow[t]{9}{*}{ C014 } & RP-4/D & A & 48 & 4.00 & 192 & 4 & \multirow[t]{15}{*}{1} & \multirow{15}{*}{ T-BAR } & \multirow{15}{*}{1.15} & \multirow[t]{15}{*}{5.09} \\
\hline & RP-4/S & B & 48 & 4.00 & 192 & 4 & & & & \\
\hline & RP-4/D & C & 48 & 4.00 & 192 & 4 & & & & \\
\hline & RP-4/S & D & 48 & 4.00 & 192 & 4 & & & & \\
\hline & RP-4/D & E & 48 & 4.00 & 192 & 4 & & & & \\
\hline & RP-4/S & $\mathrm{F}$ & 48 & 4.00 & 192 & 4 & & & & \\
\hline & RP-4/D & G & 48 & 4.00 & 192 & 4 & & & & \\
\hline & RP-4/S & $\mathrm{H}$ & 48 & 4.00 & 192 & 4 & & & & \\
\hline & RP-4/D & 1 & 48 & 4.00 & 192 & 4 & & & & \\
\hline \multirow[t]{6}{*}{$\mathrm{CO15}$} & RP-4/D & A & 48 & 4.00 & 192 & 4 & & & & \\
\hline & RP-4/S & B & 48 & 4.00 & 192 & 4 & & & & \\
\hline & RP-4/D & $C$ & 48 & 4.00 & 192 & 4 & & & & \\
\hline & $\mathrm{RP}-4 / \mathrm{S}$ & D & 48 & 4.00 & 192 & 4 & & & & \\
\hline & RP-4/D & $\mathrm{E}$ & 48 & 4.00 & 192 & 4 & & & & \\
\hline & $\mathrm{RP}-4 / \mathrm{S}$ & $\mathrm{F}$ & 48 & 4.00 & 192 & 4 & & & & \\
\hline \multirow[t]{17}{*}{$\mathrm{C} 018$} & RP-4/D & A2 & 48 & 4.00 & 192 & 4 & \multirow[t]{14}{*}{1} & \multirow[t]{14}{*}{ T-BAR } & \multirow[t]{14}{*}{0.81} & \multirow[t]{14}{*}{1.95} \\
\hline & RP-2/D & B1 & 24 & 2.00 & 96 & 4 & & & & \\
\hline & RP-2/D & $\mathrm{C} 1$ & 24 & 2.00 & 96 & 4 & & & & \\
\hline & RP-4/S & $\mathrm{C} 2$ & 48 & 4.00 & 192 & 4 & & & & \\
\hline & $\mathrm{RP}-2 / \mathrm{S}$ & D1 & 24 & 2.00 & 96 & 4 & & & & \\
\hline & $\mathrm{RP}-4 / \mathrm{S}$ & D2 & 48 & 4.00 & 192 & 4 & & & & \\
\hline & RP-2/S & E1 & 24 & 2.00 & 96 & 4 & & & & \\
\hline & RP-4/D & E2 & 48 & 4.00 & 192 & 4 & & & & \\
\hline & $\mathrm{RP}-2 / \mathrm{S}$ & $\mathrm{F} 1$ & 24 & 2.00 & 96 & 4 & & & & \\
\hline & RP-4/S & F2 & 48 & 4.00 & 192 & 4 & & & & \\
\hline & $\mathrm{RP}-2 / \mathrm{S}$ & G1 & 24 & 2.00 & 96 & 4 & & & & \\
\hline & RP-4/S & G2 & 48 & 4.00 & 192 & 4 & & & & \\
\hline & RP-2/D & $\mathrm{H} 1$ & 24 & 2.00 & 96 & 4 & & & & \\
\hline & RP-4/D & 12 & 48 & 4.00 & 192 & 4 & & & & \\
\hline & RP-2/D & A3 & 24 & 2.00 & 96 & 4 & \multirow[t]{3}{*}{1} & \multirow[t]{3}{*}{ T-BAR } & \multirow[t]{3}{*}{1.15} & \multirow[t]{3}{*}{5.09} \\
\hline & RP-4/D & A4 & 48 & 4.00 & 192 & 4 & & & & \\
\hline & RP-2/D & B3 & 24 & 2.00 & 96 & 4 & & & & \\
\hline
\end{tabular}




\begin{tabular}{|c|c|c|c|c|c|c|c|c|c|c|}
\hline Room \# & Panel Type & Panel Tag & $\begin{array}{l}\text { Wall-Wall } \\
\text { Length } \\
\text { (in) }\end{array}$ & $\begin{array}{l}\text { Active Length } \\
\text { (ft) }\end{array}$ & $\begin{array}{c}\text { Actual } \\
\text { Output } \\
\text { (BTU) }\end{array}$ & $\begin{array}{l}\text { \# of Coil } \\
\text { Passes }\end{array}$ & $\begin{array}{c}\text { \# of } \\
\text { Circuits }\end{array}$ & $\begin{array}{c}\text { Panel } \\
\text { Install } \\
\text { Type }\end{array}$ & $\begin{array}{l}\text { Flow } \\
\text { Rate } \\
\text { (gpm) }\end{array}$ & $\begin{array}{c}\text { Press. } \\
\text { Drop } \\
\text { (ft Of } \\
\text { Head) }\end{array}$ \\
\hline & RP-2/D & B5 & 24 & 2.00 & 96 & 4 & & & & \\
\hline & RP-2/S & C3 & 24 & 2.00 & 96 & 4 & & & & \\
\hline & RP-4/S & C4 & 48 & 4.00 & 192 & 4 & & & & \\
\hline & RP-2/D & $\mathrm{C} 5$ & 24 & 2.00 & 96 & 4 & & & & \\
\hline & RP-2/S & D3 & 24 & 2.00 & 96 & 4 & & & & \\
\hline & RP-4/S & D4 & 48 & 4.00 & 192 & 4 & & & & \\
\hline & RP-2/S & D5 & 24 & 2.00 & 96 & 4 & & & & \\
\hline & RP-2/S & E3 & 24 & 2.00 & 96 & 4 & & & & \\
\hline & RP-4/D & E4 & 48 & 4.00 & 192 & 4 & & & & \\
\hline & RP-2/S & E5 & 24 & 2.00 & 96 & 4 & & & & \\
\hline & RP-2/S & F3 & 24 & 2.00 & 96 & 4 & & & & \\
\hline & RP-4/S & F4 & 48 & 4.00 & 192 & 4 & & & & \\
\hline & RP-2/S & F5 & 24 & 2.00 & 96 & 4 & & & & \\
\hline & RP-2/S & G3 & 24 & 2.00 & 96 & 4 & & & & \\
\hline & RP-4/S & G4 & 48 & 4.00 & 192 & 4 & & & & \\
\hline & RP-2/S & G5 & 24 & 2.00 & 96 & 4 & & & & \\
\hline & RP-2/S & H3 & 24 & 2.00 & 96 & 4 & & & & \\
\hline & RP-2/D & H5 & 24 & 2.00 & 96 & 4 & & & & \\
\hline & RP-2/S & 13 & 24 & 2.00 & 96 & 4 & & & & \\
\hline & RP-4/D & 14 & 48 & 4.00 & 192 & 4 & & & & \\
\hline \multirow[t]{5}{*}{ C018A } & RP-5/D & A & 72 & 6.00 & 288 & 4 & \multirow[t]{5}{*}{1} & \multirow[t]{5}{*}{ T-BAR } & \multirow[t]{5}{*}{0.58} & \multirow[t]{5}{*}{0.79} \\
\hline & RP-5/S & B & 72 & 6.00 & 288 & 4 & & & & \\
\hline & RP-5/D & C & 72 & 6.00 & 288 & 4 & & & & \\
\hline & RP-5/S & D & 72 & 6.00 & 288 & 4 & & & & \\
\hline & RP-5/D & $E$ & 72 & 6.00 & 288 & 4 & & & & \\
\hline \multirow[t]{15}{*}{ C018B } & RP-1 & A & 96 & 8.00 & 768 & 8 & \multirow[t]{4}{*}{1} & \multirow[t]{4}{*}{ CLOUD } & \multirow[t]{4}{*}{1.23} & \multirow[t]{4}{*}{6.06} \\
\hline & RP-1 & B & 96 & 8.00 & 768 & 8 & & & & \\
\hline & RP-1 & C & 96 & 8.00 & 768 & 8 & & & & \\
\hline & RP-1 & D & 96 & 8.00 & 768 & 8 & & & & \\
\hline & RP-1 CLOUD & C1 & 48 & 4.00 & 192 & 4 & \multirow[t]{11}{*}{1} & \multirow[t]{11}{*}{ CLOUD } & \multirow[t]{11}{*}{0.84} & \multirow[t]{11}{*}{3.44} \\
\hline & RP-1 CLOUD & A1 & 48 & 4.00 & 192 & 4 & & & & \\
\hline & RP-1 CLOUD & A2 & 48 & 4.00 & 192 & 4 & & & & \\
\hline & RP-1 CLOUD & A3 & 48 & 4.00 & 192 & 4 & & & & \\
\hline & RP-1 CLOUD & A4 & 48 & 4.00 & 192 & 4 & & & & \\
\hline & RP-1 CLOUD & A5 & 48 & 4.00 & 192 & 4 & & & & \\
\hline & RP-1 CLOUD & A6 & 48 & 4.00 & 192 & 4 & & & & \\
\hline & RP-1 CLOUD & C6 & 48 & 4.00 & 192 & 4 & & & & \\
\hline & RP-1 CLOUD & $\mathrm{C} 4$ & 48 & 4.00 & 192 & 4 & & & & \\
\hline & RP-1 CLOUD & C3 & 48 & 4.00 & 192 & 4 & & & & \\
\hline & RP-1 CLOUD & $\mathrm{C} 2$ & 48 & 4.00 & 192 & 4 & & & & \\
\hline \multirow[t]{5}{*}{ C019 } & RP-2/D & A1 & 24 & 2.00 & 96 & 4 & \multirow[t]{5}{*}{1} & \multirow[t]{5}{*}{ T-BAR } & \multirow[t]{5}{*}{0.69} & \multirow[t]{5}{*}{1.29} \\
\hline & RP-2/D & $\mathrm{A} 2$ & 24 & 2.00 & 96 & 4 & & & & \\
\hline & RP-2/D & A3 & 24 & 2.00 & 96 & 4 & & & & \\
\hline & RP-2/D & A4 & 24 & 2.00 & 96 & 4 & & & & \\
\hline & RP-2/D & A5 & 24 & 2.00 & 96 & 4 & & & & \\
\hline
\end{tabular}




\begin{tabular}{|c|c|c|c|c|c|c|c|c|c|c|}
\hline Room \# & Panel Type & Panel Tag & $\begin{array}{l}\text { Wall-Wall } \\
\text { Length } \\
\text { (in) }\end{array}$ & \begin{tabular}{|} 
Active Length \\
(ft)
\end{tabular} & $\begin{array}{l}\text { Actual } \\
\text { Output } \\
\text { (BTU) }\end{array}$ & $\begin{array}{l}\text { \# of Coil } \\
\text { Passes }\end{array}$ & $\begin{array}{c}\text { \# of } \\
\text { Circuits }\end{array}$ & $\begin{array}{c}\text { Panel } \\
\text { Install } \\
\text { Type }\end{array}$ & $\begin{array}{l}\text { Flow } \\
\text { Rate } \\
\text { (gpm) }\end{array}$ & $\begin{array}{c}\text { Press. } \\
\text { Drop } \\
\text { (ft Of } \\
\text { Head) }\end{array}$ \\
\hline & RP-2/D & A6 & 24 & 2.00 & 96 & 4 & & & & \\
\hline & RP-4/S & B1 & 48 & 4.00 & 192 & 4 & & & & \\
\hline & RP-4/S & B3 & 48 & 4.00 & 192 & 4 & & & & \\
\hline & RP-4/S & $\mathrm{B} 6$ & 48 & 4.00 & 192 & 4 & & & & \\
\hline & RP-2/D & $\mathrm{C} 1$ & 24 & 2.00 & 96 & 4 & & & & \\
\hline & RP-2/D & $\mathrm{C} 2$ & 24 & 2.00 & 96 & 4 & & & & \\
\hline & RP-2/D & C3 & 24 & 2.00 & 96 & 4 & & & & \\
\hline & RP-2/D & C4 & 24 & 2.00 & 96 & 4 & & & & \\
\hline & RP-2/D & $\mathrm{C5}$ & 24 & 2.00 & 96 & 4 & & & & \\
\hline & RP-2/D & C6 & 24 & 2.00 & 96 & 4 & & & & \\
\hline \multirow[t]{12}{*}{$\mathrm{CO} 20$} & $\mathrm{RP}-2 / \mathrm{S}$ & $\mathrm{A} 1$ & 24 & 2.00 & 96 & 4 & \multirow[t]{12}{*}{1} & \multirow[t]{12}{*}{ T-BAR } & \multirow[t]{12}{*}{0.65} & \multirow[t]{12}{*}{1.10} \\
\hline & RP-4/D & $\mathrm{A} 2$ & 48 & 4.00 & 192 & 4 & & & & \\
\hline & $\mathrm{RP}-2 / \mathrm{S}$ & B1 & 24 & 2.00 & 96 & 4 & & & & \\
\hline & $\mathrm{RP}-2 / \mathrm{S}$ & $\mathrm{C} 1$ & 24 & 2.00 & 96 & 4 & & & & \\
\hline & RP-4/S & $\mathrm{C} 2$ & 48 & 4.00 & 192 & 4 & & & & \\
\hline & $\mathrm{RP}-2 / \mathrm{S}$ & D1 & 24 & 2.00 & 96 & 4 & & & & \\
\hline & $\mathrm{RP}-4 / \mathrm{S}$ & D2 & 48 & 4.00 & 192 & 4 & & & & \\
\hline & $\mathrm{RP}-2 / \mathrm{S}$ & E1 & 24 & 2.00 & 96 & 4 & & & & \\
\hline & RP-4/S & E2 & 48 & 4.00 & 192 & 4 & & & & \\
\hline & RP-2/S & $\mathrm{F} 1$ & 24 & 2.00 & 96 & 4 & & & & \\
\hline & $\mathrm{RP}-2 / \mathrm{S}$ & G1 & 24 & 2.00 & 96 & 4 & & & & \\
\hline & RP-4/D & G2 & 48 & 4.00 & 192 & 4 & & & & \\
\hline \multirow[t]{5}{*}{$\mathrm{CO} 21$} & RP-4/D & A & 48 & 4.00 & 192 & 4 & \multirow[t]{5}{*}{1} & \multirow[t]{5}{*}{ T-BAR } & \multirow[t]{5}{*}{0.38} & \multirow[t]{5}{*}{0.17} \\
\hline & RP-4/S & B & 48 & 4.00 & 192 & 4 & & & & \\
\hline & RP-4/S & C & 48 & 4.00 & 192 & 4 & & & & \\
\hline & $\mathrm{RP}-4 / \mathrm{S}$ & D & 48 & 4.00 & 192 & 4 & & & & \\
\hline & RP-4/D & $E$ & 48 & 4.00 & 192 & 4 & & & & \\
\hline \multirow[t]{12}{*}{ C021A } & RP-4/D & $\mathrm{A} 1$ & 48 & 4.00 & 192 & 4 & \multirow[t]{12}{*}{1} & \multirow[t]{12}{*}{ T-BAR } & \multirow[t]{12}{*}{0.65} & \multirow[t]{12}{*}{1.10} \\
\hline & RP-2/D & $\mathrm{A} 2$ & 24 & 2.00 & 96 & 4 & & & & \\
\hline & RP-2/D & B2 & 24 & 2.00 & 96 & 4 & & & & \\
\hline & RP-4/S & $\mathrm{C} 1$ & 48 & 4.00 & 192 & 4 & & & & \\
\hline & RP-2/D & $\mathrm{C} 2$ & 24 & 2.00 & 96 & 4 & & & & \\
\hline & RP-4/S & $\mathrm{D} 1$ & 48 & 4.00 & 192 & 4 & & & & \\
\hline & RP-2/D & D2 & 24 & 2.00 & 96 & 4 & & & & \\
\hline & RP-4/S & E1 & 48 & 4.00 & 192 & 4 & & & & \\
\hline & RP-2/D & E2 & 24 & 2.00 & 96 & 4 & & & & \\
\hline & RP-2/D & F2 & 24 & 2.00 & 96 & 4 & & & & \\
\hline & RP-4/D & G1 & 48 & 4.00 & 192 & 4 & & & & \\
\hline & RP-2/D & G2 & 24 & 2.00 & 96 & 4 & & & & \\
\hline \multirow[t]{6}{*}{ C021B } & RP-2/D & $\mathrm{A} 1$ & 24 & 2.00 & 96 & 4 & \multirow[t]{6}{*}{1} & \multirow[t]{6}{*}{ T-BAR } & \multirow[t]{6}{*}{0.69} & \multirow[t]{6}{*}{1.29} \\
\hline & RP-2/D & $\mathrm{A} 2$ & 24 & 2.00 & 96 & 4 & & & & \\
\hline & RP-2/D & A3 & 24 & 2.00 & 96 & 4 & & & & \\
\hline & RP-2/D & A4 & 24 & 2.00 & 96 & 4 & & & & \\
\hline & RP-2/D & A5 & 24 & 2.00 & 96 & 4 & & & & \\
\hline & RP-2/D & A6 & 24 & 2.00 & 96 & 4 & & & & \\
\hline
\end{tabular}




\begin{tabular}{|c|c|c|c|c|c|c|c|c|c|c|}
\hline Room \# & Panel Type & Panel Tag & $\begin{array}{l}\text { Wall-Wall } \\
\text { Length } \\
\text { (in) }\end{array}$ & $\begin{array}{l}\text { Active Length } \\
\text { (ft) }\end{array}$ & $\begin{array}{l}\text { Actual } \\
\text { Output } \\
\text { (BTU) }\end{array}$ & $\begin{array}{c}\text { \# of Coil } \\
\text { Passes }\end{array}$ & $\begin{array}{c}\text { \# of } \\
\text { Circuits }\end{array}$ & $\begin{array}{l}\text { Panel } \\
\text { Install } \\
\text { Type }\end{array}$ & $\begin{array}{l}\text { Flow } \\
\text { Rate } \\
\text { (gpm) }\end{array}$ & $\begin{array}{l}\text { Press. } \\
\text { Drop } \\
\text { (ft Of } \\
\text { Head) }\end{array}$ \\
\hline & $\mathrm{RP}-4 / \mathrm{S}$ & B1 & 48 & 4.00 & 192 & 4 & & & & \\
\hline & $\mathrm{RP}-4 / \mathrm{S}$ & B3 & 48 & 4.00 & 192 & 4 & & & & \\
\hline & RP-4/D & B6 & 48 & 4.00 & 192 & 4 & & & & \\
\hline & $\mathrm{RP}-2 / \mathrm{D}$ & $\mathrm{C} 1$ & 24 & 2.00 & 96 & 4 & & & & \\
\hline & $\mathrm{RP}-2 / \mathrm{D}$ & $\mathrm{C} 2$ & 24 & 2.00 & 96 & 4 & & & & \\
\hline & $\mathrm{RP}-2 / \mathrm{D}$ & $\mathrm{C3}$ & 24 & 2.00 & 96 & 4 & & & & \\
\hline & $\mathrm{RP}-2 / \mathrm{D}$ & $\mathrm{C4}$ & 24 & 2.00 & 96 & 4 & & & & \\
\hline & $\mathrm{RP}-2 / \mathrm{D}$ & $\mathrm{C5}$ & 24 & 2.00 & 96 & 4 & & & & \\
\hline & $\mathrm{RP}-2 / \mathrm{D}$ & $\mathrm{C6}$ & 24 & 2.00 & 96 & 4 & & & & \\
\hline \multirow[t]{7}{*}{ c031 } & RP-5/S & A & 144 & 12.00 & 576 & 4 & \multirow[t]{4}{*}{1} & \multirow[t]{4}{*}{ T-BAR } & \multirow[t]{4}{*}{0.92} & \multirow[t]{4}{*}{2.79} \\
\hline & $\mathrm{RP}-5 / \mathrm{S}$ & $B$ & 144 & 12.00 & 576 & 4 & & & & \\
\hline & RP-5/S & C & 144 & 12.00 & 576 & 4 & & & & \\
\hline & RP-5/D & $\mathrm{D}$ & 144 & 12.00 & 576 & 4 & & & & \\
\hline & $\mathrm{RP}-5 / \mathrm{S}$ & $\mathrm{E}$ & 144 & 12.00 & 576 & 4 & \multirow[t]{3}{*}{1} & \multirow[t]{3}{*}{ T-BAR } & \multirow[t]{3}{*}{0.69} & \multirow[t]{3}{*}{1.29} \\
\hline & $\mathrm{RP}-5 / \mathrm{D}$ & $\mathrm{F}$ & 144 & 12.00 & 576 & 4 & & & & \\
\hline & RP-5/D & G & 144 & 12.00 & 576 & 4 & & & & \\
\hline
\end{tabular}

Table B-16. Radiant panel heating schedule.

\begin{tabular}{|c|c|c|c|c|c|c|c|c|c|c|}
\hline \multicolumn{11}{|c|}{ Manufacturer: TWA } \\
\hline $\begin{array}{l}\text { Panel } \\
\text { Type }\end{array}$ & Description & Coil Passes & $\begin{array}{c}\text { Output } \\
\text { (BTUH/ft) }\end{array}$ & \multicolumn{2}{|c|}{ TWA Panel Code } & $\begin{array}{c}\text { Nominal } \\
\text { Width } \\
\text { (in.) }\end{array}$ & \multicolumn{3}{|c|}{ Min Flow Rate (gpm) } & 0.44 \\
\hline RP-1 & Linear & 8 & 363 & \multicolumn{2}{|c|}{ SHSASASASASASASASASH } & 48 & \multicolumn{3}{|c|}{$\Delta \mathrm{T}\left({ }^{\circ} \mathrm{F}\right)$} & 20.0 \\
\hline RP-2/D & Linear & 4 & 200 & \multicolumn{2}{|l|}{ MOD } & 24 & \multicolumn{3}{|c|}{ Mean Fluid Temp $\left({ }^{\circ} \mathrm{F}\right)$} & 130.0 \\
\hline RP-4/D & Linear & 4 & 200 & \multicolumn{2}{|l|}{ MOD } & 24 & \multicolumn{3}{|c|}{ Room Temp ( $\left.{ }^{\circ} \mathrm{F}\right)$} & 70.0 \\
\hline RP-5/D & Linear & 4 & 214 & \multicolumn{2}{|c|}{ SHSASASASASH } & 24 & & & & \\
\hline Room \# & Panel Type & Panel Tag & $\begin{array}{l}\text { Wall-Wall } \\
\text { Length } \\
\text { (in.) }\end{array}$ & $\begin{array}{l}\text { Active } \\
\text { Length } \\
\text { (ft) }\end{array}$ & $\begin{array}{l}\text { Actual } \\
\text { Output } \\
\text { (BTU) }\end{array}$ & $\begin{array}{l}\text { \# of Coil } \\
\text { Passes }\end{array}$ & $\begin{array}{c}\text { \# Of } \\
\text { Circuits }\end{array}$ & $\begin{array}{c}\text { Panel } \\
\text { Install Type }\end{array}$ & $\begin{array}{l}\text { Flow } \\
\text { Rate } \\
\text { (gpm) }\end{array}$ & $\begin{array}{l}\text { Press. } \\
\text { Drop } \\
\text { (ft of } \\
\text { Head) }\end{array}$ \\
\hline \multirow[t]{8}{*}{ coo2 } & RP-2/D & A1 & 24 & 2.00 & 400 & 4 & \multirow[t]{8}{*}{1} & \multirow[t]{8}{*}{ T-BAR } & \multirow[t]{8}{*}{0.32} & \multirow[t]{8}{*}{0.12} \\
\hline & RP-2/D & A3 & 24 & 2.00 & 400 & 4 & & & & \\
\hline & RP-2/D & B1 & 24 & 2.00 & 400 & 4 & & & & \\
\hline & RP-2/D & B3 & 24 & 2.00 & 400 & 4 & & & & \\
\hline & RP-2/D & $\mathrm{C} 1$ & 24 & 2.00 & 400 & 4 & & & & \\
\hline & $\mathrm{RP}-2 / \mathrm{D}$ & C3 & 24 & 2.00 & 400 & 4 & & & & \\
\hline & $\mathrm{RP}-2 / \mathrm{D}$ & D1 & 24 & 2.00 & 400 & 4 & & & & \\
\hline & $\mathrm{RP}-2 / \mathrm{D}$ & D3 & 24 & 2.00 & 400 & 4 & & & & \\
\hline \multirow[t]{8}{*}{$\mathrm{co03}$} & RP-4/D & A2 & 48 & 4.00 & 800 & 4 & \multirow[t]{8}{*}{1} & \multirow[t]{8}{*}{ T-BAR } & \multirow[t]{8}{*}{0.40} & \multirow[t]{8}{*}{0.22} \\
\hline & RP-2/D & B3 & 24 & 2.00 & 400 & 4 & & & & \\
\hline & $\mathrm{RP}-2 / \mathrm{D}$ & $\mathrm{C} 1$ & 24 & 2.00 & 400 & 4 & & & & \\
\hline & RP-2/D & C3 & 24 & 2.00 & 400 & 4 & & & & \\
\hline & RP-2/D & D1 & 24 & 2.00 & 400 & 4 & & & & \\
\hline & $\mathrm{RP}-2 / \mathrm{D}$ & D3 & 24 & 2.00 & 400 & 4 & & & & \\
\hline & RP-2/D & E3 & 24 & 2.00 & 400 & 4 & & & & \\
\hline & RP-4/D & F2 & 48 & 4.00 & 800 & 4 & & & & \\
\hline
\end{tabular}




\begin{tabular}{|c|c|c|c|c|c|c|c|c|c|c|}
\hline Room \# & Panel Type & Panel Tag & $\begin{array}{l}\text { Wall-Wall } \\
\text { Length } \\
\text { (in.) }\end{array}$ & $\begin{array}{l}\text { Active } \\
\text { Length } \\
\text { (ft) }\end{array}$ & $\begin{array}{l}\text { Actual } \\
\text { Output } \\
\text { (BTU) }\end{array}$ & $\begin{array}{l}\text { \# of Coil } \\
\text { Passes }\end{array}$ & $\begin{array}{c}\text { \# Of } \\
\text { Circuits }\end{array}$ & $\begin{array}{c}\text { Panel } \\
\text { Install Type }\end{array}$ & $\begin{array}{l}\text { Flow } \\
\text { Rate } \\
\text { (gpm) }\end{array}$ & $\begin{array}{l}\text { Press. } \\
\text { Drop } \\
\text { (ft of } \\
\text { Head) }\end{array}$ \\
\hline \multirow[t]{6}{*}{$\mathrm{COO4}$} & RP-2/D & $\mathrm{A} 1$ & 24 & 2.00 & 400 & 4 & \multirow[t]{6}{*}{1} & \multirow[t]{6}{*}{ T-BAR } & \multirow[t]{6}{*}{0.32} & \multirow[t]{6}{*}{0.12} \\
\hline & RP-2/D & A4 & 24 & 2.00 & 400 & 4 & & & & \\
\hline & RP-4/D & B2 & 48 & 4.00 & 800 & 4 & & & & \\
\hline & RP-4/D & B3 & 48 & 4.00 & 800 & 4 & & & & \\
\hline & RP-2/D & $\mathrm{C} 1$ & 24 & 2.00 & 400 & 4 & & & & \\
\hline & RP-2/D & C4 & 24 & 2.00 & 400 & 4 & & & & \\
\hline \multirow[t]{9}{*}{ C005 } & RP-2/D & A1 & 24 & 2.00 & 400 & 4 & \multirow[t]{9}{*}{1} & \multirow[t]{9}{*}{ T-BAR } & \multirow[t]{9}{*}{0.40} & \multirow[t]{9}{*}{0.22} \\
\hline & \begin{tabular}{|l|} 
RP-2/D \\
\end{tabular} & A3 & 24 & 2.00 & 400 & 4 & & & & \\
\hline & RP-2/D & A5 & 24 & 2.00 & 400 & 4 & & & & \\
\hline & RP-2/D & A7 & 24 & 2.00 & 400 & 4 & & & & \\
\hline & RP-4/D & B7 & 48 & 4.00 & 800 & 4 & & & & \\
\hline & RP-2/D & $\mathrm{C} 1$ & 24 & 2.00 & 400 & 4 & & & & \\
\hline & RP-2/D & $\mathrm{C} 3$ & 24 & 2.00 & 400 & 4 & & & & \\
\hline & RP-2/D & C5 & 24 & 2.00 & 400 & 4 & & & & \\
\hline & RP-2/D & $\mathrm{C} 7$ & 24 & 2.00 & 400 & 4 & & & & \\
\hline \multirow[t]{4}{*}{$\mathrm{CO06}$} & RP-4/D & A1 & 48 & 4.00 & 800 & 4 & \multirow[t]{4}{*}{1} & \multirow[t]{4}{*}{ T-BAR } & \multirow[t]{4}{*}{0.32} & \multirow[t]{4}{*}{0.12} \\
\hline & RP-4/D & $\mathrm{A} 6$ & 48 & 4.00 & 800 & 4 & & & & \\
\hline & RP-4/D & D1 & 48 & 4.00 & 800 & 4 & & & & \\
\hline & RP-4/D & D6 & 48 & 4.00 & 800 & 4 & & & & \\
\hline \multirow[t]{5}{*}{$\mathrm{CO14}$} & RP-4/D & A & 48 & 4.00 & 800 & 4 & \multirow[t]{8}{*}{1} & \multirow[t]{8}{*}{ T-BAR } & \multirow[t]{8}{*}{0.64} & \multirow[t]{8}{*}{0.8} \\
\hline & RP-4/D & $\mathrm{C}$ & 48 & 4.00 & 800 & 4 & & & & \\
\hline & RP-4/D & $E$ & 48 & 4.00 & 800 & 4 & & & & \\
\hline & RP-4/D & G & 48 & 4.00 & 800 & 4 & & & & \\
\hline & RP-4/D & 1 & 48 & 4.00 & 800 & 4 & & & & \\
\hline \multirow[t]{3}{*}{$\mathrm{C015}$} & RP-4/D & A & 48 & 4.00 & 800 & 4 & & & & \\
\hline & RP-4/D & C & 48 & 4.00 & 800 & 4 & & & & \\
\hline & RP-4/D & $\mathrm{E}$ & 48 & 4.00 & 800 & 4 & & & & \\
\hline $\mathrm{CO18}$ & RP-4/D & A2 & 48 & 4.00 & 800 & 4 & 1 & T-BAR & 0.80 & 1.46 \\
\hline & RP-2/D & A3 & 24 & 2.00 & 400 & 4 & & & & \\
\hline & RP-4/D & A4 & 48 & 4.00 & 800 & 4 & & & & \\
\hline & RP-2/D & B1 & 24 & 2.00 & 400 & 4 & & & & \\
\hline & RP-2/D & B3 & 24 & 2.00 & 400 & 4 & & & & \\
\hline & RP-2/D & B5 & 24 & 2.00 & 400 & 4 & & & & \\
\hline & RP-2/D & $\mathrm{C} 1$ & 24 & 2.00 & 400 & 4 & & & & \\
\hline & RP-2/D & C5 & 24 & 2.00 & 400 & 4 & & & & \\
\hline & RP-4/D & E2 & 48 & 4.00 & 800 & 4 & & & & \\
\hline & RP-4/D & E4 & 48 & 4.00 & 800 & 4 & & & & \\
\hline & RP-2/D & $\mathrm{H} 1$ & 24 & 2.00 & 400 & 4 & & & & \\
\hline & RP-2/D & H5 & 24 & 2.00 & 400 & 4 & & & & \\
\hline & RP-4/D & 12 & 48 & 4.00 & 800 & 4 & & & & \\
\hline & RP-4/D & 14 & 48 & 4.00 & 800 & 4 & & & & \\
\hline C018A & RP-5/D & A & 72 & 6.00 & 1284 & 4 & 1 & T-BAR & 0.39 & 0.19 \\
\hline & RP-5/D & $\mathrm{C}$ & 72 & 6.00 & 1284 & 4 & & & & \\
\hline & RP-5/D & $\mathrm{E}$ & 72 & 6.00 & 1284 & 4 & & & & \\
\hline C018B & RP-1 & A & 96 & 8.00 & 2907 & 8 & 1 & CLOUD & 1.16 & 4.45 \\
\hline
\end{tabular}




\begin{tabular}{|c|c|c|c|c|c|c|c|c|c|c|}
\hline Room \# & Panel Type & Panel Tag & $\begin{array}{l}\text { Wall-Wall } \\
\text { Length } \\
\text { (in.) }\end{array}$ & $\begin{array}{l}\text { Active } \\
\text { Length } \\
\text { (ft) }\end{array}$ & $\begin{array}{c}\text { Actual } \\
\text { Output } \\
\text { (BTU) }\end{array}$ & $\begin{array}{l}\text { \# of Coil } \\
\text { Passes }\end{array}$ & $\begin{array}{l}\text { \# Of } \\
\text { Circuits }\end{array}$ & $\begin{array}{c}\text { Panel } \\
\text { Install Type }\end{array}$ & $\begin{array}{l}\text { Flow } \\
\text { Rate } \\
\text { (gpm) }\end{array}$ & $\begin{array}{c}\text { Press. } \\
\text { Drop } \\
\text { (ft of } \\
\text { Head) }\end{array}$ \\
\hline & RP-1 & B & 96 & 8.00 & 2907 & 8 & & & & \\
\hline & RP-1 & C & 96 & 8.00 & 2907 & 8 & & & & \\
\hline & RP-1 & $\mathrm{D}$ & 96 & 8.00 & 2907 & 8 & & & & \\
\hline \multirow[t]{12}{*}{ C019 } & RP-2/D & A1 & 24 & 2.00 & 400 & 4 & \multirow[t]{12}{*}{1} & \multirow[t]{12}{*}{ T-BAR } & \multirow[t]{12}{*}{0.48} & \multirow[t]{12}{*}{0.37} \\
\hline & $\mathrm{RP}-2 / \mathrm{D}$ & $\mathrm{A} 2$ & 24 & 2.00 & 400 & 4 & & & & \\
\hline & RP-2/D & A3 & 24 & 2.00 & 400 & 4 & & & & \\
\hline & RP-2/D & A4 & 24 & 2.00 & 400 & 4 & & & & \\
\hline & RP-2/D & A5 & 24 & 2.00 & 400 & 4 & & & & \\
\hline & $\mathrm{RP}-2 / \mathrm{D}$ & A6 & 24 & 2.00 & 400 & 4 & & & & \\
\hline & RP-2/D & C1 & 24 & 2.00 & 400 & 4 & & & & \\
\hline & RP-2/D & $\mathrm{C} 2$ & 24 & 2.00 & 400 & 4 & & & & \\
\hline & RP-2/D & C3 & 24 & 2.00 & 400 & 4 & & & & \\
\hline & RP-2/D & C4 & 24 & 2.00 & 400 & 4 & & & & \\
\hline & RP-2/D & C5 & 24 & 2.00 & 400 & 4 & & & & \\
\hline & RP-2/D & C6 & 24 & 2.00 & 400 & 4 & & & & \\
\hline \multirow[t]{2}{*}{ CO2O } & RP-4/D & A2 & 48 & 4.00 & 800 & 4 & \multirow[t]{2}{*}{1} & \multirow[t]{2}{*}{ T-BAR } & \multirow[t]{2}{*}{0.16} & \multirow[t]{2}{*}{0.01} \\
\hline & RP-4/D & G2 & 48 & 4.00 & 800 & 4 & & & & \\
\hline \multirow[t]{2}{*}{ CO21 } & RP-4/D & A & 48 & 4.00 & 800 & 4 & \multirow[t]{2}{*}{1} & \multirow[t]{2}{*}{ T-BAR } & \multirow[t]{2}{*}{0.16} & \multirow[t]{2}{*}{0.01} \\
\hline & RP-4/D & $\mathrm{E}$ & 48 & 4.00 & 800 & 4 & & & & \\
\hline \multirow[t]{9}{*}{ C021A } & RP-4/D & A1 & 48 & 4.00 & 800 & 4 & \multirow[t]{9}{*}{1} & \multirow[t]{9}{*}{ T-BAR } & \multirow[t]{9}{*}{0.44} & \multirow[t]{9}{*}{0.29} \\
\hline & RP-2/D & $\mathrm{A} 2$ & 24 & 2.00 & 400 & 4 & & & & \\
\hline & RP-2/D & B2 & 24 & 2.00 & 400 & 4 & & & & \\
\hline & $\mathrm{RP}-2 / \mathrm{D}$ & $\mathrm{C} 2$ & 24 & 2.00 & 400 & 4 & & & & \\
\hline & RP-2/D & D2 & 24 & 2.00 & 400 & 4 & & & & \\
\hline & RP-2/D & E2 & 24 & 2.00 & 400 & 4 & & & & \\
\hline & $\mathrm{RP}-2 / \mathrm{D}$ & F2 & 24 & 2.00 & 400 & 4 & & & & \\
\hline & RP-4/D & G1 & 48 & 4.00 & 800 & 4 & & & & \\
\hline & RP-2/D & G2 & 24 & 2.00 & 400 & 4 & & & & \\
\hline \multirow[t]{13}{*}{ C021B } & RP-2/D & A1 & 24 & 2.00 & 400 & 4 & 1 & T-BAR & 0.56 & 0.55 \\
\hline & $\mathrm{RP}-2 / \mathrm{D}$ & A2 & 24 & 2.00 & 400 & 4 & & & & \\
\hline & RP-2/D & A3 & 24 & 2.00 & 400 & 4 & & & & \\
\hline & RP-2/D & A4 & 24 & 2.00 & 400 & 4 & & & & \\
\hline & RP-2/D & A5 & 24 & 2.00 & 400 & 4 & & & & \\
\hline & RP-2/D & A6 & 24 & 2.00 & 400 & 4 & & & & \\
\hline & RP-4/D & B6 & 48 & 4.00 & 800 & 4 & & & & \\
\hline & $\mathrm{RP}-2 / \mathrm{D}$ & $\mathrm{C} 1$ & 24 & 2.00 & 400 & 4 & & & & \\
\hline & $\mathrm{RP}-2 / \mathrm{D}$ & $\mathrm{C} 2$ & 24 & 2.00 & 400 & 4 & & & & \\
\hline & RP-2/D & C3 & 24 & 2.00 & 400 & 4 & & & & \\
\hline & RP-2/D & C4 & 24 & 2.00 & 400 & 4 & & & & \\
\hline & $\mathrm{RP}-2 / \mathrm{D}$ & $\mathrm{C} 5$ & 24 & 2.00 & 400 & 4 & & & & \\
\hline & RP-2/D & C6 & 24 & 2.00 & 400 & 4 & & & & \\
\hline c031 & RP-5/D & D & 144 & 12.00 & 2568 & 4 & 1 & T-BAR & 0.77 & 1.23 \\
\hline & RP-5/D & $\mathrm{F}$ & 144 & 12.00 & 2568 & 4 & & & & \\
\hline & RP-5/D & G & 144 & 12.00 & 2568 & 4 & & & & \\
\hline
\end{tabular}




\section{Appendix C: Bldg 1540B Deficiencies List}

The PERTAN contract was modified on 17 Jun 2015 to add additional Task 5 to correct deficiencies in the baseline facility, Bldg 1540B. The following paragraph summarizes requirements for Task 5 .

C.10.f. Task 5 - Correct Deficiencies in Bldg 1540B: A number of unforeseen deficiencies were identified in baseline Bldg $1540 B$ that will impact its energy consumption and the ability to fairly compare the energy performance of the demonstration facility (Bldg 1540A) with the baseline facility (Bldg $1540 B$ ). This task is added to restore comparability to baseline facility. Task 5 shall be completed no-later than 45 days after award of contract modification Pooo01. The Contractor shall complete the subtasks listed in Table C-1.

Table C-1. Required contractor subtasks.

\begin{tabular}{|c|c|c|}
\hline Item & Required Action & Final Status \\
\hline B-1 & $\begin{array}{l}\text { Replace sheaves and belt on AHU-4 to cause } \\
\text { this unit to deliver design air flow. }\end{array}$ & COMPLETED - 26 Jun 2015. \\
\hline B-2 & $\begin{array}{l}\text { VAV terminal units } 1,8,11,13,14,16,15, \\
\text { and } 18 \text { are not operational. Troubleshoot } \\
\text { and repair or replace as necessary. }\end{array}$ & $\begin{array}{l}\text { COMPLETED - } 30 \text { Jul } 2015 . \\
\text { VAV's were replaced and tested. }\end{array}$ \\
\hline B-3 & $\begin{array}{l}\text { Exhaust fans } 8 \text { and } 9 \text { are not operational. } \\
\text { Troubleshoot and repair or replace as } \\
\text { necessary. }\end{array}$ & $\begin{array}{l}\text { COMPLETED - } 26 \text { Jun } 2015 . \\
\text { Fans made operational by } \\
\text { mechanical Contractor. }\end{array}$ \\
\hline B-4 & $\begin{array}{l}\text { Perform point-to-point verification of proper } \\
\text { functioning of VAV reheat coil valves. For any } \\
\text { reheat coil valves that are not functioning } \\
\text { properly, provide a recommendation of } \\
\text { repair vs. replacement. }\end{array}$ & $\begin{array}{l}\text { COMPLETED - } 30 \text { Jul } 2015 \text {. } \\
\text { Two (2) reheat valves were found not } \\
\text { functioning. Recommend replace } \\
\text { actuators in Rooms C007 and C005. }\end{array}$ \\
\hline B-5 & $\begin{array}{l}\text { Verify and update the time schedule within } \\
\text { the BAS. }\end{array}$ & $\begin{array}{l}\text { COMPLETED - } 07 \text { Aug } 2015 . \\
\text { Implemented same time schedule as } \\
\text { Bldg 1540A, the building schedule } \\
\text { operates 0600-1800 Monday to } \\
\text { Sunday. }\end{array}$ \\
\hline B-6 & $\begin{array}{l}\text { Verify proper operation of Boiler High Limit } \\
\text { Safety controls. If High Limit Safety controls } \\
\text { are found to be nonfunctional, provide a } \\
\text { recommendation of repair vs. replacement. }\end{array}$ & $\begin{array}{l}\text { COMPLETED - } 07 \text { Aug } 2015 . \\
\text { Boiler is interlocked with pump and } \\
\text { shuts down when pump is shut down } \\
\text { (In Auto). Flow switch should be } \\
\text { added to prevent boiler operation in } \\
\text { Hand without pump. }\end{array}$ \\
\hline B-7 & $\begin{array}{l}\text { Boiler lockout OA temp has been changed to } \\
85^{\circ} \mathrm{F} \text {, which leaves the boiler running all the } \\
\text { time. Adjust boiler lockout temperature so } \\
\text { unit shuts down when not needed. }\end{array}$ & $\begin{array}{l}\text { COMPLETED - } 07 \text { Aug } 2015 . \\
\text { No action was taken as the boiler is } \\
\text { needed for VAV reheat coils. }\end{array}$ \\
\hline
\end{tabular}




\begin{tabular}{|c|c|c|}
\hline Item & Required Action & Final Status \\
\hline B-8 & $\begin{array}{l}\text { Hot water system still operates when } \\
\text { Invensys system is shut off. Provide } \\
\text { necessary controls so that hot water system } \\
\text { shuts down when not needed. }\end{array}$ & $\begin{array}{l}\text { COMPLETED - } 07 \text { Aug } 2015 \text {. } \\
\text { No action was taken as the existing } \\
\text { Invensys control system controls the } \\
\text { operation of the boiler system in both } \\
1540 A \& B \text {, and it has been verified to } \\
\text { work. }\end{array}$ \\
\hline B-9 & $\begin{array}{l}\text { THIS ITEM IS DELETED. NO ACTION } \\
\text { REQUIRED. }\end{array}$ & NO ACTION REQUIRED. \\
\hline B-10 & $\begin{array}{l}\text { UH-10 has been removed. Remove } \\
\text { associated active sensor and relay. }\end{array}$ & $\begin{array}{l}\text { COMPLETED - } 30 \text { Jul } 2015 . \\
\text { The corresponding controls were } \\
\text { removed. }\end{array}$ \\
\hline B-11 & $\begin{array}{l}\text { Operation and temperature control should } \\
\text { be connected to the Invensys system for the } \\
\text { two new PTAC systems installed during } \\
\text { renovation. Interconnect new PTAC units to } \\
\text { Invensys system or provide other appropriate } \\
\text { means of controlling these units. }\end{array}$ & $\begin{array}{l}\text { COMPLETED - } 30 \text { Jul } 2015 . \\
\text { PTAC units were connected to system } \\
\text { and are on the building schedule. }\end{array}$ \\
\hline B-12 & $\begin{array}{l}\text { The UH's \& CUH's are not connected to the } \\
\text { Invensys time schedule. Incorporate these } \\
\text { into the time schedule. }\end{array}$ & $\begin{array}{l}\text { COMPLETED - } 30 \text { Jul } 2015 . \\
\text { Units are connected to building } \\
\text { schedule. }\end{array}$ \\
\hline B-13 & $\begin{array}{l}\text { THIS ITEM IS DELETED. NO ACTION } \\
\text { REQUIRED. }\end{array}$ & NO ACTION REQUIRED. \\
\hline B-14 & $\begin{array}{l}\text { Control valve actuators for baseboard units } \\
\text { in restrooms are not connected. Connect } \\
\text { actuators and make them operational. }\end{array}$ & $\begin{array}{l}\text { COMPLETED - } 30 \text { Jul } 2015 . \\
\text { Valve actuators are connected to } \\
\text { system and are operational with } \\
\text { bathroom units. }\end{array}$ \\
\hline B-15 & $\begin{array}{l}\text { Change out high limit thermostat automatic } \\
\text { reset for manual device. }\end{array}$ & $\begin{array}{l}\text { COMPLETED - } 26 \text { Jun } 2015 . \\
\text { As the coil was busted, the valve was } \\
\text { in closed position. Replaced coil and } \\
\text { system operates as designed. }\end{array}$ \\
\hline B-16 & $\begin{array}{l}\text { Determine why FCU-3 water return and } \\
\text { supply are turned off and correct problem as } \\
\text { needed. }\end{array}$ & $\begin{array}{l}\text { COMPLETED - } 26 \text { Jun } 2015 . \\
\text { Coil unit was leaking and was } \\
\text { replaced by mechanical Contractor. }\end{array}$ \\
\hline B-17 & $\begin{array}{l}\text { AHU-4 face and bypass dampers are not } \\
\text { documented in the design or controls } \\
\text { sequence. The damper is modulated with } \\
\text { the same signal as the preheat valve. } \\
\text { Provide a proper control signal to this system } \\
\text { so that it functions appropriately. }\end{array}$ & $\begin{array}{l}\text { COMPLETED } \\
\text { No action was taken. No need to } \\
\text { change the sequence of operation for } \\
\text { the face and bypass dampers and } \\
\text { the heating valve. }\end{array}$ \\
\hline
\end{tabular}




\begin{tabular}{|c|c|c|}
\hline Item & Required Action & Final Status \\
\hline B-18 & $\begin{array}{l}\text { AHU. Preheat sensor is not reading correctly } \\
\text { and is mounted in an incorrect location. The } \\
\text { sequence for the preheat valve uses the } \\
\text { common supply duct temp in its control } \\
\text { algorithm in lieu of the sensor. Repair, } \\
\text { replace and/or relocate this device to } \\
\text { provide a proper control signal to the AHU. }\end{array}$ & $\begin{array}{l}\text { COMPLETED } \\
\text { There is not a place in the unit to } \\
\text { properly place the preheat sensor. } \\
\text { The preheat coil and the DX coil are } \\
\text { side by side with no access in } \\
\text { between. A sensor cannot be located } \\
\text { on the leaving side of the preheat } \\
\text { coil and beside the original Standing } \\
\text { Operating Procedure (SOP) call for } \\
\text { the heating coil to be controlled by } \\
\text { the supply air sensor. }\end{array}$ \\
\hline B-19 & $\begin{array}{l}\text { THIS ITEM IS DELETED. NO ACTION } \\
\text { REQUIRED. }\end{array}$ & NO ACTION REQUIRED. \\
\hline B-20 & $\begin{array}{l}\text { Verify proper operation of Power Logic KW } \\
\text { meter. If unit if found function incorrectly, } \\
\text { provide recommendation of recalibration, } \\
\text { repair and/or replacement. }\end{array}$ & $\begin{array}{l}\text { COMPLETED - } 30 \text { Jul } 2015 . \\
\text { Meter appears to be operating } \\
\text { correctly. }\end{array}$ \\
\hline B-21 & $\begin{array}{l}\text { Provide a written report documenting } \\
\text { completion of above corrective actions and } \\
\text { resulting outcomes. }\end{array}$ & $\begin{array}{l}\text { COMPLETED } \\
\text { Submitted and Accepted by CERL } \\
\text { Contract Officer Representative } \\
(\text { COR) - } 17 \text { Sep } 2015 .\end{array}$ \\
\hline B-22 & $\begin{array}{l}\text { On completion of all corrective actions } \\
\text { identified above, perform Test and Balance } \\
\text { (TAB) of Bldg } 1540 B \text { and document in a } \\
\text { written TAB report. }\end{array}$ & $\begin{array}{l}\text { COMPLETED } \\
\text { Submitted and Accepted by CERL } \\
\text { COR - } 17 \text { Sep } 2015 .\end{array}$ \\
\hline
\end{tabular}




\section{Appendix D: Product Datasheets}

Figure D-1. EnTouch Remote Sensor Module (RSM-100) datasheet.

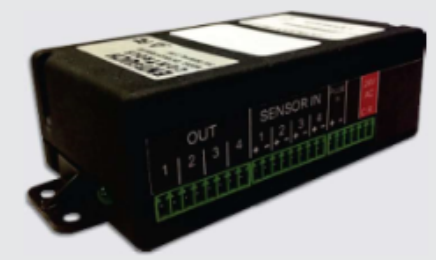

\section{RSM-100}

\section{REMOTE SENSOR MODULE}

\section{THE ENTOUCH ONE REMOTE SENSOR MODULE}

The EnTouch Remote Sensor Module is designed to work with our EnTouch One EMS family. Monitor your facilities through our cloud based system using your computer, tablet, or mobile device.

Monitor energy critical systems in your facility and reduce the risk of a facility crisis with the EnTouch Remote Sensor Module.

\section{TECHNICAL SPECIFICATIONS}

Power Requirements

-24V AC from wall mounted 120-24VAC transformer

Measurements

- Four temperature input port

- Supported sensors: 10K Type 2, 10K Type 3, 20K type 4

- Two wire NTC passive sensors. (Sensors sold separctelely)

- Digital input: Any of the temperature inputs can also be configured to sense opening or closing of a dry contact

- Pulse input: Accumulated pulse count in certain time. Software

support will be deployed in the future for water and gas metering applications

Wiring Connection

-Mating connector provided with the unit

- 1 Terminal Block, Pluggable, $3.50 \mathrm{~mm}$, 6POS - Power Supply

-2 Terminal Block, Pluggable, $3.50 \mathrm{~mm}, 8 \mathrm{POS}-$ Measurement/Control

Inputs

Terminal Designation

- Sensor 1 - Sensor 4: Temperature Input or Digital Input . Polarity insensitive.

- Pulse In: Pulse Counter Input. Requires isolated open collector/ relay input

Physical and Environmental

- Size: $5^{\prime \prime} \times 1.6^{n} \times 4^{n}$

- Weight: $4.5 \mathrm{Oz}$

- Mounting: Wall mounted with hardware provided

- Compliance: FCC, CSA

\section{RSM FEATURES}

Multiple Facility Monitoring

Our monitoring platform is designed for commercial applications.
"t can monitor energy usage temperature or can act as a contact. It can monitor energy usage, temperature or can act as a contact
sensor to monitor door openings and closings. The RSM gives total system visibility over all of your facilities Configurable Features

The system is flexible, allowing it to monitor the most complex applications. From simple contact closure inputs to thermal sensing
inputs, the RSM can handle them all. Adapt and expand as your

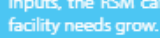

Refrigeration Monitoring

The EnTouch EMS can monitor refrigeration temperatures and de U. performance across locations.

Support for Extermal Inputs The system can accept inputs from static switches, motion detec tors, and thermal sensors. Use these inputs to facilitate problem alerts, safety features and system performance. Designed For Retrofit Applications Unlike traditional wired systems, the EnTouch Remote Sensor Module is easy to install and don't require extensive communication wiring or programming In fact there is no programming required. Pulse Metering Pulse Metering The hemote Sensor Module also supports pulse input, which allows it to track water, electricity and gas consumption. With this func tionality, a restaurant can track real time utility consumption anc
compare multiple facilities from a cloud based management portal.

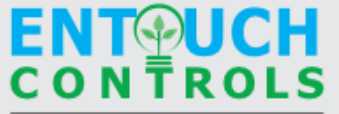

TOTAL FACILITIES INTELLIGENCE

MANAGEMENT OF:

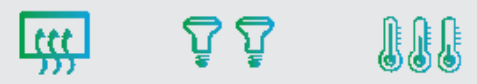

HVAC 
Figure D-2. GreenTrol airflow sensor datasheet.

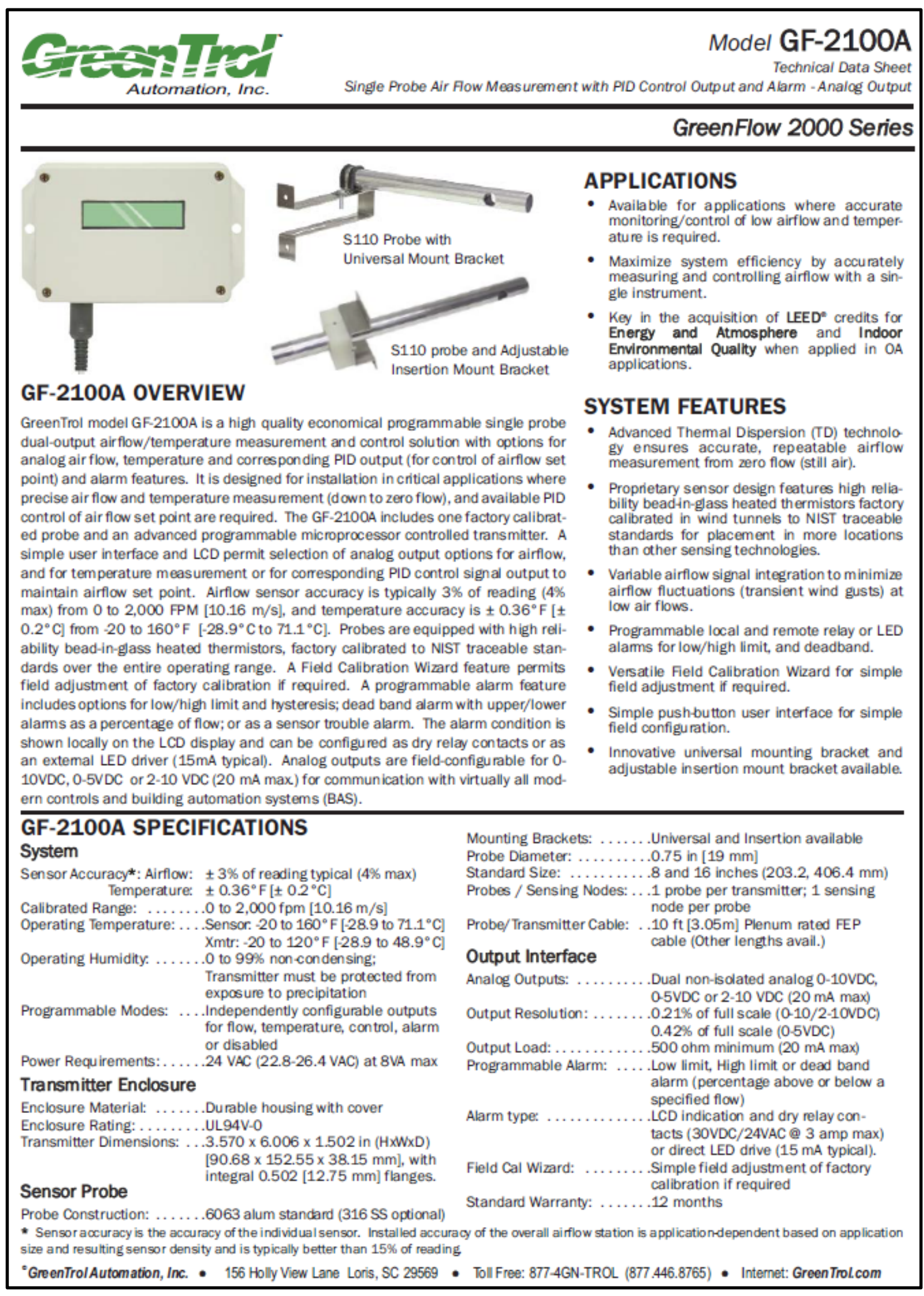


Figure D-3. Badger BTU meter datasheet.

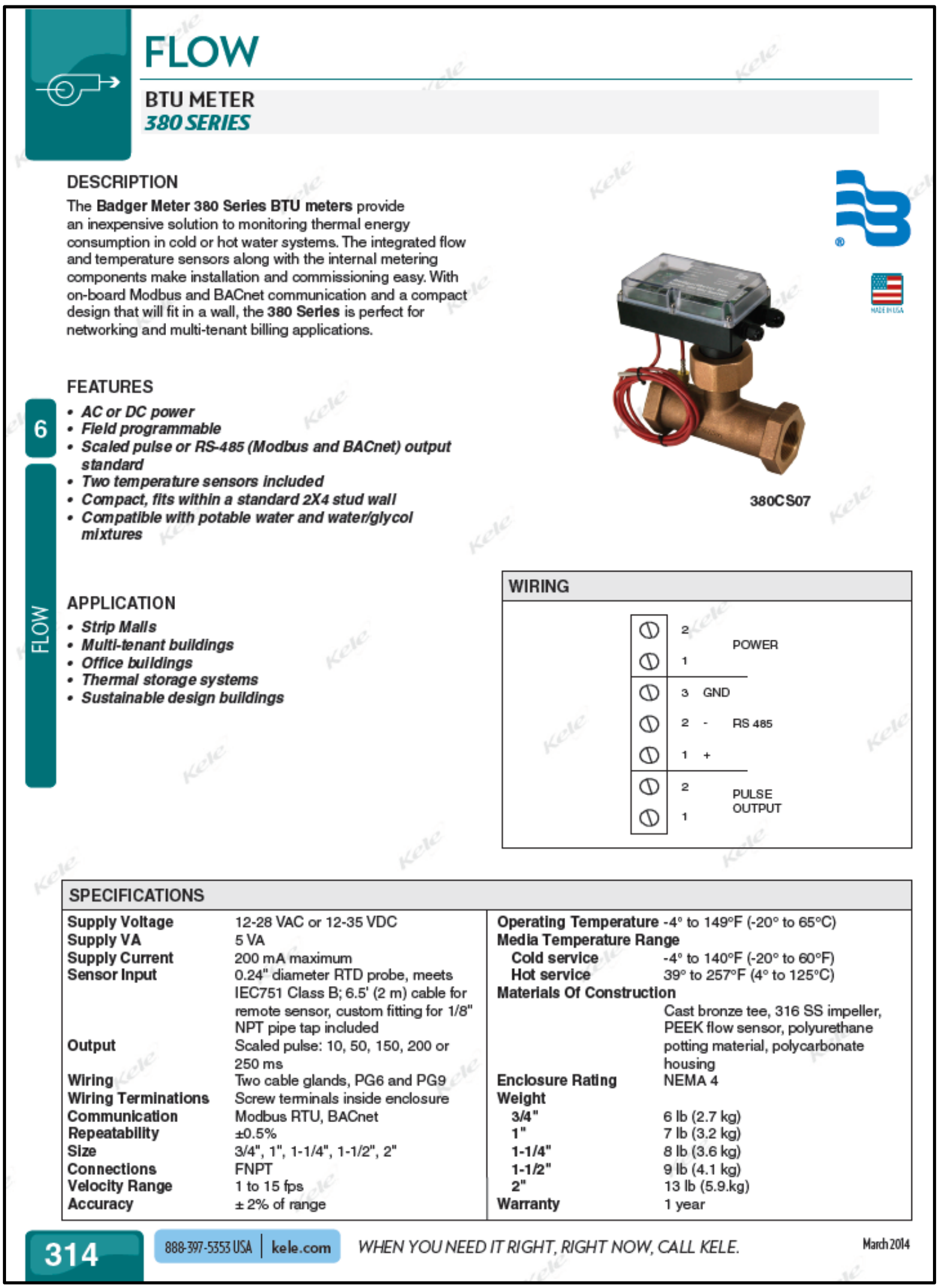


Figure D-4. Honeywell humidity/temperature sensor datasheet.

\begin{tabular}{|c|c|}
\hline \multicolumn{2}{|l|}{$\begin{array}{l}\text { Wall } \\
\text { Mount }\end{array}$} \\
\hline \multirow{3}{*}{$\begin{array}{l}\text { The H7625, H7635, and H7655 are highly accurate, stable } \\
\text { humidity transducers designed for use with HVAC controllers } \\
\text { such as the } T 7350 \text { Thermostat, H775 Remote Humidity Con- } \\
\text { troller, and W7760 Direct Digital Controllers. The Ceramic } \\
\text { Technology humidity sensor is not affected by condensation } \\
\text { and provides excellent long-term stability. }\end{array}$} & \multirow[t]{2}{*}{ SPECIFICATION DATA } \\
\hline & \\
\hline & $\begin{array}{l}\text { - Ceramic Technology overcomes the limitations of } \\
\text { other resistance based humidity sensors that use }\end{array}$ \\
\hline SPECIFICATIONS & $\begin{array}{l}\text { water soluble polymer coatings. } \\
\text { Ceramic Technology allows sensors to recover fully } \\
\text { from condensation, fog, and high humidity. }\end{array}$ \\
\hline $\begin{array}{l}\text { Models: } \\
\square \text { See Table } 1 .\end{array}$ & $\begin{array}{l}\text { Highly accurate, repeatable, stable output with } \\
\text { negligible hysteresis. }\end{array}$ \\
\hline $\begin{array}{l}\text { Dimensions: } \\
\square \text { See Fig. } 1 \text { through } 3 .\end{array}$ & $\begin{array}{l}\text { - Temperature compensated output } \\
\text { Zero and span trimmers, and increment/decrement }\end{array}$ \\
\hline $\begin{array}{l}\text { Operating RH Range: } \\
\square 0 \text { to } 100 \% \text { RH. }\end{array}$ & $\begin{array}{l}\text { recalibration feature. } \\
\text { All units have selectable } 4-20 \mathrm{~mA}, 0-10 \mathrm{Vdc} \text {, or } 0-5 \mathrm{Vdc} \\
\text { output. }\end{array}$ \\
\hline $\begin{array}{l}\text { Humidity Accuracy: } \\
\square \pm 2 \%, \pm 3 \% \text { or } \pm 5 \% \text { from } 20 \text { to } 95 \% \text { RH. }\end{array}$ & $\begin{array}{l}\text { - output. } \\
\text { NIST traceable } 2 \%, 3 \% \text {, and } 5 \% \text { calibration, every } \\
\text { sensor calibrated at } 3 \text { different points. }\end{array}$ \\
\hline $\begin{array}{l}\text { 20K Ohm Temperature Accuracy: } \\
\square \pm 0.4^{\circ} \mathrm{F} \text { at } 77^{\circ} \mathrm{F}\left( \pm 0.2^{\circ} \mathrm{C} \text { at } 25^{\circ} \mathrm{C}\right)\end{array}$ & \\
\hline $\begin{array}{l}\text { 20K Ohm Temperature Output Range: } \\
\text { Room: } 40^{\circ} \text { to } 110^{\circ} \mathrm{F}\left(4^{\circ} \text { to } 43^{\circ} \mathrm{C}\right) \text {. } \\
\text { Duct/Outdoor: }-40^{\circ} \text { to } 240^{\circ} \mathrm{F}\left(-40^{\circ} \text { to } 116^{\circ} \mathrm{C}\right) \text {. }\end{array}$ & $\begin{array}{l}\text { Compensated Temperature Range: } \\
\square-10 \text { to } 160^{\circ} \mathrm{F}\left(-23 \text { to } 71^{\circ} \mathrm{C}\right) \text {. }\end{array}$ \\
\hline $\begin{array}{l}\text { Hysteresis: } \\
\text { Hess than } \pm 0.4 \% \mathrm{RH} \text {. }\end{array}$ & $\begin{array}{l}\text { Humidity Response Time: } \\
\square 30 \text { seconds. }\end{array}$ \\
\hline $\begin{array}{l}\text { Supply Voltage: } \\
\square 18 \text { to } 36 \mathrm{Vdc} \text { or } 24 \mathrm{Vac} \text {. }\end{array}$ & $\begin{array}{l}\text { Saturation Response Time: } \\
\square 10 \text { minutes. }\end{array}$ \\
\hline $\begin{array}{l}\text { Maximum Impedance Load: } \\
\square .42 \mathrm{~K} \text { ohms at } 60 \mathrm{~Hz} \text {. }\end{array}$ & $\begin{array}{l}\text { Sensitivity: } \\
\text { व } 0.1 \% \text { RH. }\end{array}$ \\
\hline $\begin{array}{l}\text { Maximum Supply Current: } \\
\square \text { Current Mode: } 22 \mathrm{~mA} \text {. }\end{array}$ & $\begin{array}{l}\text { Interchangeability: } \\
\text { व Less than } \pm 3 \% \text { RH nominal. }\end{array}$ \\
\hline $\begin{array}{l}\text { Voltage Mode: } 5 \text { mA. } \\
\text { Finish: } \\
\text { Room Enclosure: ABS Plastic (UL94-HB rated). } \\
\text { Duct Enclosure: ABS Plastic (UL94-5VA rated). } \\
\text { Outdoor Enclosure: ASA Plastic (UL-94VO rated). }\end{array}$ & $\begin{array}{l}\text { Repeatability: } \\
\text { व } 0.5 \% \mathrm{RH} \text {. } \\
\text { Long term drift: } \\
\square \text { Less than } 2 \% \mathrm{RH} \text { drift/5 years. }\end{array}$ \\
\hline
\end{tabular}

Table 1. Models.

\begin{tabular}{|c|c|c|c|c|c|}
\hline $\begin{array}{c}\begin{array}{c}\text { Model } \\
\text { Number }\end{array} \\
\text {. }\end{array}$ & $\begin{array}{c}\mathrm{RH} \\
\text { Accuracy }\end{array}$ & Mount & $\begin{array}{l}\text { Output } \\
\text { Signal }\end{array}$ & $\begin{array}{l}\text { Voltage } \\
\text { Supply }\end{array}$ & $\begin{array}{c}\text { Temperature } \\
\text { Sensor }\end{array}$ \\
\hline H7625A & $2 \%$ & \multirow[t]{2}{*}{ Room } & \multirow{6}{*}{$\begin{array}{l}\text { Selectable: } \\
4-20 \mathrm{~mA} \text {, } \\
0-10 \mathrm{Vdc}, \\
\text { or } \\
0-5 \mathrm{Vdc}\end{array}$} & \multirow{6}{*}{$\begin{array}{l}18-36 \mathrm{Vdc} \\
\text { or } \\
24 \mathrm{Vac}\end{array}$} & \multirow[t]{6}{*}{$20 \mathrm{~K}$ ohm } \\
\hline H7635A & $3 \%$ & & & & \\
\hline H7625B & $2 \%$ & \multirow[t]{3}{*}{ Duct } & & & \\
\hline H7635B & $3 \%$ & & & & \\
\hline H7655B & $5 \%$ & & & & \\
\hline H7635C & $3 \%$ & Outdoor & & & \\
\hline
\end{tabular}




\section{Appendix E: Criteria Change Request for UFC 3-410-01}

\section{E.1 Problem}

UFC 3-410-01, Paragraph B-8 suggests considering the use of infrared radiant heating in high bay areas or where spot heating is required. Except in these specific instances, UFC 3-410-01 currently assumes that space heating will be provided by the mechanical delivery of warmed air and that the sensible component of space comfort cooling will be satisfied by mechanical delivery of cooled air. These assumptions ignore the fact that, in combination with a well-sealed building envelope and a dedicated outdoor air system (DOAS), a radiant heating and cooling system can successfully satisfy both the space heating and cooling requirements of many military facilities.

UFC 3-410-01, paragraphs 3-2 and 3-3 require provision of a DOAS system to condition the ventilation air when the total outdoor air requirements for a building (either new buildings or ones undergoing major renovation) exceed 1,000 CFM. The DOAS separates the ventilation function from the space heating and cooling functions. As a result, a completely separate system must be installed to meet the space heating and cooling requirements. These separate systems typically are VAV systems, fan coil units (FCUs), or other all-air system types. Current criteria does not recognize the alternative possibility of satisfying space heating/cooling requirements with a radiant system.

Radiant systems have been widely used in Europe and other parts of the world. They are simple in design, quiet, clean, and easily maintained. They cost effectively enable individual temperature control in small spaces because all that is required is a small two-position control valve connected to a simple room thermostat. Unlike FCUs, no air filters are required so that filter maintenance is reduced and confined to the DOAS unit in the mechanical room. Radiant systems can take advantage of lower temperature heating water and higher temperature cooling water. This facilitates the possibility of piping chilled water leaving the DOAS system's cooling coil to supply the radiant cooling panels. As a result, the chiller sees a higher chilled water return temperature, improving the chilled water system's efficiency and capacity. 


\section{E.2 Solution}

Incorporate criteria allowing broader consideration of low temperature radiant heating systems in administrative facilities, barracks facilities, and other building types with either high or low ceilings. In applications requiring no cooling, ventilation air can be provided by a dedicated ventilation air system delivering neutral or slightly warmed air with the bulk of comfort heating provided by radiant systems installed in the floor slab or ceiling. Slab mounting facilitates the use of the slab mass as thermal storage in addition to being a radiating surface. Ceiling-mounted radiant systems may be radiant mat systems incorporated in ceiling finish systems, radiant metallic "cloud" panels suspended from the structural ceiling or radiant metallic panels for mounting in a suspended ceiling grid.

In dry locations requiring combined heating and cooling (but no dehumidification), incorporate criteria allowing consideration of radiant heating and cooling systems in administrative facilities, barracks facilities, and other buildings with high or low ceilings where ventilation air requirements are provided by a separate ventilation system delivering neutral or partially tempered air. Combined radiant heating and cooling systems may be installed in the floor slab or ceiling. Slab mounting facilitates using the slab mass as thermal storage in addition to being a radiating surface. Ceiling-mounted radiant systems may be radiant mat systems incorporated in ceiling finish systems, radiant metallic "cloud" panels suspended from the structural ceiling, or radiant metallic panels for mounting in a suspended ceiling grid.

In humid locations requiring combined heating, cooling and dehumidification, incorporate criteria allowing consideration of radiant heating and cooling systems in administrative facilities, barracks facilities and other buildings with high or low ceilings. Candidate facilities in humid locations should have tight building envelopes to prevent infiltration of humid unconditioned outdoor air. Ventilation air requirements shall be provided by a DOAS system delivering neutral or partially tempered air. In the cooling mode, all latent cooling shall be handled by the DOAS system and the radiant system should provide sensible cooling only. Combined radiant heating and cooling systems may be installed in the floor slab or ceiling. Slab mounting facilitates using the slab mass as thermal storage in addition to being a radiating surface. Ceiling-mounted radiant systems may be radiant mat systems incorporated in ceiling finish systems, radiant metallic "cloud" panels suspended from the structural ceiling or radiant metallic panels for mounting in a suspended ceiling grid. 
A radiant heating/cooling system and a DOAS system were retrofitted into a Company HQ facility, successfully demonstrating that comfort conditions could be satisfied without experiencing problems with condensation forming on radiant cooling surfaces. This demonstration was performed in a hot, humid location (Frederick, MD). The installed system was found to be quiet, simple to operate and maintain, and capable of satisfying occupant comfort. Besides this project, the Army Corps of Engineers recently completed construction of a new six story cadet barracks facility using radiant heating and cooling systems embedded in the floor slab of cadet rooms. Low temperature radiant heating has also been used successfully in a deep energy retrofit project at the Presidio of Monterrey's Bldg 630 barracks facility. Low temperature radiant heating systems have also been successfully installed at a number of U.S. Army maintenance facilities and hangars in Germany.

Low temperature radiant heating systems facilitate taking full advantage of the potentially higher efficiency of condensing boilers because return water temperatures from these systems are low enough to extract latent heat from flue gases. Radiant heating and cooling systems may also be a useful alternative to all-air HVAC systems in the renovation of facilities with minimal available overhead space for both ventilation and space conditioning air ducts.

As with any system, a thorough engineering analysis and life-cycle cost analysis should be performed before deciding to install a radiant heating/cooling system. We believe that a radiant heating/cooling system may be life-cycle cost competitive with traditional all-air systems, especially in locations with low to moderate sensible and latent cooling loads. 


\section{References}

Addison, M.S., and Associates. 1999. "User Friendly" Life-Cycle Costing: The BLCC Procedure in an Easy-to-Use Spreadsheet. Albuquerque, NM: U.S. DOE Pollution Prevention Conference.

ASHRAE (American Society of Heating, Refrigerating, and Air-Conditioning Engineers). 2017. ASHRAE Owning and Operating Cost Database. "Miscellaneous - Service Life Data per Above Criteria.” Atlanta, GA: ASHRAE. Accessed January 23, 2017, http://xp20.ashrae.org/publicdatabase/system_service_life.asp?selected_system_type=8.

- 2015a. 2015 ASHRAE Handbook: HVAC Applications. Atlanta, GA: ASHRAE.

- 2014. Measurement of Energy, Demand, and Water Savings. ASHRAE Guideline 14-2014. Atlanta, GA: ASHRAE.

. 2012a. ASHRAE Handbook. Atlanta, GA: ASHRAE.

- 2012b. Performance Measurement Protocols for Commercial Buildings: Best Practice Guide. Atlanta, GA: ASHRAE.

- 2012c. 2012 ASHRAE Handbook-HVAC Systems and Equipment. Atlanta, GA: ASHRAE

2010. Thermal Environmental Conditions for Human Occupancy. ASHRAE Standard 55-2013. ASHRAE Standard 90.1-2004. Atlanta, GA: ASHRAE.

- 2004. Energy Standard for Buildings Except Low-Rise Residential Buildings. ASHRAE Standard 90.1-2004. Atlanta, GA: ASHRAE.

. 2004. Ventilation for Acceptable Indoor Air Quality. Standard 62.1. Atlanta, GA: ASHRAE.

. 1997. ASHRAE Handbook: Fundamentals. Atlanta, GA: ASHRAE.

ASTM (American Society for Testing and Materials). 2013. Standard Test Method for Air Permeance of Building Materials. ASTM E2178. West Conshohocken, PA: ASTM.

- 2011. Standard Test Methods for Determining Airtightness of Buildings Using an Orifice Blower Door. ASTM E 1827. West Conshohocken, PA: ASTM https://compass.astm.org/EDIT/html_annot.cgi?E1827+11.

. 2003a Standard Test Method for Determining Air Leakage Rate by Fan Pressurization. ASTM E779, West Conshohocken, PA: ASTM, http://www.ce.utexas.edu/prof/Novoselac/classes/CE397/Handouts/astm\%20e779\%20\%20air\%20leakage\%20by\%20fan\%20pressurization.pdf.

- 2003b Standard Practices for Air Leakage Site Detection in Building Envelopes and Air Barrier Systems. ASTM E1186, West Conshohocken, PA: ASTM. 
Bauman, Fred, Jingjuan Feng, and Stefano Schiavon. 2013. "Cooling Load Calculations for Radiant Systems: Are They the Same as Traditional Methods." ASHRAE Journal 55(12):20-27.

Energy Independence and Security Act of 2007 (EISA). 2007. Pub. L. No. 110-140, 121 Stat. 1492, originally named the Clean Energy Act of 2007.

Energy Policy Act of 2005 (EPACT). 2005. Pub.L. 109-58, 119 Stat. 594.

EnTouch. 2017. ENTOUCH: Smart Building Solutions. Web site, www.entouchgo.com.

Fuller, Sieglinde K., and Stephen R. Petersen. 1995. Life-Cycle Costing Manual for the Federal Energy Management Program. National Institute of Standards and Technology (NIST) Handbook 135. Washington, DC: U.S. Department of Commerce, Technology Administration, National Institute of Standards and Technology, https://www.wbdg.org/FFC/NIST/hdbk_135.pdf.

HQUSACE (Headquarters, U.S. Army Corps of Engineers), Naval Facilities Engineering Command (NAVFAC), Air Force Civil Engineer Support Agency (AFCESA). 2012. DoD Minimum Antiterrorism Standards for Buildings, Unified Facilities Criteria (UFC) 4-010-01. Washington, DC: HQUSACE, NAVFAC, AFCESA, https://www.wbdg.org/FFC/DOD/UFC/ufC_4_010_01_2012_c1.pdf.

2011. Architecture. UFC 3-101-01. Washington, DC: HQUSACE, NAVFAC, and AFCESA, https://www.wbdg.org/ffc/dod/unified-facilities-criteria-ufc/ufc-3-101-01.

2010. Design and O\&M: Mass Notification Systems. UFC 4-021-01. Washington, DC: HQUSACE, NAVFAC, and AFCESA, http://www.wbdg.org/ffc/dod/unified-facilities-criteria-ufc/ufc-4-021-01.

2003. Heating, Ventilating, and Air-Conditioning Systems. UFC 3-410-01 (CANCELLED). Washington, DC: HQUSACE, NAVFAC, AFCESA, http://www.wbdg.org/FFC/DOD/UFC/ufc_3_410_01_2013_c2.pdf.

HQUSACE (Headquarters, U.S. Army Corps of Engineers). 2012a. Building Air Tightness and Air Barrier Continuity Requirements. ECB 2012-16, Washington, DC: HQUSACE, https://www.wbdg.org/FFC/ARMYCOE/COEECB/ARCHIVES/ecb_2012_16.pdf.

2012b. U.S. Army Corps of Engineers Air Leakage Test Protocol for Building Envelopes. Version 3. Washington, DC: HQUSACE, http://www.ibts.org/5-11-2012_usace_airleakagetestprotocol_V3_\%20.pdf.

2009. Building Air Tightness Requirements, Engineering and Construction Bulletin (ECB) 2009-29. Washington, DC: HQUSACE, https://www.wbdg.org/FFC/ARMYCOE/COEECB/ARCHIVES/ecb_2009_29.pdf.

Mumma, S. A. 2001. "Designing dedicated outdoor air systems." ASHRAE Journal. 43(5):28-31, http://doas-radiant.psu.edu/Journal1.pdf.

Office of Management and Budget (OMB). 2016. Memorandum of Understanding (MOU) with the U.S. Department of Energy (USDOE), Subject: "2016 Strategic Sustainability Performance Plan, Energy Security," https://energy.gov/sites/prod/files/2016/09/f33/DOE\%202016\%20SSPP\%20Revision\%200 9022016.pdf. 
Parsons, Robert (ed.). 1997. 1997 ASHRAE Handbook: Fundamentals. Atlanta, GA: ASHRAE.

Sastry, Guruprakash, and Peter Rumsey. 2014. "VAV vs. Radiant: Side-by-Side Comparison.” ASHRAE Journal 56(5):16-24.

UC Regents. 2014. "Radiant Systems Research." CBE: Center for the Built Environment. Web page. Accessed 19 October 2016, http://www.cbe.berkeley.edu/research/radiantsystems.htm.

USA TODAY. 2008. “Age, mold assail military barracks.” USA TODAY. 9 May 2008.

USEPA (U.S. Environmental Protection Agency). 2006. MOU, subject: "Federal Leadership in High Performance and Sustainable Buildings," https://archive.epa.gov/greenbuilding/web/pdf/sustainable_mou.pdf also see: https://www.epa.gov/greeningepa/guiding-principles-federal-leadership-high-performance-andsustainable-buildings. 


\section{Acronyms and Abbreviations}

\begin{tabular}{|c|c|}
\hline $\begin{array}{l}\text { Term } \\
\text { AC }\end{array}$ & $\begin{array}{l}\text { Definition } \\
\text { Alternating Current }\end{array}$ \\
\hline $\mathrm{AHU}$ & Air Handling Unit \\
\hline AIRR & Adjusted Internal Rate of Return \\
\hline ANSI & American National Standards Institute \\
\hline ASHRAE & American Society of Heating, Refrigerating, and Air-Conditioning Engineers \\
\hline ASTM & American Society for Testing and Materials \\
\hline AT/FP & Antiterrorism/Force Protection \\
\hline BAS & Building Automation System \\
\hline BLCC & Building Life-Cycle Cost \\
\hline BRAC & Base Realignment and Closure \\
\hline BTU & British Thermal Unit \\
\hline BTUH & British Thermal Unit per Hour \\
\hline BV & Besloten Vennootschap (Dutch: Limited Company) \\
\hline$C \& P$ & Cost and Performance \\
\hline ccSPF & Closed-Cell Spray Polyurethane Foam \\
\hline CDD & Cooling Degree Day \\
\hline CERL & Construction Engineering Research Laboratory \\
\hline CFM & Cubic Feet per Minute \\
\hline $\mathrm{CFH}$ & Cubic Feet per Hour \\
\hline $\mathrm{CHW}$ & Chilled Water \\
\hline $\mathrm{CMU}$ & Concrete Masonry Unit \\
\hline CONUS & Continental United States \\
\hline $\mathrm{COR}$ & Contract Officer Representative \\
\hline COTS & Commercial off-the-Shelf \\
\hline CRCP & Ceiling Radiant Cooling Panel \\
\hline CT & Current Transformer \\
\hline $\mathrm{CUH}$ & Cabinet Unit Heater \\
\hline DB & Dry Bulb \\
\hline DBT & Dry Bulb Temperature \\
\hline $\mathrm{DH}$ & Dehumidifier \\
\hline DOAS & Dedicated Outdoor Air System \\
\hline DoD & U.S. Department of Defense \\
\hline DP & Differential Pressure \\
\hline DPT & Dew Point Temperature \\
\hline DPW & Directorate of Public Works \\
\hline $\mathrm{DX}$ & Direct Expansion \\
\hline ECB & Engineering and Construction Bulletin \\
\hline EER & Energy Efficiency Rating \\
\hline
\end{tabular}




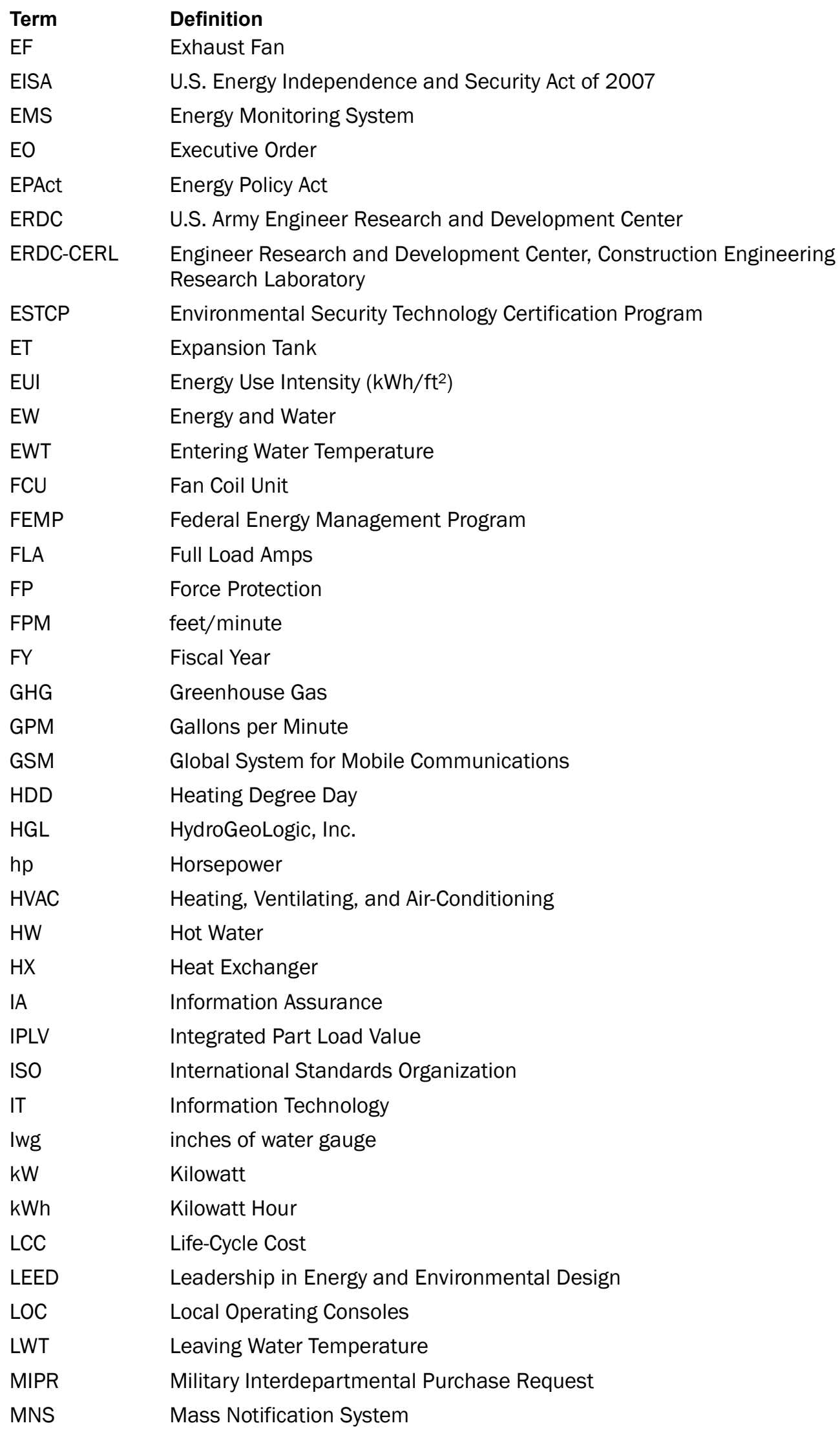




\begin{tabular}{|c|c|}
\hline Term & Definition \\
\hline MOU & Memorandum of Understanding \\
\hline NA & Not Applicable \\
\hline NEC & Network Enterprise Command \\
\hline NIST & National Institute of Standards and Technology \\
\hline NOAA & National Oceanic and Atmospheric Administration \\
\hline NSN & National Supply Number \\
\hline O\&M & Operations and Maintenance \\
\hline $\mathrm{OA}$ & Outside Air \\
\hline $\mathrm{OMB}$ & Office of Management and Budget \\
\hline OSA & Outside Air \\
\hline $\mathrm{Pa}$ & Pascal \\
\hline PC & Personal Computer \\
\hline PSIG & pound-force per square inch gauge \\
\hline PTAC & Packaged Terminal Air Conditioner \\
\hline PV & PhotoVoltaic \\
\hline $\mathrm{RH}$ & Relative Humidity \\
\hline $\mathrm{ROI}$ & Return on Investment \\
\hline RPM & Revolutions per Minute \\
\hline RSM & Remote Sensor Module \\
\hline SAR & Same as Report \\
\hline SCFM & standard cubic feet per minute \\
\hline SERDP & Strategic Environmental Research and Development Program \\
\hline SF & square feet \\
\hline SIR & Savings-to-Investment Ratio \\
\hline SITA & Southern Independent Testing Agency, Inc. \\
\hline SOP & Standing Operating Procedure \\
\hline SP & Simple Payback \\
\hline STD & Standard \\
\hline TAB & Test and Balance \\
\hline TR & Technical Report \\
\hline UFC & Unified Facilities Criteria \\
\hline $\mathrm{UH}$ & Unit Heater \\
\hline UMCS & Utility Monitoring and Control System \\
\hline USACE & U.S. Army Corps of Engineers \\
\hline USDOE & U.S. Department of Energy \\
\hline VAV & Variable Air Volume \\
\hline VSD & Variable Speed Drive \\
\hline WBDG & Whole Building Design Guide \\
\hline
\end{tabular}




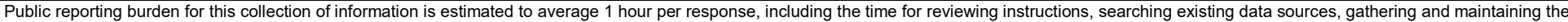

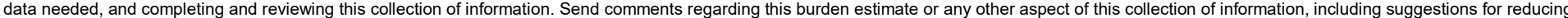

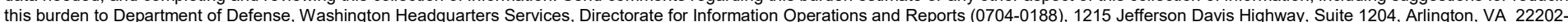

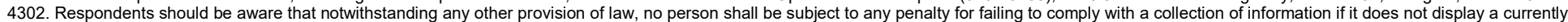
valid OMB control number. PLEASE DO NOT RETURN YOUR FORM TO THE ABOVE ADDRESS.
1. REPORT DATE (DD-MM-YYYY)
2. REPORT TYPE Final

\section{TITLE AND SUBTITLE} $02 / 01 / 19$

Systems Approach to Improved Facility Energy Performance

5a. CONTRACT NUMBER

5b. GRANT NUMBER

5c. PROGRAM ELEMENT

ESTCP

6. AUTHOR(S)

5d. PROJECT NUMBER

James P. Miller

EW-201155

5e. TASK NUMBER

5f. WORK UNIT NUMBER

8. PERFORMING ORGANIZATION REPORT NUMBER

7. PERFORMING ORGANIZATION NAME(S) AND ADDRESS(ES
U.S. Army Engineer Research and Development Center (ERDC)

ERDC/CERL TR-17-26

Construction Engineering Research Laboratory (CERL)

PO Box 9005,

Champaign, IL 61826-9005

\section{SPONSORING / MONITORING AGENCY NAME(S) AND ADDRESS(ES)}

SERDP/ESTCP

480o Mark Center Drive, Suite 17Do8

Alexandria, VA 22350-3605

10. SPONSOR/MONITOR'S ACRONYM(S)

SERPD/ESTCP

11. SPONSOR/MONITOR'S REPORT NUMBER(S)

\section{DISTRIBUTION / AVAILABILITY STATEMENT}

Approved for public release; distribution is unlimited.

\section{SUPPLEMENTARY NOTES}

Funding for this project was provided via MIPRs No. W74RDV23461416, W74RDV20749510, W74RDV20749509, W74RDV53553148, and W74RDV70303974.

\section{ABSTRACT}

The Department of Defense (DoD) is interested in improving its facilities to enhance energy performance and improve mold and mildew mitigation. This research effort used a pair of administrative facilities (Bldgs 1540A\&B) at Fort Detrick, MD to investigate the use of radiant heating and cooling systems to cost effectively improve such facilities using technologies that are easily maintainable by existing staff. This project found that: (1) it is feasible to significantly improve the air tightness of an existing building envelope without implementing major changes or disruptions to the interior or exterior surfaces of the building envelope; (2) radiant heating and cooling systems can adequately maintain comfort conditions in administrative buildings in locations with significant heating and cooling loads; (3) radiant cooling systems, when combined with a Dedicated Outdoor Air Supply (DOAS) system to properly dehumidify outdoor air and maintain proper space humidity conditions, can prevent condensation forming on the surface of the radiant cooling panels; (4) radiant heating and cooling systems are capable of improved energy efficiency when compared with conventional all-air Heating, Ventilating, and Air-Conditioning (HVAC) systems; (5) radiant systems are cost competitive with conventional all-air HVAC systems, and (6) radiant systems are easily maintainable and require no special skills for HVAC technicians.

\section{SUBJECT TERMS}

Military bases--Energy consumption, Heating, Air conditioning, Ventilation, Buildings-Airtightness, Buildings--Environmental engineering

\section{SECURITY CLASSIFICATION OF:}

\section{a. REPORT}

Unclassified

\section{b. ABSTRACT}

Unclassified

\section{c. THIS PAGE}

Unclassified
17. LIMITATION OF ABSTRACT

SAR
18. NUMBER OF PAGES

173 19a. NAME OF RESPONSIBLE PERSON

19b. TELEPHONE NUMBER (include area code) 